\title{
Morfologia e filogenia de Ceraeochrysa Adams, 1982 (Neuroptera: Chrysopidae)
}

\section{CALEB CALIFRE MARTINS}

Dissertação apresentada à Faculdade de Filosofia, Ciências e Letras de Ribeirão Preto da USP, como parte das exigências para a obtenção do título de Mestre em Ciências, Área: Entomologia.

RIBEIRÃO PRETO - SP

2014 


\section{CALEB CALIFRE MARTINS}

\section{Morfologia e filogenia de Ceraeochrysa Adams, 1982 (Neuroptera: Chrysopidae)}

Dissertação apresentada à Faculdade de Filosofia, Ciências e Letras de Ribeirão Preto da USP, como parte das exigências para a obtenção do título de Mestre em Ciências, Área: Entomologia.

Área de concentração: Sistemática

Orientador: Prof. Dr. Dalton de Souza Amorim 
Autorizo a reprodução e divulgação total ou parcial deste trabalho, por qualquer meio convencional ou eletrônico, para fins de estudo e pesquisa, desde que citada a fonte.

Martins, Caleb Califre

Morfologia e filogenia de Ceraeochrysa Adams, 1982

(Neuroptera: Chrysopidae). Ribeirão Preto, 2014.

VII + 142 p. : 108 il. ; $30 \mathrm{~cm}$

Dissertação de Mestrado, apresentada à Faculdade de Medicina de Ribeirão Preto/USP. Área de concentração: Entomologia.

Orientador: Amorim, Dalton de Souza.

1. Neuroptera. 2. Chrysopidae. 3. Chrysopinae. 4. Chrysopini. 5. Ceraeochrysa. 6. Análise filogenética. 7. Morfologia. 8. Distribuição geográfica. 
Nome: MARTINS, Caleb Califre

Título: Morfologia e filogenia de Ceraeochrysa Adams, 1982 (Neuroptera: Chrysopidae)

Dissertação apresentada à Faculdade de Filosofia, Ciências e Letras de Ribeirão Preto da USP, como parte das exigências para a obtenção do título de Mestre em Ciências, Área: Entomologia.

Aprovado em: 08 de abril de 2014

\section{Banca examinadora}

Prof. Dr. Dalton de Souza Amorim (Orientador)

Instituição/Unidade: Universidade de São Paulo/ Faculdade de Filosofia, Ciências e Letras de Ribeirão Preto (FFCLRP).

Prof. Dr. Eduardo Andrade Botelho de Almeida

Instituição/Unidade: Universidade de São Paulo/ Faculdade de Filosofia, Ciências e Letras de Ribeirão Preto (FFCLRP).

Dr. ${ }^{a}$ Rogéria Inês Rosa Lara

Instituição/Unidade: Agência Paulista de Tecnologia dos Agronegócios. 


\section{DEDICATÓRIA}

Dedico esta dissertação, bem como todos os outros trabathos acadêmicos que farei, para o amigo Prof. Dr. Sérgio de Freitas, $\sigma$ qual infelizmente não estará presente para presenciar $\sigma$ final de un cicto que só foi reatizado devido à sua grande ajuda.

Apesar do Prof. Sérgio de Freitas ter ensinado como eu devo reatizar boa ciência pensando no POR QUE, PRA QUE e O QUE de todos os trabathos que pretendo fazer, en sempre me lembrarei dele pela sua amizade e principalmente pelo grande exemplo de vida que foi.

Agradeço muito seus ensinamentos, não só acadêmicos, mas também os pessoais.

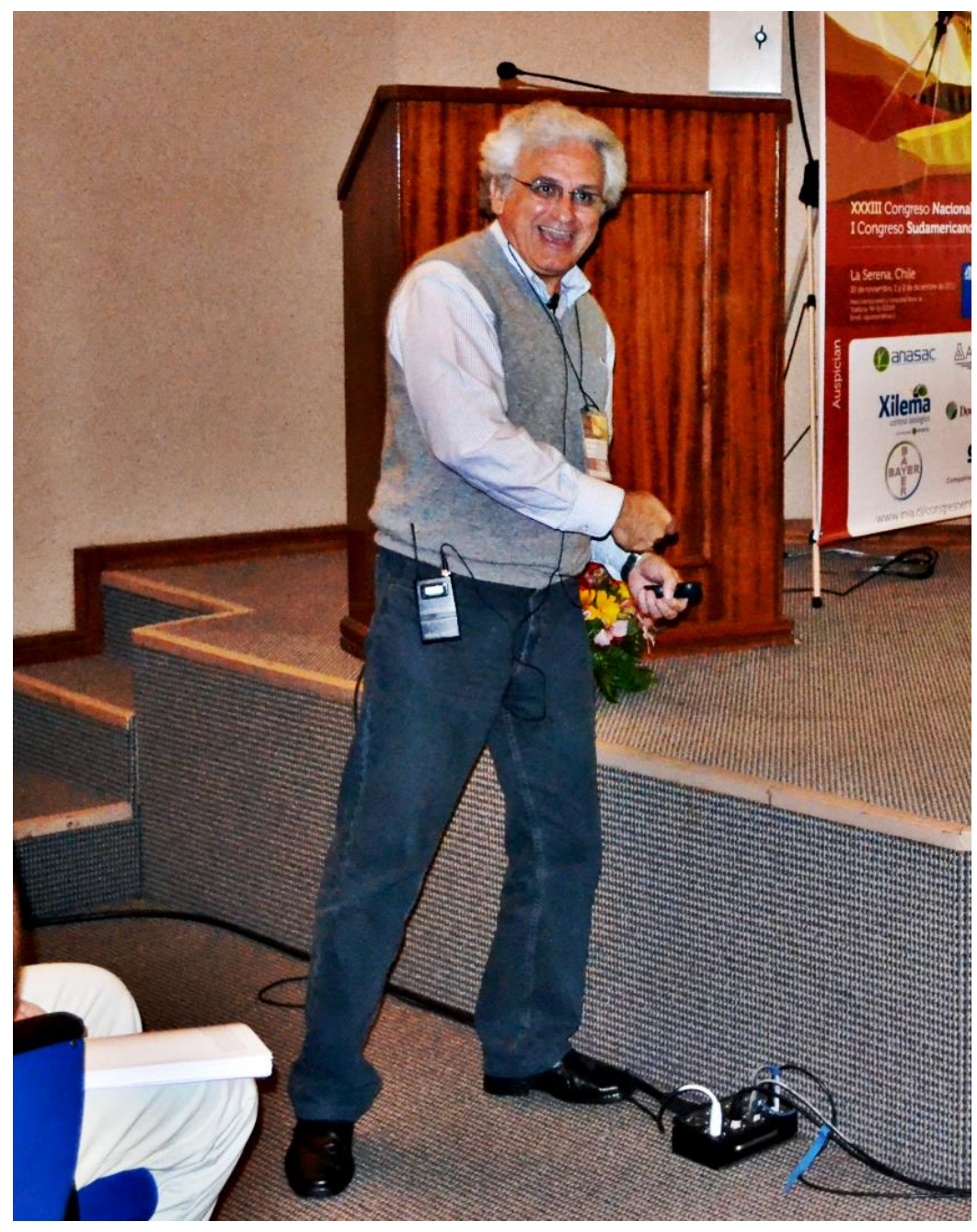




\section{AGRADECIMENTOS}

Como todo trabalho reatizado, esta dissertação só foi finalizada com $\sigma$ auxitio de várías pessoas. Então gostaría de agradecer:

primeiramente aos meus pais Aparecido C. M. Júnior e Wilmara A. C. Martins, pois sei muito bem todas as coisas que deixaram de realizar para que en pudesse chegar até este momento. Serei eternamente grato a vocês,

á minha irmã Pâmela G. C. Martins, meu cunhado Fábio Roque e mew afithado Katiel Martins Roque pelo amor e amizade que têm comigo;

á minha noiva Alana C. D. B. Malerbo, pela paciência, amizade, companheirismo e por aguentar todas minhas "depressöes" durante esses 8 anos,

á minha familia como un todo, pois, assim como uma reta é construida por infinitos pontos, a minha história foi construida com a somatória das histórias dessas pessoas;

ao men orientador Dalton de Souza Amorim, pela oportunidade oferecida e por acreditar que en seria capaz de exercer o meu trabatho da methor maneira possivel;

aos mais novos membros da familia Califre Martins, $\sigma$ mew amigo Prof. Dr. Francisco Jose Sosa Duque e sua esposa Maira Roa pela atenção que tiveram comigo na minha estadia venezuelana e principalmente pela amizade;

ao pessoal da Universidad Centroccidental Lisandro Alvarado, destacando-se o Prof. Dr. Francisco Diaz, pessoa com sabedoría e coração imensuráveis,

á Beloca (Maria Isabel Prottu de Andrade Balbi) pelo grande companheirismo diário;

ao pessoal dos laboratórios: Anne Costa, Daércio Lucena, Daniel Carmo, Diego Sasso, Fábio Quinteiro, Gabriela Pírani, 
Marco Marinho, Matens Santos, Moysés Elias Neto, Rafael Moretto, Rafaela Falaschi, Renato Capellari, Sarah de Oliveira, pela grande amizade e paciência que tiveram comigo nesses dois anos, mas gostaria de dar um agradecimento especial para Danilo Ament, Diego Fachin e Paula Ríccardi pela grande paciêncía que tiveram ao ensinar-me como trabalhar com váríos programas necessários nesta dissertação;

aos meus amigos, principalmente Bruno Andrion, Pedro H. F. Peres, Bruno Conte, Marcelo Lázaro e Rafael Rodrigues pela amizade e confiança;

aos amigos Prof. Dr. Eduardo Almeida e Dr. ${ }^{a}$ Rogéria Inês Rosa Lara, por aceitarem $\sigma$ convite de compor a banca examinadora desta dissertação;

aos funcionários da Universidade de São Pauto, pois sem eles nem mesmo as methores universidades do mundo funcionariam de modo correto, porém, gostaria de destacar a Renata Andrade Cavallari e Vera C. C. de Lucca - pela paciencia em responder todas as dividas surgidas nesses dois anos - e a "Cídinha" por deixar minhas manhãs mais animadas,

à Faculdade de Ciencias Agrárias e Veterinárias, UNESP, Campus de Jaboticabal, pelo empréstimo do material necessário para a realização da dissertação;

à Universidad Centroccidental Lisandro Alvarado pelo auxilio com material biológico venezuelano utilizado;

ao Departamento de Biologia da Faculdade de Filosofia Ciencias e Letras de Ríbeirão Preto - SP;

ao Laboratório de Microscopia Eletrônica da Faculdade de Medicina de Ribeirão Preto-SP;

à FAPESP pelo auxitio financeiro (No Proc. 2012/12157-9). 


\section{RESUMO}

Este trabalho faz uma descrição detalhada da morfologia de Ceraeochrysa, mapas de distribuição, listas de ocorrência de espécies em cultivos agrícolas para o Brasil e um estudo das relações filogenéticas entre as espécies do gênero. A análise filogenética incluiu 62 espécies de Ceraeochrysa, quatro espécies de grupos externos ao gênero em vários níveis e 50 caracteres morfológicos. Um total de 11 espécies para as quais havia pouca informação sobre machos foram inseridas na matriz uma a uma em análises separadas, de modo a diminuir o efeito de informação ausente. Foi obtida uma única árvore mais parcimoniosa, que corrobora a hipótese de monofilia do gênero. Das características consideradas sinapomórficas para Ceraeochrysa-presença de espermateca alongada e de gonapse-, a primeira é plesiomórfica para C. placita e $C$. intacta (que têm a espermateca no formato pill-box), recuperadas como irmãs do restante de Ceraeochrysa, já a segunda característica está presente também nas espécies de Cryptochrysa. O estudo da morfologia gerou uma quantidade importante de caracteres que poderão ser utilizados em novas análises filogenéticas de Chrysopidae. A maioria das espécies brasileiras de Ceraeochrysa é de distribuição conhecida da Amazônia, da Mata Atlântica e do Cerrado, mas não há informação suficiente para um estudo biogeográfico do gênero. Entre as espécies brasileiras, C. cincta, C. cubana e $C$. claveri são as que têm maior distribuição geográfica e ocorrem em grande diversidade de plantações agrícolas.

Palavras chave: Neuroptera, Chrysopidae, Chrysopinae, Chrysopini, Ceraeochrysa, Análise filogenética, Morfologia, Distribuição geográfica. 


\begin{abstract}
This work has a detailed study of the morphology of Ceraeochrysa, distribution maps for the species of the genus, lists of occurrences in crops of the Brazilian species and a phylogenetic analysis of the relationships between the species of the genus. The phylogenetic study included 62 species of Ceraeochrysa, with four outgroup species and 50 morphological characters. A total of 11 species for which there is missing data for males were included in the matrix one by one and analysed independently, so negative effect of missing data in the analysis could be reduced. The monophyly of the genus was recovered, but no uniquely derived characters were found. Of the features often considered synapomorphies of Ceraeochrysa-the presence of an elongated spermatheca and the presence of a gonapsis - the former of spermatheca is plesiomorphic for $C$. placita and $C$. intacta (which have pill-box format), recovered as sister species for the remaining of the genus, while a gonapsis was seen to also occur in Criptochrysa. The detailed morphological study resulted in a lot of information that can be used in robust phylogenetic studies of the Chrysopidae. Most of the Brazilian species of Ceraeochrysa are known from the Amazon, the Atlantic Forest and the Cerrado, but there is not information enough for a biogeographic study of the genus. Among the Brazilian species, C. cincta, C. cubana, and C. claveri are those that have most widely distributed and occur in great variety of agricultural crops.
\end{abstract}

Keywords: Chrysopidae, Chrysopinae, Chrysopini, Ceraeochrysa, Phylogenetic analysis, Morphology, Geographic distribution. 


\section{LISTA DE FIGURAS}

Figura 1. Microscopia eletrônica de varredura da cápsula cefálica de Ceraeochrysa cincta (Schneider, 1851) (Chrysopidae: Chrysopinae).

Figura 2. Tentório de Ceraeochrysa, Adams, 1982 (Chrysopidae: Chrysopinae).

Figura 3. Microscopia eletrônica de varredura da antena de Ceraeochrysa cincta (Schneider, 1851) (Chrysopidae: Chrysopinae).

Figura 4. Padrão de manchas do escapo de Ceraeochrysa, Adams, 1982, vista dorsal.

Figura 5. Peças bucais de Ceraeochrysa Adams, 1982 (Chrysopidae: Chrysopinae).

Figura 6. Microscopia eletrônica de varredura das peças bucais de Ceraeochrysa cincta (Schneider, 1851) (Chrysopidae: Chrysopinae).

Figura 7. Cérvix e protórax de Ceraeochrysa Adams, 1982 (Chrysopidae: Chrysopinae), vista lateral.

Figura 8. Microscopia eletrônica de varredura do protórax de Ceraeochrysa cincta (Schneider, 1851) (Chrysopidae: Chrysopinae).

Figura 9. Microscopia eletrônica de varredura do protórax de Ceraeochrysa cincta (Schneider, 1851) (Chrysopidae: Chrysopinae).

Figura 10. Padrão de manchas do protórax de Ceraeochrysa (Schneider, 1851) (Chrysopidae: Chrysopinae), vista dorsal.

Figura 11. Microscopia eletrônica de varredura do pterotórax de Ceraeochrysa cincta (Schneider, 1851) (Chrysopidae: Chrysopinae), vista dorsal.

Figura 12. Microscopia eletrônica de varredura do pterotórax de Ceraeochrysa cincta (Schneider, 1851) (Chrysopidae: Chrysopinae), vista ventral.

Figura 13. Pterotórax de Ceraeochrysa Adams, 1982 (Chrysopidae: Chrysopinae) vista lateral. A) Pterotórax de $C$. cincta (Scheneider, p. 34 1851).

Figura 14. Pernas de Ceraeochrysa claveri (Navás, 1911) (Chrysopidae: Chrysopinae), vista lateral.

Figura 15. Microscopia eletrônica de varredura do ápice da perna protorácica de Ceraeochrysa cincta (Schneider, 1851) (Chrysopidae: Chrysopinae).

Figura 16. Esquema dos escleritos axilares de Ceraeochrysa Adams, 1982 (Chrysopidae: Chrysopinae).

Figura 17. Esquema das nervuras alares de Ceraeochrysa Adams, 1982 (Chrysopidae: Chrysopinae).

Figura 18. Esquema geral do abdômen de Ceraeochrysa Adams, 1982 (Chrysopidae: Chrysopinae), vista lateral.

Figura 19. Microscopia eletrônica de varredura do ápice abdominal de Ceraeochrysa cincta (Schneider, 1851) (Chrysopidae: 
Figura 20. Genitálias masculinas de Ceraeochrysa Adams, 1982 (Chrysopidae: Chrysopinae).

Figura 21. Esquema em vista dorsal de genitálias femininas de Ceraeochrysa Adams, 1982 (Chrysopidae: Chrysopinae).

Figura 22. . Estruturas de Joguina constellata (Navás, [1913]) (Chrysopidae: Apochrysinae).

Figura 23. Estruturas de Chrysoperla genanigra Freitas, 2003 (Chrysopidae: Chrysopinae).

Figura 24. Estruturas de Chrysopodes (C.) polygonica Adams \& Penny, 1987 (Chrysopidae: Chrysopinae).

Figura 25. . Estruturas de Criptochrysa chloros Freitas \& Penny, 2001 (Chrysopidae: Chrysopinae).

Figura 26. Árvore obtida da análise filogenética de 51 espécies de Ceraeochrysa Adams, 1982 (Chrysopidae: Chrysopinae).

Figura 27. Árvore obtida da análise filogenética de 51 espécies de Ceraeochrysa Adams, 1982 (Chrysopidae: Chrysopinae) numerada.

Figura 28. Vista frontal esquemática da cabeça de Chrysopidae (Neuroptera), com destaque para o palpo maxilar.

Figura 29. Vista frontal esquemática da cabeça de Chrysopidae (Neuroptera), com destaque para a gena de Chrysopidae.

Figura 30. Vista frontal esquemática da cabeça de Chrysopidae (Neuroptera), com destaque para o clípeo de Chrysopidae.

Figura 31. Vista frontal esquemática da cabeça de Chrysopidae (Neuroptera), com destaque para a fronte.

Figura 32. Vista dorsal esquemática da cabeça de Chrysopidae (Neuroptera), com destaque para a área pós-ocular.

Figura 33. Vista dorsal esquemática da cabeça de Chrysopidae (Neuroptera), com destaque para o escapo.

Figura 34. Vista dorsal esquemática da cabeça de Chrysopidae (Neuroptera), com destaque para a presença de mancha no pedicelo.

Figura 35. Vista dorsal esquemática da cabeça de Chrysopidae (Neuroptera), com destaque para o pedicelo.

Figura 36. Vista dorsal esquemática da cabeça e pronoto de Chrysopidae (Neuroptera).

Figura 37. Vista dorsal esquemática da cabeça, pronoto e mesonoto de Chrysopidae (Neuroptera), com destaque para as manchas mesonotais.

Figura 38. Asa anterior de Chrysopidae (Neuroptera), com destaque para as nervuras gradiformes. 
Figura 39. Base da asa anterior de Chrysopidae (Neuroptera), com destaque para a nervura basal costal.

Figura 40. Base da asa anterior de Chrysopidae (Neuroptera), com destaque para as nervuras A1 e A2.

Figura 41. Base da asa anterior de Chrysopidae (Neuroptera), com destaque para a primeira nervura transversal intercubital.

Figura 42. Asa anterior de Chrysopidae (Neuroptera), com destaque para as forquilhas marginais.

Figura 43. Asa anterior de Chrysopidae (Neuroptera), com destaque para a célula cubital distal.

Figura 44. Asa anterior de Chrysopidae (Neuroptera), com destaque para as nervuras gradiformes.

Figura 45. Asa anterior de Chrysopidae (Neuroptera), com destaque para a célula gradiforme 1 .

Figura 46. Asa posterior de Chrysopidae (Neuroptera), com destaque para as nervuras gradiformes.

Figura 47. Asa posterior de Chrysopidae (Neuroptera), com destaque para a célula gradiforme 1.

Figura 48. Asa posterior de Chrysopidae (Neuroptera), com destaque para as gradiformes da asa posterior de Chrysopidae.

Figura 49. Vista dorsal esquemática da espermateca de Chrysopidae (Neuroptera).

Figura 50. Vista dorsal esquemática da espermateca de Chrysopidae (Neuroptera).

Figura 51. Vista dorsal esquemática do ducto espermático de Chrysopidae.

Figura 52. Vista esquemática dorsal da espermateca de Chrysopidae (Neuroptera), com destaque para a vela externa.

Figura 53. Vista lateral esquemática do abdômen masculino de Ceraeochrysa Adams, 1982 (Chrysopidae: Chrysopinae).

Figura 54. Vista ventral esquemática do esternito VIII+IX do abdômen masculino de Ceraeochrysa Adams, 1982 (Chrysopidae: Chrysopinae).

Figura 55. Vista lateral esquemática do abdômen masculino de Ceraeochrysa Adams, 1982.

Figura 56. Vista lateral esquemática do abdômen masculino de Ceraeochrysa Adams, 1982 (Chrysopidae: Chrysopinae), com destaque para o ramo ventral do apodema abdominal masculino.

Figura 57. Vista lateral esquemática da genitália masculina de Ceraeochrysa Adams, 1982 (Chrysopidae: Chrysopinae).

Figura 58. Vista esquemática dorsal do gonossaco de Ceraeochrysa Adams, 1982 (Chrysopidae: Chrysopinae). 
Figura 59. Vista dorsal esquemática da genitália masculina de Ceraeochrysa Adams, 1982 (Chrysopidae: Chrysopinae).

Figura 60. Vista dorsal esquemática da genitália masculina de Ceraeochrysa Adams, 1982 (Chrysopidae: Chrysopinae).

Figura 61. Vista lateral esquemática da genitália masculina de Ceraeochrysa Adams, 1982 (Chrysopidae: Chrysopinae).

Figura 62. Vista lateral esquemática da genitália masculina de Ceraeochrysa Adams, 1982 (Chrysopidae: Chrysopinae).

Figura 63. Vista lateral esquemática da genitália masculina de Ceraeochrysa Adams, 1982 (Chrysopidae: Chrysopinae).

Figura 64. Vista lateral esquemática da genitália masculina de Ceraeochrysa Adams, 1982 (Chrysopidae: Chrysopinae).

Figura 65. Vista lateral esquemática da genitália masculina de Ceraeochrysa Adams, 1982 (Chrysopidae: Chrysopinae).

Figura 66. Vista lateral esquemática da genitália masculina de Ceraeochrysa Adams, 1982 (Chrysopidae: Chrysopinae).

Figura 67. Vista dorsal esquemática da genitália masculina de Ceraeochrysa Adams, 1982 (Chrysopidae: Chrysopinae).

Figura 68. Vista lateral esquemática da genitália masculina de Ceraeochrysa Adams, 1982 (Chrysopidae: Chrysopinae).

Figura 69. Vista dorsal esquemática da genitália masculina de Ceraeochrysa Adams, 1982 (Chrysopidae: Chrysopinae).

Figura 70. Vista lateral esquemática da genitália masculina de Ceraeochrysa Adams, 1982 (Chrysopidae: Chrysopinae).

Figura 71. Vista dorsal esquemática da genitália masculina de Ceraeochrysa Adams, 1982 (Chrysopidae: Chrysopinae).

Figura 72. Vista dorsal esquemática da genitália masculina de Ceraeochrysa Adams, 1982 (Chrysopidae: Chrysopinae), com destaque para o arcesso.

Figura 73. Vista esquemática da genitália masculina de Ceraeochrysa Adams, 1982 (Chrysopidae: Chrysopinae), com destaque para o arcesso.

Figura 74. Vista dorsal esquemática da genitália masculina de Ceraeochrysa Adams, 1982 (Chrysopidae: Chrysopinae), com destaque para o arcesso.

Figura 75. Vista lateral esquemática da genitália masculina de Ceraeochrysa Adams, 1982 (Chrysopidae: Chrysopinae), com destaque para o arcesso.

Figura 76. Vista lateral esquemática da genitália masculina de Ceraeochrysa Adams, 1982 (Chrysopidae: Chrysopinae), com destaque para o lobo apical estreito do arcesso. 
Figura 77. Gonapses de Ceraeochrysa Adams, 1982 (Chrysopidae: Chrysopinae), vista dorsal.

Figura 78. Árvore mais parcimoniosa da análise de Ceraeochrysa Adams, 1982 (Chrysopidae: Chrysopinae) (Freitas et al., 2009).

Figura 79. Genitálias masculinas de Ceraeochrysa Adams, 1982 (Chrysopidae: Chrysopinae), grupo everes, vista dorsal.

Figura 80. Abdômen lateral masculino de Ceraeochrysa Adams, 1982 (Chrysopidae: Chrysopinae), grupo cincta, vista lateral.

Figura 81. Genitália masculina de Ceraeochrysa Adams, 1982 (Chrysopidae: Chrysopinae), grupo cincta, vista dorsal.

Figura 82. Espermateca de Ceraeochrysa Adams, 1982 (Chrysopidae:

Chrysopinae), grupo cincta, vista dorsal.

Figura 83. Genitália masculina de Ceraeochrysa Adams, 1982 (Chrysopidae: Chrysopinae), grupo lineaticornis, vista lateral.

Figura 84. Distribuição geográfica de espécies de 10 Ceraeochrysa Adams, 1982 (Neuroptera: Chrysopidae) que ocorrem no Brasil.

Figura 85. Distribuição geográfica de duas espécies de Ceraeochrysa Adams, 1982 (Neuroptera: Chrysopidae) que ocorrem no Brasil.

Figura 86. Distribuição geográfica de Ceraeochrysa achillea Freitas \& Penny, 2001 (Chrysopidae: Chrysopinae).

Figura 87. Distribuição geográfica de Ceraeochrysa acmon Penny, 1998 (Chrysopidae: Chrysopinae).

Figura 88. Distribuição geográfica de Ceraeochrysa castilloi (Navás, 1913) (Chrysopidae: Chrysopinae).

Figura 89. Distribuição geográfica de Ceraeochrysa cincta (Schneider, 1851) (Chrysopidae: Chrysopinae).

Figura 90. Distribuição geográfica de Ceraeochrysa claveri (Navás, 1911) (Chrysopidae: Chrysopinae).

Figura 91. Distribuição geográfica de Ceraeochrysa cornuta (Navás, 1925) (Chrysopidae: Chrysopinae).

Figura 92. Distribuição geográfica de Ceraeochrysa cubana (Hagen, 1861) (Chrysopidae: Chrysopinae).

Figura 93. Distribuição geográfica de Ceraeochrysa everes (Banks, 1920) (Chrysopidae: Chrysopinae).

Figura 94. Distribuição geográfica de Ceraeochrysa fairchildi (Banks, [1946]) (Chrysopidae: Chrysopinae).

Figura 95. Distribuição geográfica de Ceraeochrysa montoyana (Navás, 1913) (Chrysopidae: Chrysopinae). 
Figura 96. Distribuição geográfica de Ceraeochrysa paraguaria (Navás, 1920) (Chrysopidae: Chrysopinae).

Figura 97. Distribuição geográfica de Ceraeochrysa sanchezi (Navás, 1924) (Chrysopidae: Chrysopinae).

Figura 98. Distribuição geográfica de Ceraeochrysa scapularis (Navás, [1914]) (Chrysopidae: Chrysopinae).

Figura 99. Distribuição geográfica de Ceraeochrysa squalidens Adams \& Penny, [1987] (Chrysopidae: Chrysopinae).

Figura 100. Distribuição geográfica de Ceraeochrysa tucumana (Navás, 1919) (Chrysopidae: Chrysopinae).

Figura 101. Distribuição geográfica de Ceraeochrysa valida (Banks, 1895) (Chrysopidae: Chrysopinae).

Tabela I. Relações entre as subordens de Neuroptera.

Tabela II. Relações entre subfamílias e tribos de Chrysopidae (Neuroptera).

p. 6

Tabela III. Espécies de Ceraeochrysa Adams, 1982 (Chrysopidae:

Chrysopinae) utilizadas para a análise filogenética do gênero, que não foram observados espécimes

Tabela IV. Espécies de Ceraeochrysa Adams, 1982 (Chrysopidae: Chrysopinae) utilizadas estudo comparativo de morfologia de Ceraeochrysa e sua análise Filogenética.

Tabela V. Índice de abreviações de estruturas.

Tabela VI. Matriz com os 66 táxons terminais e 50 caracteres utilizados na análise filogenética.

Tabela VII. Homologia de genitália masculina de Ceraeochrysa Adams, 1982 (Chrysopidae: Chrysopinae). 


\section{SUMÁRIO}

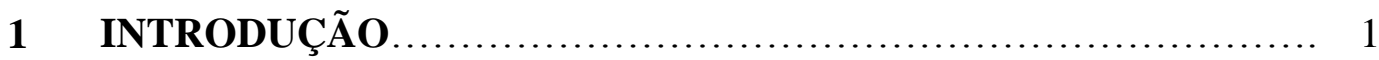

$1.1 \quad$ Ordem Neuroptera.................................................. 1

1.2 Família Chrysopidae............................................ 2

1.3 Gênero Ceraeochrysa Adams, 1982 (Chrysopidae: Chrysopinae)............ 7

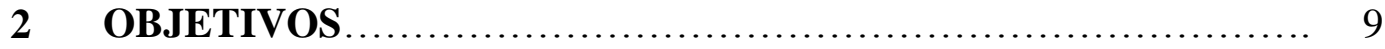

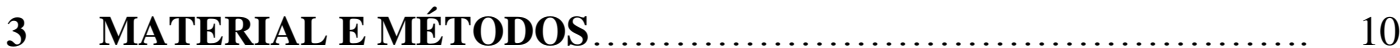

3.1 Material biológico.............................................. 10

3.2 Preparo do material biológico fotografias e desenhos..................... 10

3.3 Preparação do material biológico para o estudo de morfologia..................... 11

3.4 Análise filogenética.......................................... 12

Compilação de dados e montagem de mapas de distribuição geográfica

3.5 das espécies de Ceraeochrysa Adams, 1982 (Chrysopidae: Chrysopinae) 13 com ocorrência no Brasil....

4 RESULTADOS E DISCUSSÃO ................................ 14

4.1 Morfologia comparada de Ceraeochrysa Adams, 1982 (Chrysopidae: 14

4.2 Análise filogenética de Ceraeochrysa Adams, 1982 (Chrysopidae:

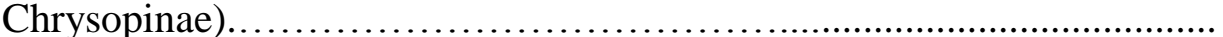

4.3 Distribuição geográfica das espécies de Ceraeochrysa Adams, 1982 (Chrysopidae: Chrysopinae) com registro para o Brasil................. 109

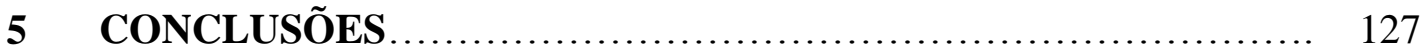

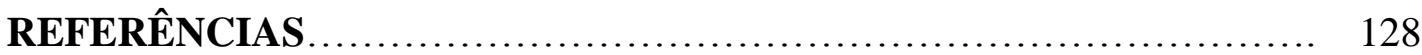

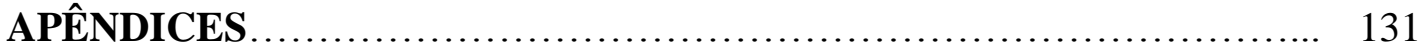




\section{INTRODUÇÃO}

\subsection{Neuroptera}

Os neurópteros são insetos de morfologia bastante conservada dentro de Holometábola e apresentam uma diversidade de formas relativamente menor que a do passado. O grupo inclui insetos com asas diáfanas entremeadas com venação reticulada. Dentre as sinapomorfias da ordem estão a associação do par de gonocoxitos do segmento nove com o gonarco, a mandíbula e maxila das larvas justapostas formando um tubo, o encerramento do intestino médio larval e a parede dupla de seda do casulo pupal (Aspöck et al., 2001; Haring \& Aspöck, 2004).

O tamanho dos adultos varia de dois a $150 \mathrm{~mm}$ de comprimento, apresentam olhos compostos, antenas com vários flagelômeros, aparelho bucal com mandíbulas desenvolvidas, quatro asas membranosas com grande quantidade de veias transversais (principalmente ao longo da área costal) e setor radial na maioria das vezes com ramos paralelos. As asas anteriores e posteriores dispõem de forma, tamanho e venação semelhantes, com exceção de Nemopteridae — na qual as asas posteriores são longas e finas—e de alguns Hemerobiidae que tem asas posteriores menores que as anteriores (Freitas \& Penny, 2012; Triplehorn e Johnson, 2011). A primeira evidência paleontológica definitiva dos Neuroptera é da família Permithonidae, do Permiano (Grimaldi \& Engel, 2005).

Neuroptera tem cerca de 6.000 espécies descritas agrupadas em 17 famílias que estão destribuídas entre três subordens: Nevrorthiformia, Myrmeleontiformia e Hemerobiiformia (Tabela 1) (Aspöck, 1992, 1993, 1995; Aspöck et al., 2001; Haring \& Aspöck, 2004; Aspöc \& Aspöck, 2008; Beutel et al., 2010b; Winterton et al., 2010; Zimermann et al., 2011; Aspöck et al., 2012).

Nevrorthiformia, que inclui somente Nevrorthidae, é considerada irmã de um clado com as outras duas subordens. Myrmeleontiformia apresenta dois subclados: (Nemopteridae + Psychopsidae $)$ e $($ Nymphidae + (Myrmeleontidae + Ascalaphidae $))$. As demais famílias 
pertencem à subordem Hemerobiiformia, o grupo mais heterogêneo e cuja monofilia ainda não está suficientemente estabelecida (Aspöck et al., 2001; Grimaldi \& Engel, 2005). Hemerobiiformia é recuperado como parafilético em vários estudos (Haring \& Aspöck, 2004; Aspöck \& Aspöck, 2008; Winterton et al., 2010; Zimermann et al. 2011)

Tabela I. Relações entre as subordens de Neuroptera.

\begin{tabular}{|l|l|}
\hline \multicolumn{1}{|c|}{ Autor } & \multicolumn{1}{c|}{ Hipótese de relação } \\
\hline Aspöck (1992) & (Nevrorthiformia + (Myrmeleontiformia + Hemerobiiformia)) \\
\hline Aspöck (1993) & (Nevrorthiformia + (Myrmeleontiformia + Hemerobiiformia)) \\
\hline Aspöck (1995) & (Nevrorthiformia + (Myrmeleontiformia + Hemerobiiformia)) \\
\hline Aspöck et al. (2001) & (Nevrorthiformia + (Myrmeleontiformia + Hemerobiiformia)) \\
\hline Haring \& Aspöck (2004) & (Nevrothiformia + (“Hemerobiiformia”+Myrmeleontiformia)) \\
\hline Aspöck \& Aspöck (2008) & (Nevrorthiformia + (“Hemerobiiformia”+Myrmeleontiformia)) \\
\hline Beutel et al. (2010b) & (Nevrorthiformia + (Myrmeleontiformia + Hemerobiiformia)) \\
\hline Winterton et al. (2010) & (Nevrorthiformia + (“Hemerobiiformia”+Myrmeleontiformia)) \\
\hline Zimmermann et al. (2011) & (Nevrorthiformia + (“Hemerobiiformia”+Myrmeleontiformia)) \\
\hline Aspöck et al. (2012) & (Nevrothiformia + (“Hemerobiiformia”+Myrmeleontiformia)) \\
“”. Parafilia &
\end{tabular}

\subsection{A família Chrysopidae}

Chrysopidae pertencente à subordem Hemerobiiformia, é a segunda maior família de Neuroptera, conhecida de todos os continentes exceto a Antártica tem mais de 1.500 espécies descritas em 81 gêneros distribuídos em três subfamílias (Tabela 2).

Nothochrysinae tem registros de ocorrência nas regiões Afrotropical, Paleártica, Australiana e Neártica (Brooks \& Barnard, 1990). Essa subfamília apresenta nove gêneros que dispõem de adultos com cabeça estreita e alongada, com o vértice abobadado; palpos maxilares e labiais arredondados apicalmente; antena menor que a asa anterior, com o pedicelo fortemente constrito medialmente e flagelômeros estreitos; asas com nervura pseudomediana pequena, que continua nas nervuras gradiformes internas; órgão timpânico na base das asas ausente. Macho: Ectoprocto masculino com pequena invaginação apical; gonarco arqueado; entoprocesso presente; tigno, gonapse, placa mediana, gonocrista e espinela ausentes. Fêmeas: ectoprocto e tergito IX não são totalmente fundidos; subgenitália 
bilobada apicalmente e estendida basalmente; espermateca grande quando comparada com as fêmeas das outras subfamílias (Brooks \& Barnard, 1990).

Apochrysinae tem distribuição pantropical, já teve status de família (Handlirsch, 1906-1908) e inclui seis gêneros (Winterton \& Brooks, 2002). Os adultos apresentam como principais características a cabeça estreita com vértice achatado; palpos maxilares e labiais largos e curtos; antenas maiores que as asas anteriores, com flagelômeros estreitos e cinco anéis de cerdas; asas anteriores grandes (entre 18 e $34 \mathrm{~mm}$ de comprimento) com nervuras densamente reticuladas, cerdas costais longas, área costal larga e manchas negras na área discal (Brooks \& Barnard, 1990); protórax estreito. Macho tem gonarco estreito e arqueado; arcesso curto e triangular com um gancho apical; gonosetas normalmente ausentes ou muito reduzidas; gonapse, placa mediana, tigno, pseudopênis, gonocrista, espinele e entoprocesso ausentes. As fêmeas apresentam subgenitália bilobada; espermateca longa e larga, com vela curta (Brooks \& Barnard, 1990).

Chrysopinae, a maior subfamília de Chrysopidae, apresenta 66 gêneros, distribuídos globalmente. Todas as espécies têm quatro anéis de cerdas nos flagelômeros. Nessa subfamília estão inclusas mais de $97 \%$ das espécies descritas da família, divididas em quatro tribos (Brooks \& Barnard, 1990; Adams \& Penny, 1987).

Ankylopterygini inclui cinco gêneros, encontrados nas regiões Afrotropical e Oriental (Brooks \& Barnard, 1990). Os adultos apresentam a cabeça curta e estreita com vértice elevado; palpos maxilares e labiais estreitos e alongados apicalmente; mandíbulas em forma de foice; antenas com flagelômeros estreitos; protórax estreito e curto; asa anterior marcada com pontos negros, normalmente com grande quantidade de cerdas e célula intramediana estreita e oval; asas posteriores estreitas; abdômen com cerdas longas e escassas; esternitos VIII e IX fundidos (Brooks \& Barnard, 1990).

Macho têm gonarco pouco arqueado; arcesso estreito e longo; gonosetas e entoprocessos normalmente presentes; tigno, gonapse, parâmeros e placa mediana ausentes. As fêmeas não apresentam subgenitália e a espermateca é estreita (Brooks \& Barnard, 1990). 
Belonopterygini agrupa 14 gêneros e tem distribuição cosmopolita. (Brooks \& Barnard, 1990). Suas espécies são as de morfologia mais conservada dentro de Chrysopinae, apresentando condição plesiomórfica para muitas características modificadas nos demais crisopideos. Adultos aprsentesm cabeça larga com vértice achatado; palpos maxilares e labiais largos e arredondados apicalmente; mandíbulas largas; antena com flagelômeros largos com quatro anéis de cerdas; protórax largo; asa anterior com área costal estreita na base e cerdas costais curtas, célula intramediana quadrangular ou grosseiramente oval; abdômen com muitas cerdas curtas e ectoprocto largo, não fundido dorsalmente com o tergito IX (Brooks \& Barnard, 1990).

Os machos apresentam gonarco curto e largo; arcesso normalmente curto e largo, com gancho mediano; parâmeros e entoprocesso normalmente presentes; pseudopênis, tigno, placa mediana, gonapse e gonosetas ausentes. As fêmeas tem espermateca com vela externa e ducto espermático longo; pré-genitália normalmente presente.

Leucochrysini inclui oito gêneros, encontrados nas regiões Neotropical e Neártica. Adultos apresentam vértice convexo; palpos maxilares e labiais com o ápice cônico; mandíbulas largas e assimétricas, com um dente na mandíbula esquerda; antena maior que a asa anterior, com flagelômeros longos e estreitos, os quais apresentam quatro anéis de cerdas; protórax estreito; asa anterior com mancha negra no pterostigma e célula intramediana quadrangular ou grosseiramente oval; abdômen com cerdas longas e escassas. Macho tem gonarco curto e largo com gancho medial; arcesso com lobos laterais curtos; gonosetas podem estar presentes; tigno, gonapse, entoprocesso e parâmetros ausentes. Fêmea com impressão ventral profunda e espermateca estreita, com vela muito curta; subgenitália estendida e pouco curvada basalmente, encaixada em uma grande placa (Brooks \& Barnard, 1990).

Chrysopini Schneider, 1851 é a maior tribo em Chrysopinae, com 36 gêneros, presentes no mundo todo. Os adultos apresentam cabeça larga; palpos maxilares e labiais cônicos apicalmente; mandíbulas largas, com um dente na base da mandíbula esquerda, algumas vezes também presente na mandíbula direita; flagelômeros longos; asa com célula 
intramediana oval, podendo em raras circunstâncias ser quadrangular; abdômen com cerdas longas e escassas (Brooks \& Barnard, 1990). Macho tem gonarco arqueado; arcesso estreito e afunilado apicalmente; gonosetas presentes; tigno, gonapse e pseudopênis podem estar presentes (Brooks \& Barnard, 1990). A fêmea não apresenta pré-genitália e sua espermateca é estreita (Brooks \& Barnard, 1990). Devido à importância econômica da maioria das espécies desta tribo, sua biologia é a mais conhecida dentro da família.

Em 2001, Aspock et al. realizaram uma análise filogenética com dados moleculares de larvas e adultos, e na topologia resultante Chrysopidae foi recuperado como grupo-irmão de Osmylidae e (Chrysopidae + Osmylidae) como grupo-irmão de (Hemerobiidae + $(($ Coniopterygidae + Sisyridae $))+(($ Dilaridae + (Mantispidae + (Rachiberothidae + Berothidae))). O clado que inclui Osmylidae e Chrysopidae tem como sinapomorfia o cardo mais curto do que a metade do comprimento da cápsula cefálica, ausência de gula e presença da constricção terminal do cardo.

Aspöck \& Aspöck (2008), por sua vez, utilizaram dados de morfologia de escleritos genitais e recuperaram Chrysopidae como grupo-irmão de Hemerobiidae, clado que possui como sinapomorfia a presença dos braços laterais do gonarco em forma de asa. Essa hipótese foi corroborada por Winterton et al. (2010) com o auxílio de dados moleculares e morfológicos.

Apesar de a posição de Chrysopidae como grupo-irmão de Hemerobiidae ser relativamente bem aceita (Aspöck \& Aspöck, 2008; Winterton et al., 2010; Aspöck et al., 2012), o conhecimento da relação entre suas tribos e gêneros ainda é limitado e problemático. Tradicionalmente, a classificação de crisopídeos foi baseada na venação alar, porém, estudos realizados por Brooks \& Barnard (1990) que utilizaram 120 caracteres de asas anteriores e posteriores, abdômen, cabeça, tórax, antenas, pernas e genitália de machos e fêmeas proporcionaram uma circunscrição mais uniforme das tribos e gêneros, principalmente para Chrysopini. 
Winterton \& Freitas (2006) utilizaram dados de dois genes mitocondriais e um gene nuclear para 33 espécies de 18 gêneros de Chrysopidae e propuseram a primeira filogenia molecular de crisopídeos. Esse estudo corroborou a monofilia de Chrysopidae e recuperou Apochrysinae como grupo-irmão de (Notochrysinae + Chrysopinae) discordando de New (1989), Brooks \& Barnard (1990) e Winterton \& Brooks, (2002), os quais propuseram baseados em dados morfológicos Nothochrysinae como grupo-irmão do restante da família e de

Em 2008, Haruyama et al. utilizaram dados de três genes nucleares de 83 espécies de 24 gêneros e também realizaram análise filogenética molecular de Chrysopidae, porém, recuperaram Apochrysinae + Nothochrysinae como grupo irmão de Chrysopinae, discordando das hipóteses já propostas.

Haruyama et al. (2008) não utilizou espécies de Leucochrysini, recuperou Belonopterygini e Ankylopterygini como grupos monofiléticos, e não recuperou Chrysopini como monofilético, ao contrário de Winterton \& Freitas (2006) que recuperaram Chrysopini como grupo-irmão de (Belonopterygini + (Leucochrysini + Ankylopterygini)), concordando com Brooks \& Barnard (1990).

Tabela II. Relações entre subfamílias e tribos de Chrysopidae (Neuroptera).

\begin{tabular}{|l|l|}
\hline \multicolumn{1}{|c|}{ Autor } & \multicolumn{1}{c|}{ Hipótese de relação } \\
\hline New (1989) & (Nothochrysinae + (Apochrysinae + Chrysopinae) $)$ \\
\hline Brooks (1990) & $\begin{array}{l}\text { (Nothochrysinae+(Apochrysinae + (Belonopterygini }+ \\
\text { (Ankylopterygini, Leucochrysini, Chrysopini) }))\end{array}$ \\
\hline Winterton \& Brook (2002) & (Nothochrysinae + (Apochrysinae + Chrysopinae) $)$ \\
\hline $\begin{array}{l}\text { Winterton \& Freitas } \\
(2006)\end{array}$ & $\begin{array}{l}\text { (Apochrysinae +( Nothochrysinae + (Chrysopini +( } \\
\text { Leucochrysini + (Belonopterygini + } \\
\text { Ankylopterygini, }))))\end{array}$ \\
\hline Haruyama et al. $(2008)$ & $\begin{array}{l}\text { (Nothochrysinae + Apochrysinae })+(\text { Chrysopini, } \\
\text { Belonopterygini, Ankylopterygini)* }\end{array}$ \\
\hline
\end{tabular}

*Não utilizou Leucochrysini. 


\subsection{Gênero Ceraeochrysa Adams, 1982 (Chrysopidae: Chrysopinae)}

Dentre os gêneros de Chrysopini encontrados na região Neotropical, Ceraeochrysa Adams, 1982 se destaca como o maior gênero da tribo nesta região (Brooks \& Barnard, 1990).

As espécies desse gênero são amplamente distribuídas nas Américas, Caribe e Antilhas; no Brasil são encontradas 28 espécies, sendo sua maioria com distribuição restrita a poucos estados. Ceraeochrysa apresenta espécies verdes e sem características morfológicas externas muito destacáveis, contudo, marcas vermelhas ou marrons são encontradas com frequência na lateral do pronoto e no escapo, bem como nervuras transversais escuras. Machos podem ser reconhecidos pela gonapse alongada entre os esternitos VIII e IX e as fêmeas por sua espermateca alongada em forma de "U" (Brooks \& Barnard, 1990; Freitas et al., 2009).

As espécies de Ceraeochrysa são encontradas normalmente em bordas de florestas, com frequência ao redor de culturas agrícolas; apresentam grande potencial para serem utilizadas em programas de controle biológico, pois suas larvas se alimentam de grande número de insetos de corpo mole, incluindo pulgões, cochonilhas e lepidópteros, vários dos quais são pragas agrícolas (Freitas et al., 2009).

Quando Adams (1982) propôs o gênero Ceraeochrysa, baseado principalmente em caracteres da genitália masculina, ele reconheceu 24 espécies e 52 sinonímias. Brooks \& Banard (1990), por sua vez, revisaram os gêneros de Chrysopidae e reconheceram 40 espécies em Ceraeochrysa.

Freitas et al. (2009) revisaram Ceraeochrysa e, posteriormente, Tauber \& Flint (2010) forneceram informações para resolver algumas imprecisões da revisão, o que ajudou a elucidar controvérsias a respeito do status de algumas espécies. Sosa \& Freitas $(2010,2011)$ descreveram três espécies e propuseram a sinonímia de C. acutipuppis Adams \& Penny, 1985. Ceraeochrysa agrupa 62 espécies válidas, das quais 28 são encontradas no Brasil. 
Apesar do trabalho realizado por Freitas et al. (2009) ter auxiliado muito no entendimento da sistemática de Ceraeochrysa, ainda é necessário um estudo filogenético do gênero com novos caracteres menos homoplásticos. A análise realizada por esses autores apresentou grandes politomias, com compreensão ainda limitada das relações filogenéticas entre as espécies. Os três principais grupos de espécies-everes, cincta e lineaticornis—não foram recuperados como monofiléticos na análise de Freitas et al. (2009).

Devido à importância de Ceraeochrysa e da relativa falta de estudos taxonômicos mais detalhados do gênero, é particularmente importante um estudo de morfologia comparada com ampla amostragem do gênero, bem como das relações filogenéticas das espécies de Ceraeochrysa. 


\section{OBJETIVOS}

Este estudo teve por objetivos principais a realização de uma análise cladística e um estudo detalhado de morfologia comparada das espécies de Ceraeochrysa. Como objetivos complementares foram realizados mapas de distribuição geográfica e compilação de dados sobre a ocorrência em cultivos agrícolas e em ambientes naturais das espécies que ocorrem no Brasil. 


\section{MATERIAL E MÉTODOS}

\subsection{Material biológico.}

Para as 30 espécies que não foram observados espécimes (Tabela 3) utilizaram-se dados da literatura (Freitas et al., 2009; Tauber \& Flint, 2010). Os espécimes das 32 espécies de Ceraeochrysa Adams, 1982 observadas (Tabela 4) foram provenientes de quatro fontes distintas.

1) Coleção particular do Prof. Dr. Sergio de Freitas que se encontra na Universidade Estadual Paulista, câmpus de Jaboticabal. Observou-se material de 20 espécies de Ceraeochrysa e outros três gêneros utilizados como grupos externos. Todo o material está mantido em via seca.

2) Coleção do Museo Entomológico Dr. "José Manuel Osorio", localizado na Universidad Centroccidental "Lisandro Alvarado, Barquisimeto, Venezuela. Foram observadas 11 espécies de Ceraeochrysa e Joguina constellata (Navás, [1913]). O Prof. Dr. Francisco Jose Sosa Duque também forneceu fotos dessas espécies.

3) Material do projeto Biota-Diptera, proveninente de coletas na Floresta Atlântica entre Santa Catarina e Paraíba. O material está em álcool armazenado na Universidade de São Paulo, câmpus de Ribeirão Preto. Observou-se material de seis espécies do gênero.

4) Material proveniente de coletas realizadas em pomares de citrus, manga, abacate e fragmentos de matas da região de Ribeirão Preto. Foram observadas 11 espécies de Ceraeochrysa, que estão armazenadas na Universidade de São Paulo, câmpus de Ribeirão Preto.

\subsection{Preparo do material biológico para fotografias e desenhos.}

Os adultos foram fotografados com estereomicroscópio Leica MZ16 e filmadora Leica DC500 e as fotos foram montadas com a utilização do programa Auto Montage. Desenhos das estruturas morfológicas foram feitos com o auxílio de camara lucida, digitalizados, e vetorizados no programa Adobe Illustrator 11.0. Posteriormente, fotos e desenhos foram editados no programa Adobe Photoshop CS4, para que fosse possível a montagem das pranchas. 
Para a observação da terminália, o abdômen de adultos foi cortado entre o segundo e o terceiro segmentos abdominais e a terminália passou pelos seguintes tratamentos.

1. Maceração em hidróxido de potássio a $10 \%$ em $80^{\circ} \mathrm{C}$ por aproximadamente duas horas.

2. Lavagem do interior do abdômen com água, com auxílio de seringa e agulha.

3. Injeção do corante clorazol black com auxílio de seringa e agulha.

4. Depois de alguns segundos, nova lavagem do interior do abdômen com água, para retirada do excesso de corante.

5. Transposição do abdômen para lâmina escavada contendo glicerina líquida.

6. Injeção de glicerina líquida no abdômen para inflá-lo.

7. Extração da genitália sob microscópio estereoscópico, com auxílio de tesoura e estiletes.

8. Observação e mensuração das estruturas da terminália e genitália.

9. Transferência do abdômen e genitália para microtubo de plástico com glicerina líquida, armazenado com o respectivo adulto.

Para a realização das triagens e preparação do material a ser fotografado, fez-se uso de pinças de relojoeiro $\mathrm{n}^{\mathrm{0}} 5$, placas de Petri, picetas, pipetas, álcool $80 \%$, vidraria, potes plásticos e lupas Leica CLS 150 XE. Parte da triagem contou com a participação da Biologista Maria Isabel Protti de Andrade Balbi.

\subsection{Preparação do material biológico para estudo de morfologia.}

Foram utilizadas 32 espécies (Tabela 4) para o estudo de morfologia comparada.

Para um estudo detalhado da morfologia de Ceraeochrysa, machos e fêmeas de Ceraeochrysa cincta (Schneider, 1851) foram fotografados. Cabeça, tórax e abdômen foram fotografados com microscópio eletrônico de varredura JEOL 6510 LV. A terminologia morfológica utilizada seguiu as hipóteses de homologias de Snodgrass (1935), Matsuda (1970) e Friedrish \& Beutel (2010).

O material biológico utilizado na microscopia eletrônica de varredura foi coletado em um pomar de Citrus sp. da região de Jaboticabal. Os espécimes foram introduzidos em glutaraldeído por cerca de duas horas e, posteriormente, armazenado em solução tampão. Nestas duas etapas, o material foi mantido em temperatura próxima de $8{ }^{\circ} \mathrm{C}$.

Após sua fixação, o material foi desidratado em bateria de álcool etílico de 80 a 100\%, com incrementos de 5\%, mantidos por 20 minutos em cada uma das soluções. Foi realizada em seguida a secagem final do material em câmara de "ponto crítico". Em seguida, o material foi colado em um suporte metálico $(s t u b)$ e a amostra recoberta com camada de $50 \mathrm{~nm}$ de ouro.

As asas foram retiradas dos espécimes secos e montadas em lâminas de vidro, enquanto que a genitália passou pela preparação descrita acima e fotografada em glicerina. As 
asas e genitálias foram fotografadas com o auxílio de estereomicroscópio Leica MZ16 e filmadora Leica DC500. As hipóteses de venação alar seguiram basicamente Adams (1996) e a nomenclatura dos escleritos de genitália seguiu Brooks \& Barnard (1990).

As abreviações utilizadas estão na Tabela 5.

\subsection{Análise filogenética.}

O estudo morfológico dos 66 táxons terminais (62 espécies de Ceraeochrysa; Joguina constellata (Navás, [1913]); Chrysoperla genanigra Freitas, 2003; Chrysopodes (Chrysopodes) polygonica Adams \& Penny, 1987 e Criptochrysa chloros Freitas \& Penny, 2001 resultou em 50 caracteres morfológicos, 25 exclusivos de machos e quatro exclusivos de fêmeas, transpostos para uma matriz de dados (Tabela 6) construída com a nova versão do programa Winclada (Nixon, 2002).

Dentre as 62 espécies de Ceraeochrysa utilizadas observaram-se espécimes de 32 espécies (Tabela 4), que também foram utilizados para o estudo de morfologia comparada do gênero. Para as 30 espécies restantes (Tabela 3) utilizaram-se as descrições feitas por Freitas et al. (2009).

11 espécies-Ceraeochrysa adornata (Lacroix, [1926]), Ceraeochrysa anceps (Navás, 1926), Ceraeochrysa castilloi (Navás, 1913), Ceraeochrysa caucana (Banks, 1910), Ceraeochrysa dolichosvela Freitas \& Penny, 2001, Ceraeochrysa fiebrigi (Navás, 1913), Ceraeochrysa indicata (Navás, [1914]), Ceraeochrysa lateralis (Guérin-Méneville, [1844]), Ceraeochrysa rafaeli Adams \& Penny, [1987], Ceraeochrysa reducta (Banks, 1944) e Ceraeochrysa silvanoi (Navás, 1916)-foram retiradas da matriz inicial por serem conhecidas apenas fêmeas e, portanto, possuírem $50 \%$ dos dados faltantes. Análises foram feitas com matrizes incluindo todos os machos e uma dessas espécies de cada vez, o que permitiu posicionar cada espécie sem o efeito negativo sobre a análise do conjunto de espécies conhecidas de cada fêmea.

Séries de transformações foram polarizadas automaticamente, conforme discutido por Nixon \& Carpenter (1993). Para o enraizamento da matriz utilizou-se a espécie Joguina constellata. O uso de uma espécie de Apochrysinae, subfamília considerada irmã das outras duas subfamílias (New, 1989; Brooks \& Barnard, 1990; Winterton \& Freitas, 2006), é mais seguro que o uso de alguma espécie de Chrysopinae, uma vez que as relações entre espécies de Chrysopinae ainda não são particularmente bem resolvidas.

As outras espécies utilizadas como grupos-externos pertencem a Chrysopini, mesma tribo a que pertence Ceraeochrysa. Chrysopodes (Chrysopodes) polygonica e Chrysoperla genanigra foram escolhidas, pois existem semelhanças consideráveis entre espécies desses gêneros e Ceraeochrysa, principalmente na genitália masculina. Os dois gêneros já foram 
considerados os mais próximos filogeneticamente de Ceraeochrysa (Winterton e Freitas, 2006; Freitas et al., 2009). Criptochrysa chloros, por sua vez, foi escolhida, pois tem a gonapse, estrutura frequentemente considerada como sinapomorfia de Ceraeochrysa. Assim, há grupos-externos em níveis sucessivos de proximidade com o grupo-interno, o que permite compreender a evolução de estruturas que compõem o plano-básico do gênero.

As análises de parcimônia foram feitas com o programa TNT (Tree Analysis Using New Technology) (Goloboff et al., 2003-2007). O cladograma mais parcimonioso foi obtido através de algoritmos heurísticos pelo método de bissecção e reconexão de árvores, utilizaram-se como parâmetros: random seed $=0$, hold $=20000$, hold $/=40 \mathrm{em}$ um TBR de 300 replicações. A otimização e a análise da evolução dos caracteres foram realizadas com o auxílio do programa Winclada (Nixon, 2002).

Os caracteres foram codificados de acordo com o modelo de codificação contingente de Forey \& Kitching (2000), que opta pela cisão de caracteres com vários estados em um caráter mais inclusivo de ausência e presença, e um mais específico com os diferentes estados, com o estado de ausência substituído por dados faltantes.

\subsection{Compilação de dados e montagem de mapas de distribuição geográfica das espécies de Ceraeochrysa Adams, 1982 (Chrysopidae: Chrysopinae) com ocorrência no Brasil.}

O estudo da distribuição das espécies de Ceraeochrysa do Brasil foi realizado a partir dos dados de coleta dos exemplares estudados e de outros estudos nos quais houve profunda confiança na identificação ao nível de espécie. Os dados do hábitat onde foi encontrada cada espécie foram compilados com o intuito de auxiliar em futuros programas de controle biológico.

Os mapas de distribuição das espécies foram construídos com auxílio do site http://www.simplemappr.net/ (Shorthouse, 2010). 


\section{RESULTADOS E DISCUSSÃO}

\subsection{Morfologia comparada de Ceraeochrysa Adams, 1982 (Chrysopidae: Chrysopinae). \\ 4.1.1. Cabeça de Ceraeochrysa Adams, 1982 (Chrysopidae: Chrysopinae) e seus apêndices.}

A cabeça hipognata apresenta aspecto retangular, sua largura $(0,9-1,5 \mathrm{~mm})$ é cerca de uma vez e meia maior que seu comprimento $(0,75-1,1 \mathrm{~mm})$. Características sexuais secundárias não são observadas na região cefálica.

Snodgrass (1935) deu nomes distintos às áreas da cápsula cefálica originadas pelas divisões da cabeça. Quando tais suturas craniais estão suprimidas, no entanto, como no caso de Chrysopidae, os limites entre essas regiões cefálicas não podem ser verificados. A cápsula cefálica de Ceraeochrysa não possui a maioria das suturas observadas em outros insetos, ou seja, as regiões da cápsula cefálica não podem ser claramente definidas. As áreas foram nomeadas pela sua localização em relação às outras áreas e aos apêndices da cápsula cefálica.

Suturas da cápsula cefálica de Ceraeochrysa Adams, 1982 (Chrysopidae: Chrysopinae) (Fig. 1).

A única linha que realmente demonstra limite claro entre duas regiões é a sutura pósoccipital. As outras suturas são inflexões secundárias da cutícula existente na cabeça, conforme indicado por Snodgrass (1935), suas localizações auxiliam, contudo, no entendimento da morfologia da cápsula cefálica.

Sutura epicranial. Tanto seu ramo dorsal (sutura coronal) quanto seus ramos ventrais (suturas frontais) são ausentes em Ceraeochrysa.

Sutura subantenal (ssa). Também chamada como sutura frontogenal, localizada lateralmente entre a fronte e a região da gena, tem origem na sutura antenal e ápice na sutura subgenal (Fig. 1). Tal sutura foi nomeada erroneamente por Morse (1931) como sutura frontal em Chrysopa perla (Linnaeus, 1758).

Sutura occipital. Ausente em Ceraeochrysa, como também foi observado em Chrysopa perla (Morse, 1931).

Sutura pós-occipital. Localizada em torno do forâmen occipital; crista pós-occipital localizada internamente, formada pela invaginação da cutícula.

Sutura subgenal (ssg). Apresenta tamanho reduzido e encontra-se na região antero-ventral da gena (Fig. 1).

Sutura epistomal (se). Subdivide a região frontoclipeal em fronte e gena, em sua extremidade encontram-se as fossas tentoriais anteriores (Fig 1). 
Sutura ocular (so). Encontra-se em torno do olho de Ceraeochrysa, e produz uma pequena crista em torno da retina, auxiliando em sua fixação (Fig. 1).

Sutura antenal (sat). É observada circundando o alvéolo antenal de Ceraeochrysa (Fig. 1).

\section{Regiões da cápsula cefálica de Ceraeochrysa Adams, 1982 (Chrysopidae: Chrysopinae)} (Fig. 1).

Occipício. Extremidade posterior da cabeça localizada posteriormente ao vértice; adjacente ao forâmen occipital; sempre verde com poucas cerdas curtas.

Vértice (VE). Arqueado dorsalmente; com poucas cerdas pequenas e esparsas; com coloração verde na maioria das espécies do gênero, mas pode apresentar manchas escuras (Fig. 1), como por exemplo, em Ceraeochrysa nigripes Adams \& Penny, 1987 e Ceraeochrysa elegans Penny, 1998.

Área frontoclipeal (AF). Localizada na região facial entre as antenas e o labro; subdividido em duas áreas (fronte e clípeo) pela sutura epistomal localizada entre as fossas tentoriais anteriores; sutura epicranial ausente, o que torna a fronte e o vértice aparentemente uma única área (Fig. 1).

Fronte é cercada lateralmente pela sutura subantenal, separando-a da área genal; tem poucas cerdas curtas, a maioria na região ventral; completamente verde na maioria das espécies, com exceção de Ceraeochrysa placita (Banks, 1908), Ceraeochrysa intacta (Navas, 1912) e Ceraeochrysa caucana (Banks, 1910) que tem manchas negras ou vermelhas. Fossas tentoriais anteriores (FTA), depressões que marcam os pontos de invaginação da parede corpórea que formam o braço anterior do tentório, tem forma de fenda em Ceraeochrysa (Fig. 1); são conectadas através da sutura epistomal. Clípeo tem largura $(0,37-0,7 \mathrm{~mm})$ duas vezes e meia maior que o comprimento $(0,15-0,23 \mathrm{~mm})$; forma trapezoidal; poucas cerdas na região ventral; com exceção de algumas espécies que têm manchas escuras lateralmente, como por exemplo, Ceraeochrysa digitata Freitas \& Penny, 2009 e Ceraeochrysa derospogon Freitas \& Penny, 2009, o clípeo é totalmente verde.

Labro (LBR). Ceraeochrysa apresenta o labro estreito em forma de retângulo com poucas cerdas longas no ápice (Fig. 1); não apresenta variações evidentes, quando comparado com outros gêneros de Chrysopidae.

Gena (GE). Localizada lateralmente na cápsula cefálica, logo abaixo e a frente dos olhos compostos; separada da fronte pela sutura subantenal e, tem em sua região ântero-ventral, a sutura subgenal (Fig. 1); completamente verde na maioria das espécies do gênero, no entanto, algumas espécies possuem manchas escuras que cobrem total ou parcialmente sua superfície, como por exemplo, Ceraeochrysa achillea Freitas \& Penny, 2009 e Ceraeochrysa curvabilis 
Freitas \& Penny, 2009. Em Ceraeochrysa, a pós-gena é fundida com a gena e está localizada na região ventral, imediatamente posterior ao forâmen occipital.

Olhos compostos (OC). São semi-esféricos; com grande quantidade de facetas; verdes e iridescentes; posicionados dorso-lateralmente na cápsula cefálica; altura é cerca de uma vez e meia maior que sua largura e representa metade da altura da cabeça (Fig. 1).

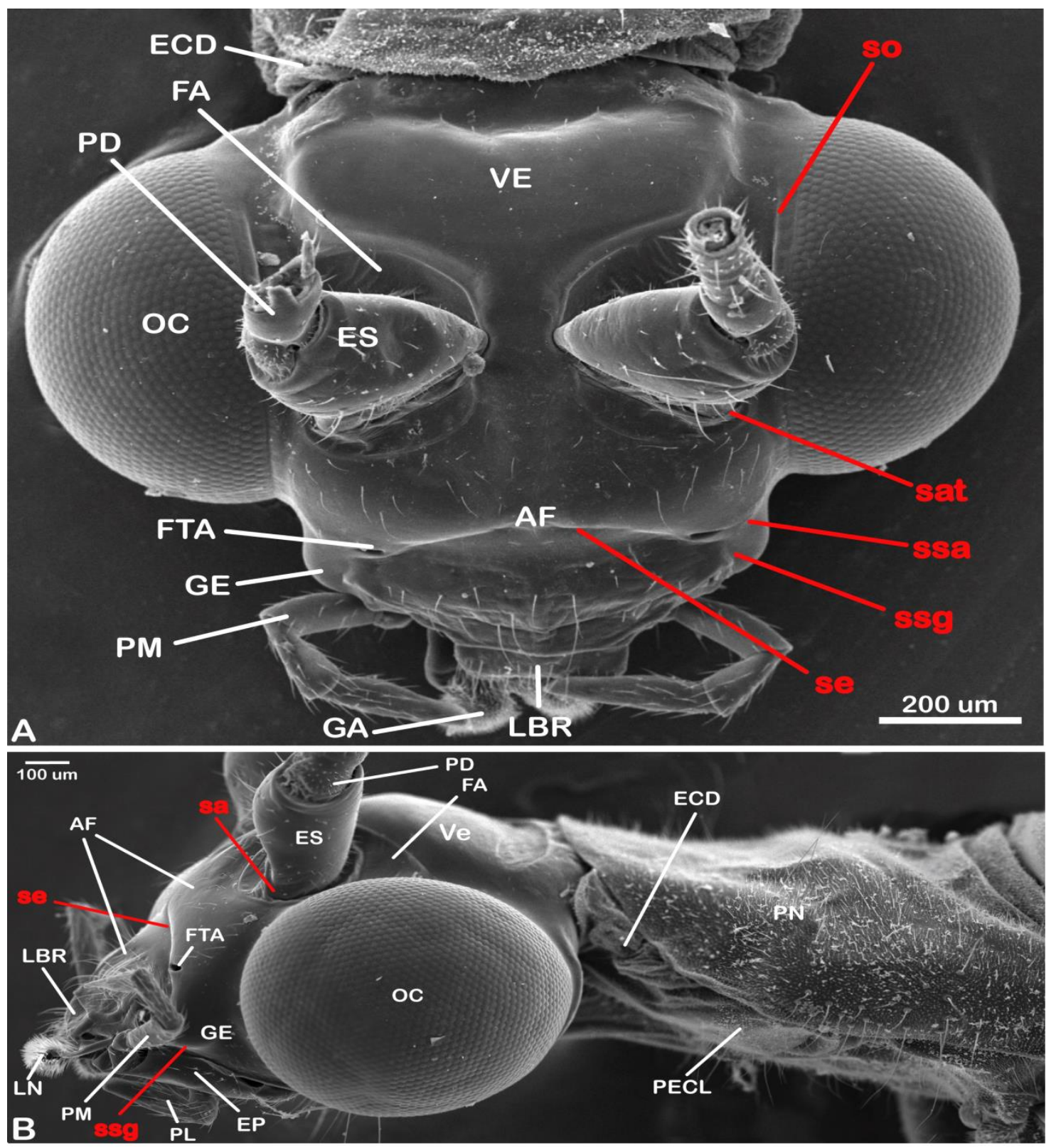

Figura 1. Microscopia eletrônica de varredura da cápsula cefálica de Ceraeochrysa cincta (Schneider, 1851) (Chrysopidae: Chrysopinae). A) Cabeça em vista frontal; B) Cabeça em vista lateral. Área frontoclipeal (AF); esclerito cervical dorsal (ECD); estipe (EP); escapo (ES); fossa antenal (FA); fossa tentorial anterior (FTA); gálea (GA); gena (GE); labro (LBR); lacínia (LN); olho composto (OC); primeiro esclerito cervical lateral (PECL); pedicelo (PD); palpo labial (PL); palpo maxilar (PM); pósnoto (PN); Sutura antenal (sat); sutura epistomal (se); sutura ocular (so); sutura subantenal (ssa); sutura subgenal (ssg); vértice (VE). 
Tentório de Ceraeochrysa Adams, 1982 (Chrysopidae: Chrysopinae) (Fig. 2).

Segundo Snodgrass (1935), o tentório é formado por dois pares de invaginações cuticulares que se unem no interior da cápsula cefálica. Essas invaginações compõem uma estrutura rígida em forma de arco, que auxilia na sustentação da cabeça e na inserção dos músculos cefálicos. Contudo, em Ceraochrysa, o tentório é formado pelo corpo do tentório e três pares de braços, fato que também foi observado para Chrysopa perla (Morse, 1931) e Chrysoperla carnea (Stephens, [1836]) (Zimermann et al., 2011).

A partir de cada uma das fossas tentoriais anteriores surge um braço anterior do tentório (BAT) com um pequeno processo triangular em suas bases; os braços se estendem em sentido dorso-posterior até o corpo do tentório. Do corpo do tentório (CT), surgem ainda dois pares de braços: braços posteriores, que se estendem no sentido látero-posterior até a fossa tentorial posterior (BPT), e braços dorsais (BDT), que seguem em direção ao vértice e fundem-se na região dorsal da cabeça. Ceraeochrysa possui o tentório altamente esclerotizado, que pode ser visto quando a cápsula cefálica é clareada com $\mathrm{KOH} 10 \%$.
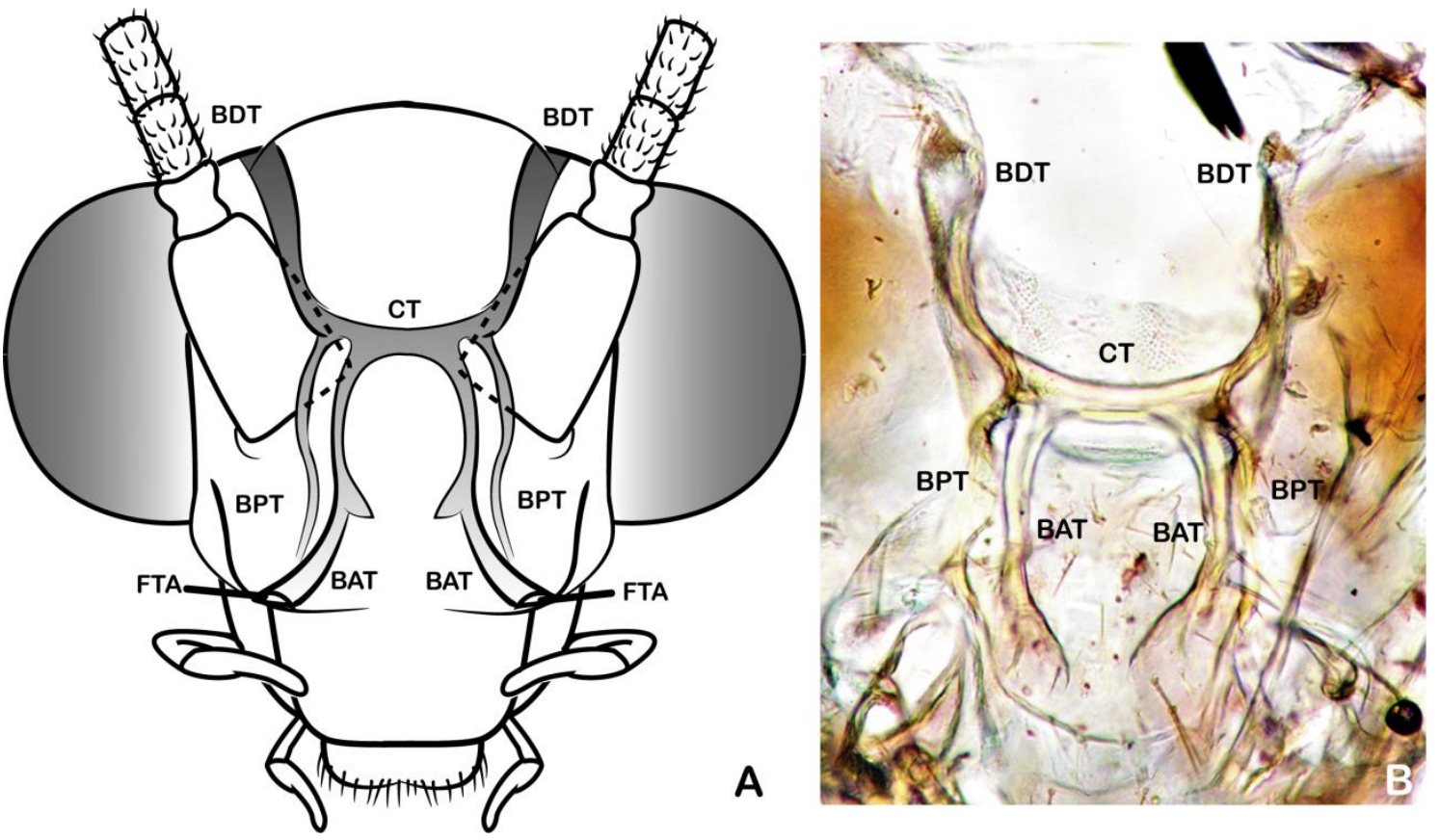

Figura 2. Tentório de Ceraeochrysa ${ }_{s}$ Adams, 1982 (Chrysopidae: Chrysopinae). A) Cabeça em vista frontal; B) Tentório de Ceraeochrysa cornuta (Návas, 1925), vista frontal. Braço anterior do tentório (BAT); braço dorsal do tentório (BDT); braço posterior do tentório (BPT); corpo do tentório (CT); fossa tentorial anterior (FTA).

Apêndices da cápsula cefálica de Ceraeochrysa Adams, 1982 (Chrysopidae: Chrysopinae) (Figs. 3-6).

Antenas (Figs. 3 e 4). Longas, filiformes, muito delicadas e apresentam aproximadamente o mesmo tamanho da asa anterior. Escapo (ES) é achatado dorso-ventralmente; em forma de trapézio; robusto quando comparado aos outros segmentos da antena; sua maior altura $(0,2-$ 
$0,3 \mathrm{~mm})$ é semelhante à sua largura $(0,2-0,35 \mathrm{~mm})$; superfície posterior com quantidade maior de cerdas que a superfície anterior; cerdas da área posterior aproximadamente quatro vezes mais longas (aproximadamente $0,1 \mathrm{~mm}$ ) que as cerdas da área anterior (cerca de 0,025 $\mathrm{mm}$ ); base do escapo com minúsculas cerdas em grande número (Fig. 3).

Escapo verde com manchas em diferentes padrões, que variam desde uma listra vertical dorso-lateral, uma listra vertical dorso-medial, uma listra horizontal, uma listra vertical dorso-medial + uma listra vertical dorso-lateral, uma mancha difusa lateral até o escapo manchado por completo. $\mathrm{O}$ formato da mancha é utilizado como carácter diagnóstico para as espécies (Fig. 4).

Pedicelo (PD) é quadrangular; com base densamente coberta por cerdas minúsculas; apresenta um anel de cerdas longas e espessas apicalmente; tem diferentes padrões de manchas, como uma listra vertical dorso-lateral, uma listra vertical dorso-medial, uma mancha difusa, pode estar totalmente manchado e também pode apresentar uma mancha que forma um anel na região apical (Fig. 3).

Flagelômero (Fig.3) cerca de duas vezes mais longos (cerca de 0,25 mm) do que largos (cerca de 0,13 mm); de coloração clara ou escura (característica diagnóstica de muitas espécies); com quatro anéis de cerdas longas (CFL) (cerca de 0,1 mm) (sinapomorfia de Chrysopinae) intercaladas com cerdas curtas $(0,025 \mathrm{~mm})$; ápice com um anel de cerdas médias $(0,05 \mathrm{~mm})$.
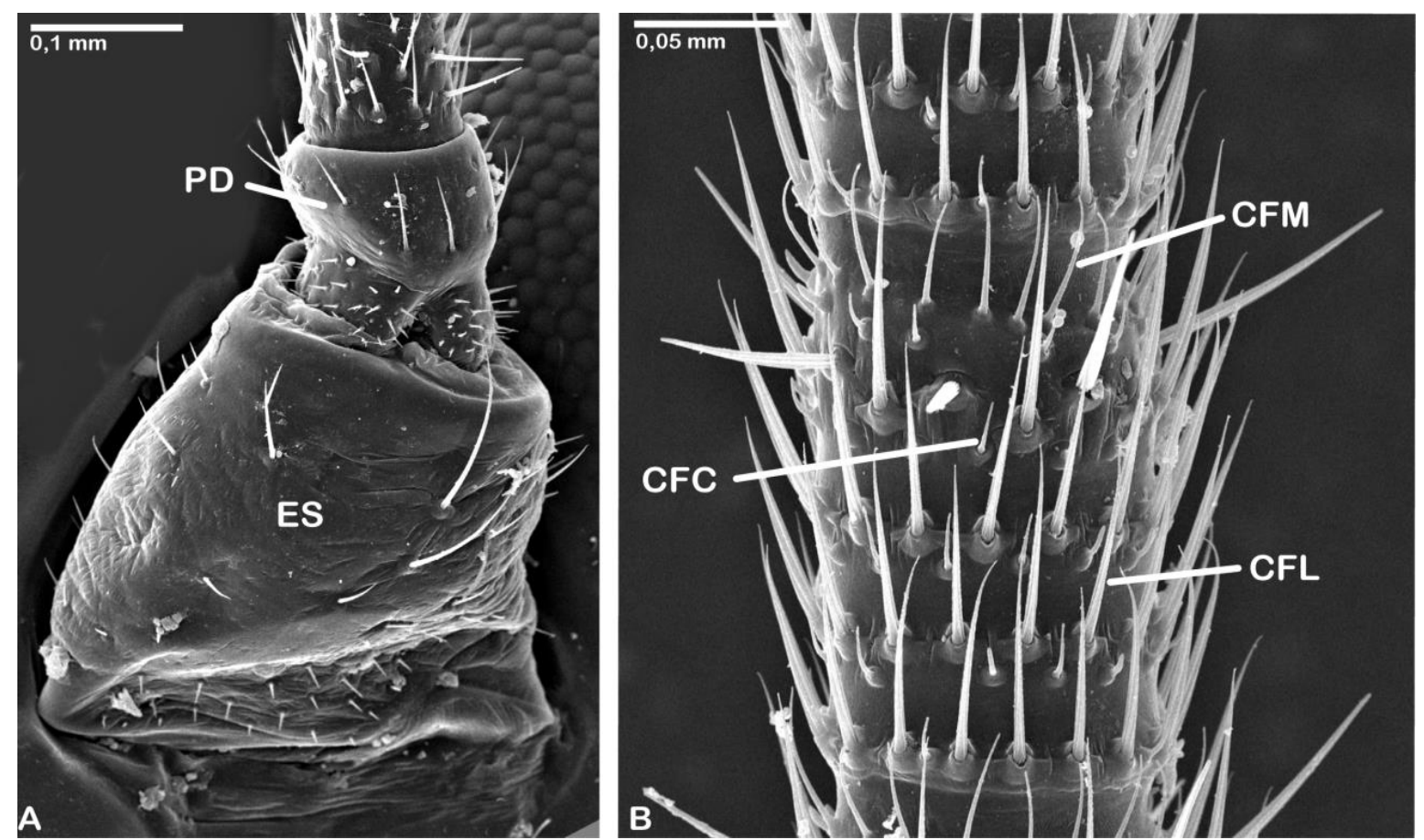

Figura 3. Microscopia eletrônica de varredura da antena de Ceraeochrysa cincta (Schneider, 1851) (Chrysopidae: Chrysopinae). A) Escapo e pedicelo, vista frontal; B) Anéis de cerdas dos flagelômeros. Cerdas flagelares curtas (CFC); cerdas flagelares longas (CFL); cerdas flagelares médias (CFM); Escapo (ES); pedicelo (Pd). 


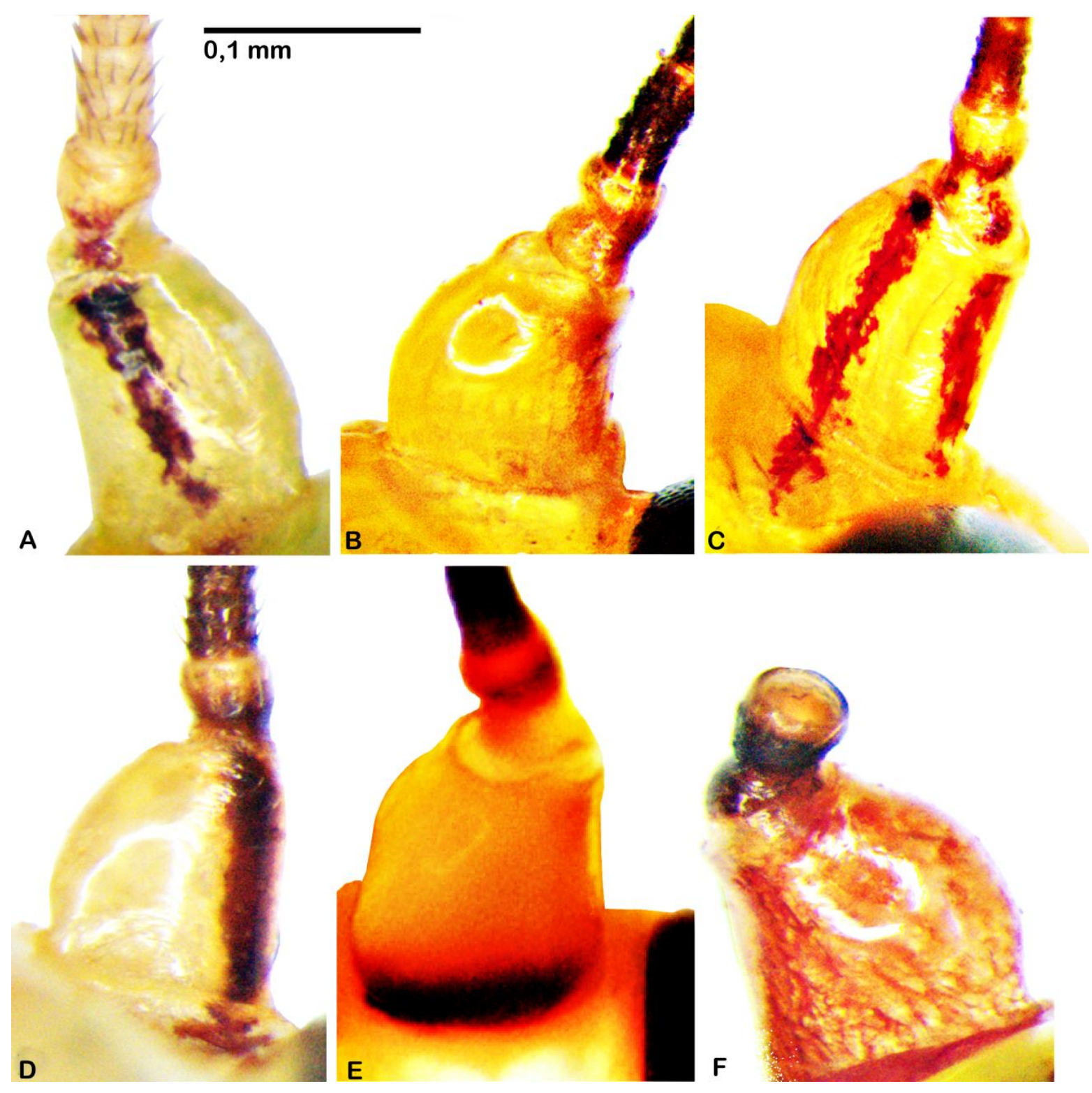

Figura 4. Padrão de manchas do escapo de Ceraeochrysa, Adams, 1982, vista dorsal. A) C. cornuta (Navás, 1925); B) C. everes Banks, (1920); C) C. montoyana (Navás, 1913); D) C. scapularis (Navás, 1914); E) C. nigripes Adams, \& Penny, 1987; F) C. smithi (Navás, 1914).

Mandíbulas (Fig. 5). A mandíbula de Ceraeochrysa é semelhante à de Chrysopa perla Morse (1931). São bem desenvolvidas; adaptadas para triturar; apresentam três faces e formato semelhante a uma pirâmide. Face externa, lisa com afunilamento da região medial até o ápice mandibular; face anterior, convexa nas regiões submolar (RSBM) e molar (RM), e côncava na região do incisivo (RI), tem um pente de cerdas (PC) adjacentes à submola em sua superfície dorso-anterior; face posterior apresenta a margem interior (MI) afiada e paralela à margem medial (MM), que se origina do meio da área submolar e possui curvatura antes de chegar ao ápice da mandíbula. Nesta margem observa-se um dente na mandíbula esquerda, o qual é ausente na mandíbula direita.

A porção basal de cada mandíbula é triangular e tem dois pontos de articulação (côndilos (CO)) encontrados nas extremidades da margem póstero-lateral (MPL). O primeiro 
encontra-se no ápice posterior e se encaixa na margem látero-ventral da gena e, o segundo que se encaixa em uma depressão existente no clípeo é localizado no ápice anterior da margem póstero-lateral. Entre os dois côndilos está inserido o tendão extensor (te) e, no ápice pósterointerior mandibular insere-se o tendão flexor (tf).

Maxilas (Figs. 5 e 6). As maxilas de Ceraeochrysa são semelhantes às de Chrysopa perla Morse (1931), são divididas em cardo (CD), estipe (EP), gálea (GA), lacínia (LN) e palpo maxilar (PM).

$\mathrm{O}$ cardo apresenta forma retangular, com cerdas pequenas escarsas, principalmente em sua margem exterior. Ligada ao cardo encontra-se a estipe, esclerito alongado de forma retangular que compõem a porção intermediária da maxila, apresenta várias cerdas longas (cerca de 0,06 mm) em sua margem exterior. Em seu ápice interno encontra-se a lacínia, basalmente esclerotizada e distalmente membranosa com a borda externa bem esclerotizada, o que auxilia em sua sustentação; tem forma côncava e em sua margem interior há um grande número de cerdas longas e espessas (Figs. 5 e 6).

A gálea, localizada entre o lado externo da lacínia e o palpo maxilar, tem o ápice menos esclerotizado que a base, com grande número de cerdas alongadas e cilíndricas, e um pequeno grupo de cerdas achatadas que circunda as cerdas cilíndricas, de função ainda incerta (Figs. 5 e 6).

O palpo maxilar está localizado na metade anterior da maxila, tem cinco segmentos semelhantes em tamanho, com muitas cerdas pequenas (Figs. 5 e 6); completamente verde na maioria das espécies do gênero, com exceção de algumas espécies, como exemplo Ceraeochrysa cubana (Hagen, 1861) e Ceraeochrysa effusa (Navás, 1911), que possuem manchas escuras, principalmente nos dois segmentos apicais. O padrão de coloração dos palpos maxilares é utilizado como característica diagnóstica de várias espécies do gênero.

Lábio (Figs. 5 e 6). De acordo com Snodgrass (1935), o lábio corresponde à fusão das segundas maxilas dos insetos, e é divido em pós-mento (PME), pré-mento (PEME), paraglossa (PGL), glossa (GL) e palpos labiais (PL).

O pós-mento é a parte basal do lábio, tem forma retangular, várias cerdas longas ao longo de sua superfície e está ligado posteriormente ao pró-esterno e anteriormente a uma área membranosa que, por sua vez, está ligada ao pré-mento (Figs. 5 e 6). A gula é ausente em Chrysopidae.

Ceraeochrysa tem o pré-mento pequeno, triangular, em que está inserida a base dos palpos labiais (Figs. 5 e 6). Cada palpo labial é formado por três segmentos, o primeiro é 
pequeno comparado ao segundo e terceiro (Figs. 5 e 6); em geral são de coloração verde e podem apresentar manchas negras.

Glossa e paraglossa estão fundidadas, altamente esclerotizadas e possuem muitas cerdas pequenas no ápice (Figs. 5 e 6).

Região basal do lábio é pouco móvel, quando comparada à região do pré-mento, palpos labiais, glossa e paraglossa.
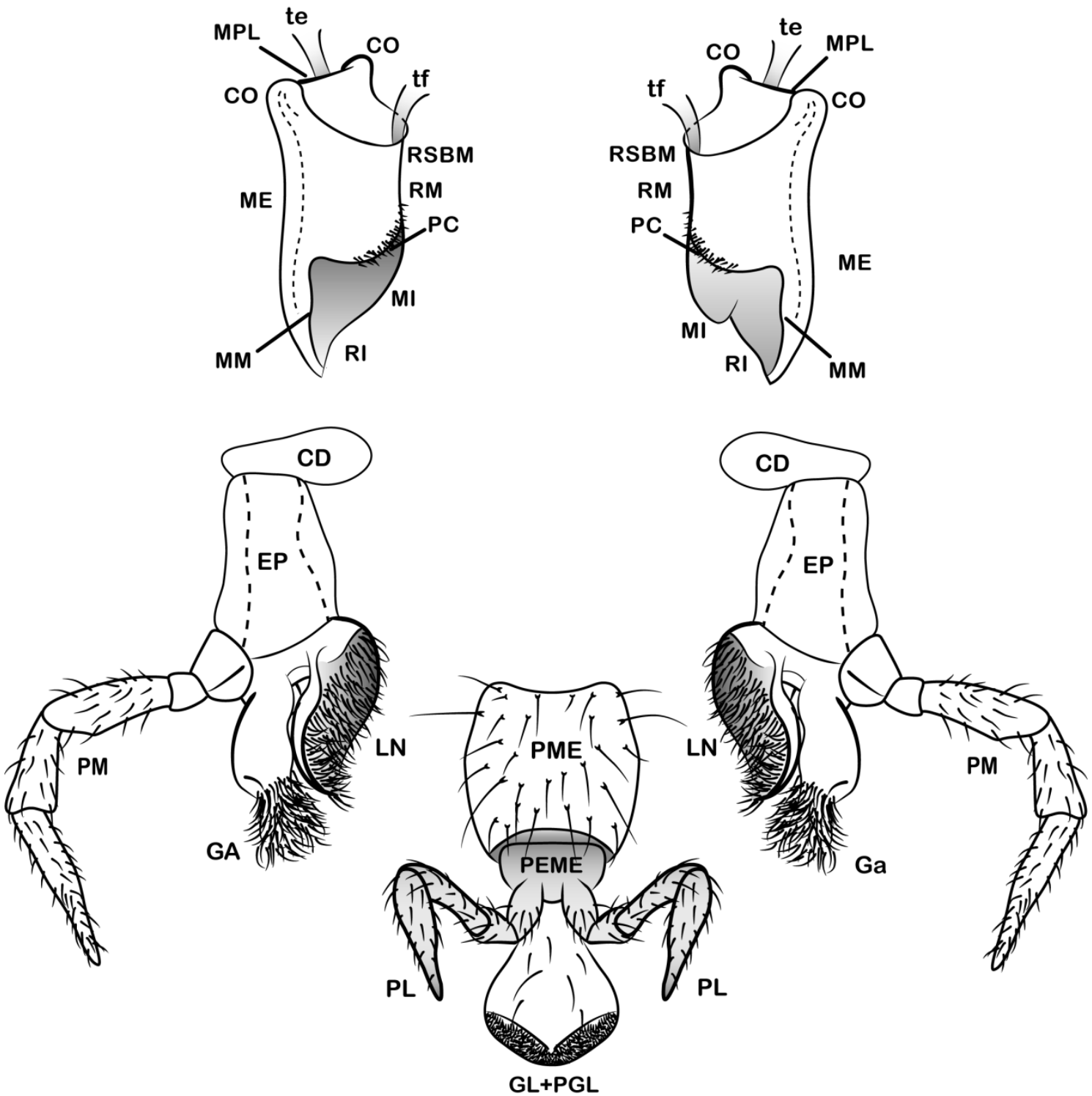

Figura 5. Peças bucais de Ceraeochrysa Adams, 1982 (Chrysopidae: Chrysopinae). Cardo (CD); côndilo (CO); estipe (EP); gálea (GA); glossa (GL); lacínia (LN); margem exterior (ME); margem interior (MI); margem medial (MM); margem póstero-lateral (MPL); palpo labial (PL); palpo maxilar (PM); paraglossa (PGL); pente de cerdas (PC); pós-mento (PME); pré-mento (PEME); região do incisivo (RI); região molar (RM); região submolar (RSBM); tendão extensor (te); tendão flexor (tf). 

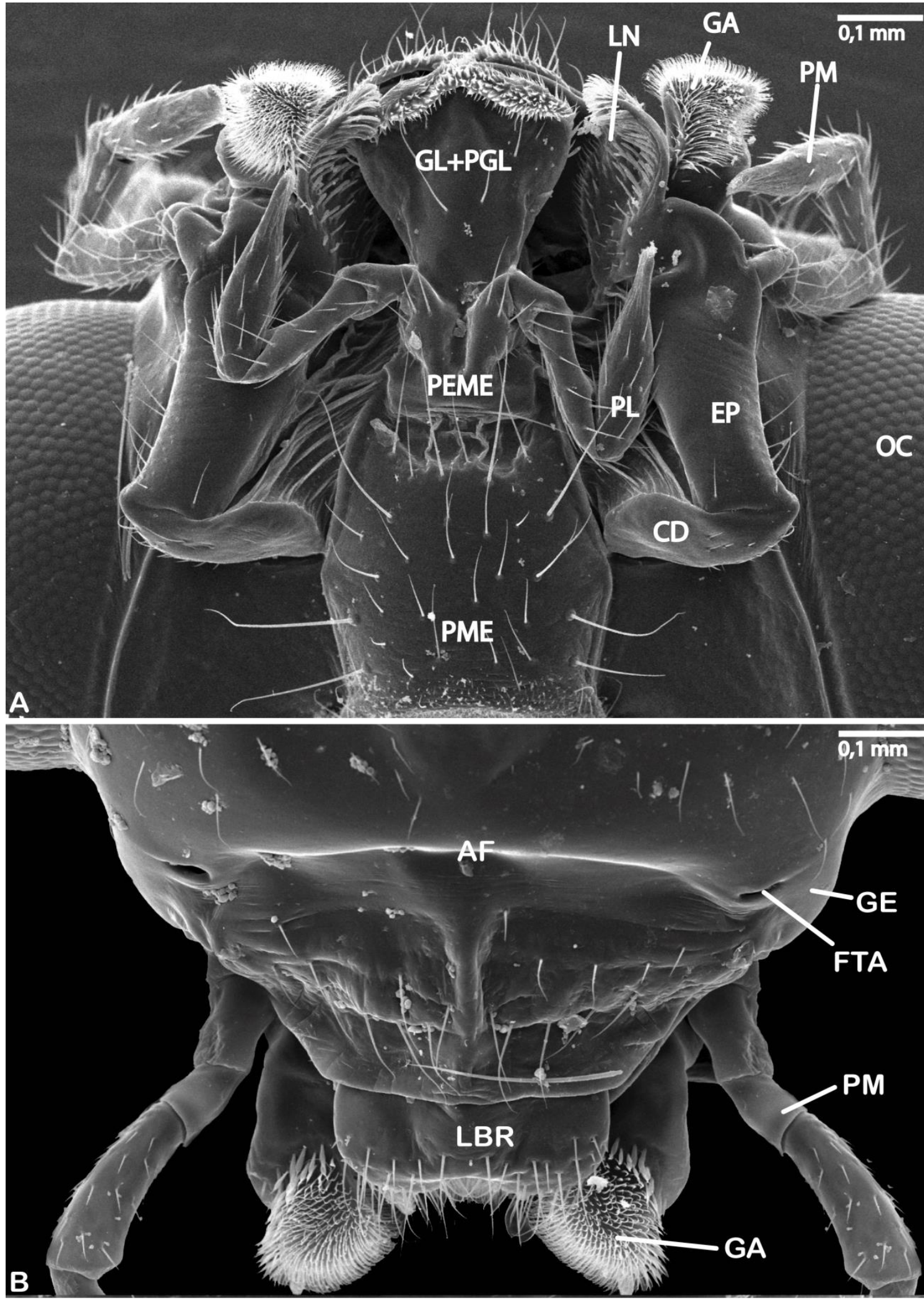

Figura 6. Microscopia eletrônica de varredura das peças bucais de Ceraeochrysa cincta (Schneider, 1851) (Chrysopidae: Chrysopinae). A) Peças bucais em vista ventral; B) Peças bucais em vista frontal. Área frontoclipeal (AF); cardo (CD); estipe (EP); fossa tentorial anterior (FTA); gálea (GA); gena (GE); labro (LBR); lacínia (LN); olho composto (OC); palpo labial (PL); palpo maxilar (PM); prémento (PEME); pós-mento (PME). 


\subsubsection{Tórax e apêndices de Ceraeochrysa Adams, 1982 (Chrysopidae: Chrysopinae).}

O tórax dos insetos é considerado uma máquina perfeita para a função de voo, nos Pterygota; apresentam músculos que auxiliam na movimentação das pernas e das asas (Snodgrass, 1935). O tórax tem três segmentos, denominados prótorax, mesotórax e metatórax, cada um dos quais com um par de pernas, cuja função é bastante variável.

Ceraeochrysa possui no tórax de algumas áreas membranosas, a maior delas é o cérvix, que articula a cabeça e o prótorax. As demais regiões membranosas do tórax são as pleuras protorácicas, membranas intersegmentares e membranas de articulação com as pernas ou asas; essas membranas têm grande importância, pois fornecem a flexibilidade necessária para a realização do movimento das asas e das pernas.

Ceraeochrysa tem dois espiráculos torácicos, o mesotóracico que está localizado entre a pleura protorácica e a mesopleura, ovóide com cerca de $0,1 \mathrm{~mm}$ e, o espiráculo torácico posterior, localizado entre o epímero mesotorácico e o anepisterno metatorácico.

\section{Cérvix de Ceraeochrysa Adams, 1982 (Chrysopidae: Chrysopinae) (Fig. 7).}

A área entre a cabeça e o tórax —às vezes referida como "pescoço" dos insetos-é estreita e membranosa; em geral é curta e fica oculta entre as partes do prótorax (Snodgrass, 1935). Morse (1931) descreveu para Chrysopa perla três escleritos cervicais, também observados em Ceraeochrysa, dois desses escleritos são laterais e um é dorsal, fato também observado nos outros neurópteros por Friedrich \& Beutel (2010).

O esclerito cervical dorsal (ECD) tem tamanho médio, forma triangular e está dorsalmente entre o pronoto e a cabeça. O primeiro esclerito cervical lateral (PECL) também de forma triangular, com ângulos mais arredondados e situa-se na região látero-ventral do pronoto. O segundo esclerito cervical lateral (SECL), referido por Morse (1931) como póscervical, é o menor dos três escleritos cervicais, tem forma de $\mathrm{V}$ invertido e está próximo ao ápice anterior do episterno protorácico.

\section{Protórax de Ceraeochrysa Adams, 1982 (Chrysopidae: Chrysopinae) (Figs. 7-10).}

Ceraeochrysa apresenta o protórax alongado, achatado dorso-ventralmente. Pronoto (PN) transverso, retangular, com sua margem anterior arredondada e as laterais estendendo-se até a metade da altura do protórax; região dorso-mediana com fina depressão e grande número de cerdas, algumas longas com a base larga e cônica (Fig. 9c), provavelmente com função químio ou mecanorreceptora.

O pronoto é coberto por microcerdas e, na grande maioria das espécies de Ceraeochrysa apresenta coloração verde, com manchas escuras na região lateral, as quais podem apresentar vários padrões que são utilizados como características diagnósticas de 
espécies do gênero. Os principais padrões de variações dessas manchas são: listra dorsolateral, mancha circular dorso-lateral, duas manchas circulares dorso-laterais ou ausência de manchas (Fig. 10).

A maior parte da região pleural do protórax é membranosa, contudo existem alguns escleritos: o maior deles é o episterno (EP), ventral à margem lateral do pronoto, de base larga, estreitando-se em direção à margem anterior, que é bifurcada e se encaixa com o segundo esclerito cervical lateral. O segundo esclerito é o epímero (EPM), localizado posteriormente ao episterno, é alongado dorso-ventralmente e tem formato retangular (Fig. 7).

Trocantin (TC) protorácico é oval, de pequeno tamanho. Suturas pleural e paracoxal ausentes nesse segmento. Basisterno (BS) é uma placa em forma de diamante pouco esclerotizada, localizada na região ventral do protórax, é semelhante ao de Chrysopa perla (Morse, 1931) (Figs. 7 e 8). Próesterno (PES), região do esterno protorácico que se estende até a região ventral da cápsula cefálica, é localizado anteriormente ao basisterno (Fig. 8); na região posterior ao basisterno observa-se o espinasterno (EO) (Fig. 8). Não são observadas pontes pré e pós-coxais no protórax de Ceraeochrysa. 

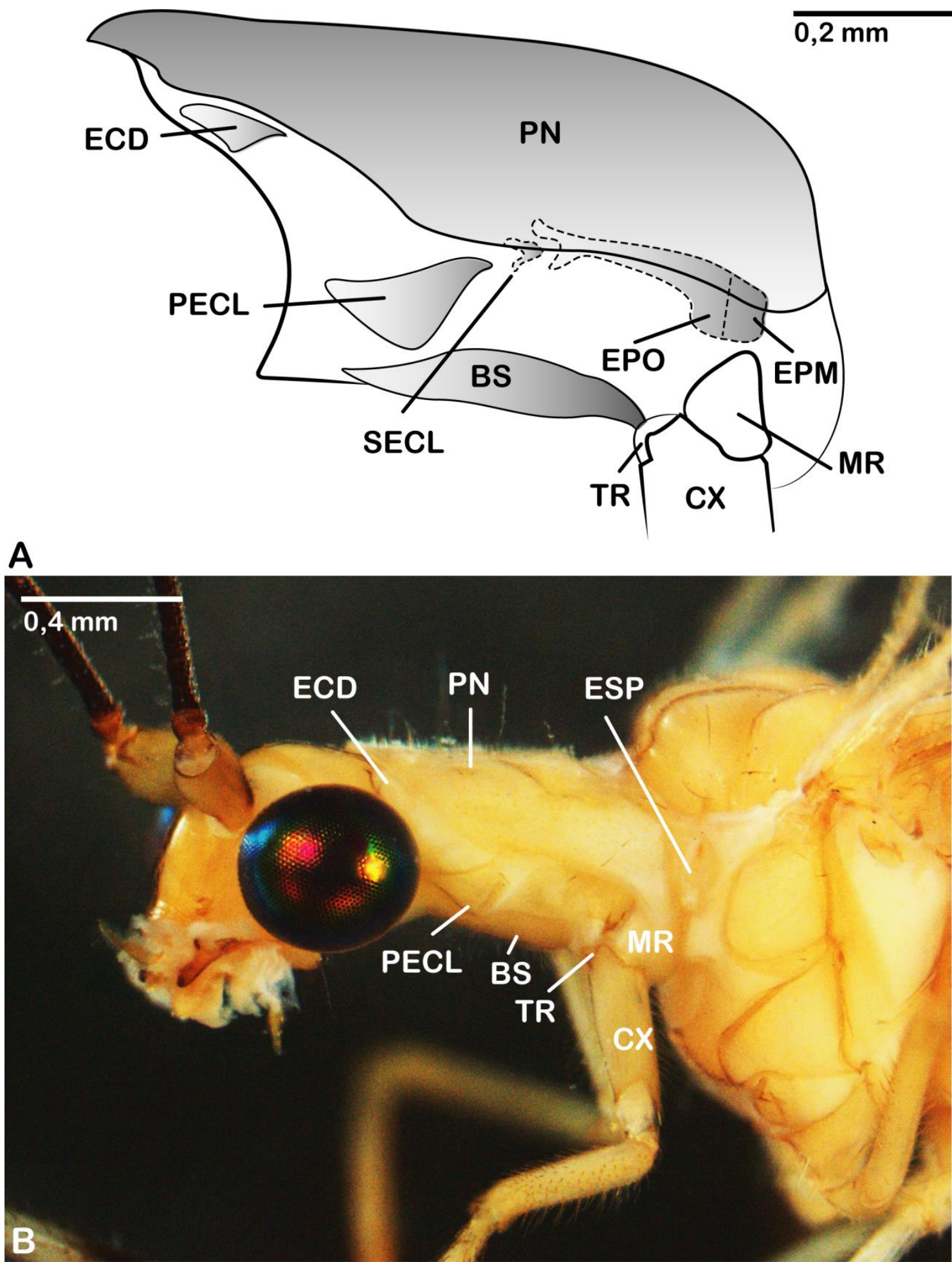

Figura 7. Cérvix e protórax de Ceraeochrysa Adams, 1982 (Chrysopidae: Chrysopinae), vista lateral. A) Esquema dos escleritos cervicais; B) Escleritos cervicais de Ceraeochrysa nigripes Adams \& Penny, 1987. Basisterno (BS); coxa (CX); epímero (EPM); episterno (EPO); esclerito cervical dorsal (ECD); espiráculo (ESP); méron (MR); primeiro esclerito cervical lateral (PECL); pronoto (PN); segundo esclerito cervical lateral (SECL); trocantin (TR). 

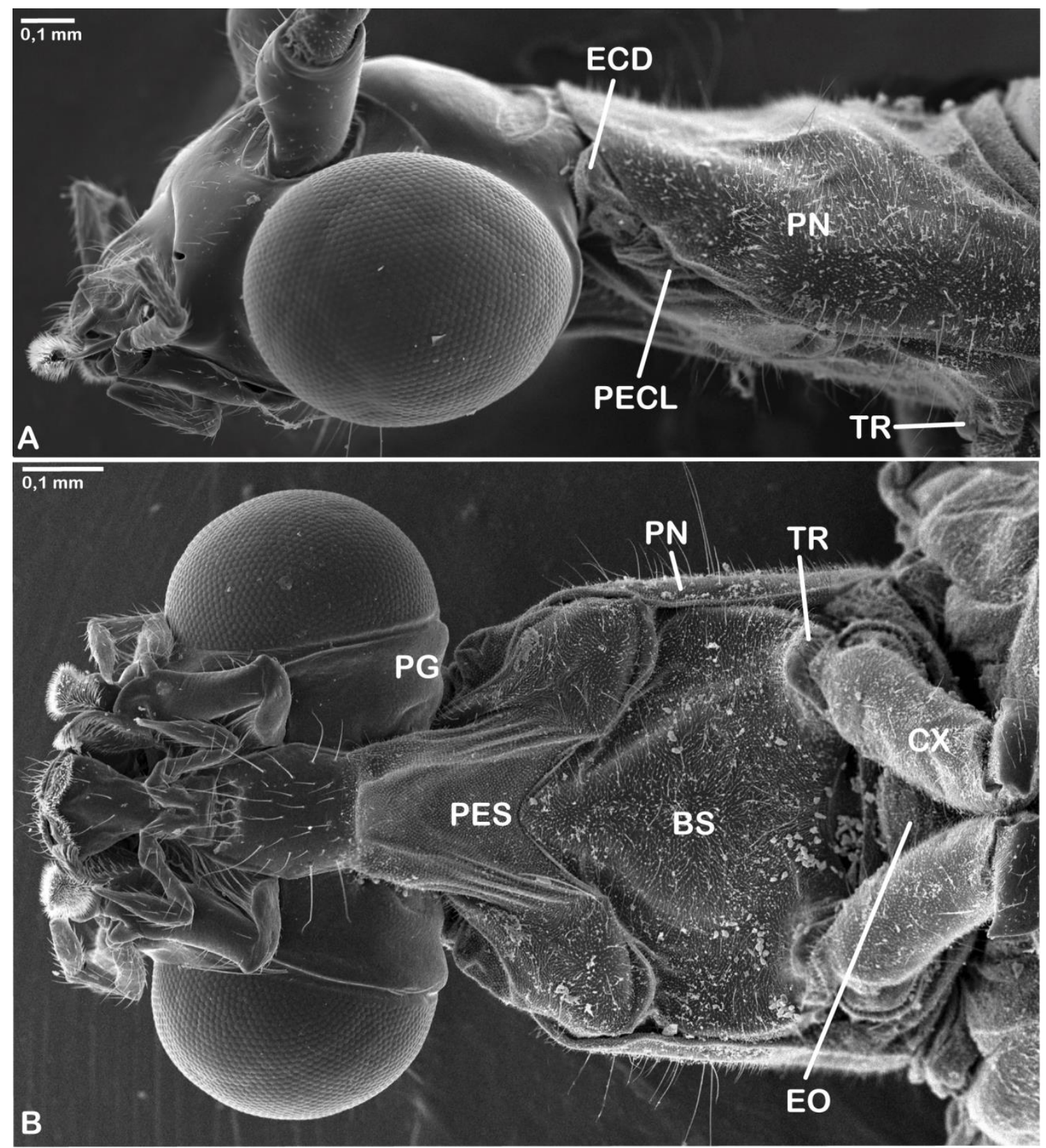

Figura 8. Microscopia eletrônica de varredura do protórax de Ceraeochrysa cincta (Schneider, 1851) (Chrysopidae: Chrysopinae). A) Vista lateral; B) Vista ventral. Basisterno (BS); coxa (CX); esclerito cervical dorsal (ECD); espinasterno (EO); próexterno (PES); primeiro esclerito cervical lateral (PECL); pós-gena (PG); pronoto (PN); trocantin (TR). 

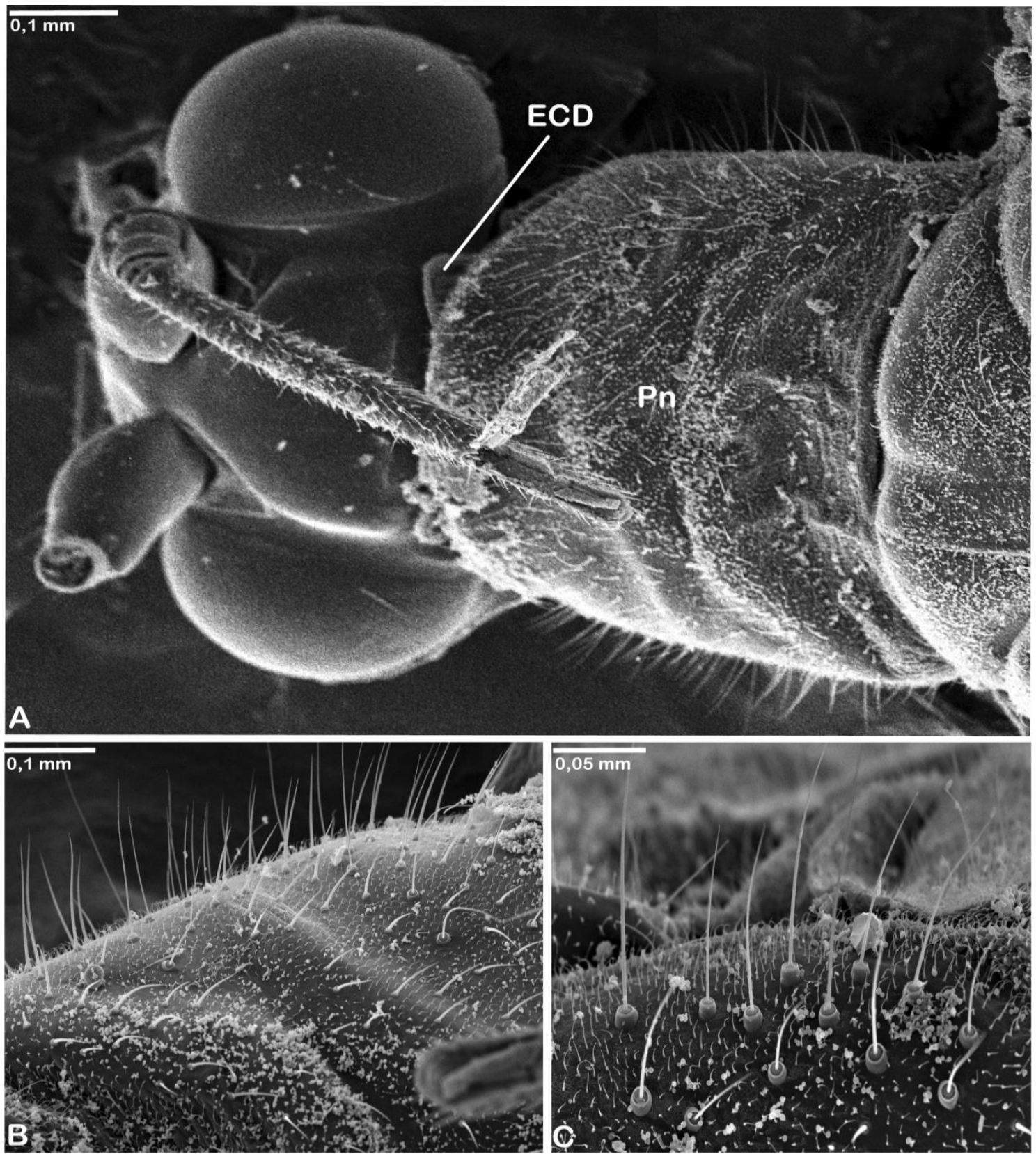

Figura 9. Microscopia eletrônica de varredura do protórax de Ceraeochrysa cincta (Schneider, 1851) (Chrysopidae: Chrysopinae). A) Vista dorsal; B) Cerdação do protórax; C) Detalhe da base das cerdas do protórax. Esclerito cervical dorsal (ECD); pronoto (PN). 

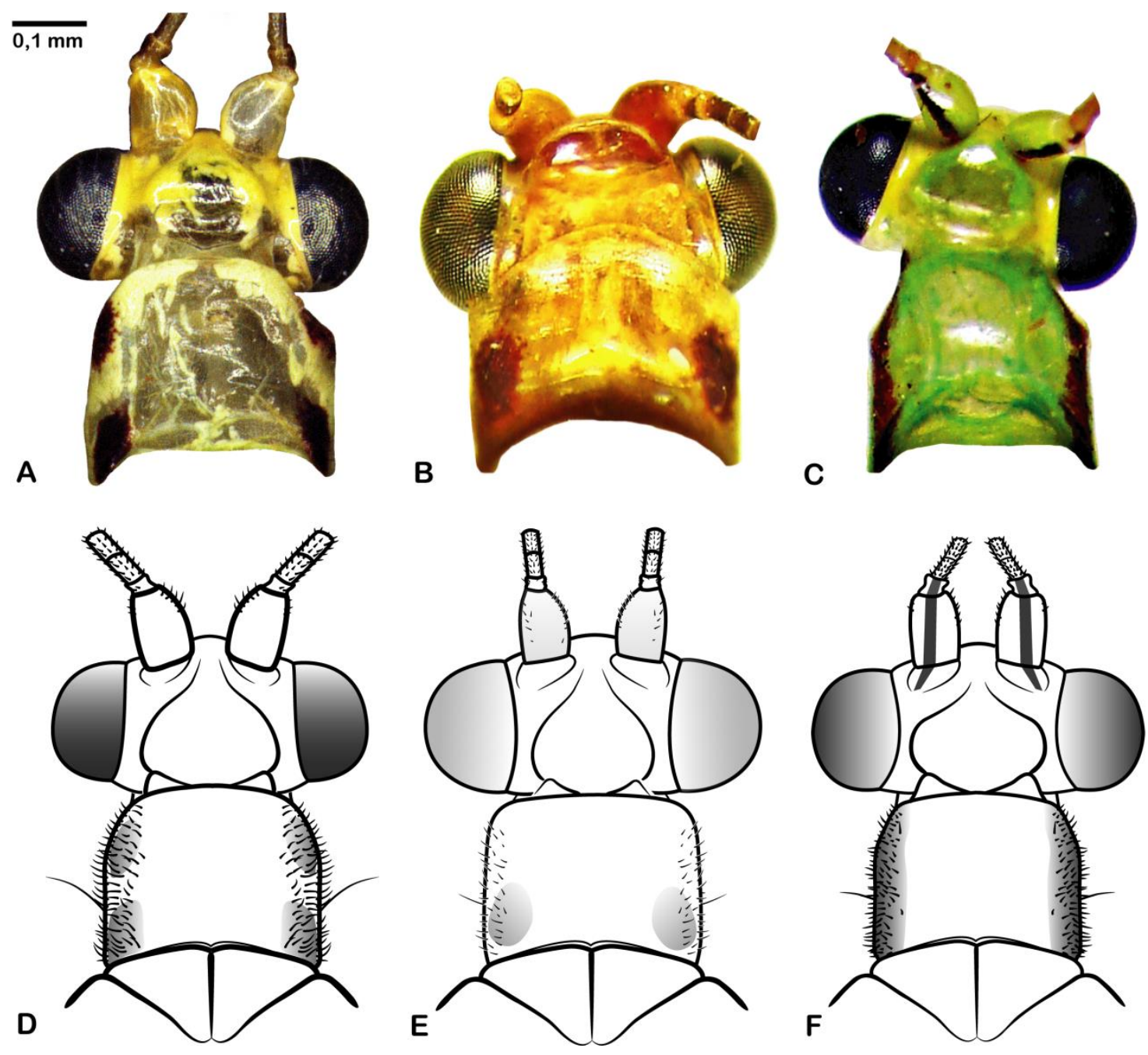

Figura 10. Padrão de manchas do protórax de Ceraeochrysa (Schneider, 1851) (Chrysopidae: Chrysopinae), vista dorsal. A, D) C. angulata (Navás, 1929); B, E) C. costaricensis (Penny, 1997); C, F) C. cornuta (Navás, 1925).

\section{Pterotórax de Ceraeochrysa Adams, 1982 (Chrysopidae: Chrysopinae) (Figs. 11-13).}

Em muitos Neuroptera, mesonoto e metanoto são semelhantes em tamanho e forma (Matsuda, 1970) (Fig. 11). Em Ceraeochrysa, o metanoto é mais estreito ânteroposteriormente em relação ao mesonoto. Ambos têm coloração verde na maioria das espécies do gênero, entretanto algumas espécies, como exemplo C. michaelmuris Adams \& Penny, 1987 e C. scapularis (Navás, 1914), podem apresentar um conjunto de manchas escuras (pretas, marrons ou vermelhas) as quais são utilizadas como características diagnósticas. Pterotórax é coberto por microcerdas.

Acrotergito presente na região anterior dos tergos meso e metatorácicos. $\mathrm{O}$ acrotergito mesotorácico, junto com a parte anterior do prescuto (PR), está localizado abaixo da base do pronoto (PN); ambos auxiliam no suporte do protórax, como observado em Plega Navás 1928 (Mantispidae) (Ferris, 1940b).

O acrotergito e o prescuto metatorácico encontram-se na região posterior do mesotórax e auxiliam na estabilidade do pterotórax; ambos não são vistos externamente. 
Morse (1931) descreveu o acrotergito de Chrysopa perla como o esclerito marginal, segundo oque pode-se inferir pela localização e semelhança com o de Ceraeochrysa. Apesar de nomeá-lo erroneamente, Morse (1931) observou que o esclerito marginal era, na verdade, uma expansão dos tergos meso e metatorácicos.

O mesonoto é dividido em quatro partes (prescuto (PR), escuto (EST), escutelo (ECO) e posnoto (PO)) separadas por profundas suturas, tais escleritos são convexos (Fig. 11)..

Em Ceraeochrysa, parte do prescuto mesotorácico, região entre o acrotergito e escuto, está inserida abaixo do pronoto, sua parte posterior é observável externamente e tem forma de uma larga placa triangular. A região posterior do prescuto tem a sutura mediana mesonotal (smm), que o divide ântero-posteriormente e forma duas partes triangulares menores; essa sutura também foi observada em Chrysoperla carnea (Stephens, [1836]) por Friedrish e Beutel (2010) (Fig. 13a).

Internamente na região posterior do mesotórax, é encontrado o prescuto unido ao acrotergito metatorácico, o qual apresenta um prolongamento lateral, o braço prealar, que se estende até a membrana intersegmentar. Posteriormente ao prescuto, observa-se o alinoto estrutura nomeada por Snodgrass (1935), subdividida em escuto e escutelo.

O mesoscuto é separado do prescuto pela sutura lateral parapsidal (slp), ausente no metascuto. Meso e metascuto são arredondados na região dorsal, com sua lateral mais elevada que a região medial. $\mathrm{O}$ mesoscuto é cerca de 1,3 vezes mais largo do que o metascuto, e ambos apresentam poucas cerdas longas sobre a superfície (Fig. 11).

As margens laterais dos escutos são fundidas com o prescuto e escutelo, onde são encontrados processos com os quais as asas se articulam. O processo mais anterior, articulado com o primeiro esclerito axilar, é nomeado como suralar (SAL); é seguido posteriormente por uma fissura tergal.

$\mathrm{Na}$ região medial da margem lateral do escuto, localizado posteriormente à fissura tergal, é encontrado um processo curto, pouco desenvolvido, o processo noto-medial (PNM) (Matsuda, 1970) que também se articula com o primeiro esclerito axilar. Ainda na margem lateral posterior do escuto, existe o pequeno processo noto-posterior (PNP), que se articula com o terceiro esclerito axilar e com o cordão axilar do escutelo, formando um ponto de inserção posterior da asa de Ceraeochrysa (Fig. 11).

O meso e metaescutelos estão localizados nas regiões posteriores dos escutos, tem forma de diamante invertido e são separados do escuto pela sutura escuto-escutelar (see) em forma de V invertido, comum em Neuroptera (Snodgrass, 1935) (Fig. 11). O mesoscutelo é maior que o metascutelo e os dois apresentam poucas cerdas longas sobre sua superfície. O final do escutelo é contínuo lateralmente, formando o cordão axilar (CAE). 
Nas margens posteriores do meso e metascutelo, encontra-se o posnoto (PO), que é pequeno e tem a região medial dividida. No mesotórax, é conectado com o prescuto do metatórax e, no metatórax, é reduzido e conectado com o primeiro tergito abdominal, que se estende ventralmente e termina próximo ao primeiro espiráculo abdominal (Fig. 11).

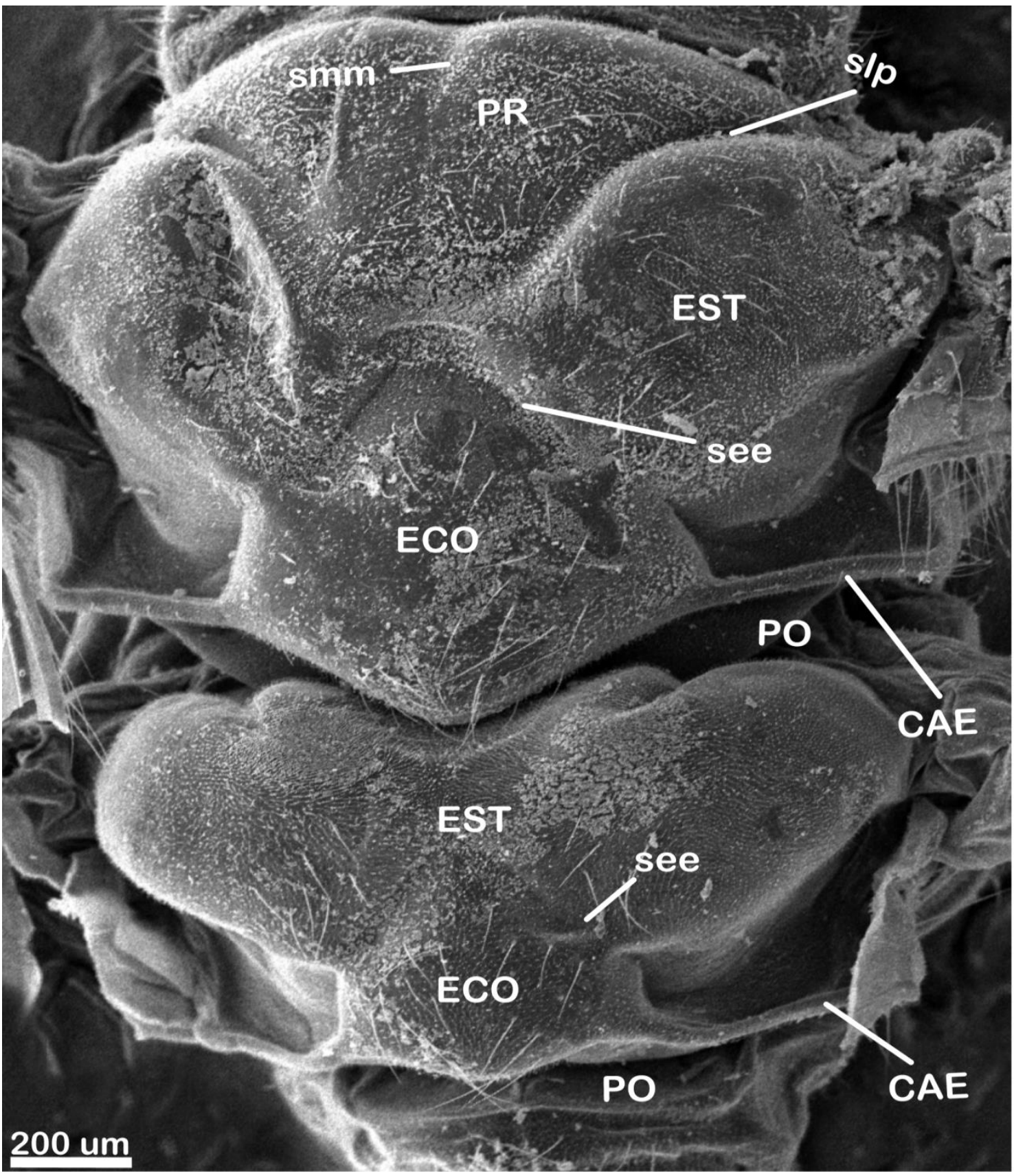

Figura 11. Microscopia eletrônica de varredura do pterotórax de Ceraeochrysa cincta (Schneider, 1851) (Chrysopidae: Chrysopinae), vista dorsal. Cordão axilar do escutelo (CAE); escutelo (ECO); escuto (EST); posnoto (PO); prescuto (PR); sutura escuto-escutelar (see); sutura lateral parapsidal (slp); sutura mediana mesonotal (smm).

$\mathrm{Na}$ região lateral de cada segmento do pterotórax, está localizada a pleura, que apresenta duas regiões principais: o episterno (EPO), localizado anteriormente, e o epímero (EPM), na região posterior, os quais são separados pela sutura pleural (sp), entre o processo pleural alar (PPA) até o processo pleural coxal (PPC) (Fig. 13a). 
O meso e metaepisterno são semelhantes (Fig. 13a); de coloração clara; com cerdas longas em sua superfície; subdividos em anepisterno (ANP) e catepisterno (CAT). O primeiro representa a região dorsal do episterno; tem forma subquadrangular; vértices anteriores arredondados; margem dorsal posterior fundida à margem dorsal anterior do anepímero formando o processo pleural alar, que funciona como ponto de apoio a asa. $\mathrm{O}$ segundo corresponde à metade ventral do episterno; alongado anteriormente; formato subretangular; vértices arredondados; margem posterior em contato com a sutura pleural; ápice ventroposterior, junto com o ápice ventro-anterior do catepímero, forma o processo pleural coxal, que irá funcionar como ponto de articulação para a coxa.

Entre o anepisterno e o catepisterno existe o pré-episterno (PE), separado do anepisterno pela sutura anapleural (as) e do catepisterno pela sutura paracoxal (spc) (Fig. 13a); é menos esclerotizado que o catepisterno e anepisterno; os dois pré-episternos encontram-se ventromedianamente, região nomeada por Morse (1931) como esternopleura.

Abaixo do catepisterno do meso e metatórax observa-se o trocantin (TR) em forma de vírgula invertida, contudo, o trocantin mesotorácico é maior que o metatorácico; ambos são claramente separados do catepisterno, ao contrário do que foi descrito por Morse (1931) para Chrysopa perla (Fig. 13a).

Posteriormente ao episterno está o epímero divido em dois escleritos, anepímero (AN) e catepímero $(\mathrm{CM})$, tem poucas cerdas longas e apresenta a mesma cor nos dois segmentos torácicos. Ao contrário do que ocorre com o episterno, a forma do mesoepímero é diferente da forma do metaepímero (Fig. 13a).

O anepímero do mesotoráx, esclerito dorsal do mesoepímero, tem forma trapezoidal; sua margem ântero-ventral está separada do catepímero pela sutura transepimeral (st). O esclerito ventral do epímero (catepímero) tem forma de L e envolve o anepímero por inteiro em sua região ventral e anterior (Fig. 13a).

O anepímero metatorácico tem forma trapezoidal e é totalmente separado do catepímero retangular, pela sutura transepimeral, a qual ao contrário do que é observado no mesotórax, não é deslocada e está completa.

$\mathrm{Na}$ região dorsal do anepisterno, encontra-se o esclerito basalar (EB) que tem forma quadrangular, e na região dorsal do anepímero é encontrado o esclerito subalar (ESA) de forma oval. Tais epipleuritos são relacionados com a inserção da musculatura de vôo (Fig. 13a).

Na região ventral do catepisterno e do catepímero é observada a coxa (CX), com o méron (MR) de forma quadrangular em sua região posterior; ela se articula com o processo pleural coxal e com o processo esterno-coxal (Fig. 13a). 
Em Ceraeochrysa, a ponte pós-coxal não é observada, o que corrobora os relatos de Matsuda (1970) de que em Neuroptera essa ponte é ausente ou reduzida. Em Ceraeochrysa, a sutura pleuroesternal não é visualizada, o basisterno é completamente invaginado e as furcas (F) aparecem externamente como uma simples fenda. Ceraeochrysa apresenta a meso e metaespina bem desenvolvidas, o que concorda com o relato de Matsuda (1970), o qual citou que em Neuropterida tais regiões são bem desenvolvidas (Fig. 12).

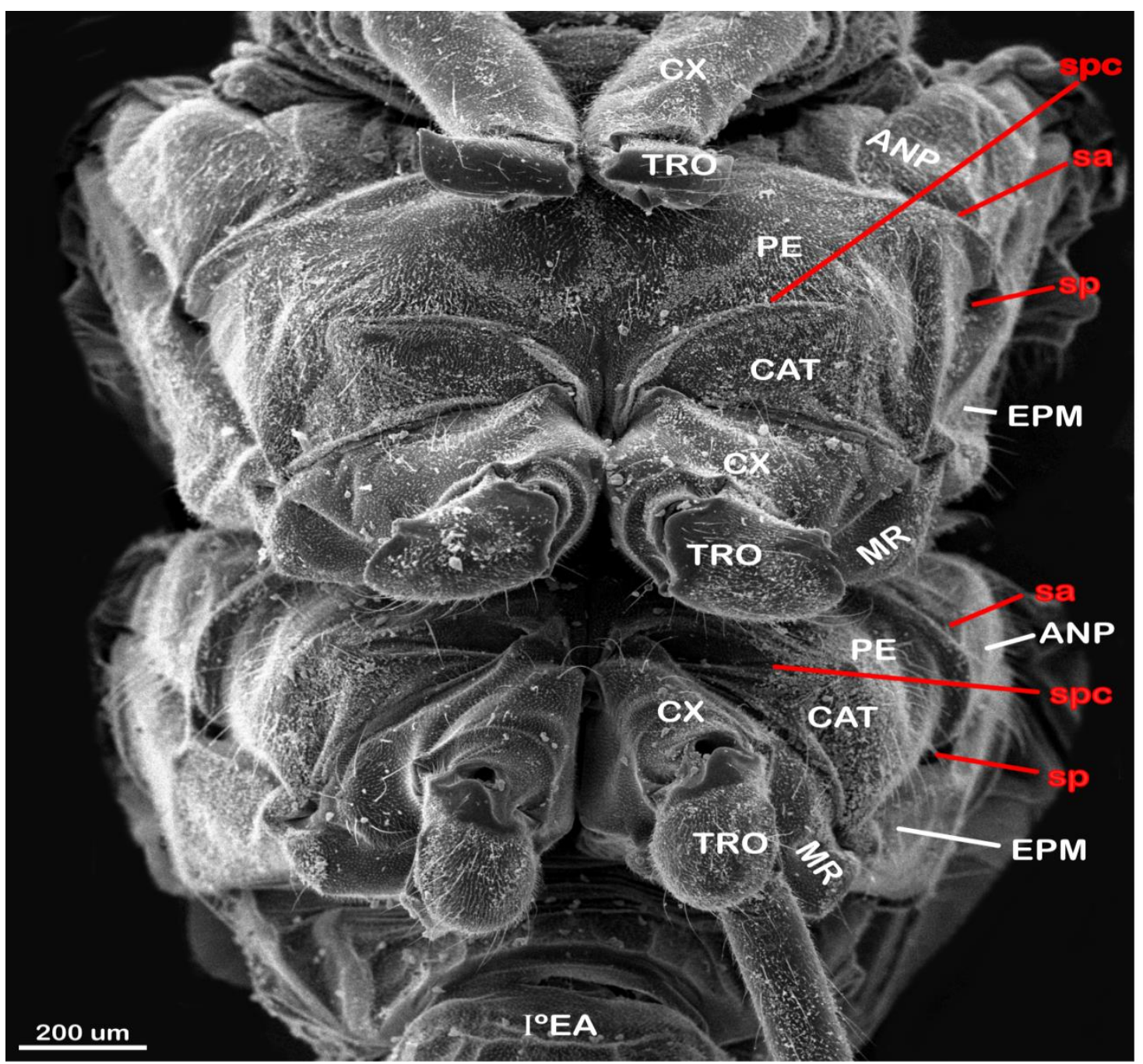

Figura 12. Microscopia eletrônica de varredura do pterotórax de Ceraeochrysa cincta (Schneider, 1851) (Chrysopidae: Chrysopinae), vista ventral. Anepisterno (ANP); catepisterno (CAT); coxa (CX); epímero (EPM); méron (MR); pré-episterno (PE); sutura anapleural (sa); sutura pleural (sp); sutura paracoxal (spc); trocânter (TRO); primeiro esternito abdominal (IEA).

\section{Morfologia esqueletal interna do pterotórax de Ceraeochrysa Adams, 1982} (Chrysopidae: Chrysopinae) (Fig. 13).

O "endoesqueleto" de Ceraeochrysa é composto por apódemas que sustentam os órgãos e se inserem os músculos, muito semelhante à Chrysopa perla (Morse, 1931). 
Na região dorsal do prótorax, o acrotergito mesotorácico (referido como esclerito marginal por Morse (1931)) não é separado do prescuto por uma crista interna, ao contrário do acrotergito metatorácico que é separado do prescuto por uma pequena crista.

O prescuto possui crista dorsal nos dois segmentos do pterotórax. A região anterior da crista dorsal do prescuto mesotorácico está no interior do protórax, enquanto que a região anterior da crista metatorácica é observada dentro do mesotórax.

Meso e metatórax possuem crista entre o prescuto e escuto, porém, esta é mais desenvolvida no metatórax (Figs. 13b e 13c).

Entre a margem lateral do escuto e região lateral do escutelo, a qual termina no cordão axial, existe uma crista. Esta crista é bem desenvolvida no mesotórax, enquanto que no metatórax é quase imperceptível. Ambos os pós-notos possuem um fragma (FRG) em seu interior. No mesotórax, o fragma é maior que no metatórax, este último com algum grau de projeção no primeiro tergito abdominal (Figs. 13b e 13c).

$\mathrm{Na}$ região pleural, nos dois segmentos pterotorácicos existe a crista pleural $(\mathrm{CP})$, um apódema que se estende entre o processo pleural alar e o processo pleural coxal, formado pela invaginação da cutícula entre o episterno e o epímero. Da região mediana dessa crista, surge o braço pleural (BPL), o qual se estende para o interior do tórax e se funde com os braços furcais (F) (Figs. 13b e 13c). Segundo Matsuda (1970), na crista pleural estão fixados os músculos que se estendem para a coxa e para o trocantin.

O epímero do mesotórax é circundado posteriormente por um apódema largo, o qual é estreito no segmento metatorácico. O metatórax apresenta as subdivisões do epímero de maneira diferente do mesotórax, o que também é percebido nos apódemas pleurais. Mesotórax possui uma crista muito fina entre a região do anepímero e do catepímero, enquanto que no metatórax se nota uma crista bem desenvolvida entre os dois escleritos (Figs. $13 b$ e $13 c)$.

No episterno do meso e do metatórax, é encontrada uma placa ântero-dorsal interna. O anepisterno e o catepisterno são rodeados por um grande apódema, no meso e no metatórax. O trocantin está localizado abaixo do catepisterno como um esclerito bem demarcado. 

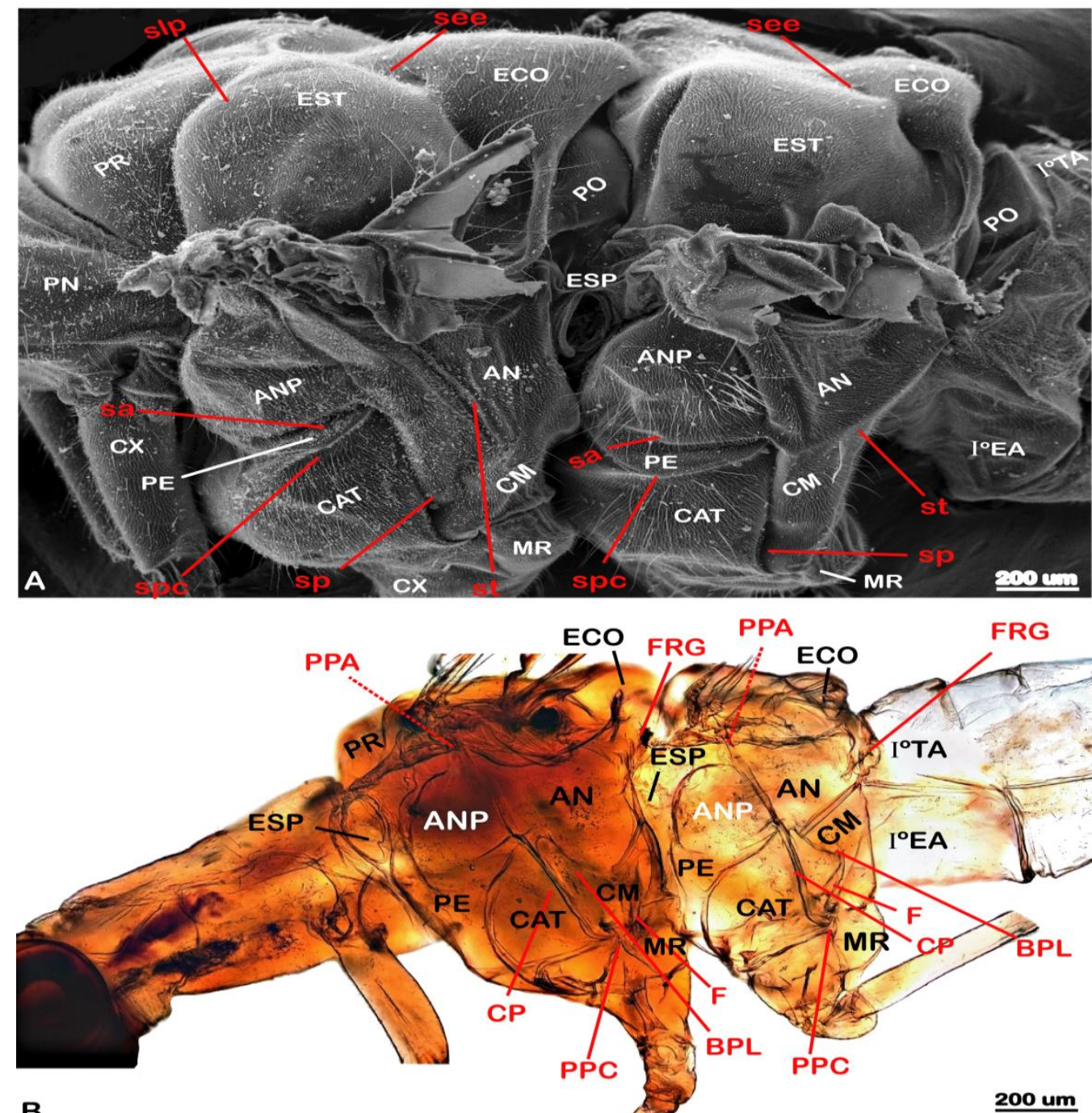

B

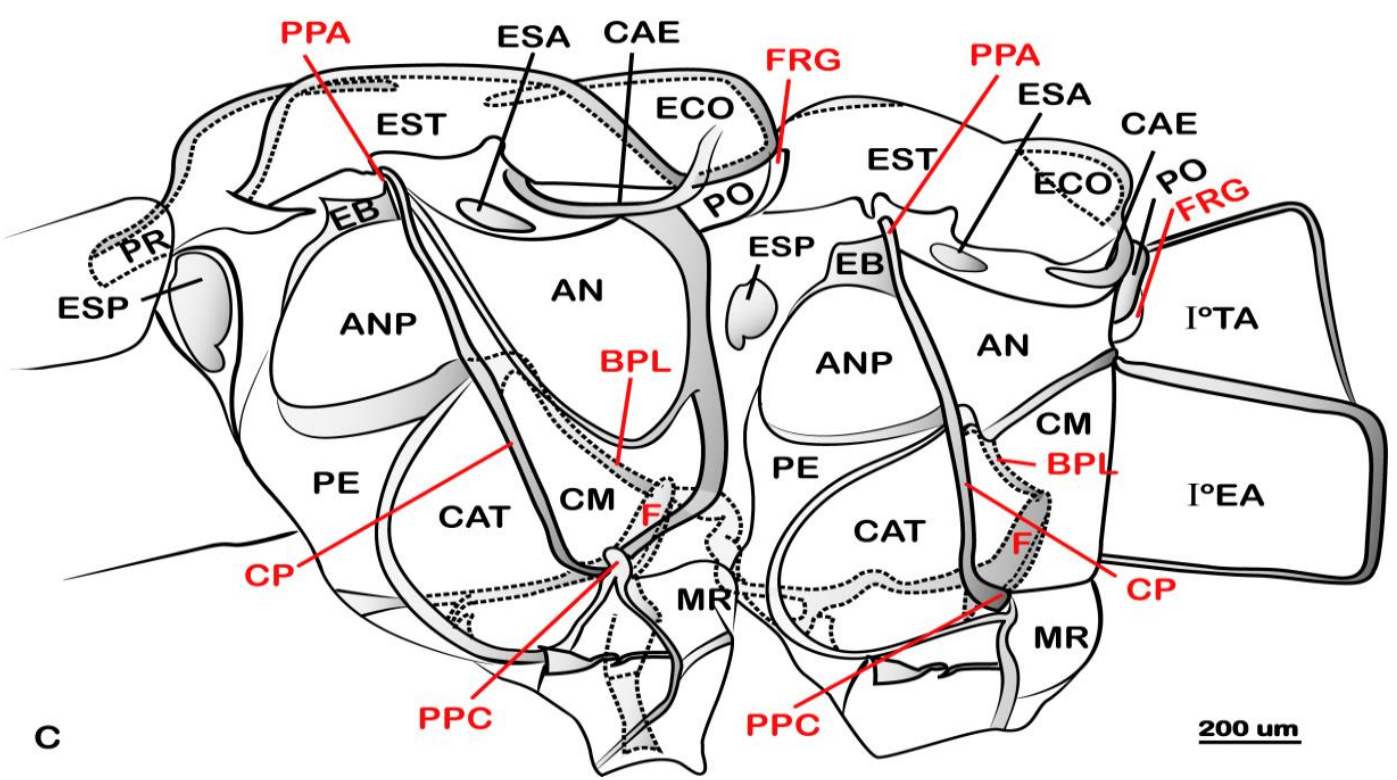

Figura 13. Pterotórax de Ceraeochrysa Adams, 1982 (Chrysopidae: Chrysopinae) vista lateral. A) Pterotórax de C. cincta (Scheneider, 1851). B) Apódemas de C. cornuta (Navás, 1925); C) Esquema geral de Ceraeochrysa. Anepímero (AN); anepisterno (ANP); braço pleural (BPL); catepímero (CM); catepisterno (CAT); cordão axilar do escutelo (CAE); coxa (CX); crista pleural (CP); esclerito basalar (EB); esclerito subalar (ESA); escutelo (ECO); escuto (EST); espiráculo (ESP); fragma (FRG); furca (F); méron (MR); posnoto (PO); pré-episterno $(\mathrm{PE})$; prescuto $(\mathrm{PR})$; primeiro esclerito abdominal $\left(\mathrm{I}^{\circ} \mathrm{EA}\right)$; primeiro tergito abdominal ( $\left.{ }^{\circ} \mathrm{TA}\right)$; processo pleural coxal (PPC); processo pleurar alar (PPA); pronoto (PN); sutura anapleural (sa); sutura escuto-escutelar (see); sutura lateral parapsidal (slp); sutura paracoxal (spc); sutura pleural (sp); sutura transepimeral (st); trocantin (TR). 
O esterno pterotorácico de Ceraeochrysa tem os basisternos fortemente reduzidos e invaginados; internamente o basisterno forma uma crista medial em frente à furca, concordando com o relato de Friedrish \& Beutel (2010) para Endopterygota; em sua região posterior é encontrado o furcasterno, que tem uma invaginação formando dois braços furcais, os quais se fundem com braços pleurais da crista pleural (Figs. 13b e 13c). Como descrito por Friedrish \& Beutel (2010) para Endopterygota, a parte visível ventralmente do pterotórax é uma derivação pleural e não esternal (Fig. 12).

\section{Pernas de Ceraeochrysa Adams, 1982 (Chrysopidae: Chrysopinae) (Figs. 14 e 15).}

A perna anterior apresenta diferenças em relação às pernas mediana e posterior; coxa protorácica apresenta forma cilíndrica e alongada, ao contrário do que é observado nas meso e metatorácicas, que têm forma cônica; somente as pernas meso e metatorácias têm méron bem desenvolvido; todas as coxas apresentam grande quantidade de microcerdas e algumas cerdas longas (Fig. 14).

Os trocânteres dos três pares de pernas são semelhantes, triangulares com microcerdas; o trocânter anterior é menor que o mediano e posterior. O fêmur nos três pares de pernas é cilíndrico, alongado, com grande quantidade de cerdas longas, em Ceraeochrysa nunca com manchas (Fig. 14).

A tíbia de Ceraeochrysa é alongada com sua região mediana achatada lateralmente; é cerca de uma vez e meia mais longa que o fêmur; pode apresentar manchas negras (como em C. nigripes Adams \& Penny, 1987); o ápice tibial pró e mesotorácico têm um esporão e o metatorácico dois (Fig. 14).

Os três pares de pernas têm cinco tarsômeros; primeiro e último são mais longos que o restante; todos tarsômeros apresentam grande quantidade de cerdas e pequenos esporões ventralmente, os quais têm variados padrões de distribuição em diferentes espécies; o tarsômero distal tem em seu ápice uma região membranosa com duas garras em forma de gancho com a base dilatada, entre as quais está o arólio (Fig. 14); coloração dos tarsômeros pode ser verde, como em C. cincta (Schneider, 1851) e C. claveri (Navás, 1911), ou negra, como em C. nigripedis Penny, 1997; esporões, cerdas ventrais, garras tarsais e o arólio auxiliam na aderência do inseto quando em contato com alguma superfície lisa (Fig. 15). 

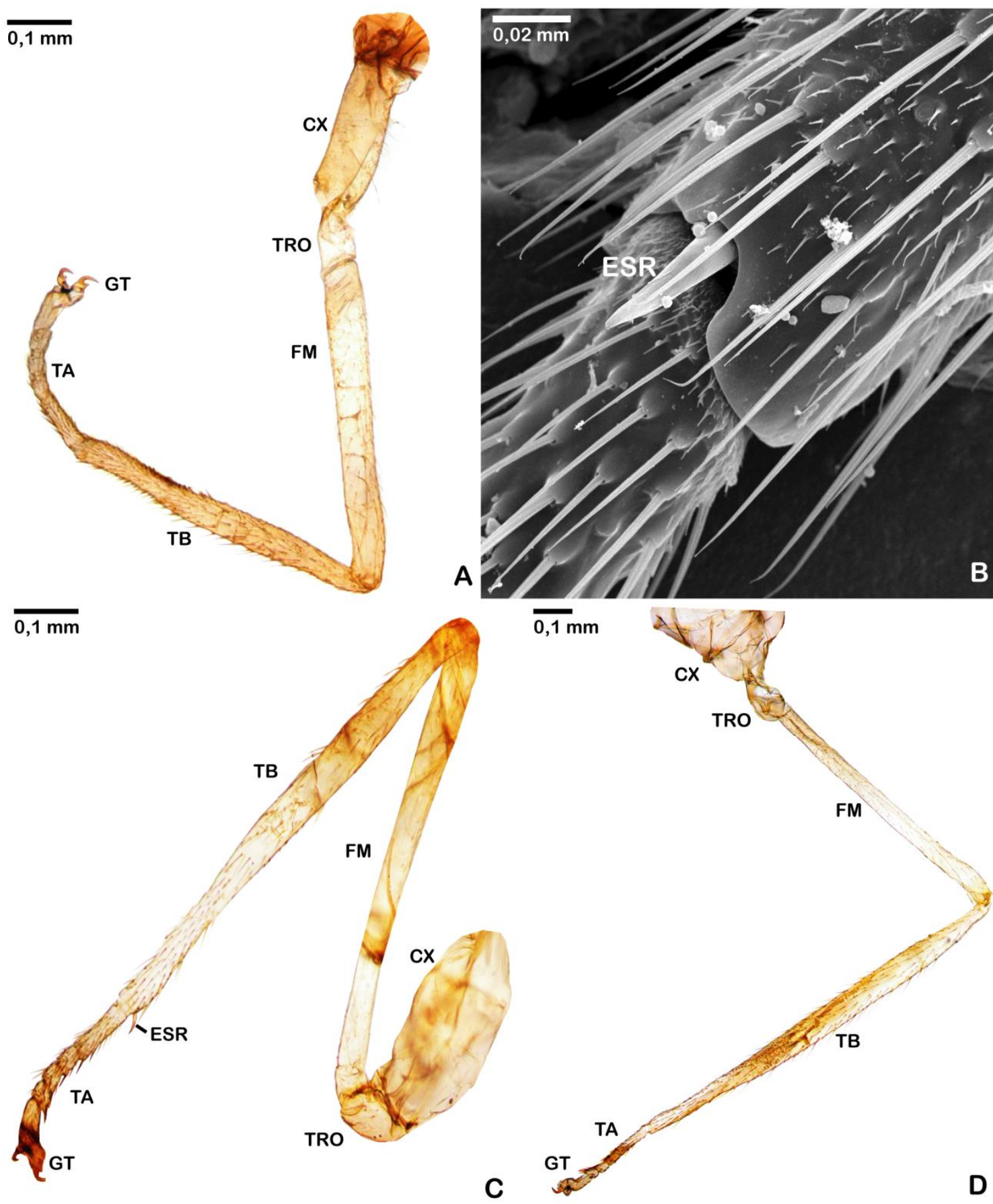

Figura 14. Pernas de Ceraeochrysa claveri (Navás, 1911) (Chrysopidae: Chrysopinae), vista lateral. A) Perna protorácica; B) Microscopia eletrônica de varredura do esporão do ápice tibial da perna mesotorácica de $C$. cincta (Schneider, 1851); C) Perna mesotorácica; D) Perna metatorácica. Coxa (CX); esporão (ESR); fêmur (FM); garras tarsais (GT); tarso (TA); tíbia (TB); trocanter (TRO). 

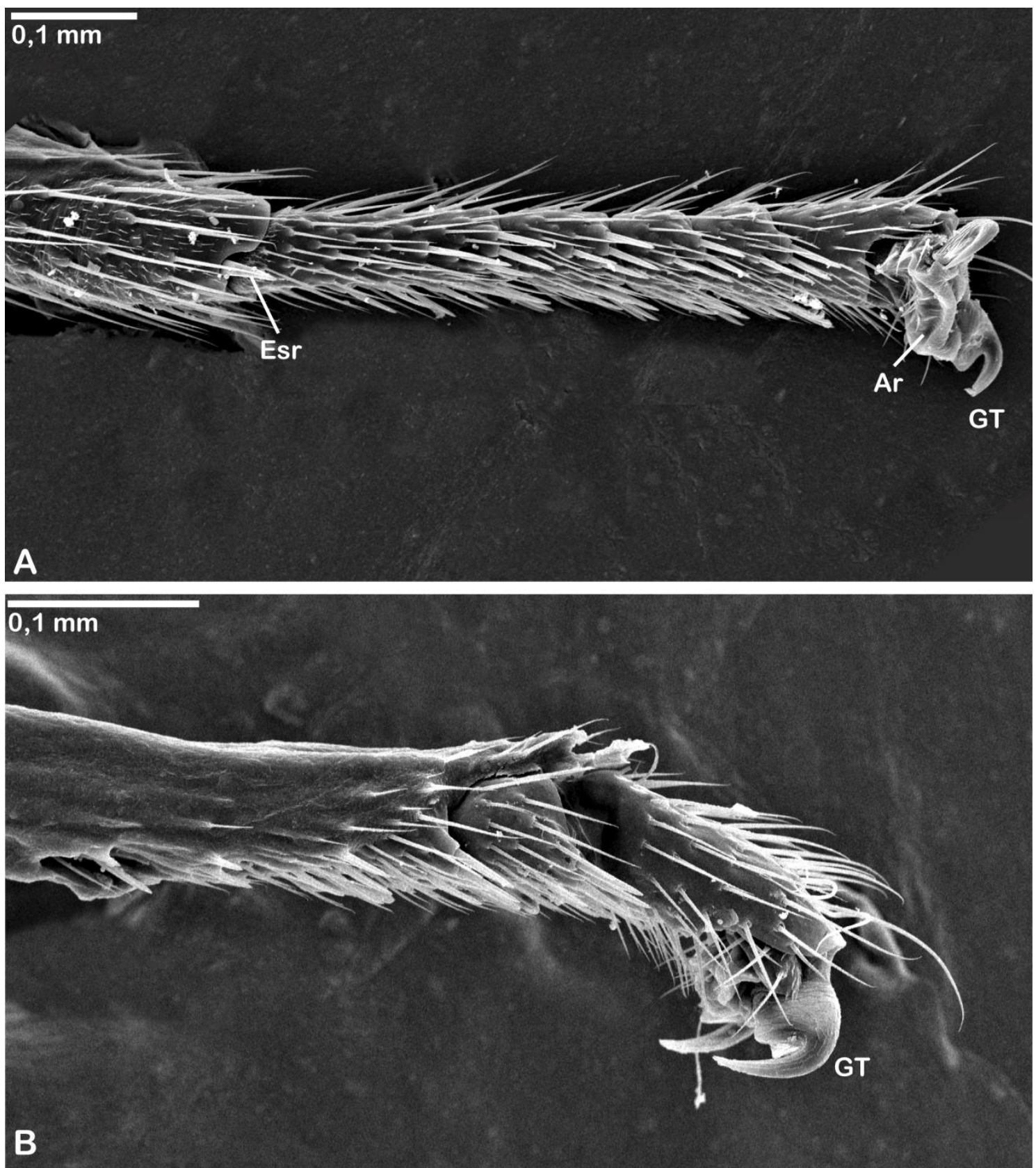

Figura 15. Microscopia eletrônica de varredura do ápice da perna protorácica de Ceraeochrysa cincta (Schneider, 1851) (Chrysopidae: Chrysopinae). A) Ápice da perna protorácica; B) Tarsômero distal da perna protorácica. Arólio (AR); esporão (ESR); garras tarsais (GT).

\section{Escleritos axilares e nervuras alares de Ceraeochrysa Adams, 1982 (Chrysopidae:} Chrysopinae) (Figs. 16 e 17).

As asas anterior e posterior de Ceraeochrysa apresentam os mesmos escleritos em sua base, sem variação significativa entre as espécies do gênero. O mais anterior é a tégula (TG), um pequeno esclerito triangular com cerdas longas; posteriormente está o primeiro esclerito axilar (PEA) articulado com o processo noto-medial do escuto (PNM) em sua margem proximal, com o suralar (SAL) por sua margem anterior e com o segundo esclerito axilar (SEA) através de sua margem distal. O segundo esclerito axilar é articulado posteriormente ao terceiro esclerito axilar (TEA); o terceiro esclerito axilar é o menor e está articulado 
posteriormente com o processo noto-posterior (PNP). Todos os quatro escleritos são dorsolaterais (Fig. 16).

$\mathrm{Na}$ região ventral, encontram-se três escleritos. O primeiro deles, acima do anapisterno, denomina-se esclerito intra-alar; o segundo, de forma quandrangular, é nomeado de basalar (EB); o terceiro esclerito, nomeado de subalar (ESA), é o maior dos três, localizado logo acima da margem dorsal do catepímero. O esclerito basalar está localizado anteriormente ao processo pleural alar, enquanto que os outros dois são dorsais ao processo pleural (Fig. 16).

A terminologia das nervuras alares de Chrysopidae não está suficientemente resolvida, foram propostas várias hipóteses (Schneider, 1851; Tillyard, 1916b; Navás, 1923; Banks, 1944; Adams, 1996). Para a padronização da nomenclatura, utilizou-se a hipótese de homologia proposta de Adams (1996).

Em Ceraeochrysa as asas apresentam grande variação no número, cor e forma das nervuras alares. Essa variação ocorre em especial no nível interespecífico, mas também intraespecífico, com destaque para o setor radial.

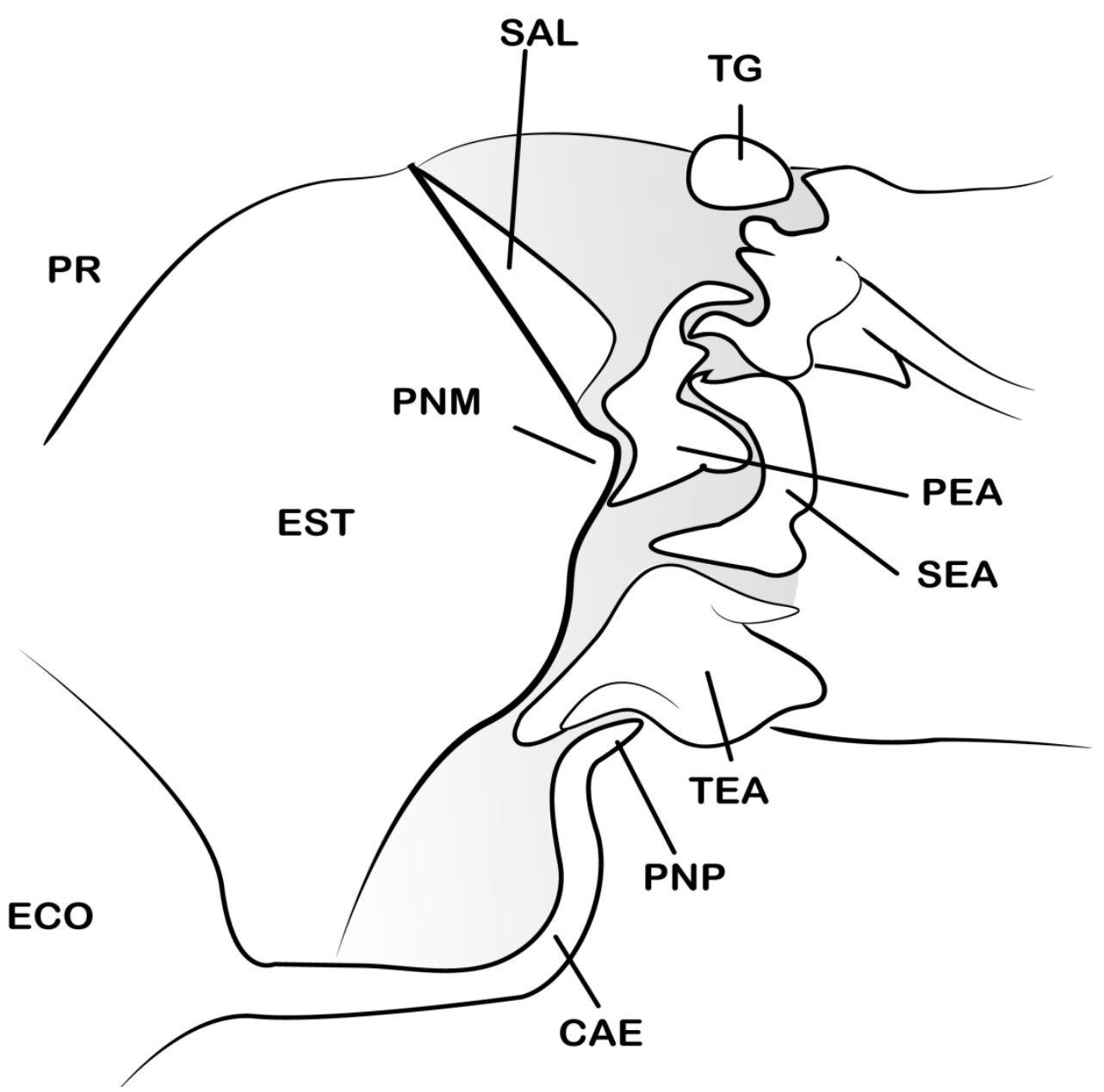

Figura 16. Esquema dos escleritos axilares de Ceraeochrysa Adams, 1982 (Chrysopidae: Chrysopinae). Cordão axilar do escutelo (CAE); escutelo (ECO); escuto (EST); primeiro esclerito axilar (PEA); processo noto-medial (PNM); processo noto-posterior (PNP); prescuto (PR); suralar (SAL); segundo esclerito axilar (SEA); terceiro esclerito axilar (TEA); tégula (TG). 


\section{Asa anterior (Fig. 17).}

A grande maioria das nervuras alares de Ceraeochrysa apresentam poucas cerdas.

A nervura costal pode ser de coloração clara ou escura; segue para o ápice da asa com uma leve curvatura.

Nervura subcostal com origem próxima à base da nervura costal; segue retilínea até a região do pterostigma e continua paralela à nervura costal até o ápice alar; seu ápice pode ser um ramo simples ou bifurcado.

A área costal, localizada entre as nervuras costal e subcostal, é larga basalmente e estreita-se em direção ao pterostigma; tem muitas nervuras transversais costais que podem apresentar manchas escuras.

O pterostigma, bem marcado nas asas de Ceraeochrysa, é claro na maioria das espécies, porém, pode possuir manchas escuras, como em C. achillea Freitas \& Penny, 2009.

Nervura radial anterior é paralela à subcostal até a região do pterostigma, local em que se afasta um pouco da subcostal e segue até o ápice da asa, onde pode terminar em um ramo simples ou bifurcado; de sua base surge outro ramo, formado pela fusão do setor radial e medial anterior.

Entre a nervura subcostal e radial anterior é possível observar a nervura basal costal localizada na base das células costais, com a posição variando entre as espécies de Ceraeochrysa.

O setor radial em Ceraeochrysa origina-se na base da nervura radial anterior junto com a nervura medial anterior; apresenta um aspecto de zigue-zague com número de ramos altamente variável, mesmo em nível intraespecífico.

Em Ceraeochrysa, o número de ramos no setor radial varia entre sete e 12 ramos, com o número mais frequente de 10 ramos. A redução do número de ramos do setor radial é devido à perda dos ramos um a cinco no ápice alar. Normalmente, os ramos do setor radial são bifurcados e podem ser de coloração clara, como em C. acmon Penny, 1998 e C. torresi Sosa \& Freitas, 2010, ou escura como C. cubana (Hagen, 1861) e C. valida (Banks, 185). A ausência ou presença desses ramos influencia na forma da asa deste gênero, quanto maior o número de ramos do setor radial maior o comprimento da asa e quantidade de nervuras gradiformes internas e externas.

As nervuras gradiformes externas e internas podem ser encontradas entre os ramos dois e dez do setor radial; podem também ser de coloração clara, como em C. squamma Freitas \& Penny, 2001, ou escura, como na maioria das espécies do gênero; podem ser paralelas (como na maioria das espécies de Ceraeochrysa) convergentes ou divergentes entre 
si, como em C. infausta (Banks, 1946), C. effusa (Navás, 1911) e C. achillea Freitas \& Penny, 2009.

Entre a nervura radial anterior e o setor radial notam-se nervuras transversais radiais que apresentam grande variação inter e intraespecíficas.

Da base do setor radial, sai o ramo correspondente à medial anterior, que segue para a margem anal da asa anterior em forma sinuosa, com uma bifurcação em seu ápice. Em todas as espécies de Ceraeochrysa, esta bifurcação tem um ramo simples e uma forquilha.

$\mathrm{Na}$ base da nervura radial anterior, também tem origem a nervura medial posterior, que é sinuosa semelhante à medial anterior.

Próximo à base da nervura medial posterior, observa-se a célula intramediana, que é ovalada em Ceraeochrysa e não possui grande variação de forma e tamanho entre as espécies.

A nervura medial posterior segue uma curta distância em sentido apical e se divide em dois ramos, medial posterior 1 e 2, que bifurcam-se e seguem em direção à margem anal da asa.

As nervuras cubitais, anterior e posterior, têm um tronco comum na base da asa, separando-se após uma curta distância e seguindo em direção à margem. A cubital anterior apresenta curvatura em direção à base da asa, e antes de atingir a margem bifurca-se em um ramo basal simples e um ramo apical bifurcado. A cubital posterior segue em sentido à base e bifurca-se antes de atingir a margem alar.

Entre as duas nervuras cubitais são encontradas três células, a terceira célula mais apical, nomeada célula cubital distal, tem manchas escuras em algumas espécies como, por exemplo, C. angulata (Navás, 1929).

Após as nervuras cubitais, são encontradas as nervuras anais, nervura anal 1, que segue em direção à margem anal da asa e se bifurca um pouco antes de atingí-la e, nervura anal 2, a qual também segue para margem anal com sua bifurcação próximo à base.

Da fusão de partes das nervuras medial posterior, medial anterior e ramos 10, 11 e 12 do setor radial, forma-se uma pseudo-nervura retilínea, referida como pseudomediana.

O mesmo ocorre com a pseudocubital, formada pela fusão de partes das nervuras cubital anterior, medial anterior, medial posterior e ramos 11 e 12 do setor radial.

\section{Asa posterior (Fig. 17).}

As nervuras costal, subcostal e radial anterior da asa posterior são semelhantes às nervuras correspondentes da asa anterior. A área costal, entre as nervuras costal e subcostal, é mais estreita, quando comparada com a mesma região da asa anterior, onde também são observadas nervuras transversais costais que podem ser claras, como na maioria das espécies 
de Ceraeochrysa, ou escuras, como em C. castilloi (Navás, 1913) e C. cincta (Schneider, 1851).

De forma semelhante ao que ocorre na asa anterior, o setor radial e a medial anterior se originam de um único ramo da base da nervura radial anterior.

O setor radial forma um zigue-zague e apresenta grande quantidade de ramos, que variam em número dependendo da espécie; a maioria das espécies tem nove ramos do setor radial, mas este número varia entre seis e 11 ramos. Poucos ramos no setor radial das asas posteriores é resultado da perda dos ramos mais apicais, numerados de um a cinco.

O número de ramos do setor radial influencia no comprimento, na forma da asa e no número de gradiformes internas e externas. Existe grande variabilidade do número de ramos do setor radial no nível inter e intraespecífico; tais ramos terminam bifurcados e apresentam coloração clara ou escura.

As nervuras gradiformes internas e externas são paralelas na maioria das espécies, mas, podem ser convergentes ou divergentes como em C. belizensis Freitas \& Penny, 2009, C. derospogon Freitas \& Penny, 2009 e C. infausta (Banks, 1946)

Entre a radial anterior e o setor radial encontra-se grande número de nervuras transversais radiais, cujo número tem variação muito em nível interespecífico.

A medial anterior é semelhante ao da asa anterior, termina em uma bifurcação com um ramo simples e outro bifurcado. A medial posterior segue em direção à margem anal e, seu último trecho, bifurca-se em dois ramos (medial posterior 1 e 2), os quais têm uma segunda bifurcação.

As nervuras, cubital anterior e posterior, estão fusionadas na base da asa e seguem em direção à margem anal. A nervura cubital anterior bifurca-se em um ramo simples e outro bifurcado que seguem em sentido à margem anal, enquanto que, a cubital posterior tem somente um ramo. Observam-se duas células cubitais entre as nervuras cubitais.

A nervura anal 1 possui um ramo simples, que se estende até a região basal da margem anal, enquanto que a anal 2 tem a mesma forma da asa anterior.

Assim como ocorre na asa anterior, existem duas pseudonervuras na asa posterior de Ceraeochrysa; a pseudomedial, formada pela nervura medial anterior e pelo setor radial, e a pseudocubital, formada pelo setor radial e nervuras medial anterior, medial posterior e cubital anterior. 

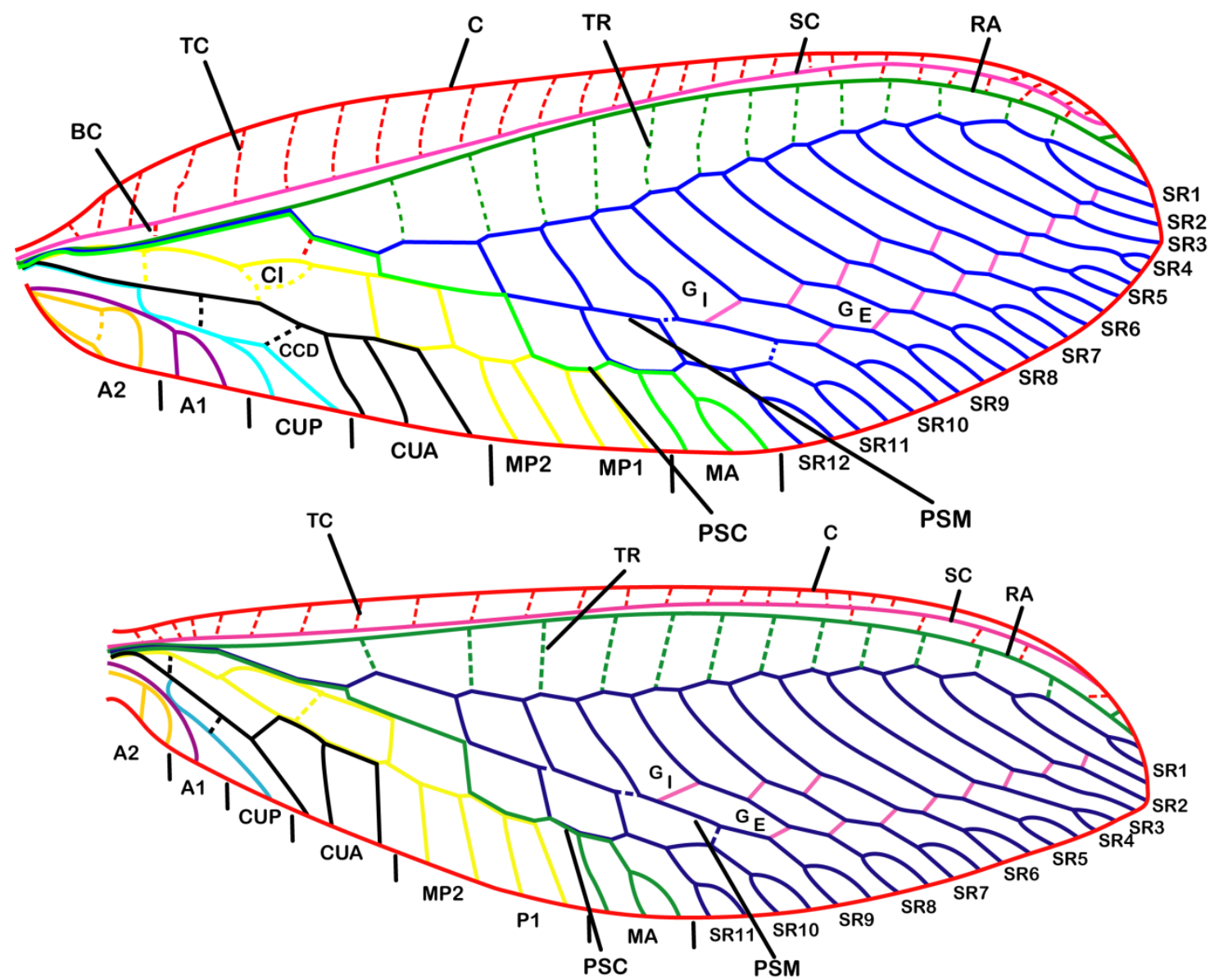

Figura 17. Esquema das nervuras alares de Ceraeochrysa Adams, 1982 (Chrysopidae: Chrysopinae). Anal 1 (A1); Anal 2 (A2); basal costal (BC); célula cubital distal (CCD); célula intramediana (CI); costal (C); cubital anterior (CUA); cubital posterior (CUP); gradiformes externas (GE); gradiformes internas (GI); medial anterior (MA); medial posterior 1 (MP1); medial posterior (MP2); "Nervura" Pseudocubital (Psc); "Nervura" Pseudomedial (Psm); radial anterior (RA); transversais Costais (TC); transversais radiais (TR); subcostal (SC); Ramos do setor radial (SR1 - SR12).

\subsubsection{Abdômen e genitália de Ceraeochrysa Adams, 1982 (Chrysopidae: Chrysopinae)}

(Figs. 18-21).

O abdômen de Ceraeochrysa tem nove segmentos bem definidos, entre eles o ectoprocto, que é formado pelo tergito X ou pelos tergitos X + XI (Aspöck \& Aspöck, 2008). Os oito primeiros segmentos abdominais não apresentam grande diferenciação entre si, exceto o primeiro esternito que é reduzido. Cada um dos oito primeiros segmentos apresenta um par de espiráculos, como o que foi descrito para Chrysopidae Brooks e Barnard (1990) (Fig. 18).

A coloração abdominal de Ceraeochrysa geralmente é verde, porém, algumas espécies apresentam manchas escuras nos tergitos abdominais. A presença ou ausência de manchas abdominais tem variação intraespecífica. 

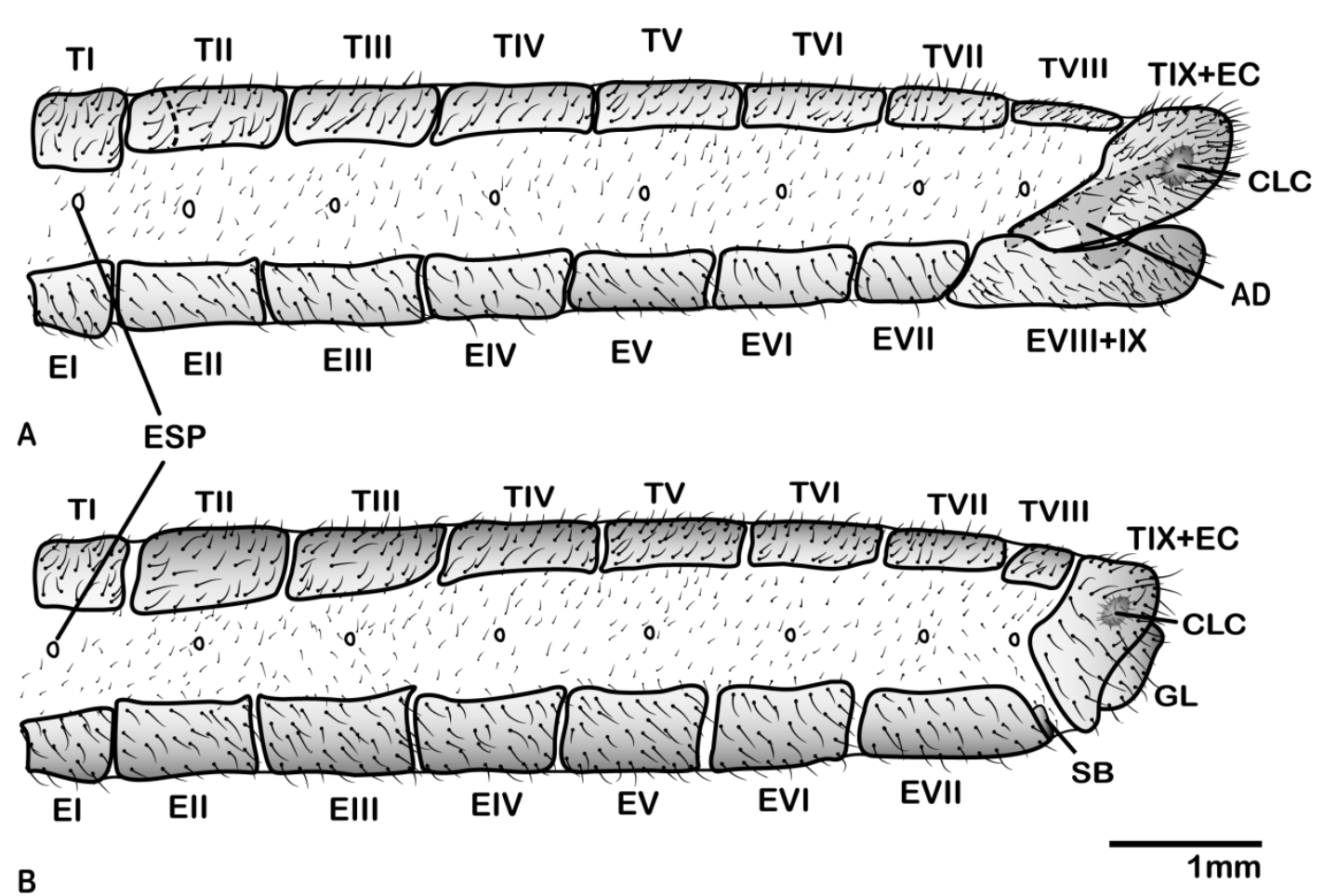

Figura 18. Esquema geral do abdômen de Ceraeochrysa Adams, 1982 (Chrysopidae: Chrysopinae), vista lateral. A) Macho; B) Fêmea. Apódema dorsal (AD); callus cerci (CLC); esternito 1-9 (EI EIX); ectoprocto (EC); espiráculo (ESP); gonapófise lateral (GL); subgenitália (SB); tergito 1-9 (TI TIX).

\section{Macho (Figs. 18a - 20).}

Apresenta o tergito IX fundido com o ectoprocto, que pode apresentar projeção ventral em algumas espécies, como em C. achillea Freitas \& Penny, 2009, C. acmon Penny, 1998 e C. squamma Freitas \& Penny, 2001.

A placa conformada pela fusão do tergito IX e do ectoprocto possui grande variedade de formas; pode ser estreita dorso-ventralmente, como ocorre em C. costaricensis Penny, 1997 e C. dislepis Freitas \& Penny, 2001; ter aspecto lateral triangular, como em C. everes (Banks, 1920) e C. michaelmuris Adams \& Penny, 1987; ou ter forma lateral mais arredondada, como em C. angulata (Navás, 1929) e C. cincta (Schneider, 1851).

No ápice abdominal de algumas espécies de Ceraeochrysa, como exemplo C. effusa (Navás, 1911), podem ser encontradas cerdas com bases grossas, chamadas de "cerdas chalazate".

Na região dorsal do ápice abdominal, é encontrado o apódema dorsal (AD) do tergito IX + ectoprocto, que apresenta grande variedade de formas entre as espécies de Ceraeochrysa. Uma característica marcante do apódema em algumas espécies é a presença de processo ventral apódemal, que normalmente apresenta duas possíveis condições: aspecto retílinio, observado em $C$. derospogon Freitas \& Penny, 2009 ou em $C$. digitata Freitas \& Penny, 2009, ou forma de gancho, como exemplo em C. discolor (Navás, 1914) e C. inbio 
Penny, 1997. O ápice do apódema dorsal pode ser bifurcado, observado na maioria das espécies de Ceraeochrysa, ou rombudo, como em C. cubana (Hagen, 1861).

No tergito IX + ectoprocto de Ceraeochrysa, é encontrado o callus cerci (Fig. 19) que pode ter forma oval ou circular - com grande quantidade de tricobótrios, cerdas muito espessas, com pequena abertura na base, provavelmente relacionada à quimiorrecepção. A presença do callus cerci é sinapomorfia de Neuropterida, porém o número de tricobótrios é altamente variável.

A região ventral do ápice abdominal de Ceraeochrysa é formada pela fusão dos esternitos VIII e IX, que pode ter características semelhantes às apresentadas pela placa do tergito IX + ectoprocto; cerdas com base grossa, como observado em C. effusa e C. fairchildi (Banks, 1946); bifurcação apical, como em C. cubana; apódema ventral, como observado em C. paraguaria (Navás, 1920) e C. valida (Banks, 1895).
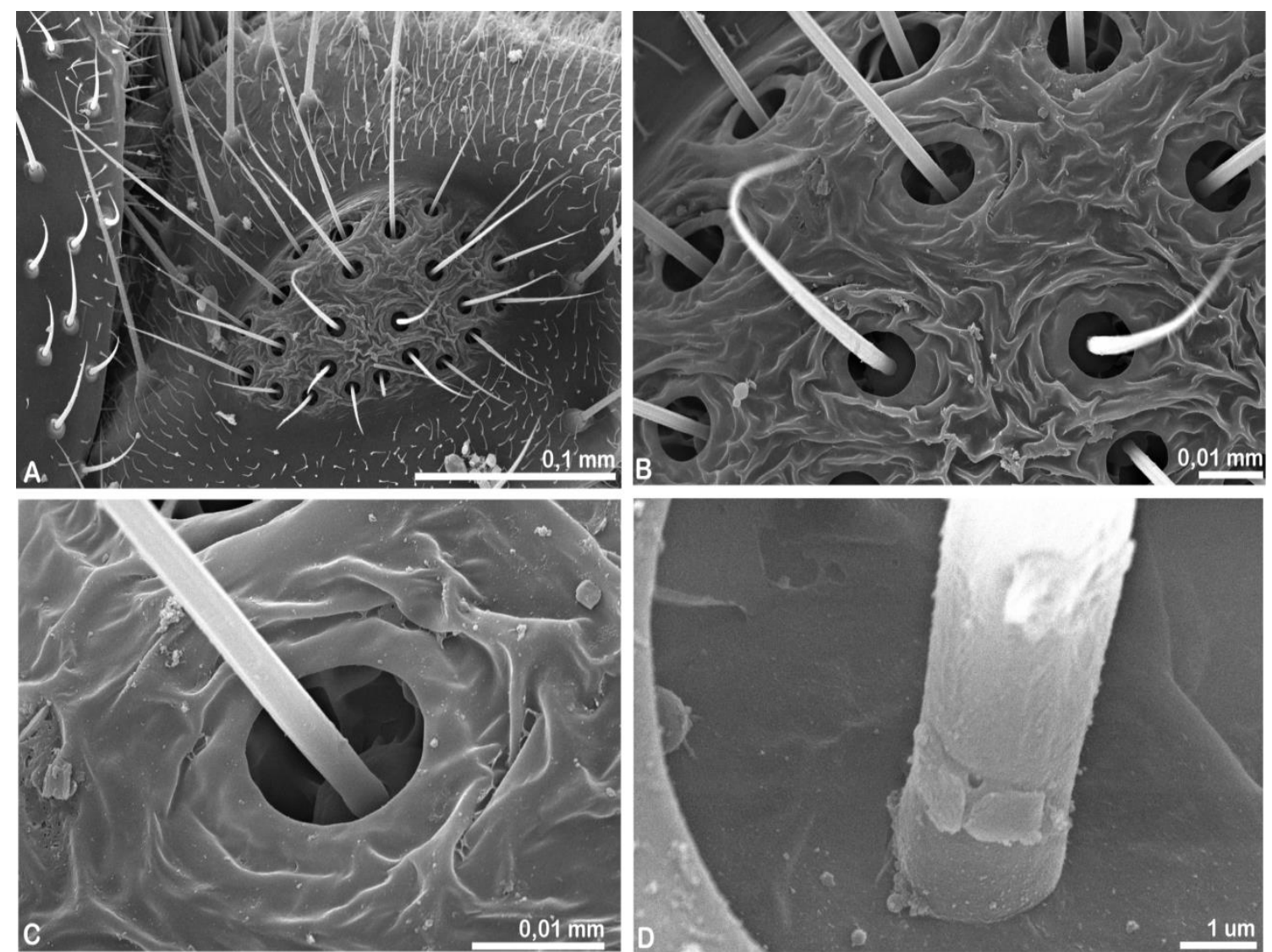

Figura 19. Microscopia eletrônica de varredura do ápice abdominal de Ceraeochrysa cincta (Schneider, 1851) (Chrysopidae: Chrysopinae). A) Callus cerci vista dorsal; B) Tricobótrios; C) Detalhe da base de um tricobótrio; D) Abertura na base de um tricobótrio.

As principais características úteis para a separação das espécies de Ceraeochrysa são encontradas na genitália masculina. A genitália masculina nas espécies do gênero não possui pseudopênis, tigno, parâmero e espinela e, é formada por várias estruturas com grande 
variação interespecífica. O gonarco é formado pelo arco medial do gonarco e pelos braços laterais do gonarco (Fig. 20).

O arco medial do gonarco (AMG) pode ser espesso, como em C. bitacornua Freitas \& Penny, 2009 e C. squamma Freitas \& Penny, 2001, ou estreito, como em C. paraguaria (Navás, 1920); pode estar alinhado aos braços laterais do gonarco, como em C. paraguaria, ou estar na região anterior ao ápice dos braços, observado em espécies como $C$. ariasi Adams \& Penny, 1987 e C. berlandi (Navás, 1924); pode ter uma placa dorsal, denominada placa dorsal do gonarco (PDG), encontrada em um grupo de espécies (C. dislepis Freitas \& Penny, 2001, C. everes (Banks, 1920), C. melanopaeira Sosa \& Freitas, 2010, C. squamma Freitas \& Penny, 2001, C. costaricensis Penny, 1997 e C. squalidens Adams \& Penny, 1987, C. torresi Sosa \& Freitas, 2010); pode ter um pequeno processo digitiforme na região frontal do gonarco, encontrado em C. claveri (Navás, 1911), C. montoyana (Navás, 1913) e C. berlandi (Navás, 1924). Segundo Aspöck et al. (2008), o gonarco é a fusão dos gonocoxitos do IX segmento do abdômen.

Os gonocornos (GC) podem estar presentes no arco medial do gonarco, podem ser digitiformes, como em $C$. everes, $C$. melanopaeira e $C$. squamma, ou em forma de gancho pontiagudo, como na maioria das espécies do gênero; podem ser reduzidos e possuir processo ventral (PVG) (Fig. 20).

O entoprocessos (ENT) também pode estar presente no gonarco de algumas espécies do gênero, como em C. tucumana (Navás, 1919), C. paraguaria e C. divaricata Freitas \& Penny, 2009, o qual corresponde às gonapófises do segmento abdominal IX (Aspöck \& Aspöck, 2008) (Tabela 5).

Na lateral do gonarco, são observados dois braços laterais (BLG). Estes podem ter seu ápice maior que a base, como ocorre na maioria das espécies do gênero, ou apresentar base mais larga que o ápice, condição evidente em $C$. paraguaria; outra característica dos braços laterais do gonarco é a presença de processo dorso-lateral, como observado em $C$. acmon, $C$. torresi e C. angulata, ou sua ausência, como ocorre na maioria das espécies de Ceraeochrysa.

$\mathrm{Na}$ região antero-ventral do gonarco, está presente o mediunco (MD) com uma projeção denominada arcesso (ARC), estrutura formada pela fusão dos gonóstilos do segmento IX (Aspöck \& Aspöck, 2008) (Tabela 5) que pode apresentar várias formas, a mais comum entre as espécies de Ceraeochrysa é a alongada com o ápice dividido; em algumas espécies, como C. montoyana, o arcesso é tão largo quanto longo, o que lhe dá forma subquadrangular; seu comprimento é altamente variável entre as espécies (Fig. 20)

O ápice do arcesso pode estar dividido ou não, eventualmente com ganchos dorsais ou laterais, como ocorre em alguns grupos de espécies, por exemplo: $C$. ariasi e $C$. berlandi. Esta 
estrutura pode ser quase retilíneo, como observado em $C$. squalidens e $C$. squamma, ou ter grande curvatura na região ventral, como observado em $C$. smithi (Navás, 1914) ou $C$. angusta Freitas \& Penny, 2009.

Espécies de Ceraeochrysa tem uma estrutura fina e alongada, denominada gonapse (Figs. 20e, f, g), que pode possuir várias formas apicais: rombudo, como em $C$. cincta, $C$. divaricata e C. tucumana; bifurcado, como observado em $C$. digitata e $C$. claveri; denteado (C. paraguaria) ou filamentoso (apenas em C. smithi e C. squalidens). Segundo Aspöck et al. (2008) a gonapse é formada pela fusão dos gonocoxitos do segmento X e seus gonóstilos e gonapófises, quando presentes (Tabela 5).

O gonarco, arcesso e gonapse estão conectados ao gonossaco (GSU), um saco membranoso que é evertido no momento da cópula, dentro do qual se encontra a abertura do ducto ejaculatório. No exterior do gonossaco, podem ser encontradas as gonosetas (GST), cerdas modificadas que podem estar arranjadas de duas maneiras: cerdas esparsas sobre toda a superfície do gonossaco, condição observada na maioria das espécies de Ceraeochrysa, ou as gonosetas formam dois grupos separados de cerdas. Ainda pode ser encontradas microevaginações denominadas gonocristas (GCA).

Tabela VII. Homologia de genitália masculina de Ceraeochrysa Adams, 1982 (Chrysopidae: Chrysopinae).

\begin{tabular}{|l|l|}
\hline \multicolumn{1}{|c|}{ Estrutura Ceraeochrysa } & \multicolumn{1}{c|}{ Estrutura Hexapoda } \\
\hline ectoprocto & tergito X ou tergito X + XI \\
\hline gonarco & $\begin{array}{l}\text { fusão dos gonocoxitos do IX segmento do } \\
\text { abdômen }\end{array}$ \\
\hline entoprocesso & Gonapófise do IX segmento do abdômen \\
\hline arcesso & fusão dos gonóstilos do segmento IX \\
\hline gonapse & $\begin{array}{l}\text { fusão dos gonocoxitos do segmento X e } \\
\text { seus gonóstilos e gonapófises, quando } \\
\text { presentes. }\end{array}$ \\
\hline
\end{tabular}

\section{Fêmea (Figs. 18b e 21).}

No abdômen das fêmeas de Ceraeochrysa o tergito IX é fundido com o ectoprocto (Fig. 21), mas não têm apódemas no ápice. Ventralmente a essa linha de fusão são encontradas as gonapófises laterais (GL), e ventralmente a estas, a abertura da câmara genital feminina. O esternito VII apresenta margem posterior modificada, a qual se encaixa com a subgenitália (SB), que é bilobada.

As fêmeas de Ceraeochrysa, de modo geral não apresentam características na genitália úteis para a taxonomia do gênero. A estrutura mais estudada da genitália feminina de 
crisopídeos é a espermateca (EPA), que é alongada em todas as espécies do gênero, formada por uma vela externa (VEE), uma vela interna (VIE) e um ducto espermático (DE) (Fig. 21).

Em Ceraeochrysa a espermateca abre-se na bursa copulatrix (BC) por uma fenda alongada e, pode ter forma de $\mathrm{U}$, como observado em $C$. angulata; de $\mathrm{J}$, como em $C$. cornuta, ou pode ter forma alongada não definida, como ocorre em $C$. dolichosvela Freitas \& Penny, 2001. Na maioria das fêmeas de Ceraeochrysa, a vela interna tem o comprimento menor que a metade do comprimento da vela externa; em algumas espécies, o comprimento da vela interna é semelhante ao da vela externa, como pode ser observado em $C$. cubana.

O ducto espermático de Ceraeochrysa pode ser dilatado apicalmente, como em $C$. cornuta e C. montoyana.

Na bursa copulatrix são observadas duas glândulas bursais (GB), que tem forma oval ou circular.
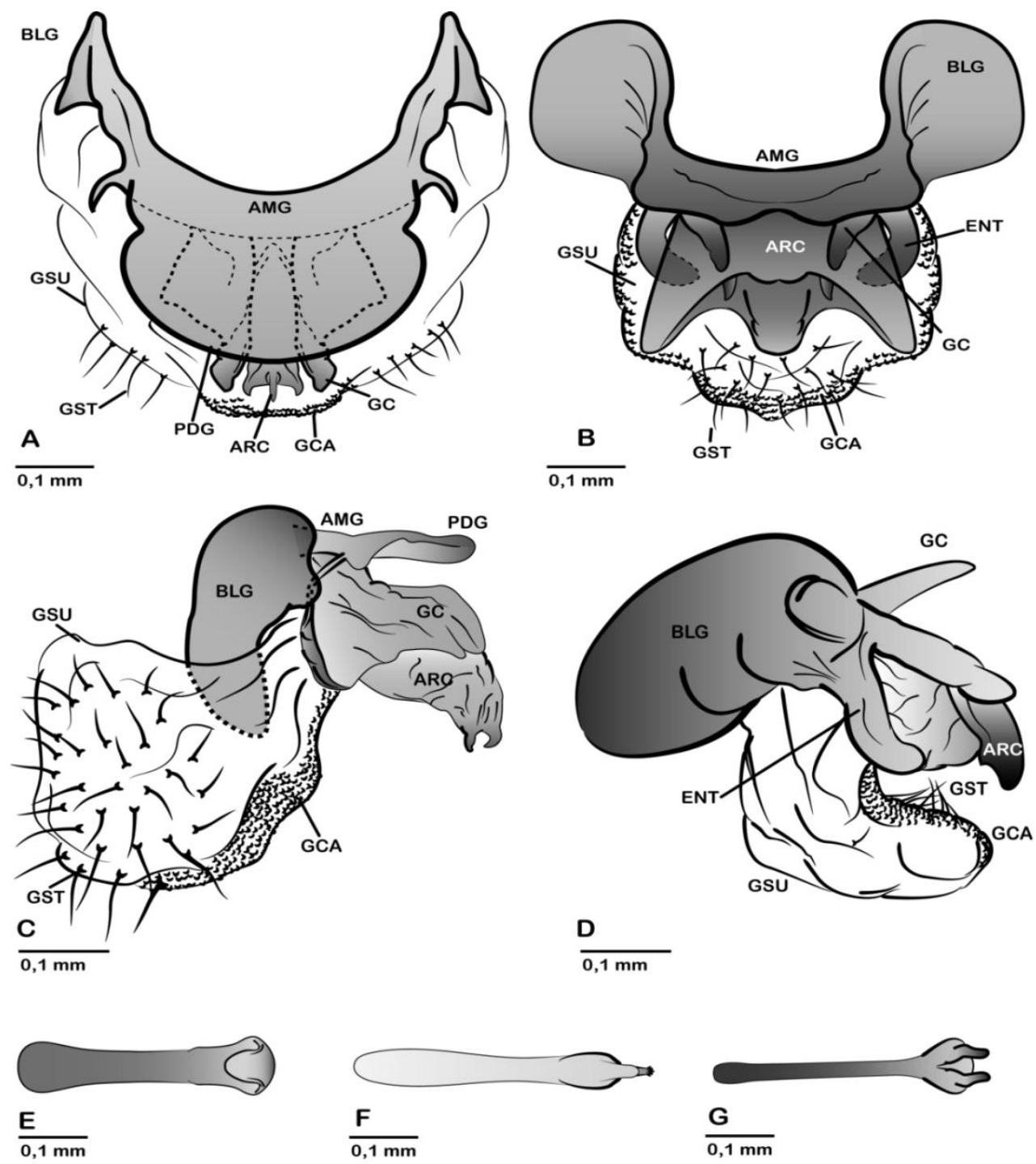

Figura 20. Genitálias masculinas de Ceraeochrysa Adams, 1982 (Chrysopidae: Chrysopinae). A) $C$. everes (Banks, 1920), vista dorsal; B) C. cincta (Schneider, 1851), vista dorsal; C) C. everes, vista lateral, D) $C$. cincta, vista lateral; E) Gonapse de $C$. cincta F) Gonapse de $C$. everes; G) Gonapse de C. achillea Freitas \& Penny, 2009. Arcesso (ARC); arco medial do gonarco (AMG); braço lateral do gonarco (BLG); entoprocesso (ENT); gonocorno (GC); gonocrista (GCA); gonoseta (GST); gonossaco (GSU); placa dorsal do gonarco (PDG). 

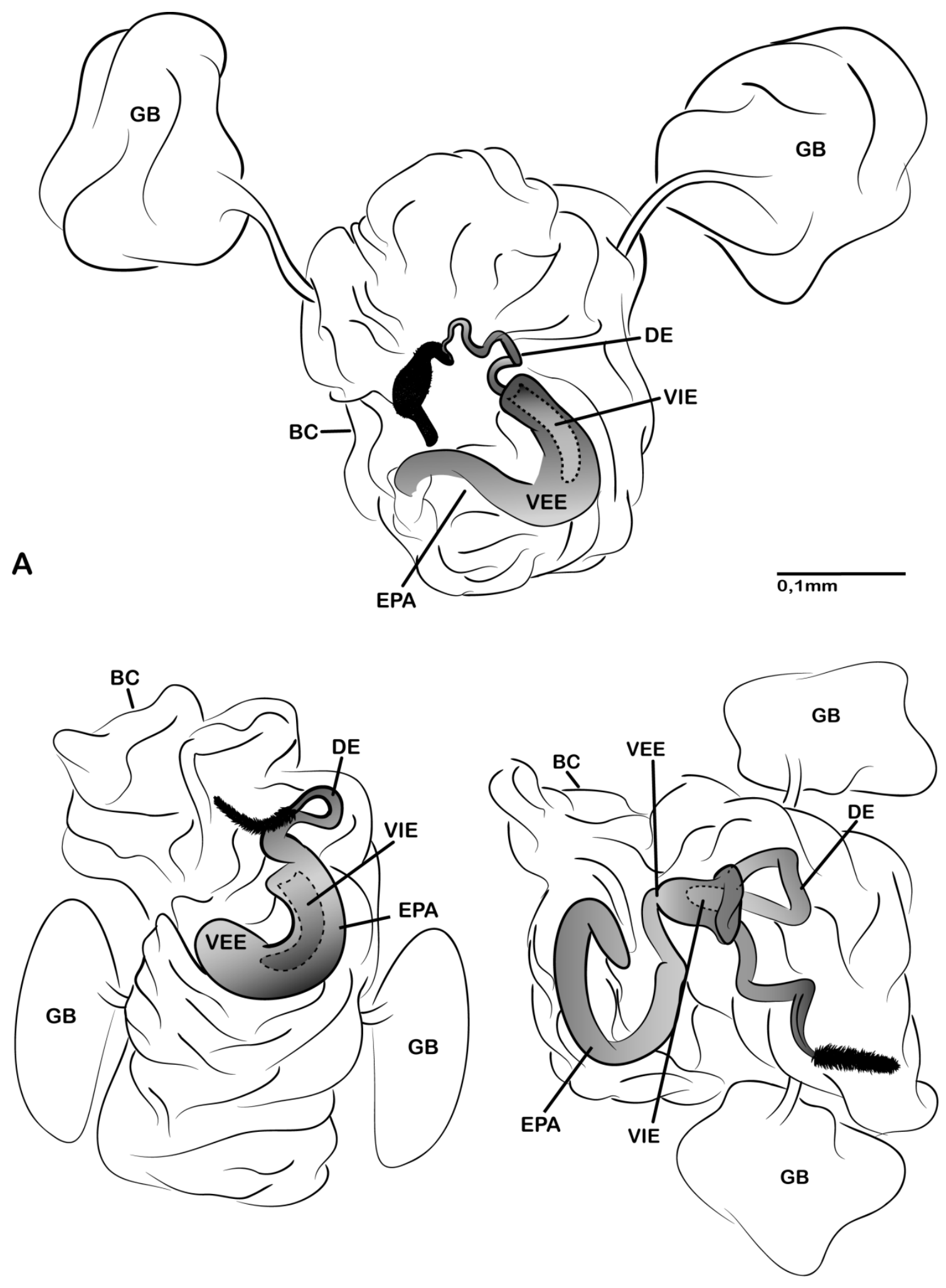

B

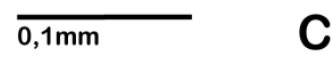

$0,1 \mathrm{~mm}$

Figura 21. Esquema em vista dorsal de genitálias femininas de Ceraeochrysa Adams, 1982 (Chrysopidae: Chrysopinae). A) Espermateca em forma de J; B) Espermateca em forma de U; C) Espermateca alongada sem forma definida. Bursa copulatrix (BC); ducto espermático (DE); espermateca (EPA); glândula bursal (GB); vela exterior da espermateca (VEE); vela interior da espermateca (VIE). 


\subsection{Análise filogenética de Ceraeochrysa Adams, 1982 (Chrysopidae: Chrysopinae).}

\section{Descrição dos grupos externos.}

\section{$\checkmark$ Subfamília Apochrysinae}

Joguina constellata (Navás, [1913]) (Fig. 22).

Material examinado: 2̧̂ e 1q, México, Xalapa, 03/09/1984, L. Peña col. Depositado no Museo Entomológico Dr. "José Manuel Osorio"

J. constellata apresenta cabeça estreita com vértice achatado com uma listra vermelha; antena com pedicelo constricto medianamente de coloração marrom, flagelômeros três vezes mais longos que largos, com cerdas que formam 5 anéis; palpos truncados; palpos truncados; pronoto com cerdas longas e pálidas é marcado com pequena listra lateral vermelha; meso e metanoto sem manchas; asas anteriores largas, arredondadas no ápice, sem nervuras transversais subcostais e célula intramediana, com grande quantidade de nervuras transversais, presença pústulas negras, cerdas costais longas, nervura subcostal curta e próxima da radial; área costal ampla; pseudomediana e pseudocubital curtas e, nervura anal 1 bifurcada; asa posterior mais estreita que a asa anterior, poré, com nervuras semelhantes; pernas sem manchas, com cerdas longas e claras; garras tarsais com dilatação na base.

Macho apresenta tergito IX + ectoprocto arredondado e curto; gonarco estreito e pouco arqueado; arcesso curto, triangular, com gancho apical e cerdas; gonossaco ausente; gonapse, placa mediana, tigno, pseudopênis, gonocrista, espinela e entoprocesso ausentes.

Fêmeas apresentam subgenitália bilobada, em forma de $\mathrm{U}$; espermateca tem forma globulosa (pill-box), com aspecto enovelado, e tem velas interna e externa curtas,

\section{$\checkmark$ Subfamília Chrysopinae: Tribo Chrysopini}

\section{Chrysoperla genanigra Freitas, 2003 (Fig. 23).}

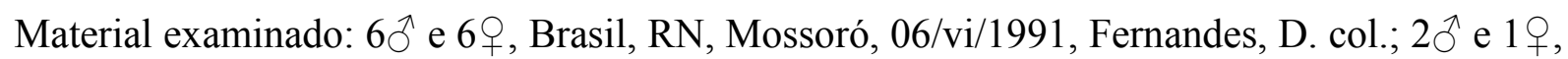
Brasil, SP, Jaboticabal, Manga, 20/iv/2010, Caleb Martins col. Depositado na FCAV, UNESP-Jaboticabal.

Chrysoperla Steinmann (1964), pertence à subfamília Chrysopinae, tribo Chrysopini. Este gênero é considerado por Brooks \& Barnard, 1990 e Winterton \& Freitas, 2006, como grupo-irmão de Ceraeochrysa. Existem aproximadamente 40 espécies distribuídas ao redor do mundo, exceto na região Holártica. 
C. genanigra apresenta cabeça estreita; vértice achatado sem estrias transversais; fronte sem manchas; clípeo e gena com mancha negra em forma de listra vertical; palpos maxilares escuros; escapo amarelo claro sem manchas; pedicelo amarelo claro sem manchas; flagelômeros de coloração amarelo claro, mais longos que largos e com cerdas distribuídas em quatro anéis; pronoto verde, amarelo medianamente, estreito e manchado lateralmente com uma listra cinza; meso e metanoto verdes sem manchas; asa anterior aproximadamente quatro vezes mais longa que larga, com gradiformes paralelas, área costal estreita, com poucos ramos no setor radial; asa posterior estreita, aproximadamente quatro vezes mais longa que larga, com gradiformes paralelas; pernas sem machas; abdômen verde com linha mediana amarela, sem manchas.

Macho tem a fusão do tergito IX + ectoprocto em forma triangular; apódema dorsal e ventral no abdômen; esternito VIII+IX globoso; tigno muito estreito e alongado com acumen triangular; gonanco estreito, pouco aqueado, com braços laterais robustos; arcesso longo e afunilado, curvado no ápice; gonossaco com poucas cerdas longas que formam dois grupos separados.

Fêmea apresenta espermateca curta com ducto espermático longo e sinuoso; subgenitália bilobada apicalmente..

\section{Chrysopodes (Chrysopodes) polygonica Adams \& Penny, 1987 (Fig. 24).}

Material examinado: $3 \hat{\jmath}$ e 3 \% , Brasil, SP, Jaboticabal, 20/i/1997, Freitas, S. col.; $3 \widehat{\jmath}$ e 3 q , Brasil, MT, Itiquira, 11/iii/2005, Carvalho, J.S. Depositado na FCAV, UNESP-Jaboticabal.

Ch. (C.) polygonica apresenta cabeça amarelada; vértice com marcas vermelhas na região pós-ocular; gena e clípeo com duas listras pretas verticais; escapo amarelado sem manchas; pedicelo amarelado sem manchas; flagelômeros amarelado sem manchas, com quatro anéis de cerdas; palpos maxilar e labial negros; pronoto verde com listra lateral vermelho-amarronzada; meso e metanoto verdes sem manchas; asa anterior cerca de três vezes mais longa que larga, com gradiformes paralelas e nervuras transversais com um pouco de sombreamento; asa posterior aproximadamente três vezes mais longa que larga, com gradiformes paralelas; abdômen verde com listra amarela mediana, sem manchas.

Macho tem tergito IX + ectoprocto com a margem caudal prolongada; esternito VIII + IX com cerdas de base cônica no ápice; placa subanal larga com muitas cerdas; gonarco estreito e muito arqueado, com o ápice dos braços laterais do gonarco expandidos; arcesso estreito, alongado e curvado apicalmente; gonossaco com poucas cerdas longas e muitas cerdas curtas. 
Fêmea apresenta espermateca cilíndrica, com ducto espermático longo e sinuoso; subgenitália bilobada apicalmente.

\section{Criptochrysa chloros Freitas \& Penny, 2001 (Fig. 25).}

Material examinado: 4へ e 4우, Brasil, SP, Jaboticabal, 20/i/1997, Freitas, S. col. Depositado na FCAV, UNESP-Jaboticabal.

C. chloros apresenta o vértice verde, sem manchas, com a margem anterior bem definida; fronte sem manchas; gena com listra negra vertical que continua lateralmente no clípeo; palpo maxilar negro; palpômero apical do palpo labial negro; escapo retangular, duas vezes mais longo que largo, sem manchas; pedicelo sem manchas; flagelômeros de cor amarelada com quatro anéis de cerdas; pronoto verde com listra lateral vermelhoamarronzada; meso e metanoto verdes e sem manchas; asa anterior cerca de três vezes mais longa que larga, com gradiformes paralelas, célula intramediana triangular; asa posterior cerca de três vezes mais larga que longa, sem manchas, com gradiformes paralelas; abdômen verde sem manchas.

O macho tem tergito IX + ectoprocto alongado, com grande quantidade de cerdas; esternito VIII+IX parcialmente fundido ao esternito VII; apodema ventral abdominal tem o ápice denteado; gonarco estreito, com braços laterais do gonarco quadrangulares; gonocorno achatado, curvado apicalmente; arcesso altamente esclerotizado com dentículos subapicais e ventrais, lobos laterais presentes, gancho apical fino e curvado; gonossaco com duas linhas de cerdas longas; gonapse longa com cerdas apicais e dois tufos ventro-mediais.

A fêmea apresenta espermateca curta e desenrolada; ducto espermatecal torcido; subgenitália bilobada. 

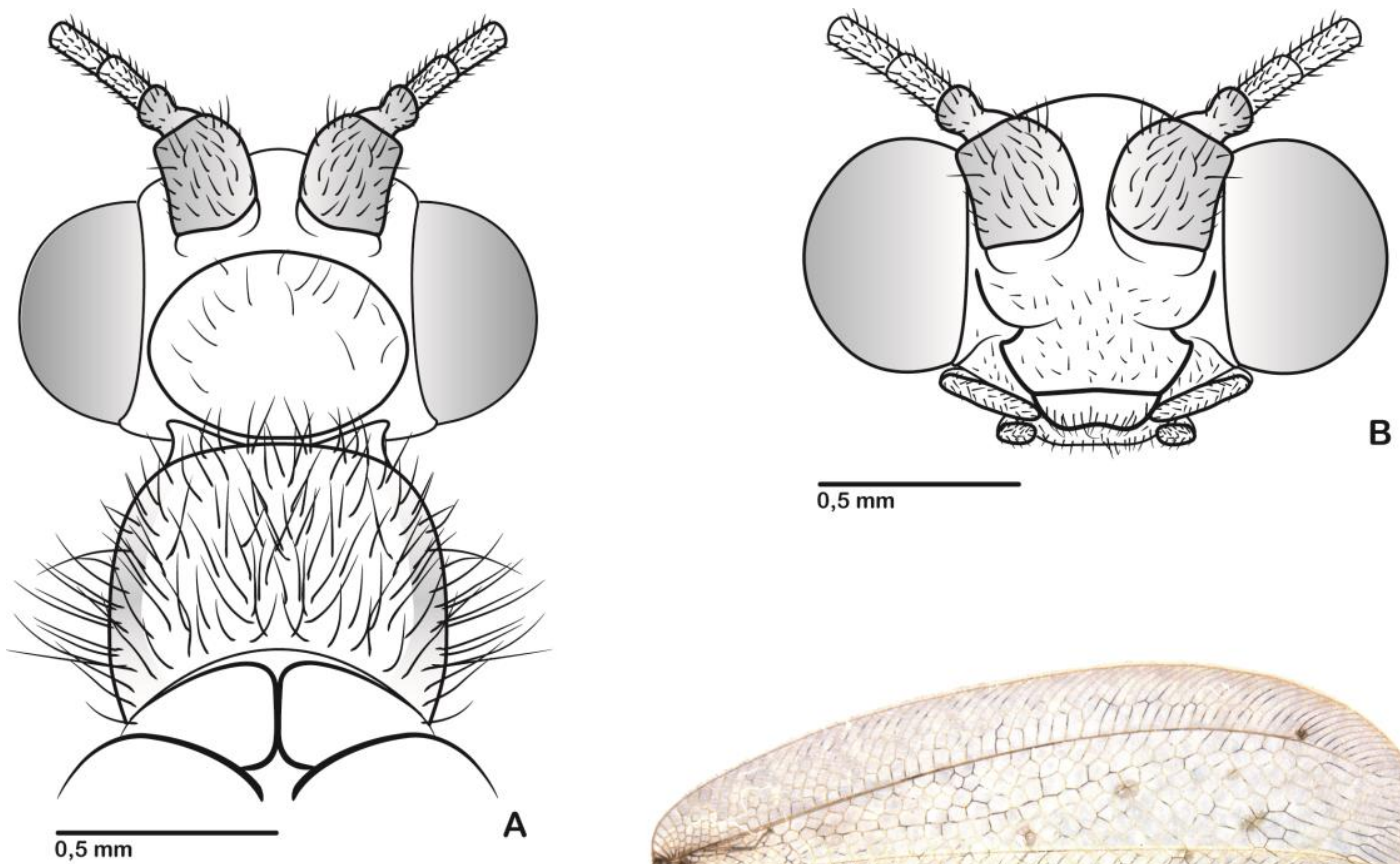

$\overline{0,5 \mathrm{~mm}}$
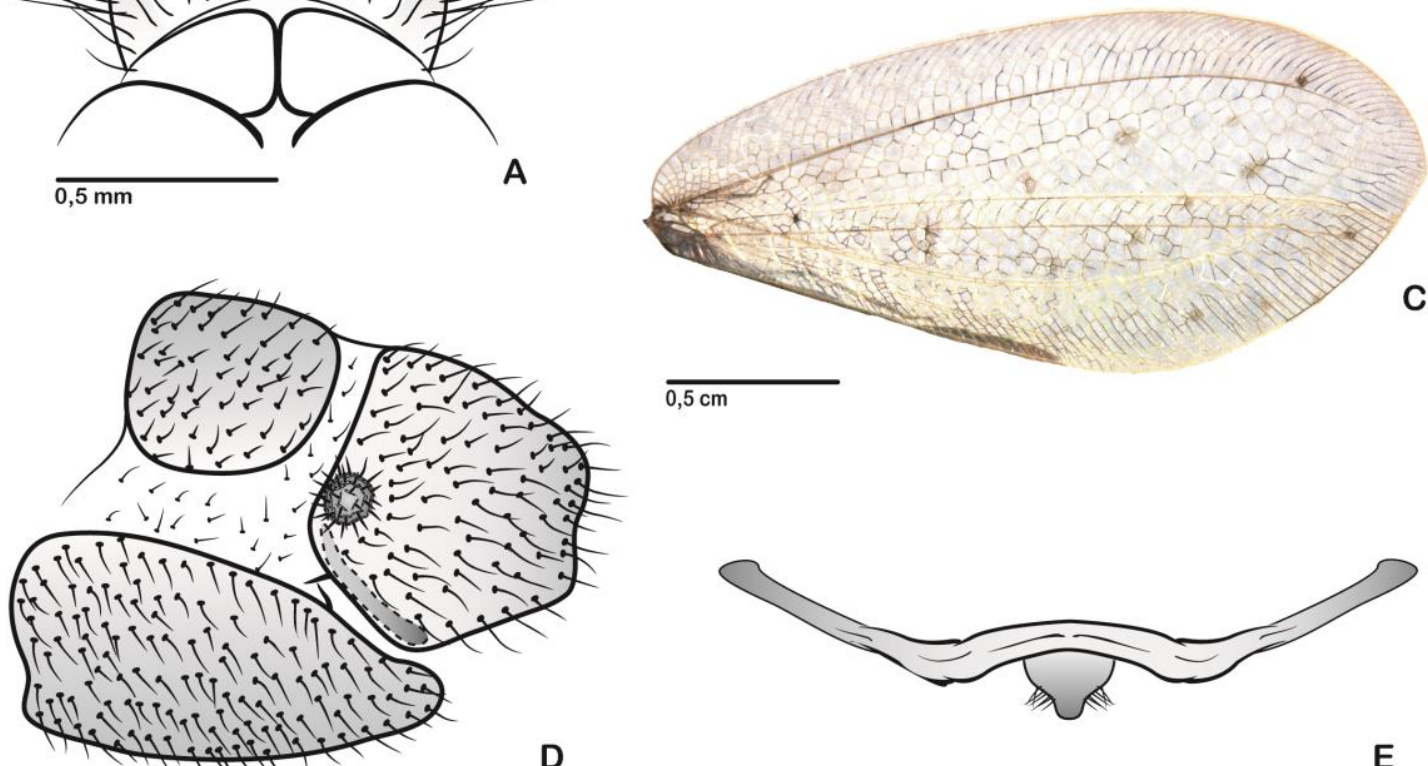

$\overline{0,5 \mathrm{~cm}}$

$0,5 \mathrm{~mm}$

D

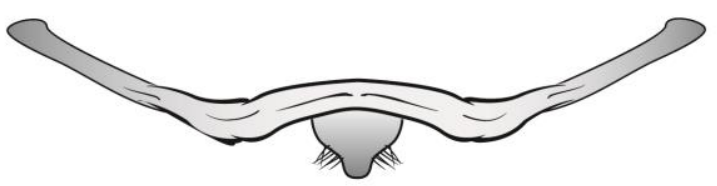

E
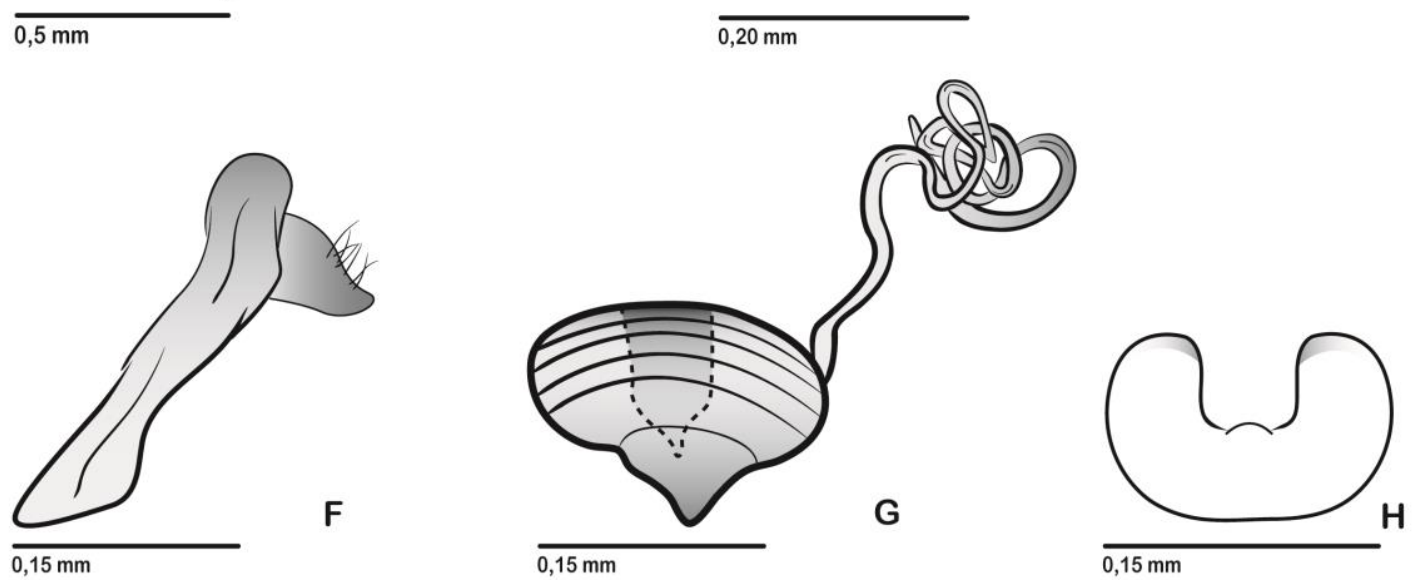

Figura 22. Estruturas de Joguina constellata (Navás, [1913]) (Chrysopidae: Apochrysinae). A) Cabeça e pronoto, vista dorsal; B) Cabeça, vista frontal; C) Asa anterior; D) Ápice abdominal masculino, vista lateral; E) Genitália masculina, vista dorsal; F) Genitália masculina, vista lateral; G) Espermateca, vista dorsal; H) Subgenitália, vista dorsal. 

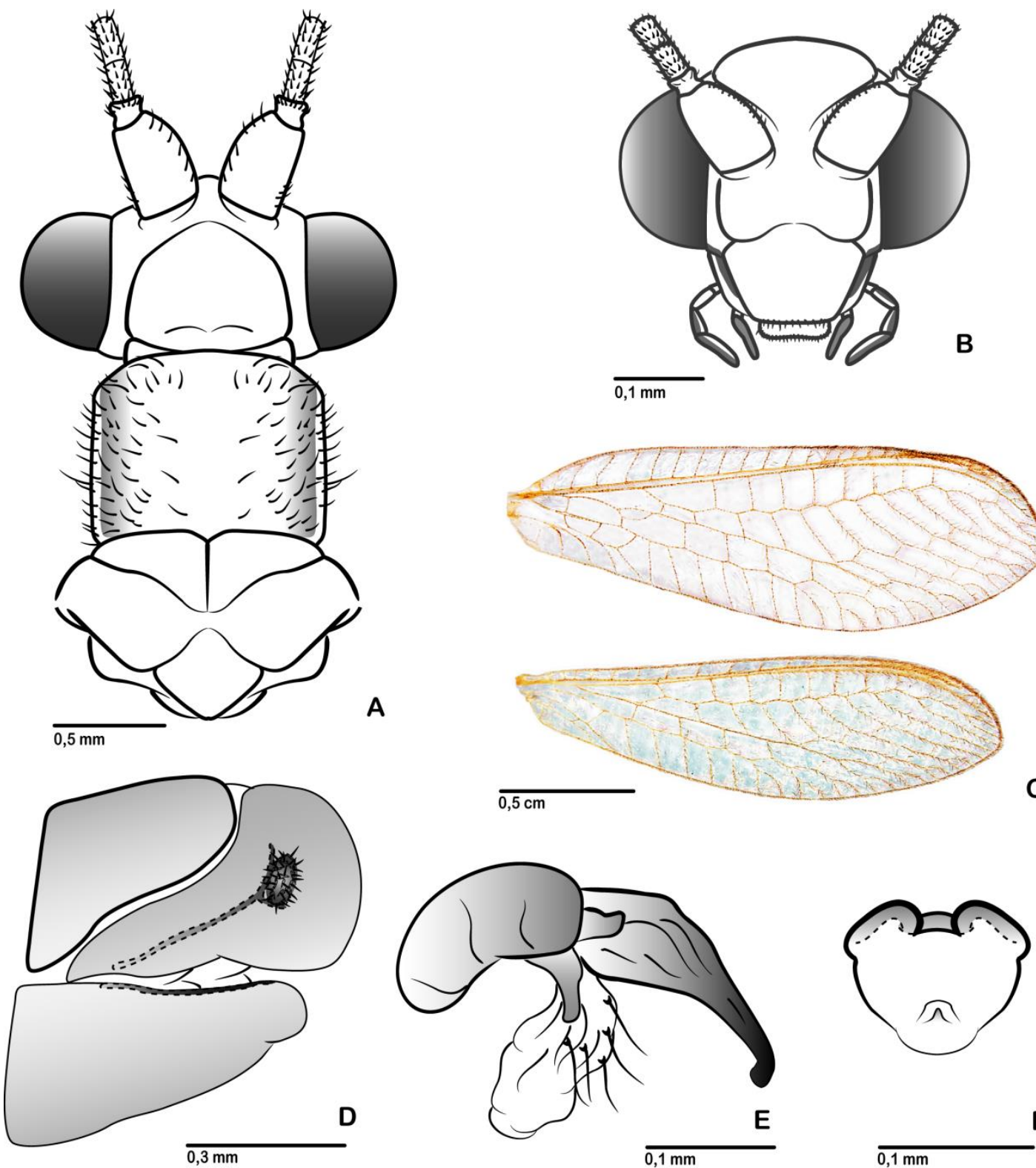

C

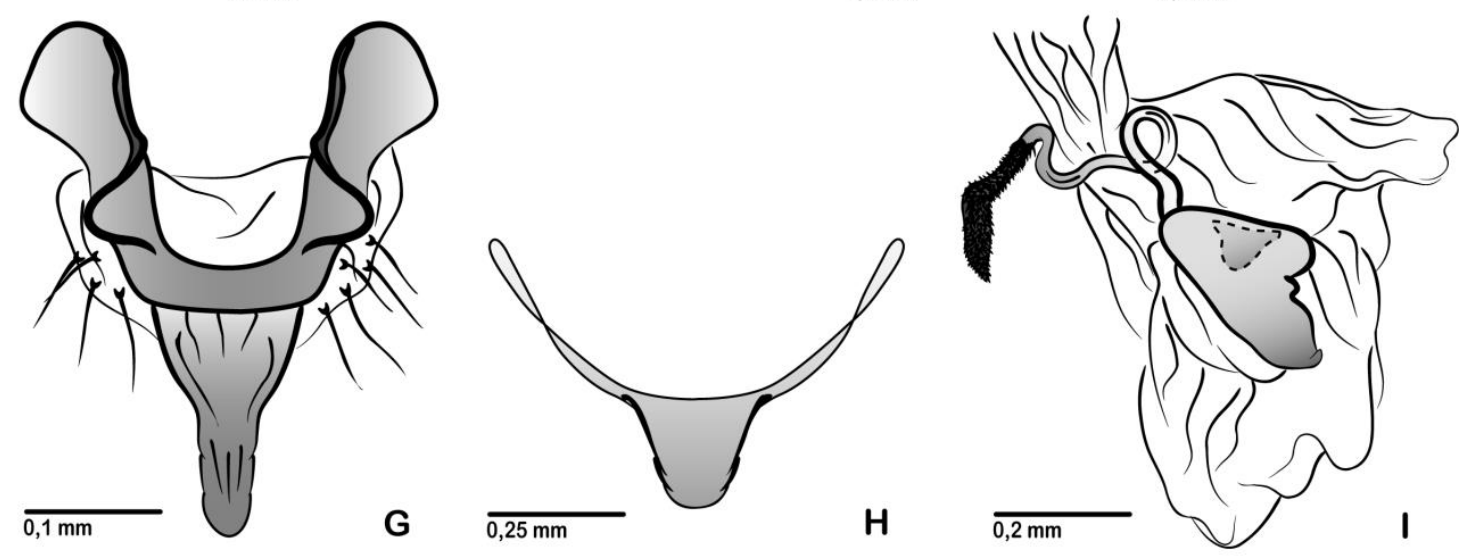

Figura 23. Estruturas de Chrysoperla genanigra Freitas, 2003 (Chrysopidae: Chrysopinae). A) Cabeça e pronoto, vista dorsal; B) Cabeça, vista frontal, C) Asas anterior e posterior; D) Ápice abdominal masculino, vista lateral; E) Genitália masculina, vista lateral; F) Subgenitália, vista dorsal; G) Genitália masculina, vista dorsal; H) Tigno, vista dorsal; I) Espermateca, vista dorsal. 

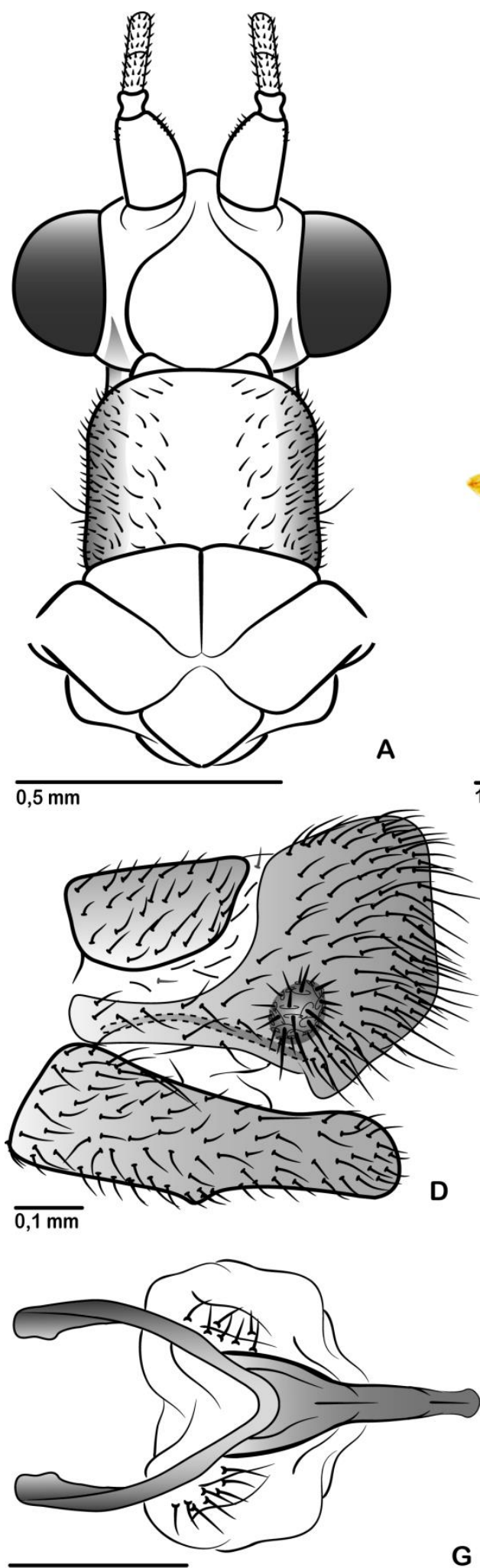

$0,1 \mathrm{~mm}$

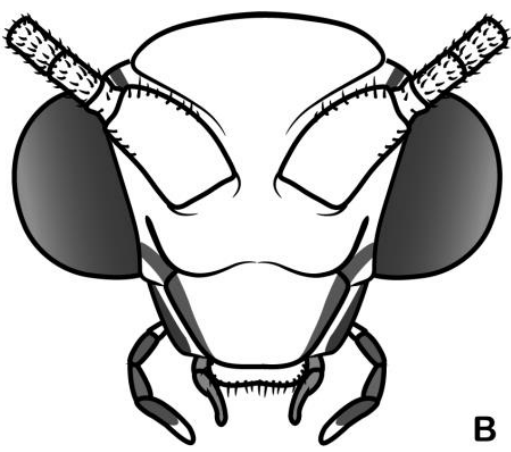

$\overline{0,1 \mathrm{~mm}}$

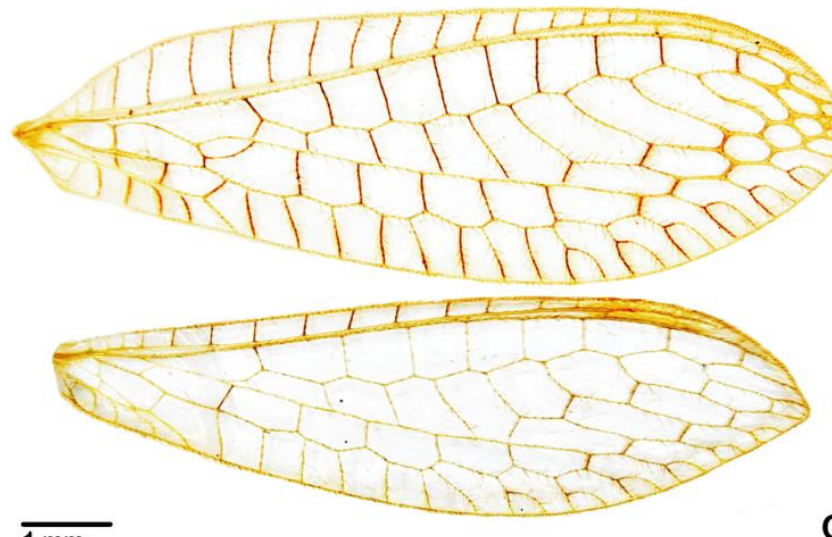

$\overline{1 \mathrm{~mm}}$

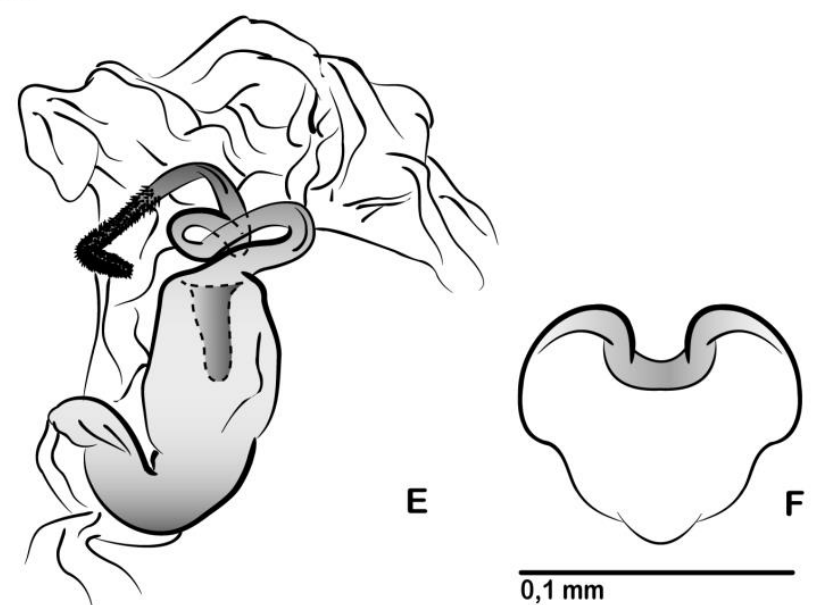

$\overline{0,1 \mathrm{~mm}}$

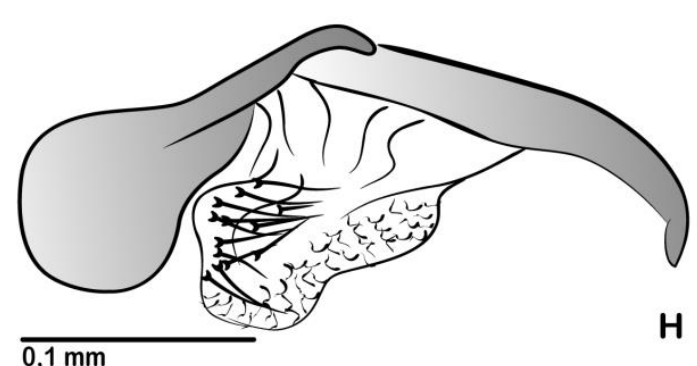

Figura 24. Estruturas de Chrysopodes (C.) polygonica Adams \& Penny, 1987 (Chrysopidae: Chrysopinae). A) Cabeça e pronoto, vista dorsal; B) Cabeça, vista frontal, C) Asas anterior e posterior; D) Ápice abdominal masculino, vista lateral; E) Espermateca, vista dorsal; F) Subgenitália, vista dorsal; G) Genitália masculina, vista dorsal; H) Genitália masculina, vista lateral. 


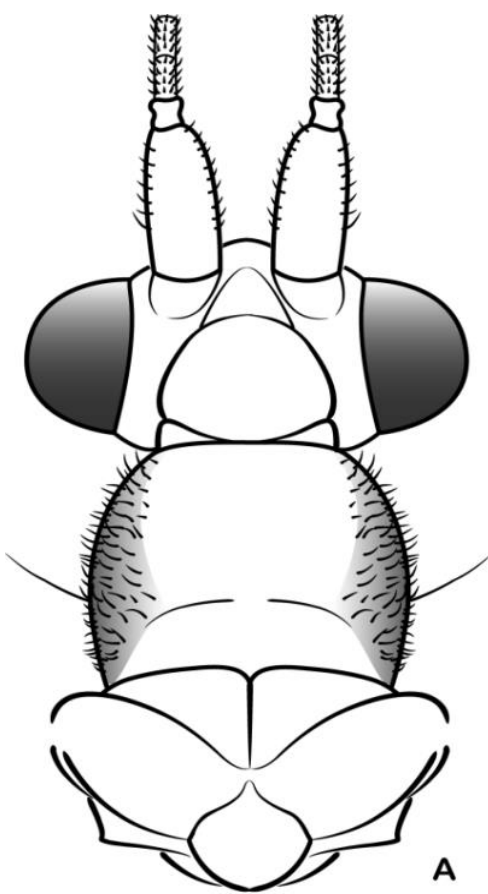

$0,5 \mathrm{~mm}$
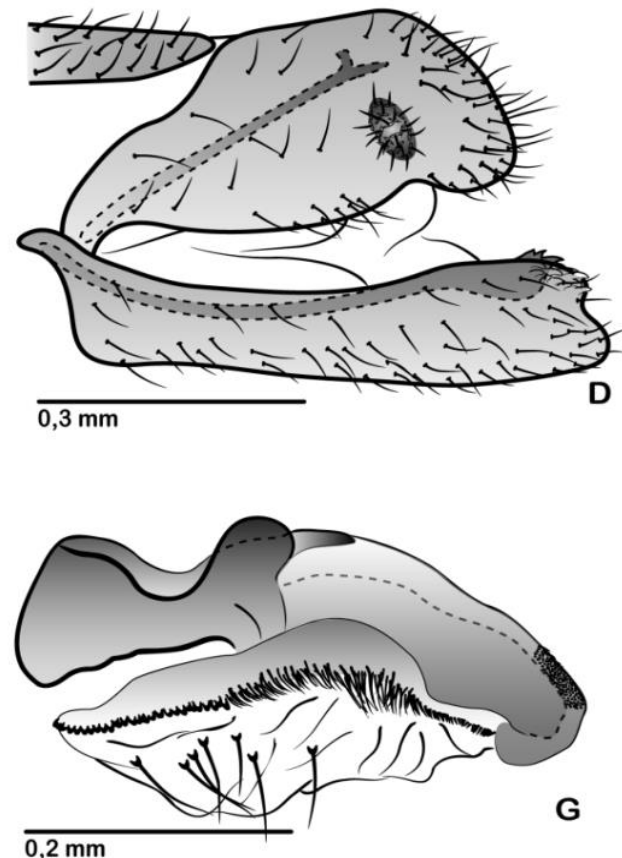

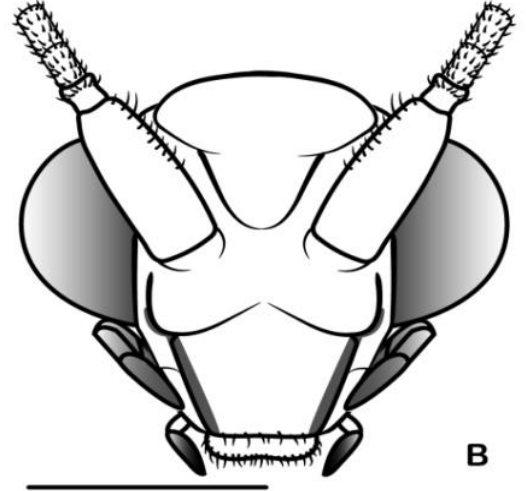

$0,5 \mathrm{~mm}$
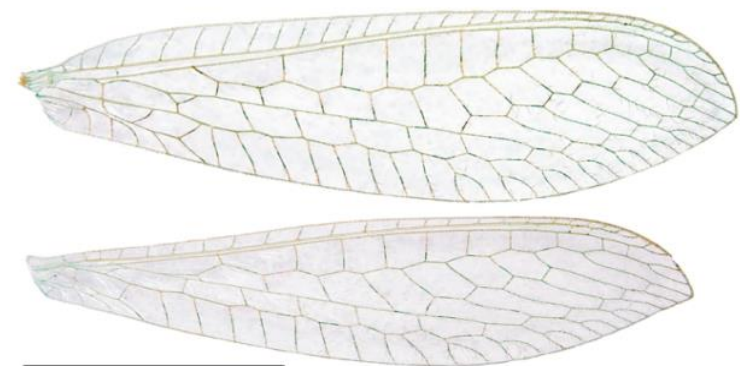

$0,5 \mathrm{~cm}$

C
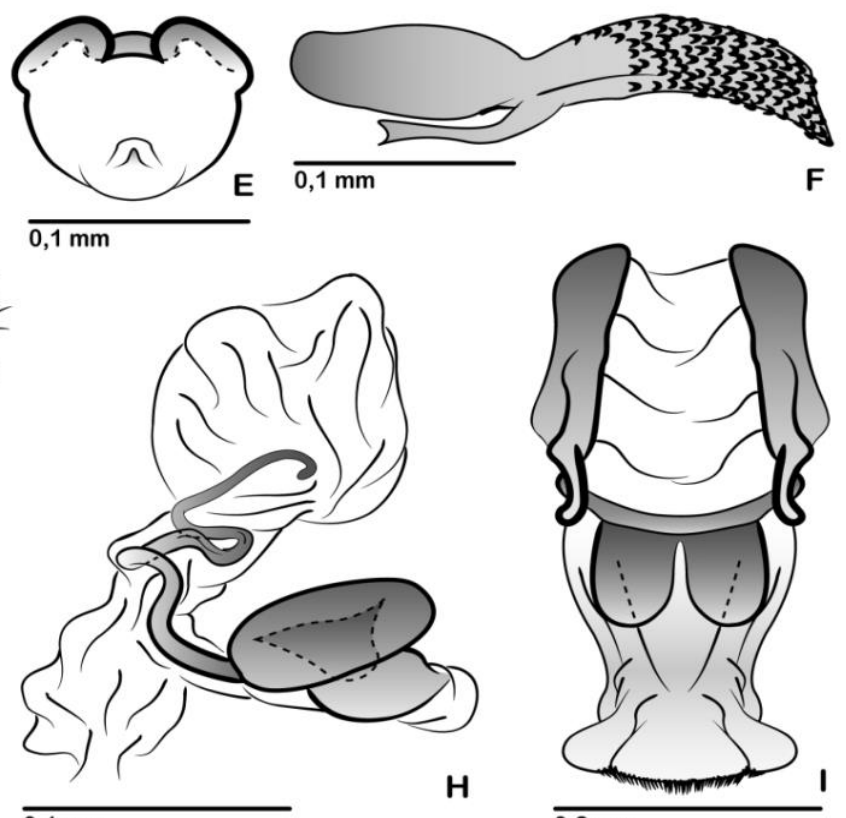

$0,1 \mathrm{~mm}$

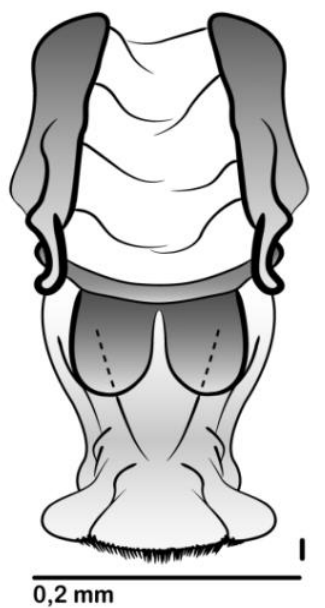

Figura 25. Estruturas de Criptochrysa chloros Freitas \& Penny, 2001 (Chrysopidae: Chrysopinae). A) Cabeça e pronoto, vista dorsal; B) Cabeça, vista frontal, C) Asas anterior e posterior; D) Ápice abdominal masculino, vista lateral; E) Subgenitália, vista dorsal; F) Gonapse, vista lateral; G) Genitália masculina, vista lateral; H) Espermateca, vista dorsal; I) Genitália masculina, vista dorsal.

\section{Topologia resultante}

A busca heurística resultou em uma única árvore mais parciomoniosa (Fig. 26), com 187 passos, índice de consistência 0,27 e índice de retenção de 0,77. 


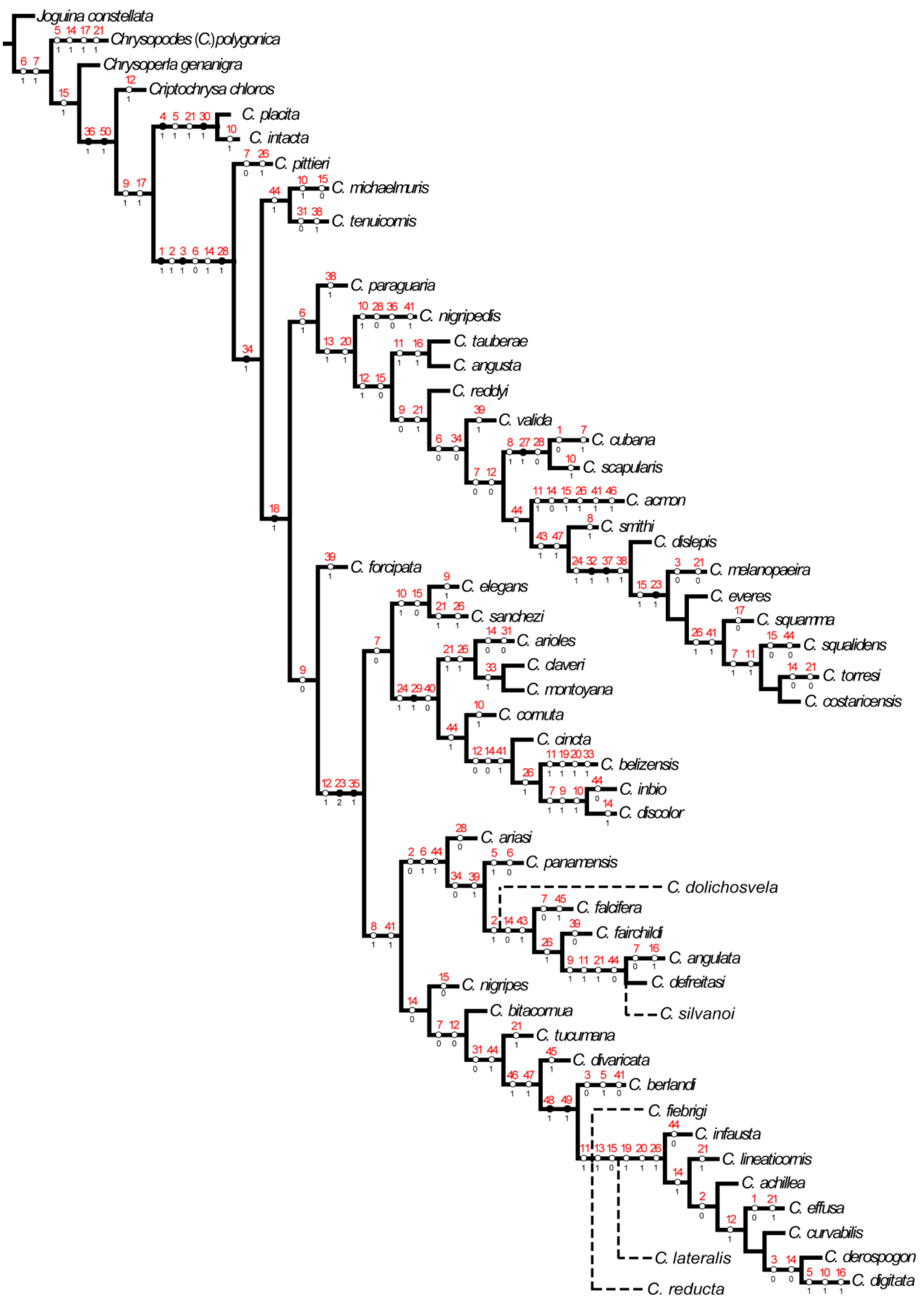

Figura 26. Árvore obtida da análise filogenética de 51 espécies de Ceraeochrysa Adams, 1982 (Chrysopidae: Chrysopinae). Círculos negros são sinapomorfias; círculos brancos são homoplasias ou reversões; em vermelho o número dos caracteres; em negro o número dos estados; linhas pontilhadas são espécies inseridas uma por vez na análise. 
A árvore da Figura 26 foi utilizada como referência para discutir as hipóteses de homologias, o agrupamento dos táxons e a evolução dos caracteres. Para facilitar a discussão dos caracteres, alguns clados foram numerados (Figura 27).

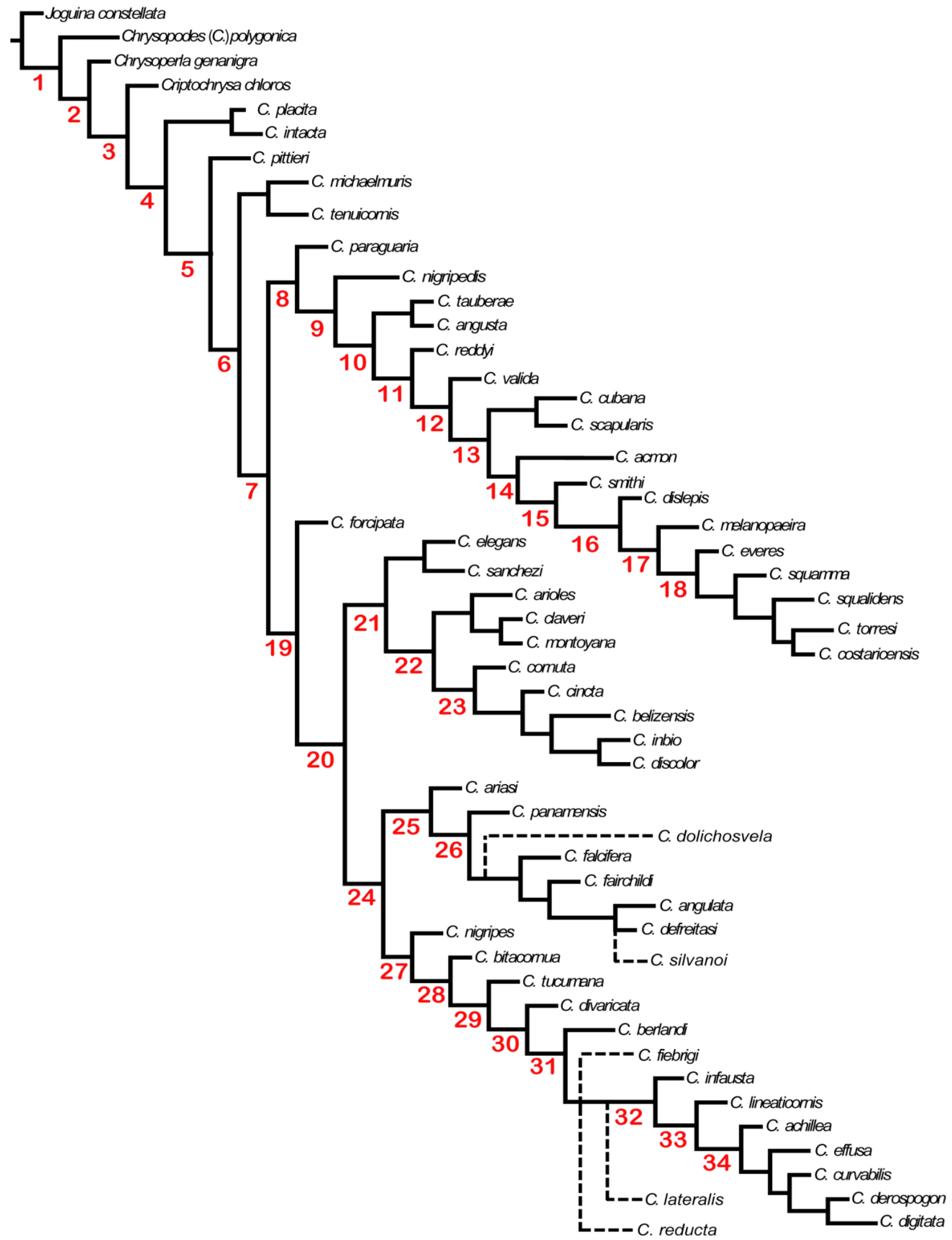

Figura 27. Árvore obtida da análise filogenética de 51 espécies de Ceraeochrysa Adams, 1982 (Chrysopidae: Chrysopinae) numerada. Principais clados numerados. Linhas pontilhadas são espécies inseridas uma por vez na análise. 


\section{Lista de caracteres:}

\section{Cabeça}

Caráter 1. Mancha escura do palpo maxilar: (0) presente; (1) ausente. IC: 0,33/IR: 0,71 (Fig. 28).

A ausência de mancha escura no palpo maxilar é sinapomórfica para o clado 5. Contudo, ocorrem duas reversões, em Ceraeochrysa cubana (Hagen, 1861) e C. effusa (Navás, 1911), que tem palpos manchados de negro.
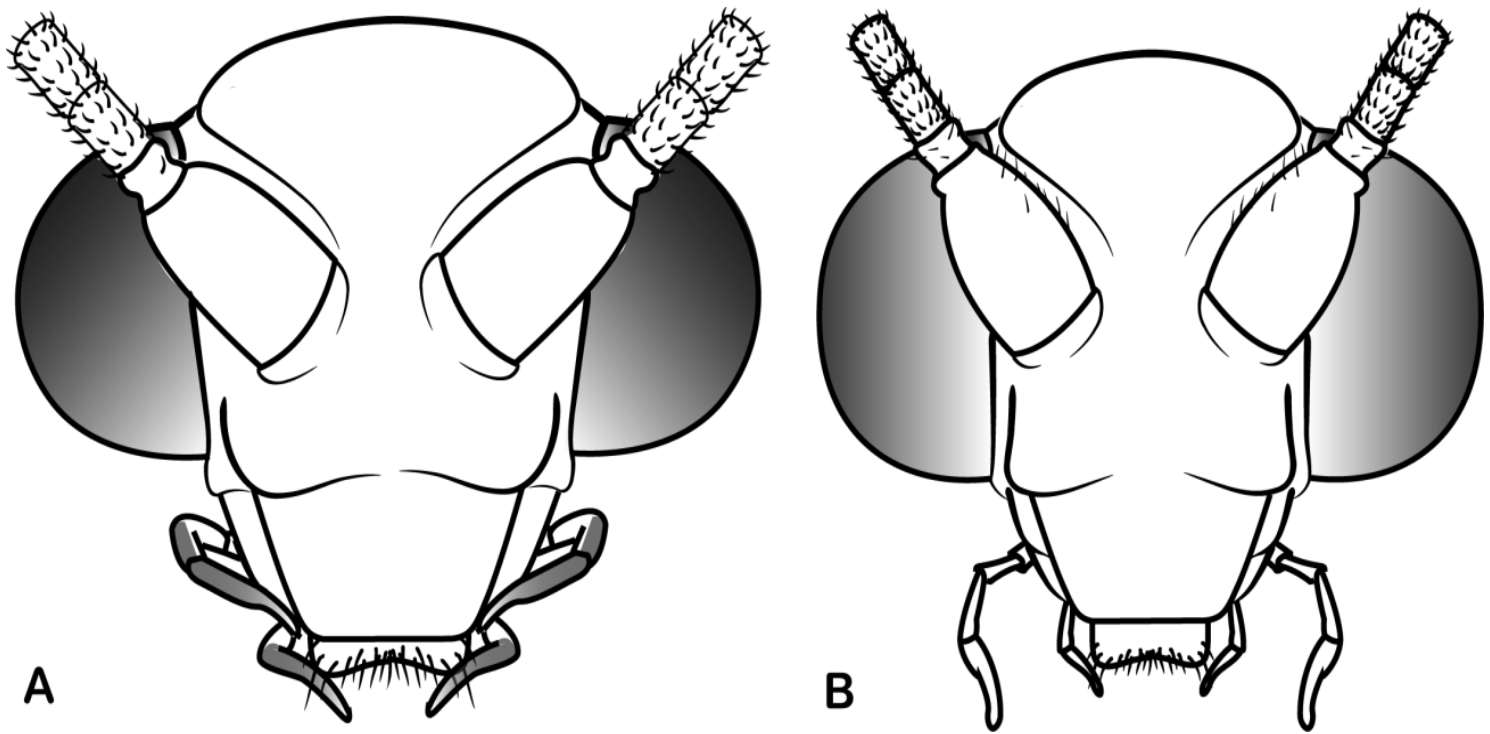

Figura 28. Vista frontal esquemática da cabeça de Chrysopidae (Neuroptera), com destaque para o palpo maxilar. A) Com mancha; B) Sem mancha.

Caráter 2. Mancha escura na gena: (0) presente; (1) ausente. IC: 0,25/IR: 0,80 (Fig. 29).

A ausência de manchas escuras da gena é um estado apomórfico que surge no clado 5. Observam-se duas reversões dentro de Ceraeochrysa, no clado 25, com um segundo surgimento no clado formado por (Ceraeochrysa falcifera Adams, \& Penny, $1987+((C$. fairchildi (Banks, 1946)) $+($ C. angulata (Navás, 1929) + C. defreitasi Penny, 2002))), e no clado 34. 
A

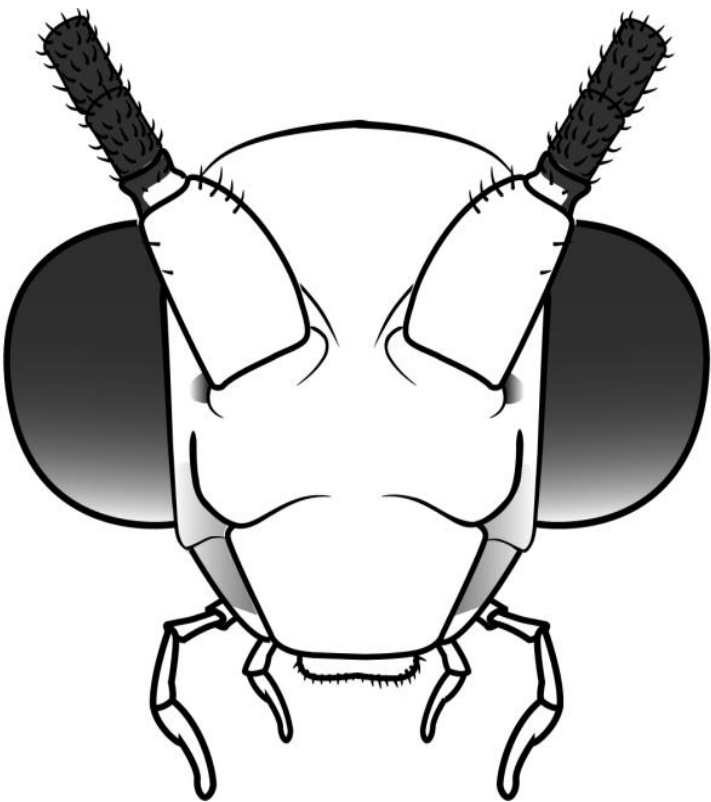

B

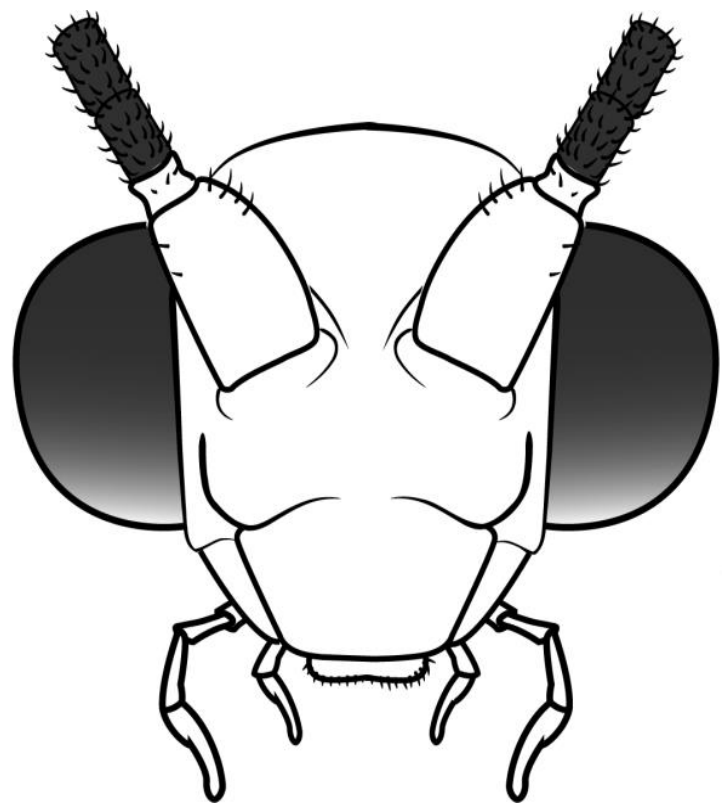

Figura 29. Vista frontal esquemática da cabeça de Chrysopidae (Neuroptera), com destaque para a gena de Chrysopidae. A) Com mancha; B) Sem mancha.

Caráter 3. Mancha escura no clípeo: (0) presente; (1) ausente. IC: 0,25/IR: 0,70 (Fig. 30).

Assim como ocorre com o palpo maxilar e com a gena, a ausência de mancha no clípeo (estado 1) surgiu no clado 5, com três reversões para o estado 0, em Ceraeochrysa melanopaeira Sosa \& Freitas, 2010, C. berlandi (Navás, 1924) e no clado (C. derospogon Freitas \& Penny, $2009+$ C. digitata Freitas \& Penny, 2009).
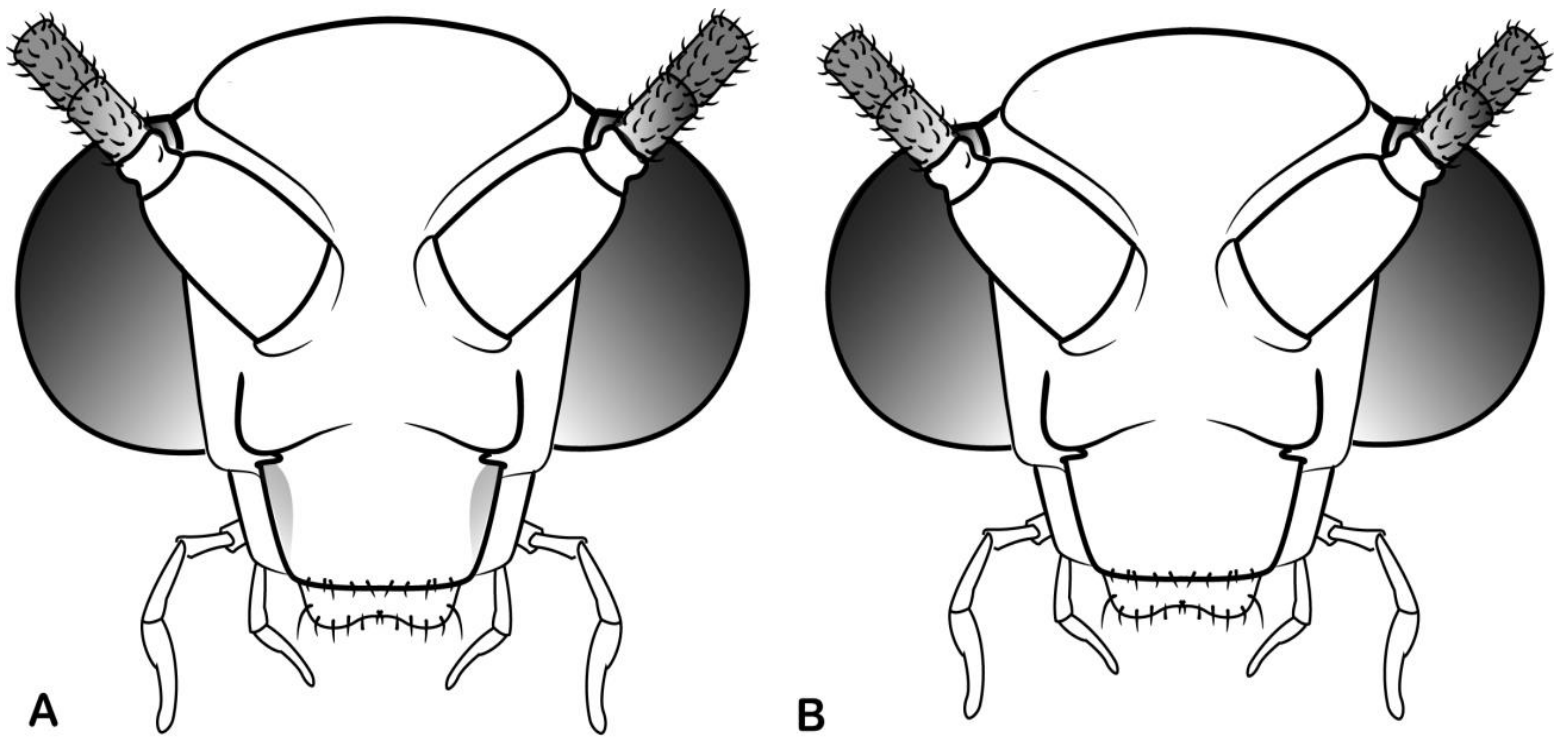

Figura 30. Vista frontal esquemática da cabeça de Chrysopidae (Neuroptera), com destaque para o clípeo de Chrysopidae. A) Com mancha negra; B) Sem mancha negra. 
Caráter 4. Mancha escura da fronte: (0) ausente; (1) presente. IC: 1/IR: 1 (Fig. 31).

A presença de mancha escura da fronte é sinapomorfia de (Ceraeochrysa placita (Banks, 1908) + C. intacta (Navás, 1912)). Este caráter foi utilizado por Freitas et al. (2009) com três estados, separados conforme a coloração das manchas. Neste estudo, prefiriu-se não utilizar os estados relacionados às cores das manchas, pois a coloração de adultos de Chrysopidae pode variar segundo a idade e a alimentação.

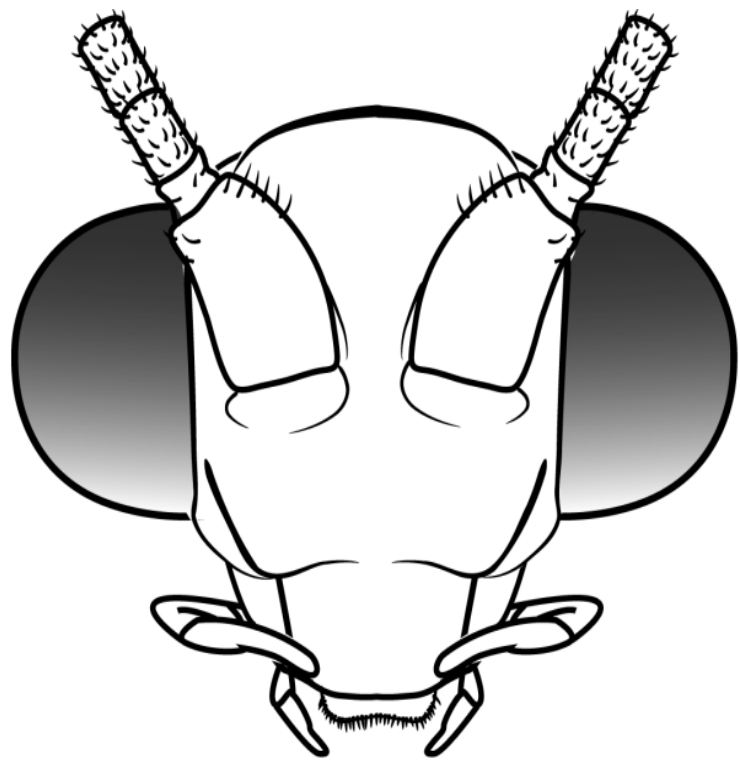

A

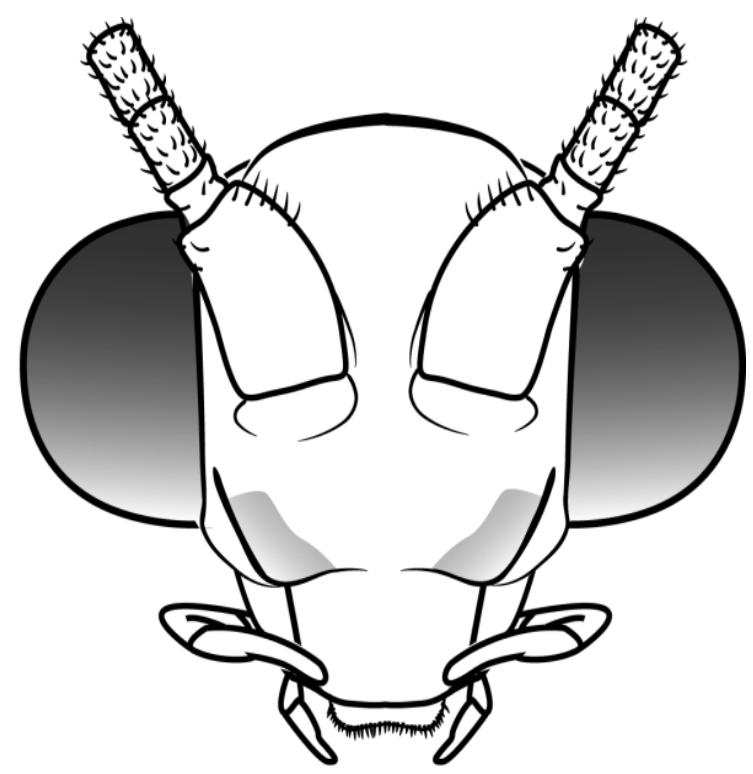

B

Figura 31. Vista frontal esquemática da cabeça de Chrysopidae (Neuroptera), com destaque para a fronte. A) Sem mancha negra; B) Com mancha negra.

Caráter 5. Mancha da região pós-ocular: (0) ausente; (1) presente. IC: 0,20/IR: 0,20 (Fig. 32).

A presença de manchas na região pós-ocular é apomórfica e ocorreu independentemente cinco vezes: em Chrysopodes (C.) polygonica Adams \& Penny, 1987; em (C. placita + C. intacta $) ;$ C. digitata; C. berlandi; C. panamensis Freitas \& Penny, 2009.

Caráter 6. Mancha escura do escapo: (0) presente; (1) ausente. IC: 0,16/IR: 0,72 (Fig. 33).

Há manchas no escapo de Joguina constellata (Navás, [1913]), sua perda (estado 1) ocorre nos gêneros de Chrysopini utilizados nesta análise (clado 1), porém, existe reversão no clado 5 .

A ausência de manchas ocorre nos clados 8 e 21, contudo, observa-se duas reversões (presença de manchas) no clado 12 e em C. panamensis. 
Freitas et al. (2009) utilizaram sete estados para fazer referência aos padrões de manchas do escapo. No presente trabalho, foi utilizado somente dois estados, presença ou ausência de manchas do escapo, dada a grande plasticidade desses estados.
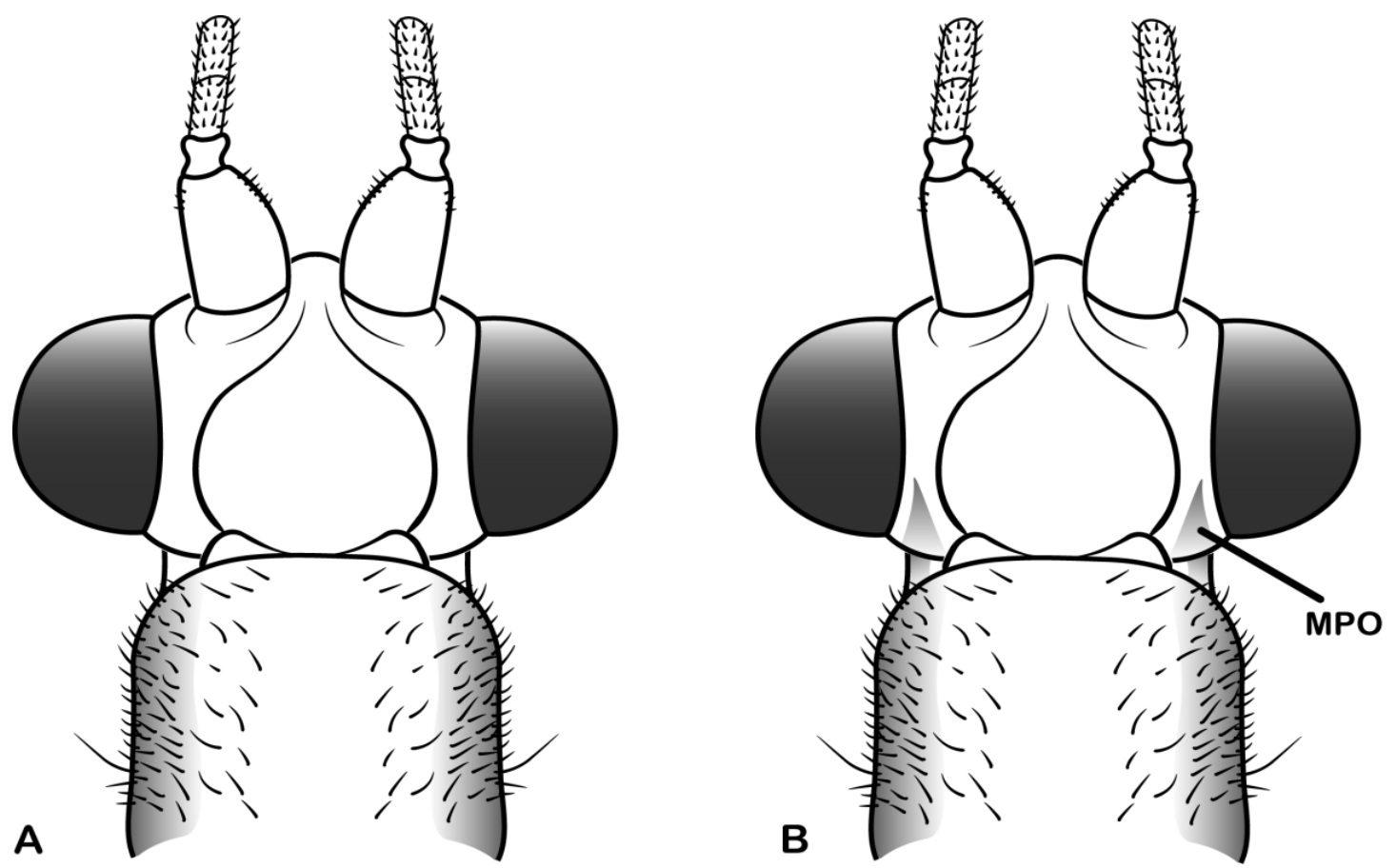

Figura 32. Vista dorsal esquemática da cabeça de Chrysopidae (Neuroptera), com destaque para a área pós-ocular. A) Sem macha pós-ocular; B) Com mancha pós-ocular. Mancha pós-ocular (MPO).

A

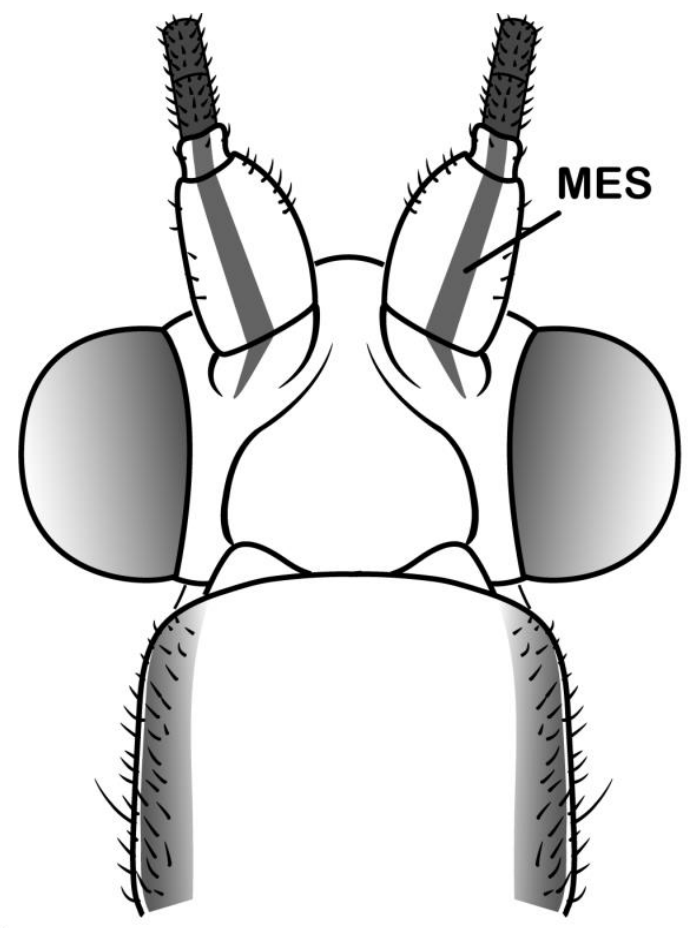

B

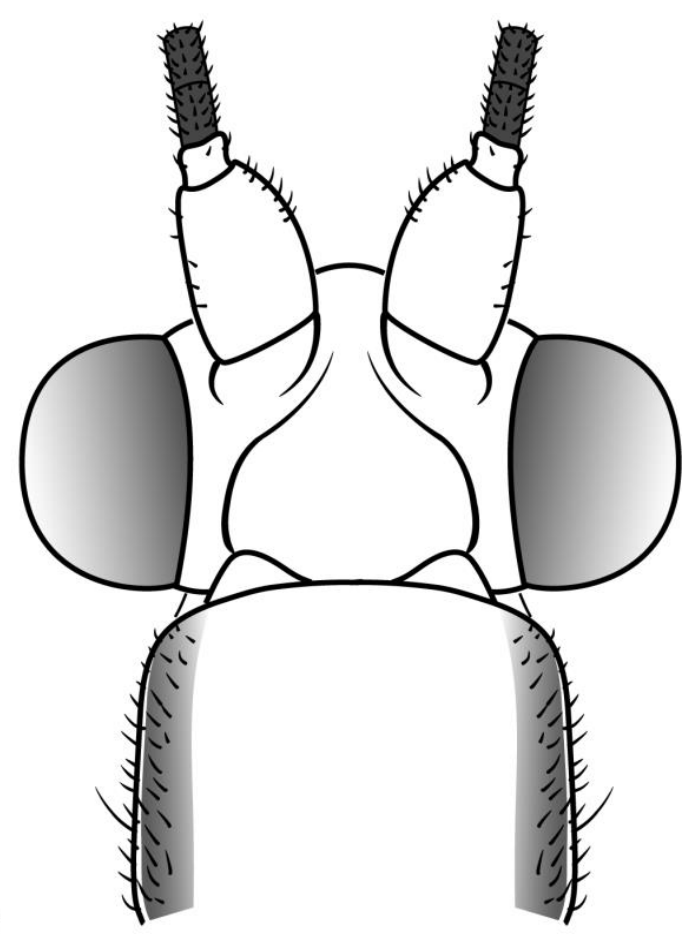

Figura 33. Vista dorsal esquemática da cabeça de Chrysopidae (Neuroptera), com destaque para o escapo. A) Com mancha escura; B) Sem mancha escura. Mancha escura (MES). 
Caráter 7. Mancha do pedicelo: (0) presente; (1) ausente. IC: 0,10/IR: 0,66 (Fig. 34).

A presença de mancha no pedicelo é um estado plesiomórfico, encontrado em Joguina constellata, sua perda ocorre no clado 1, ou seja, em Chrysopini. São observadas seis reversões (estado 0) dentro de Ceraeochrysa, três ocorrem nos grandes clados 13, 21 e 28 e três ocorrem como autapomorfias de Ceraeochrysa pittieri Sosa \& Freitas, 2010, C. falcifera e C. angulata.

A ausência de mancha no pedicelo ocorre também nas espécies $C$. cubana e nos clados (C. inbio + C. discolor $)$ e C. squalidens $+($ C. torresi + C. costaricensis $)$.

A

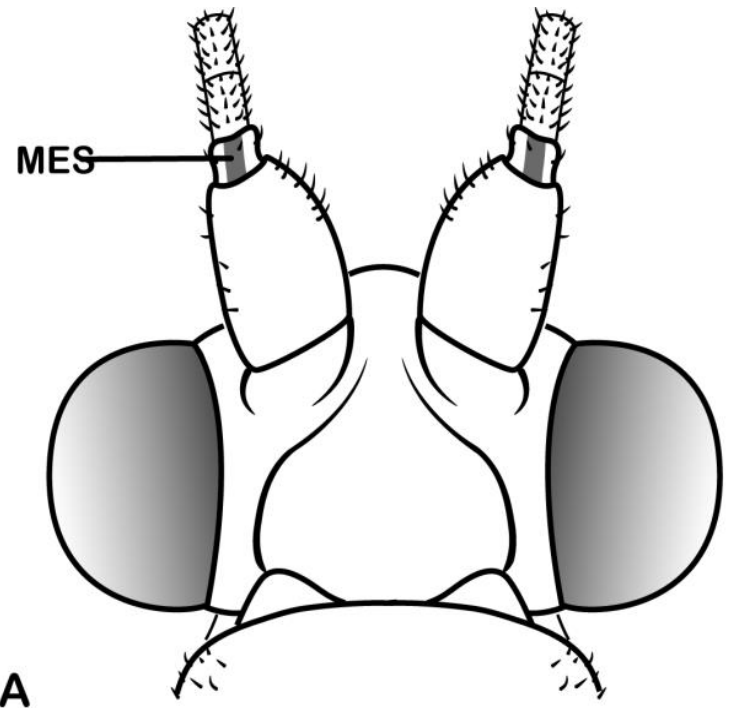

B

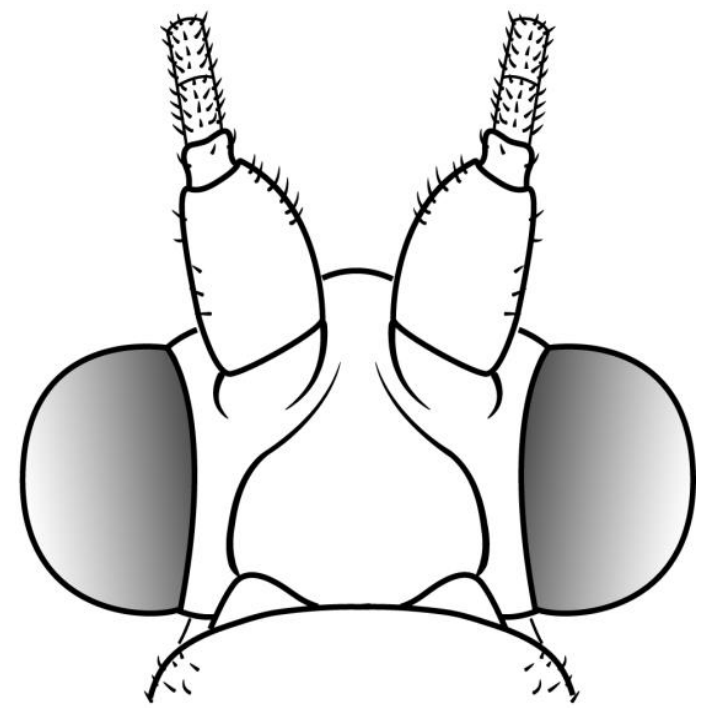

Figura 34. Vista dorsal esquemática da cabeça de Chrysopidae (Neuroptera), com destaque para a presença de mancha no pedicelo. A) Com mancha escura; B) Sem mancha escura. Mancha escura (MES).

Caráter 8. Padrão de manchas do pedicelo: (0) amorfas; (1) formam um anel em volta do pedicelo. IC: 0,33/IR: 0,86 (Fig. 35).

Este caráter é contingente à presença de manchas no pedicelo. As manchas amorfas, estado plesiomórfico, ocorrem na maioria das espécies de Ceraeochrysa com pedicelo manchado. Manchas que formam um anel em torno do pedicelo surgem três vezes no gênero, uma no grande grupo de espécies do clado 24 e duas como autapomorfias de $C$. scapularis (Navás, 1914) e de C. smithi (Navás, 1914). 

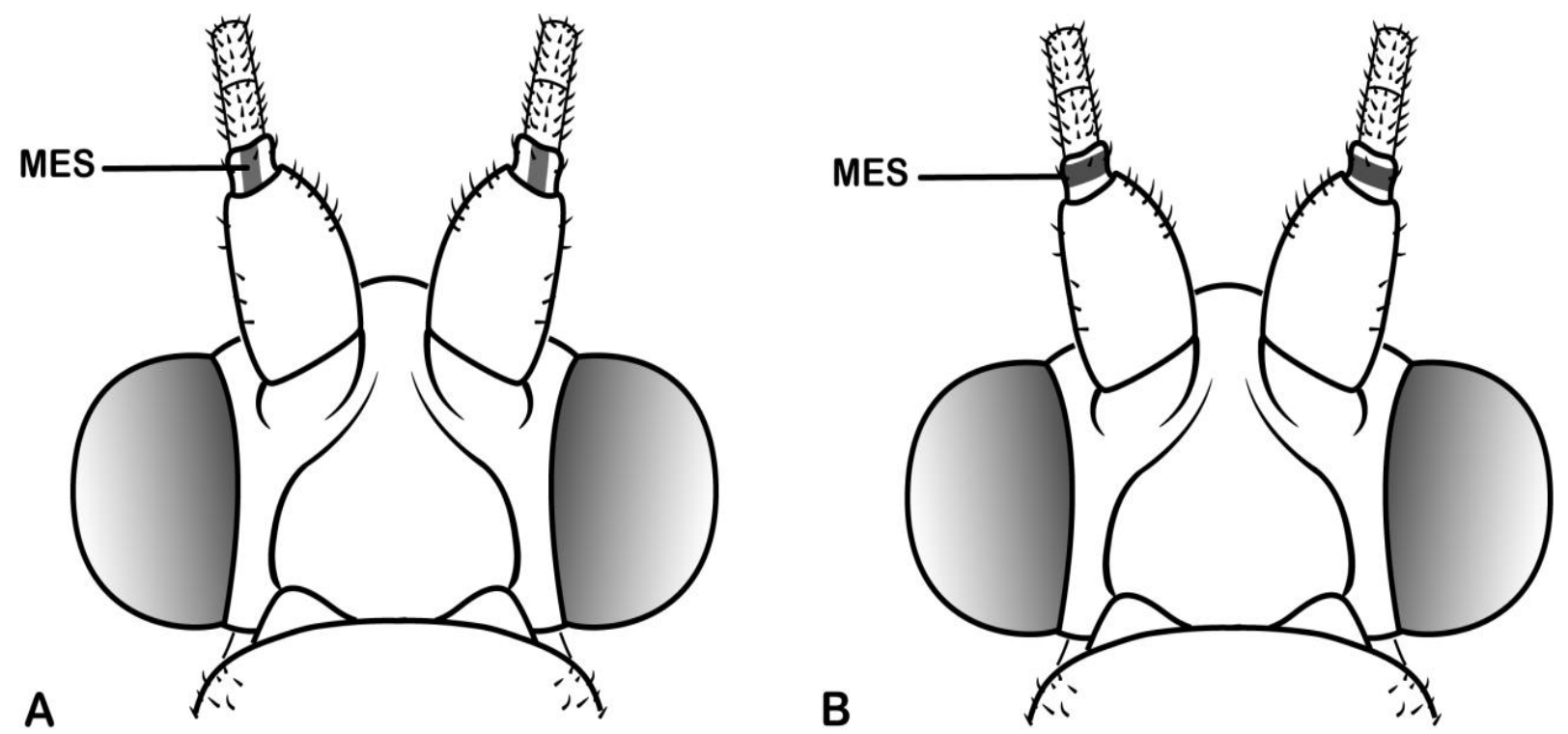

Figura 35. Vista dorsal esquemática da cabeça de Chrysopidae (Neuroptera), com destaque para o pedicelo. A) Com mancha amorfa; B) Com mancha em forma de anel. Mancha escura (MES).

Caráter 9. Padrão de manchas do pronoto (vista lateral): (0) mancha contínua; (1) manchas descontínuas. IC: 0,16/IR: 0,61 (Fig. 36).

Manchas descontínuas no pronoto surgiram na base de Ceraeochrysa, com duas reversões, nos clados 11 e 19. Dentro deste último clado, ocorreram três surgimentos independentes do estado 1: em C. elegans Penny, 1998 em (C. inbio Penny, $1997+C$. discolor (Navás, 1914)) e em (C. angulata + C. defreitasi).

Freitas et al. (2009) utilizaram caráter similar a este com cinco estados: sem manchas; com uma listra lateral; com somente uma mancha em forma de ponto em cada lado; com duas manchas em forma de pontos em cada lado; com uma mancha submedial. Neste trabalho, o estado 0 de Freitas et al. (2009) foi codificado como dado ausente, os caracteres 2, 3 e 4 foram agrupados em um único caráter nomeado como manchas descontínuas. Essa fusão de estados foi realizada com o intuito de diminuir as possíveis dúvidas de codificação das espécies para os vários estados.

Caráter 10. Manchas do mesonoto (vista dorsal): (0) ausente; (1) presente. IC: 0,12/IR: 0,30 (Fig. 37).

A presença de mancha no mesonoto é apomórfica e surgiu independentemente sete vezes em Ceraeochrysa, em C. intacta, C. michaelmuris Adams \& Penny, 1987, C. nigripedis Penny, 1997, C. scapularis, (C. elegans + C. sanchezi), C. cornuta (Navás, 1925), (C. inbio + C. discolor) e C. digitata. 

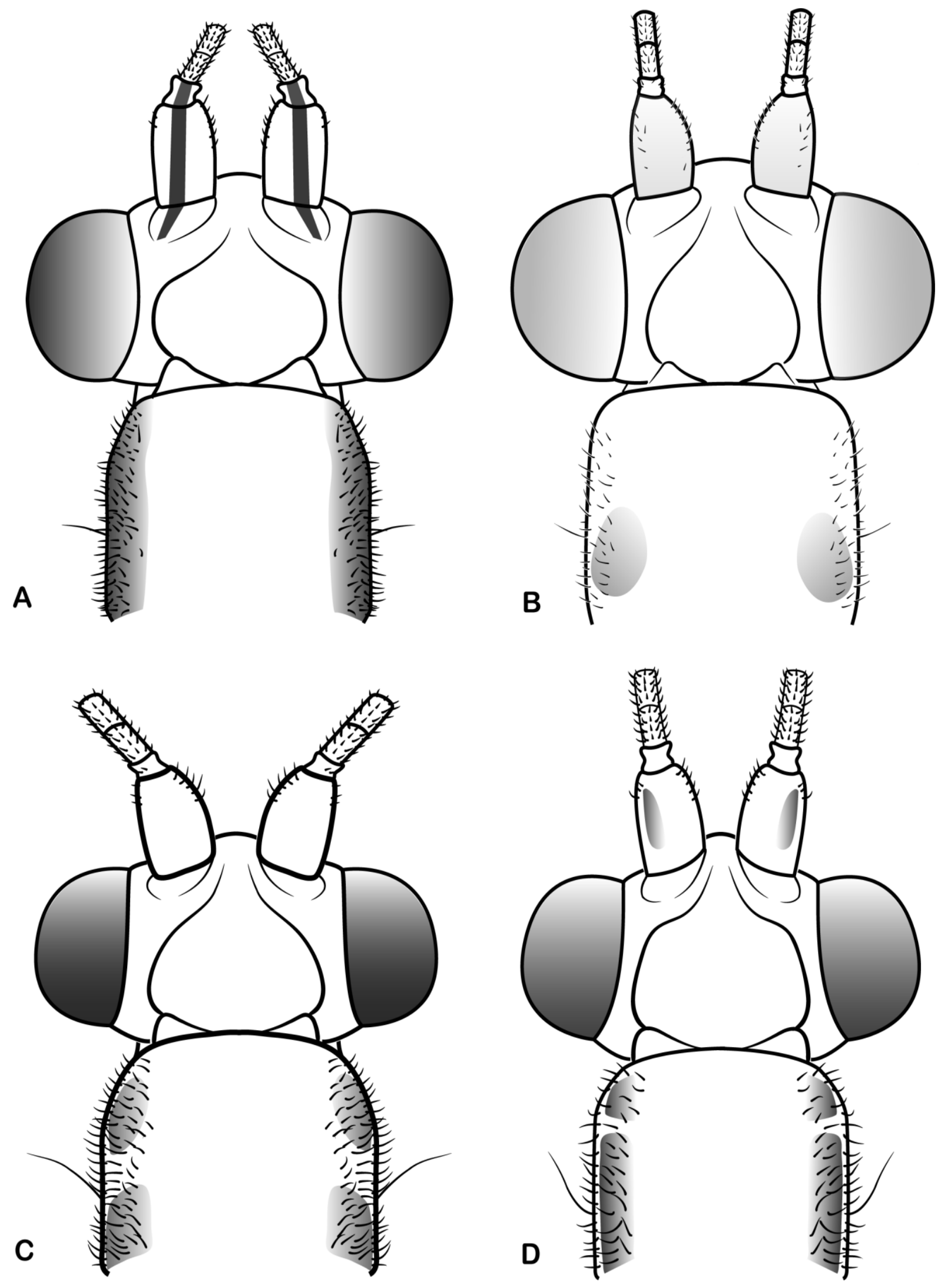

Figura 36. Vista dorsal esquemática da cabeça e pronoto de Chrysopidae (Neuroptera). A) Pronoto com mancha lateral em forma de listra; B) Pronoto com mancha lateral circular; C) Pronoto com duas manchas circulares laterais; D) Pronoto com duas manchas em forma de listra lateral. 
A

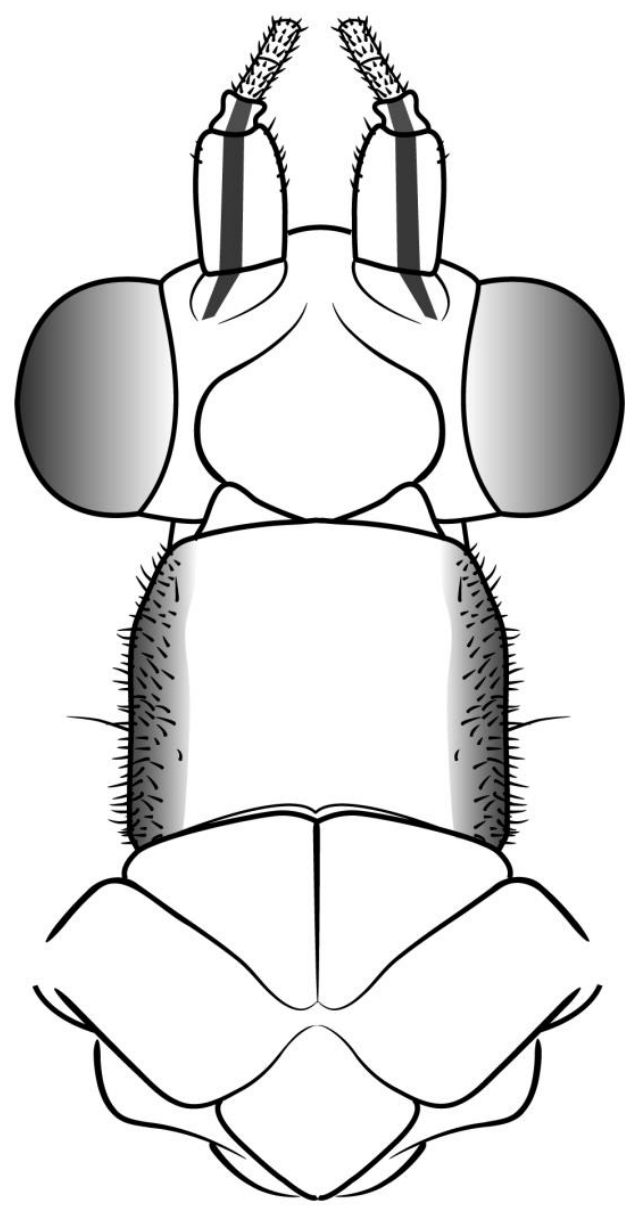

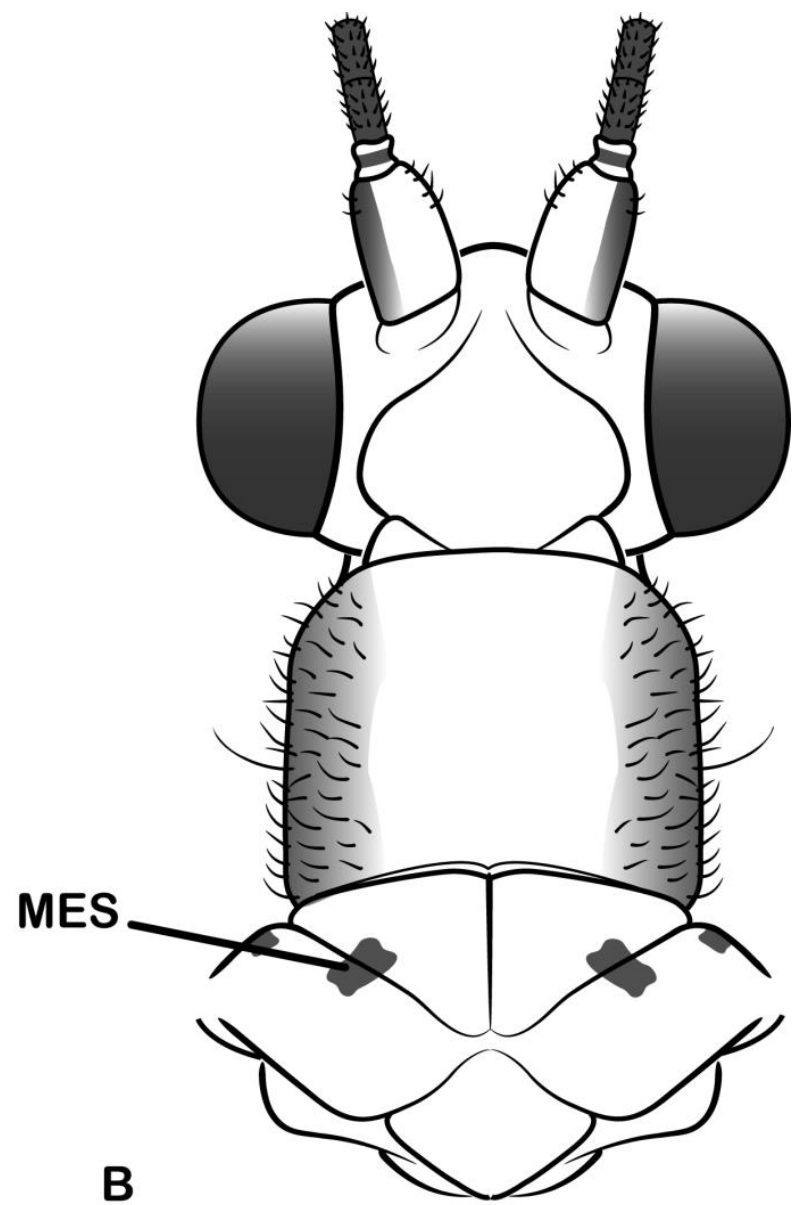

B

Figura 37. Vista dorsal esquemática da cabeça, pronoto e mesonoto de Chrysopidae (Neuroptera), com destaque para as manchas mesonotais. A) Manchas mesonotais ausentes; B) Manchas mesonotais presentes. Mancha escura (MES).

\section{Asa anterior}

Caráter 11. Disposição das nervuras gradiformes da asa anterior: (0) paralelas; (1) não paralelas. IC: 0,16/IR: 0,73 (Fig. 38).

Nervuras gradiformes paralelas na asa anterior são a condição plesiomórfica, asas anteriores com nervuras gradiformes convergentes ou divergentes foram codificadas como o estado 1 que surgiu independentemente seis vezes em Ceraeochrysa: $(C$. angulata $+C$. defreitasi); (C. tauberae Penny, 1997 + C. angusta Freitas \& Penny, 2009); C. belizensis Freitas \& Penny, 2009; (C. squalidens Adams \& Penny, $1987+$ (C. torresi Sosa \& Freitas, $2010+$ C. costaricensis Penny, 1997)); C. acmon Penny, 1987; e no clado 32.

Freitas et al. (2009) utilizaram este caráter com três estados, porém foi decidido fundir dois estados (convergente e divergente) no estado 1. 

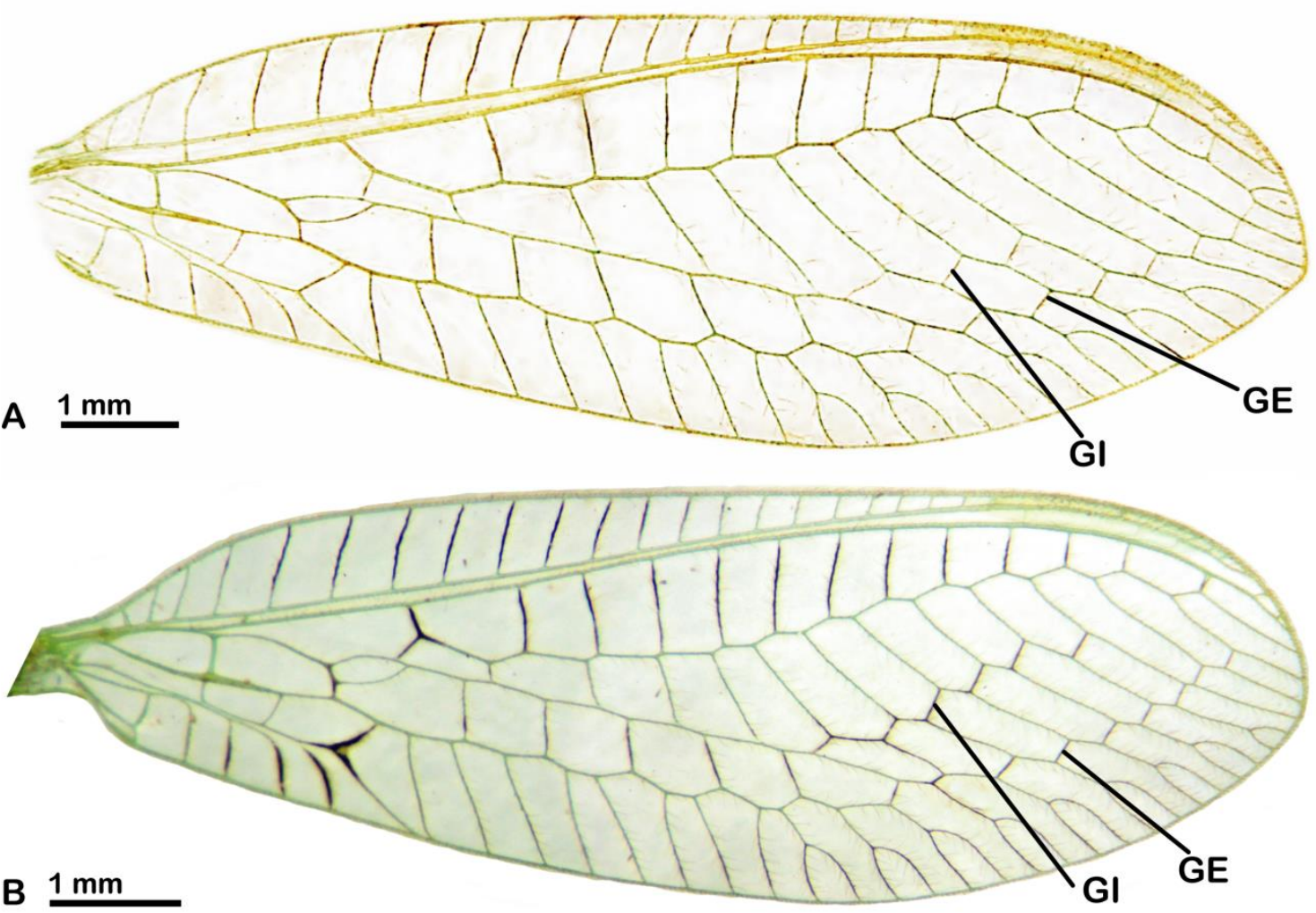

Figura 38. Asa anterior de Chrysopidae (Neuroptera), com destaque para as nervuras gradiformes. A) Ceraeochrysa cincta (Scheneider, 1851) com nervuras gradiformes paralelas; B) Ceraeochrysa angulata (Navás, 1929) com nervuras gradiformes não paralelas. Gradiformes internas (GI); gradiformes externas (GE).

Caráter 12. Localização da nervura transversal basal costal da asa anterior: (0) apical à quarta nervura transversal costal; (1) basal à quarta nervura transversal costal. IC: 0,12/IR: 0,69 (Fig. 39).

A nervura transversal basal costal localizada apicalmente a quarta nervura transversal costal é plesiomórfico em Chrysopini, a presença da basal costal localizada basalmente a quarta nervura transversal costal surgiu independentemente quatro vezes: Criptochrysa chloros; clado 10; clado 20; clado (C. effusa $+(C$. curvabilis Freitas \& Penny, $2009+(C$. derospogon $+C$. digitata $))$ ). Há quatro reversões para o estado 0 : no clado 13 ; no clado $(C$. cincta $($ Schneider, 1851) $+(C$. belizensis $+(C$. inbio $+C$. discolor $)))$; em $(C$. angulata $+C$. defreitasi); e no clado 28.

Caráter 13. Nervuras A1 e A2 da asa anterior: (0) fundindo-se medianamente; (1) separadas. IC: 0,50/IR: 0,96 (Fig. 40).

O estado 1 surgiu independentemente duas vezes em Ceraeochrysa, nos clados 9 e 32. 

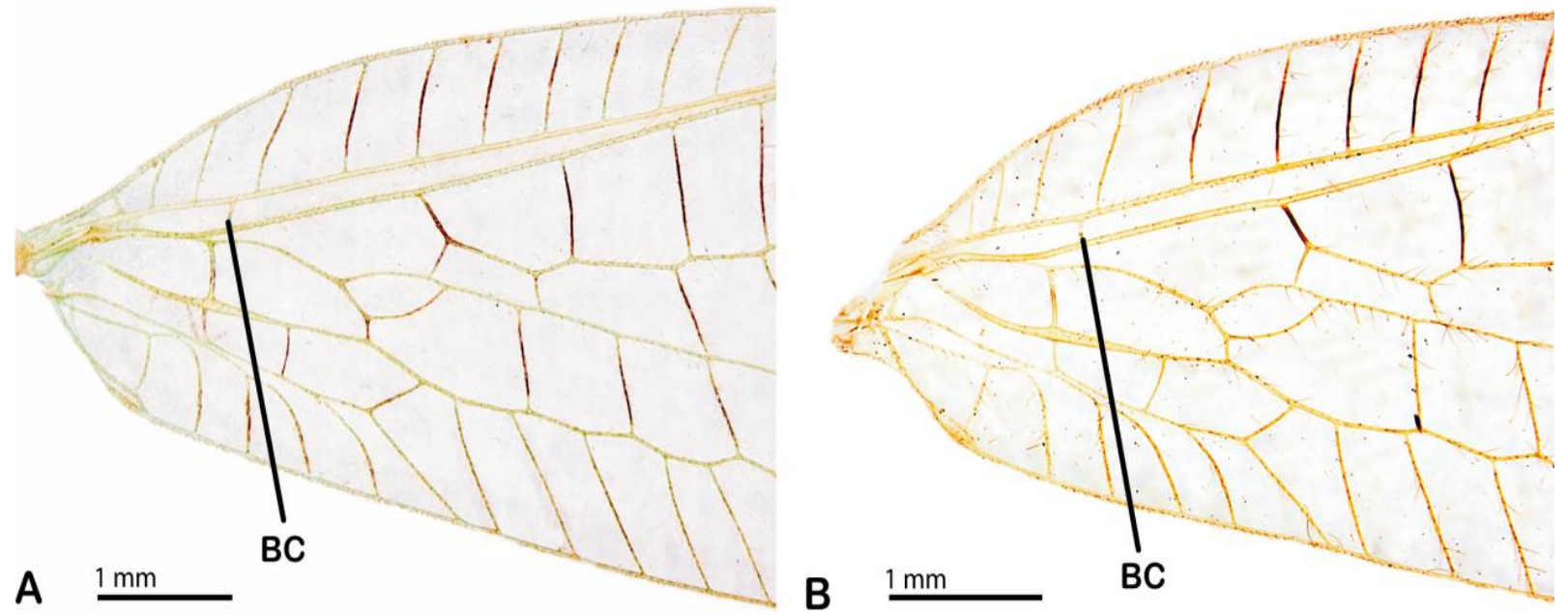

Figura 39. Base da asa anterior de Chrysopidae (Neuroptera), com destaque para a nervura basal costal. A) Nervura basal costal de Ceraeochrysa cornuta (Navás, 1925) localizada basalmente a quarta costal transversal; B) Nervura basal costal de Ceraeochrysa everes (Banks, 1920) localizada apicalmente a quarta nervura costal transversal. Basal costal (BC).

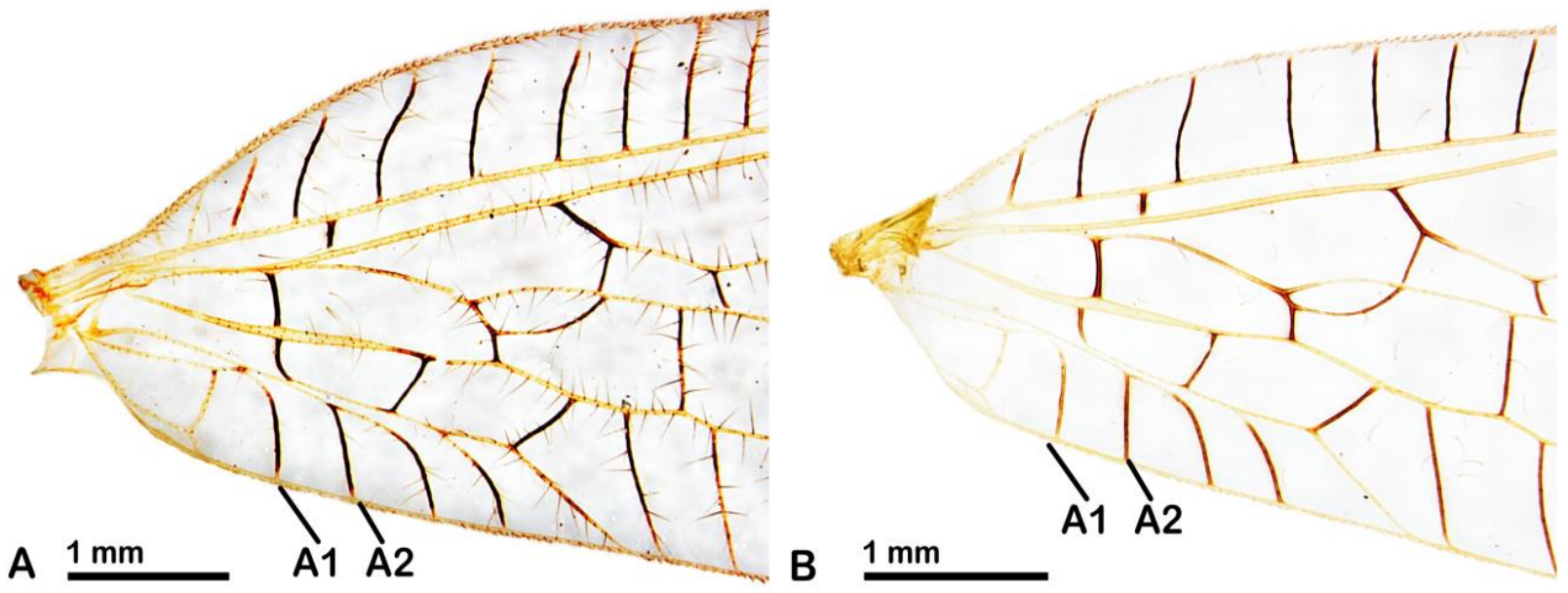

Figura 40. Base da asa anterior de Chrysopidae (Neuroptera), com destaque para as nervuras A1 e A2. A) A1 e A2 fundidas medianamente em Ceraeochrysa paraguaria (Navás, 1920); B) A1 e A2 separadas em Ceraeochrysa valida (Banks, 1895). Anais 1 e 2 (A1 e A2).

\section{Caráter 14. Primeira nervura transversal intercubital da asa anterior: (0) sem mancha} negra; (1) com mancha negra. IC: 0,09/IR: 63 (Fig. 41).

A presença de mancha negra na primeira nervura transversal intercubital surge em Chrysopodes $(C$.) polygonica e no clado 5. Neste último clado, contudo, existem seis reversões, três ocorrem como autapomorfias em $C$. acmon, $C$. torresi e $C$. arioles e três em grupos de espécies: no clado $(C$. cincta $+(C$. belizensis $+(C$. inbio $+C$. discolor $)))$, porém, $C$. discolor apresenta a primeira nervura transversal intercubital da asa anterior negra; no clado $(C$. falcifera $+(C$. fairchildi $+(C$. angulata $+C$. defreitasi $)))$ e no clado 27 . O clado 33, no entanto, tem a primeira nervura transversal intercubital da asa anterior negra. 

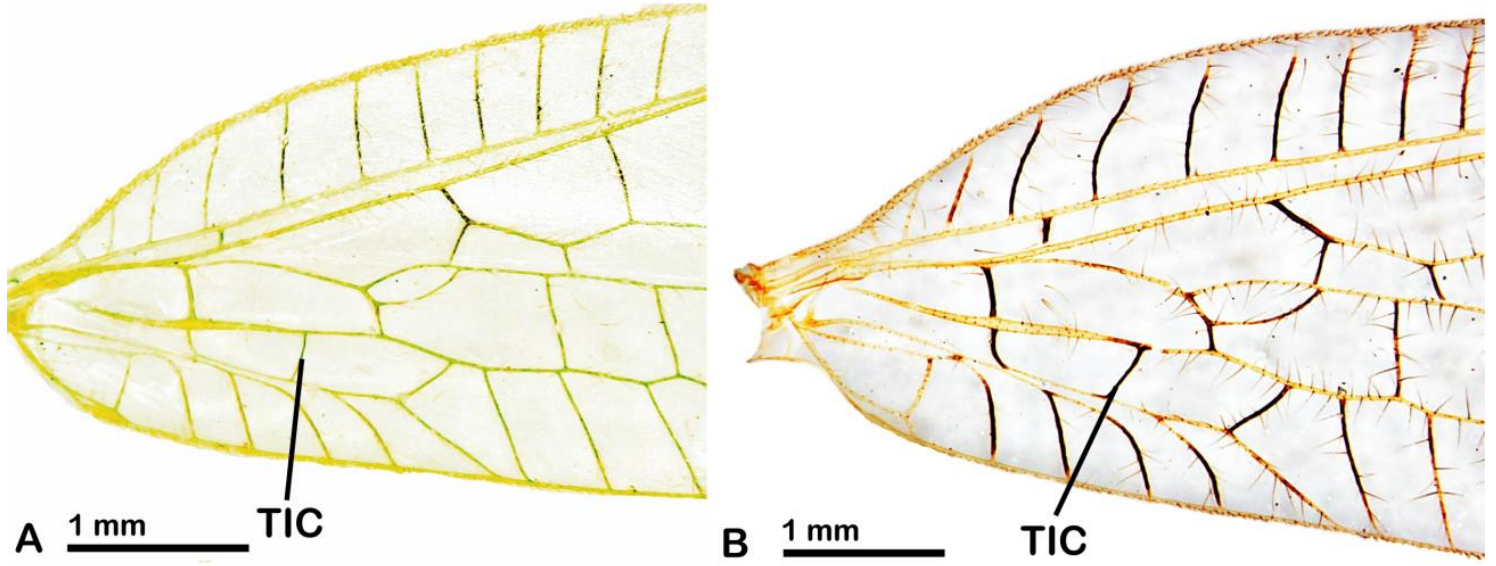

A $\stackrel{1 \mathrm{~mm}}{ }$ TIC

B $\underline{1 \mathrm{~mm}}$ TIC

Figura 41. Base da asa anterior de Chrysopidae (Neuroptera), com destaque para a primeira nervura transversal intercubital. A) Primeira nervura transversal intercubital negra de Ceraeochrysa cincta (Schneider, 1851); B) Primeira nervura transversal intercubital sem mancha negra de Ceraeochrysa paraguaria (Navás, 1920). Transversal intercubital (TIC).

Caráter 15. Forquilhas marginais da asa anterior: (0) com mancha negra; (1) sem mancha negra. IC: 0,11/IR: 0,66 (Fig. 42).

A perda de mancha negra nas forquilhas marginais da asa anterior ocorre no clado 2 (Chrysoperla genanigra Freitas, 2003 + (Criptochrysa chloros Freitas \& Penny, 2001 + Ceraeochrysa)). Existem, contudo, várias reversões para o estado 0, que são observadas em C. michaelmuris, C. squalidens, (C. elegans + C. sanchezi (Navás, 1924)), C. nigripes Adams \& Penny, 1987, no clado 32 e no clado 10, no qual as espécies $C$. everes, $C$. melanopaeira, $C$. squamma, C. costaricensis, C. torresi não apresentam forquilhas marginais da asa anterior negras.

Caráter 16. Mancha da célula cubital distal da asa anterior: (0) ausente; (1) presente. IC: 0,33/IR: 0,33 (Fig. 43).

A mancha na célula cubital distal da asa anterior é uma característica marcante em algumas espécies de Ceraeochrysa, que surgiu independentemente três vezes: em $C$. angulata, $C$. digitata e no clado (C. tauberae $+C$. angusta $)$. 
A $1 \mathrm{~mm}$
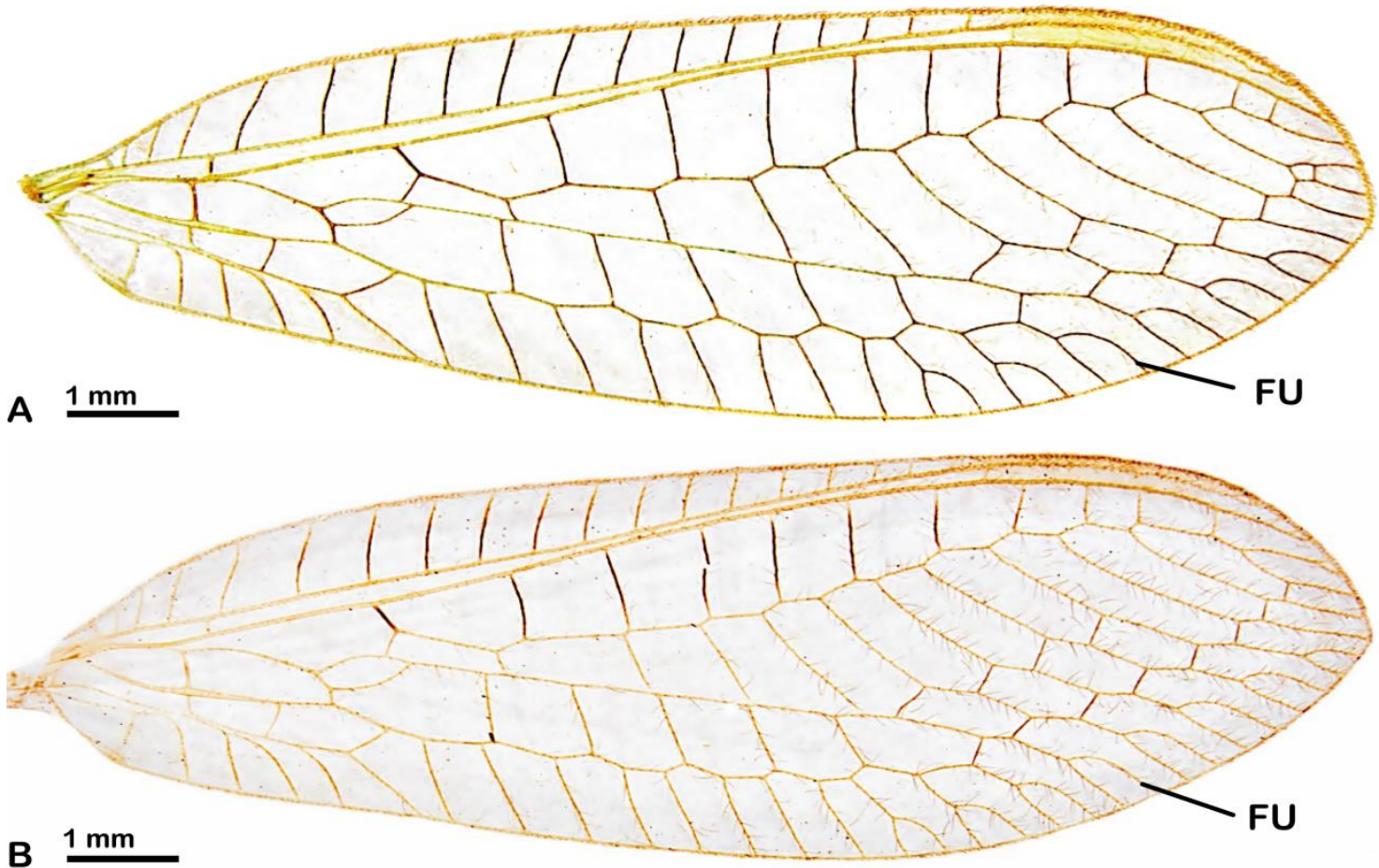

Figura 42. Asa anterior de Chrysopidae (Neuroptera), com destaque para as forquilhas marginais. A) Forquilhas com manchas negras em Ceraeochrysa dislepis Freitas \& Penny, 2001; B) Forquilhas sem manchas negras em Ceraeochrysa everes (Banks, 1920). Forquilhas marginais (FU).

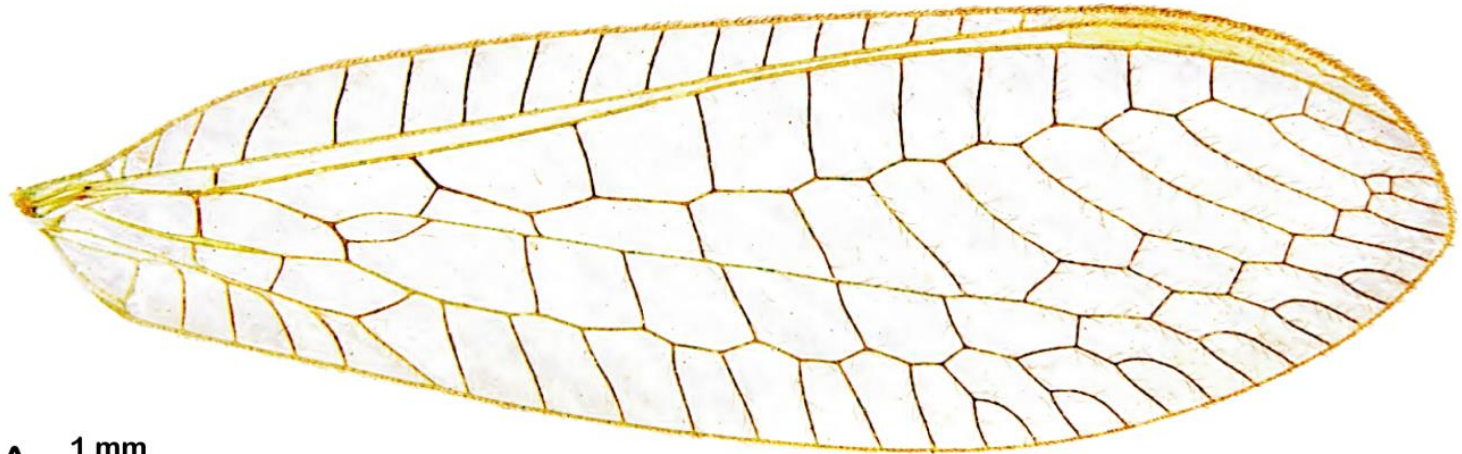

A $1 \mathrm{~mm}$

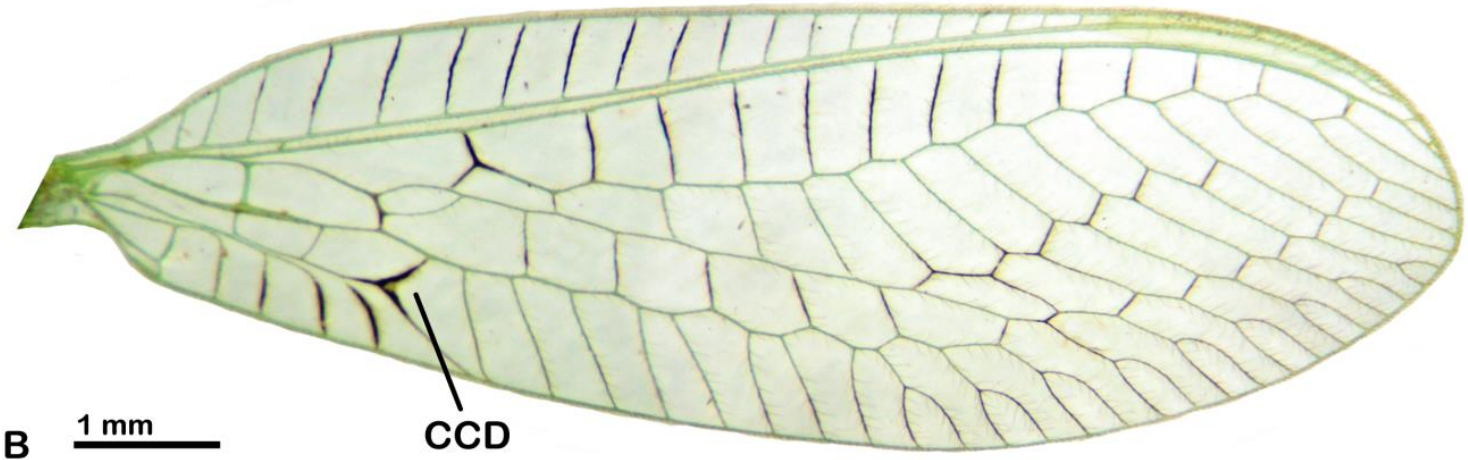

Figura 43. Asa anterior de Chrysopidae (Neuroptera), com destaque para a célula cubital distal. A) Célula cubital distal sem mancha negra em Ceraeochrysa dislepis Freitas \& Penny, 2001; B) Célula cubital distal com mancha negra em Ceraeochrysa angulata (Navás, 1929). Célula cubital distal (CCD). 
Caráter 17. Coloração das nervuras gradiformes da asa anterior: (0) verdes; (1) negras. IC: 0,33/IR: 0,33 (Fig. 44).

A coloração negra das nervuras gradiformes da asa anterior é apomórfica e surge em Chrysopodes (C.) polygonica e em Ceraeochrysa. Somente C. squamma Freitas \& Penny, 2001 não apresenta as nervuras gradiformes negras na asa anterior, o que corresponde a uma perda secundária.

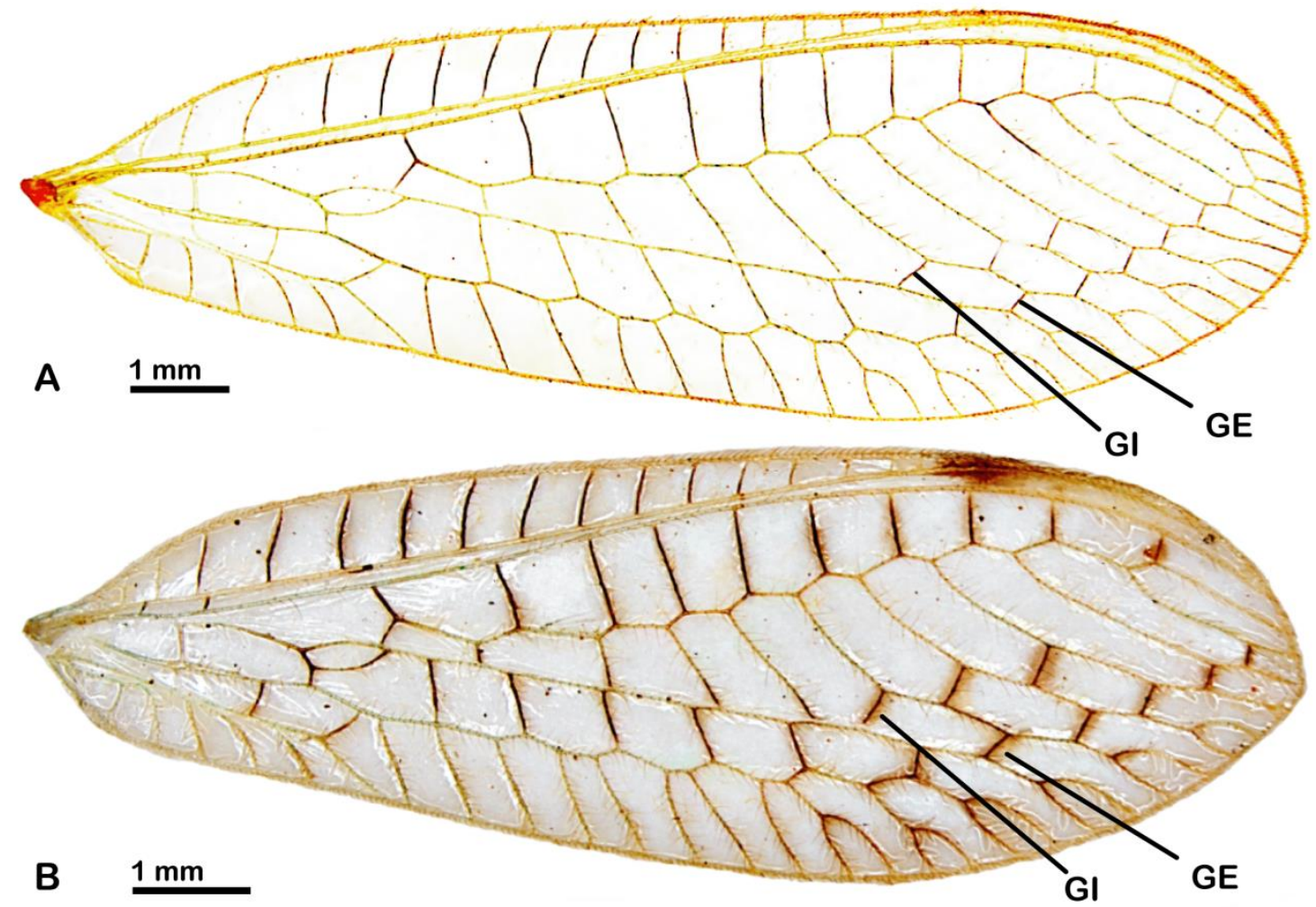

Figura 44. Asa anterior de Chrysopidae (Neuroptera), com destaque para as nervuras gradiformes. A) Nervuras gradiformes esverdeada em Ceraeochrysa squamma Freitas \& Penny, 2001; B) Nervuras gradiformes negras em Ceraeochrysa achillea Freitas \& Penny, 2009. Gradiformes internas (GI); gradiformes externas (GE).

Caráter 18. Relação entre o comprimento da célula gradiforme 1 e o comprimento da primeira gradiforme externa até a base da quarta transversal radial da asa anterior: (0) maior que a metade; (1) menor que a metade. IC: 1/IR: 1 (Fig. 45).

A célula gradiforme 1 mais longa que a metade da primeira gradiforme externa até a base da quarta transversal radial da asa anterior é sinapomorfia do clado 7 . 

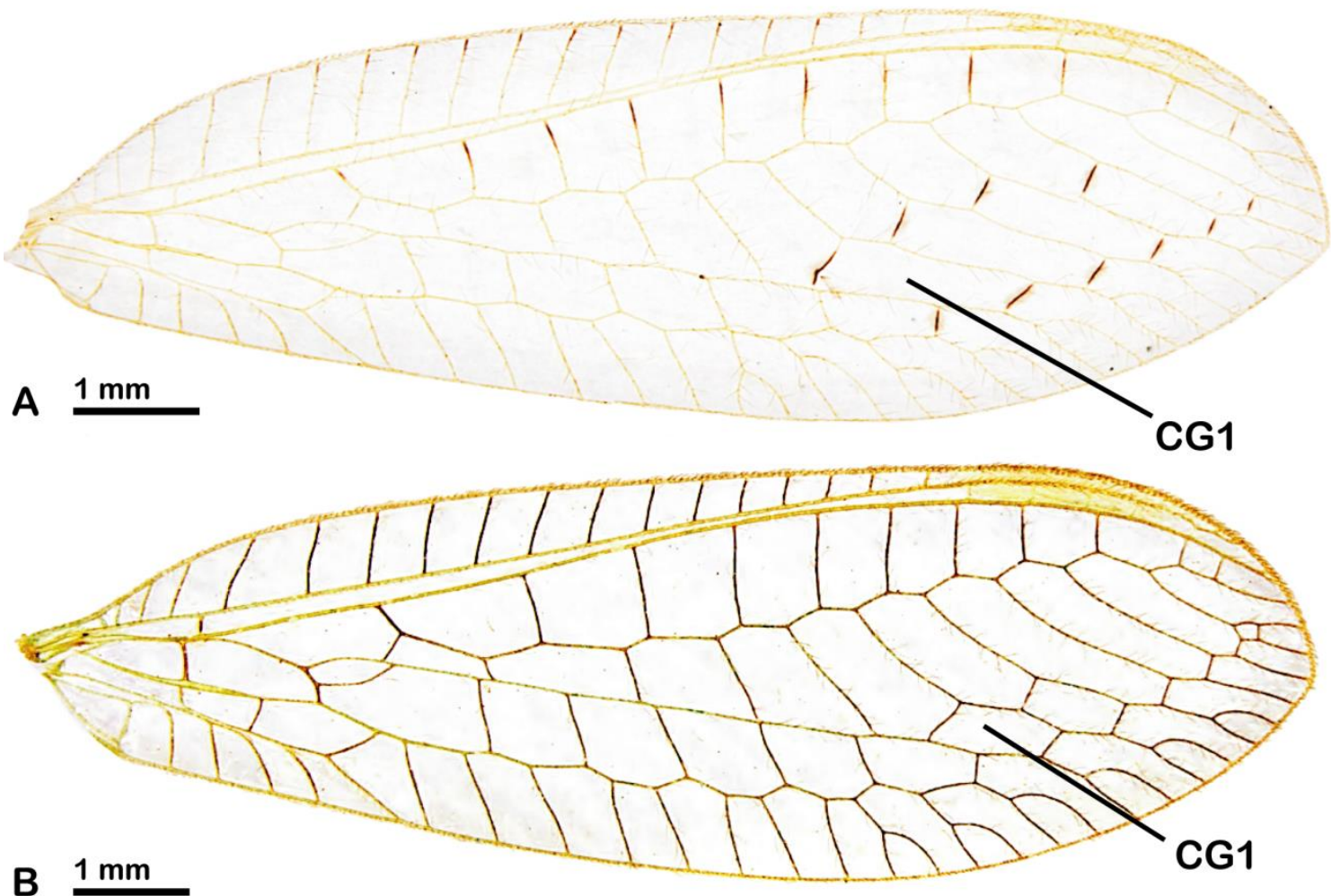

Figura 45. Asa anterior de Chrysopidae (Neuroptera), com destaque para a célula gradiforme 1. A) Célula gradiforme 1 mais longa que a metade da primeira gradiforme externa até a base da quarta transversal radial da asa anterior de Ceraeochrysa tenuicornis Adams \& Penny, 1987; B) Célula gradiforme 1 menor que o comprimento da metade da primeira gradiforme externa até a base da quarta transversal radial da asa anterior de Ceraeochrysa dislepis Freitas \& Penny, 2001. Célula Gradiforme 1 (CG1).

\section{Asas posterior}

Caráter 19. Disposição das gradiformes da asa posterior: (0) paralelas; (1) não paralelas. IC: 0,50/IR: 0,88 (Fig. 46).

Nervuras gradiformes convergentes ou divergentes foram codificadas como o estado 1, o qual surgiu no clado 32 e em C. belizensis.

Caráter 20. Proporção entre o comprimento da célula gradiforme 1 e o comprimento da primeira gradiforme externa até a base da terceira transversal radial da asa posterior: (0) maior que metade; (1) menor que a metade. IC: 0,33/IR: 0,92 (Fig. 47).

A condição apomórfica desse caráter surgiu independentemente em $C$. belizensis e nos clado 9 e 32. 

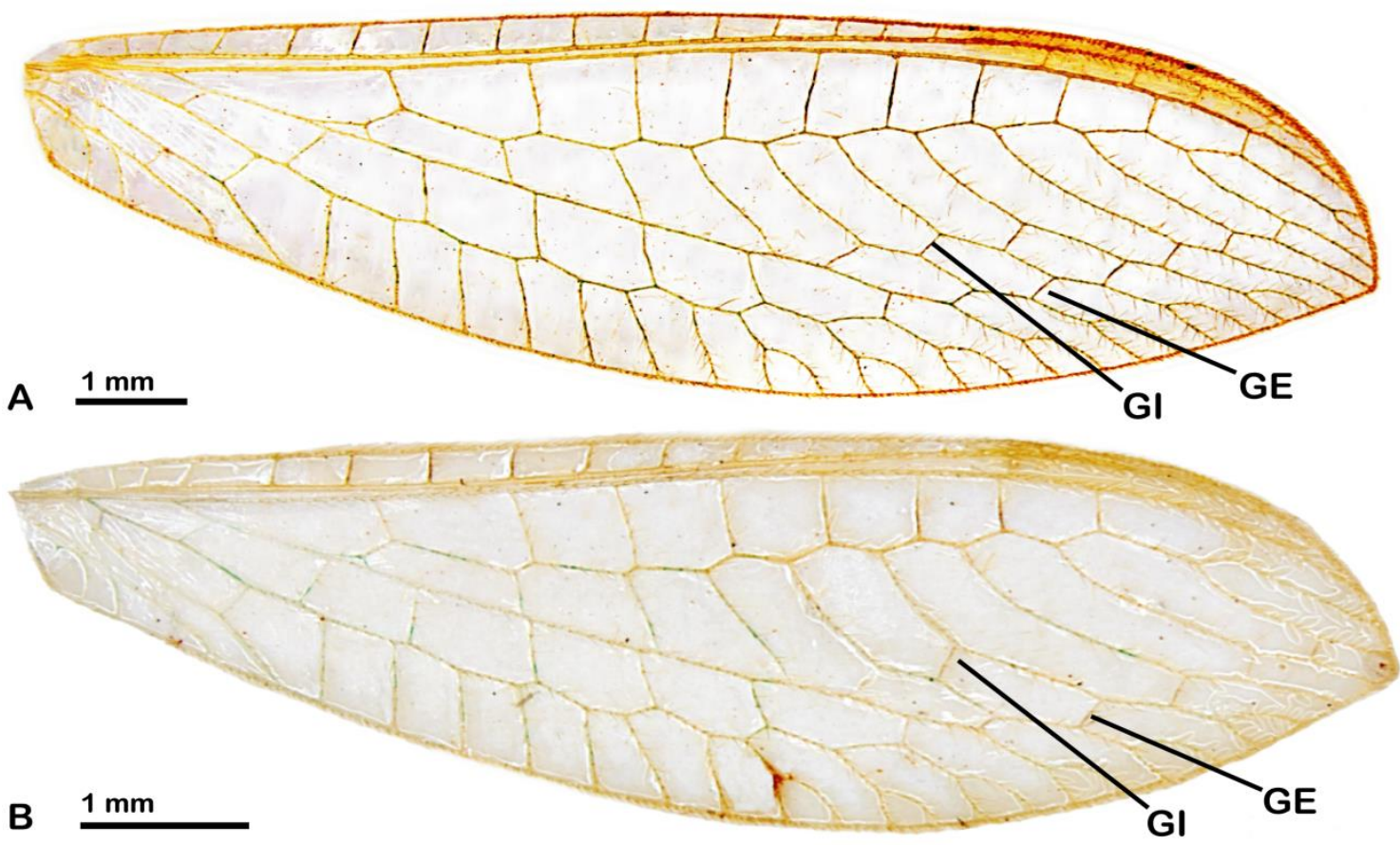

Figura 46. Asa posterior de Chrysopidae (Neuroptera), com destaque para as nervuras gradiformes. A) Nervuras gradiformes paralelas em Ceraeochrysa paraguaria (Navás,1920); B) Nervuras gradiformes não paralelas em Ceraeochrysa achillea (Freitas \& Penny, 2009). Gradiformes internas (GI); gradiformes externas (GE).
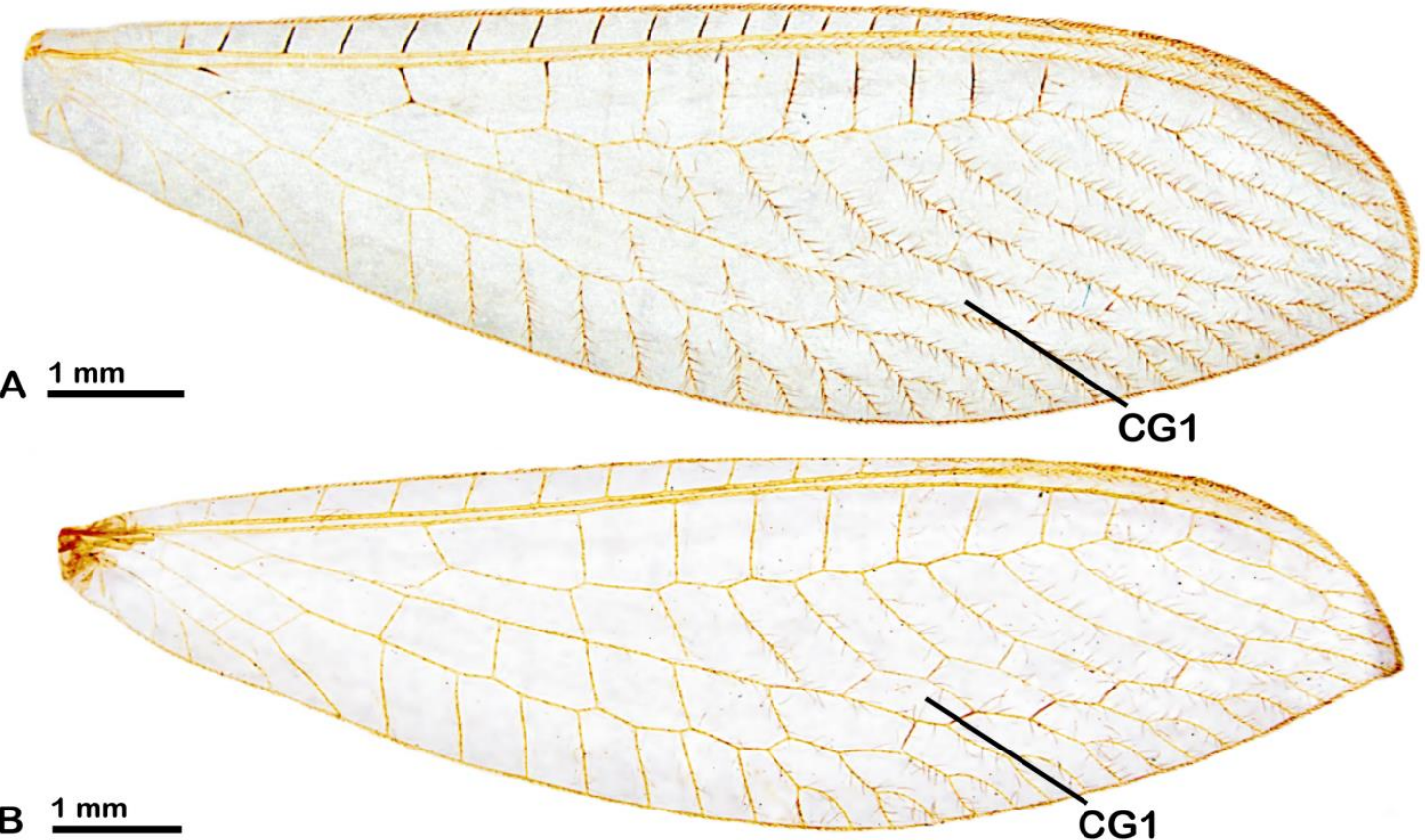

Figura 47. Asa posterior de Chrysopidae (Neuroptera), com destaque para a célula gradiforme 1. A) Célula gradiforme 1 mais longa que a metade da primeira gradiforme externa até a base da terceira transversal radial em Ceraeochrysa paraguaria (Navás, 1920); B) Célula gradiforme 1 menor que a metade do comprimento da primeira gradiforme externa até a base da terceira transversal radial em Ceraeochrysa everes (Banks, 1920). Célula gradiforme 1 (CG1). 
Caráter 21. Coloração das nervuras gradiformes da asa posterior: (0) verdes; (1) negras. IC: 0,09/IR: 0,56 (Fig. 48).

A coloração negra das nervuras gradiformes da asa posterior é apomórfico e surgiu nove vezes em Chrysopini: Chrysopodes (C.) polygonica; (C. placita + C. intacta); no clado 11; C. sanchezi; (C. arioles (Banks, 1944) + (C. claveri (Navás, 1911) + C. montoyana (Navás, 1913)); (C. angulata + C. defreitasi); C. tucumana (Navás, 1919); C. lineaticornis (Fitch, 1855) e C. effusa. No clado 11, ocorreram duas reversões, uma em C. melanopaeira e outra em C. torresi.

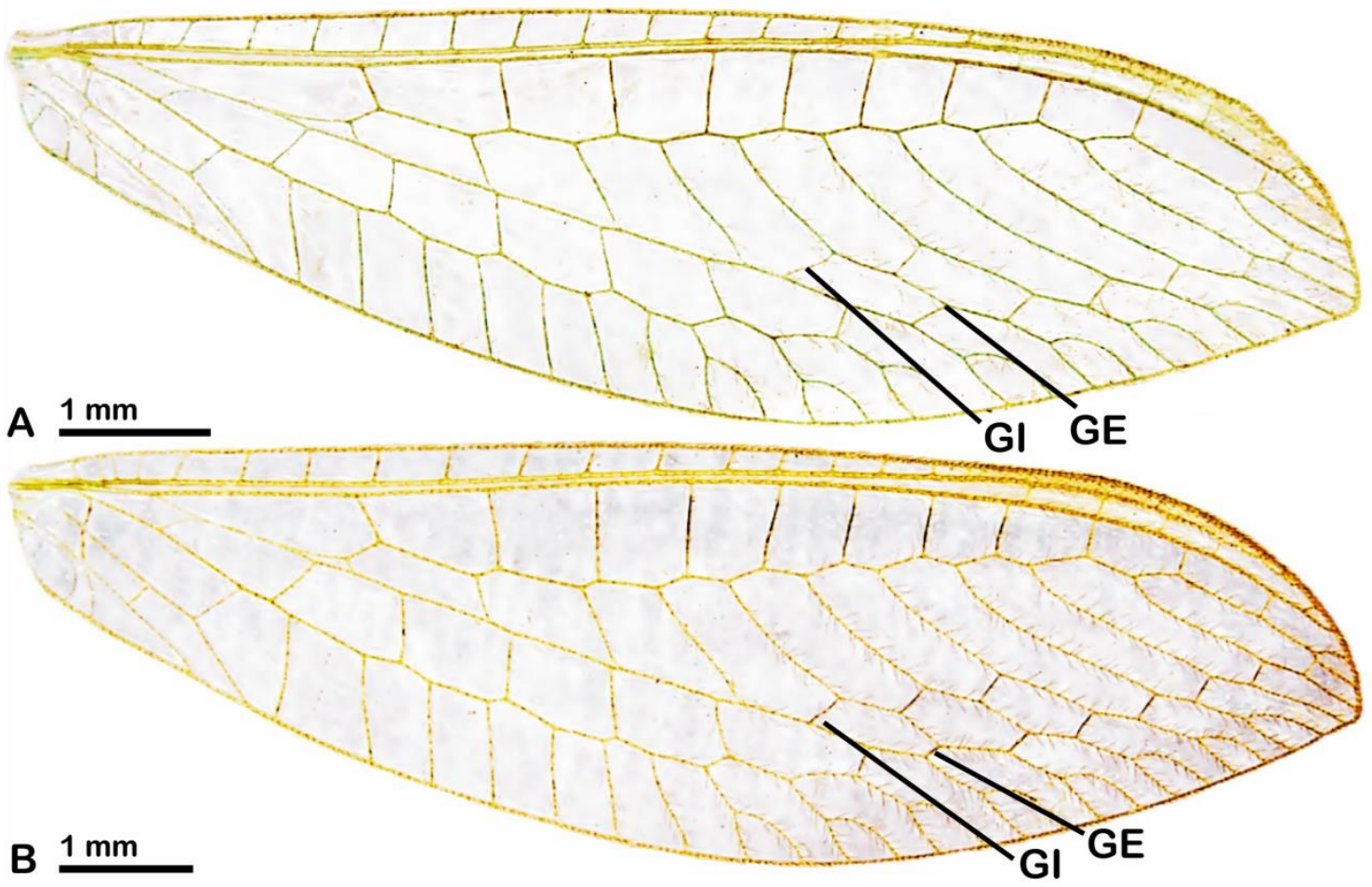

Figura 48. Asa posterior de Chrysopidae (Neuroptera), com destaque para as gradiformes da asa posterior de Chrysopidae. A) Nervurs gradiformes esverdeadas em Ceraeochrysa cincta (Scheneider, 1851); B) Nervuras gradiformes negras em Ceraeochrysa claveri (Navás, 1911). Gradiformes internas (GI); gradiformes externas (GE).

\section{Genitália feminina}

A forma da espermateca foi codificada em dois caracteres, seguindo o modelo de Forey \& Kitching (2000), ou seja, em vez de utilizar um caráter multiestado, optou-se por utilizar um caráter mais inclusivo de ausência e presença (caráter 22), e um mais específico com os diferentes estados, contingente à presença da espermateca alongada (caráter 23); o estado de ausência da espermateca alongada foi substituído por dado faltante. 
Caráter 22. Forma da espermateca: (0) esférica (pill-box); (1) alongada. IC: 1/IR: 1 (Fig. 49).

A espermateca esférica é plesiomórfica e a forma alongada é sinapomorfia do clado 5, composto por todas espécies de Ceraeochrysa, exceto (C. placita $+C$. intacta), espécies recuperadas como grupo-irmão de todas as demais espécies de Ceraeochrysa.

A

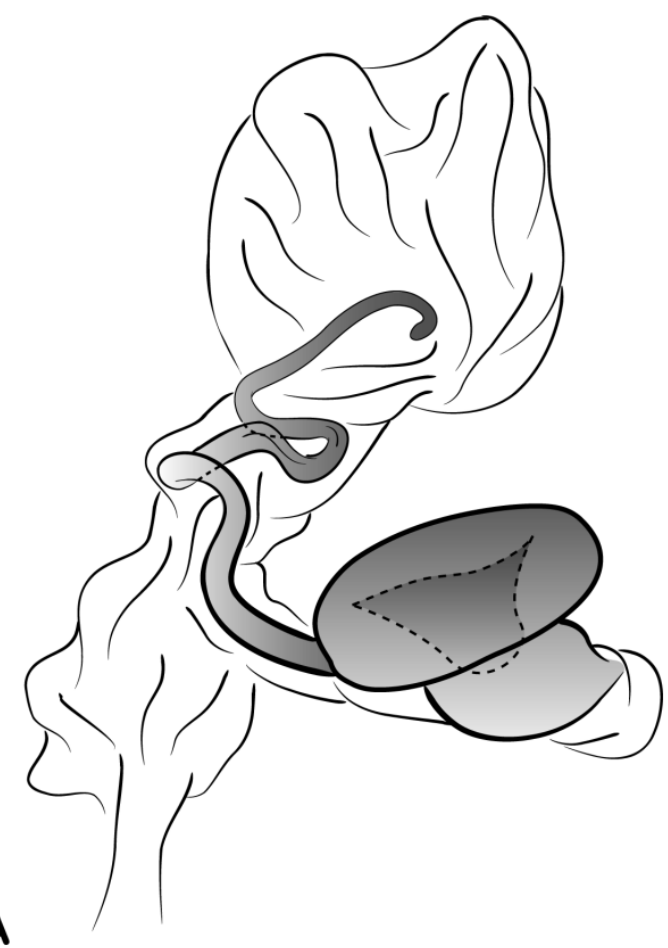

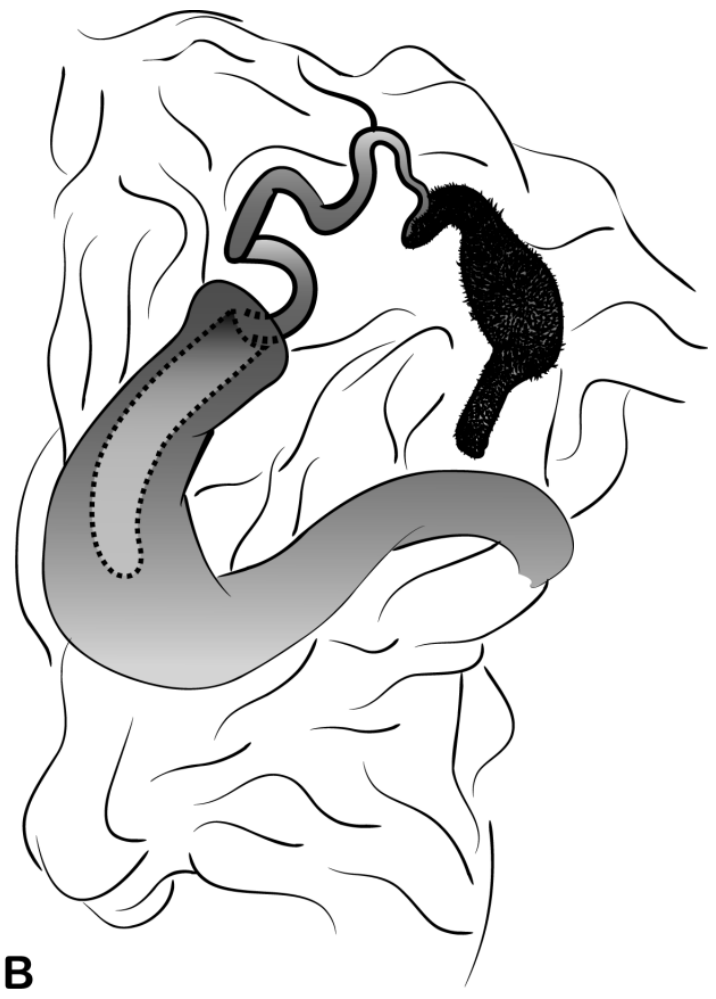

Figura 49. Vista dorsal esquemática da espermateca de Chrysopidae (Neuroptera). A) Espermateca "pill-box"; B) Espermateca alongada.

Caráter 23. Forma da espermateca: (0) sem forma definida; (1) em forma de J; (2) em forma de U. IC: 1/IR: 1 (Fig. 50).

Este caráter se aplica apenas a espécies que possuem a espermateca alongada. A espermateca alongada sem forma definida é o estado plesiomórfico e ocorre na maioria das espécies de Ceraeochrysa. A espermateca em forma de $\mathrm{J}$ é sinapomorfia da maioria das espécies do "grupo everes", que corresponde ao clado 16 (C. dislepis, C. everes, $C$. melanopaeira, C. squamma, C. costaricensis, $C$. torresi e $C$. squalidens), destes somente $C$. dislepis possui espermateca com forma indefinida. Espermateca alongada em forma de $\mathrm{U}$ é sinapomorfia do clado 20; tanto a espermateca alongada em forma de $\mathrm{J}$ quanto em forma de $\mathrm{U}$ surgiram a partir da espermateca alongada sem forma definida. 

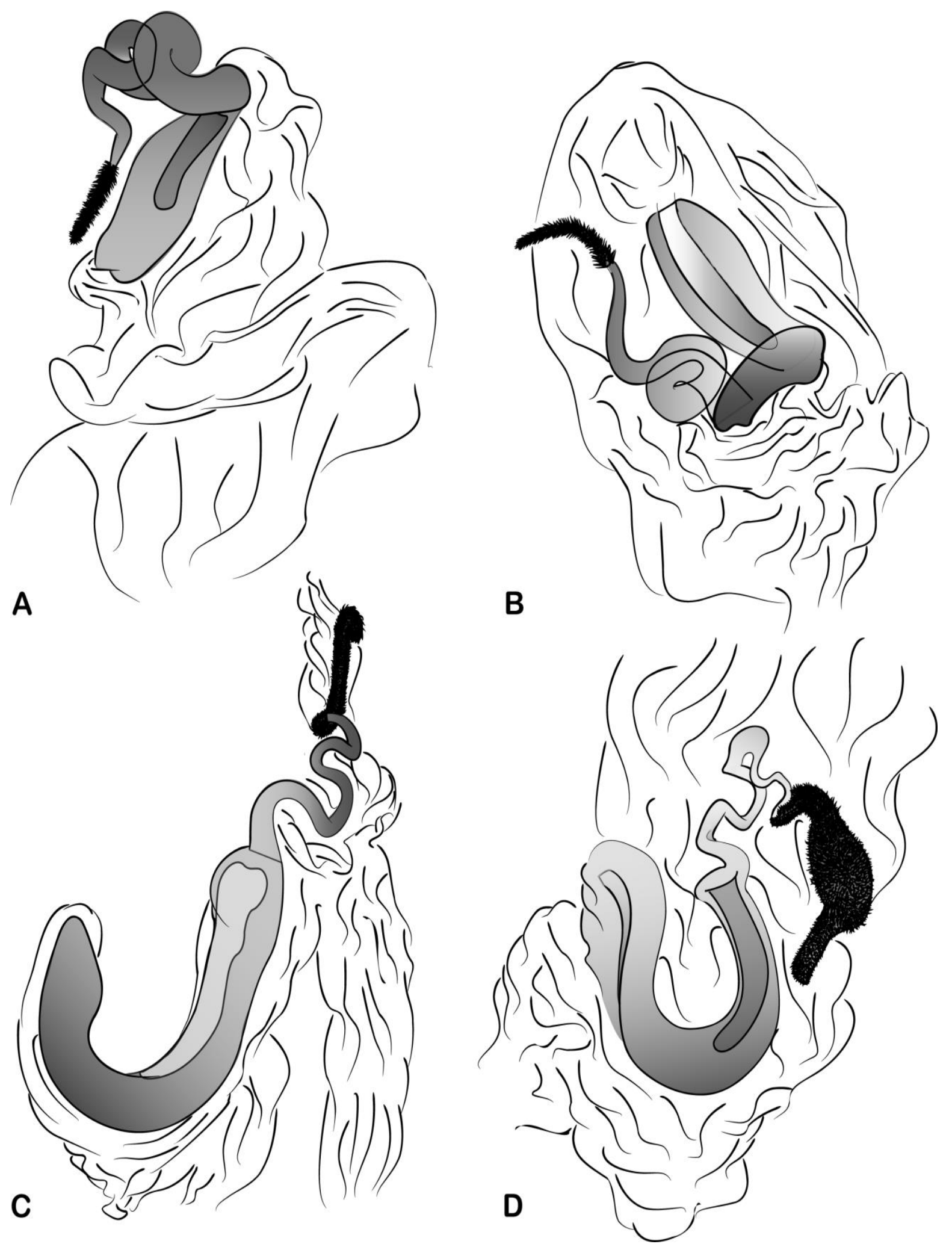

Figura 50. Vista dorsal esquemática da espermateca de Chrysopidae (Neuroptera). A-B) Espermateca alongada em forma não definida; C) Espermateca alongada em forma de J; D) Espermateca alongada em forma de $\mathrm{U}$. 
Caráter 24. Dilatação final do ducto espermático: (0) ausente; (1) presente. IC: 0,33/IR: 0,84 (Fig. 51).

A presença da dilatação no final do ducto espermático é uma condição apomórfica, surgiu três vezes em Ceraeochrysa: nos clados 16, 22 e (C. fairchildi $+($ C. angulata + C. defreitasi)).

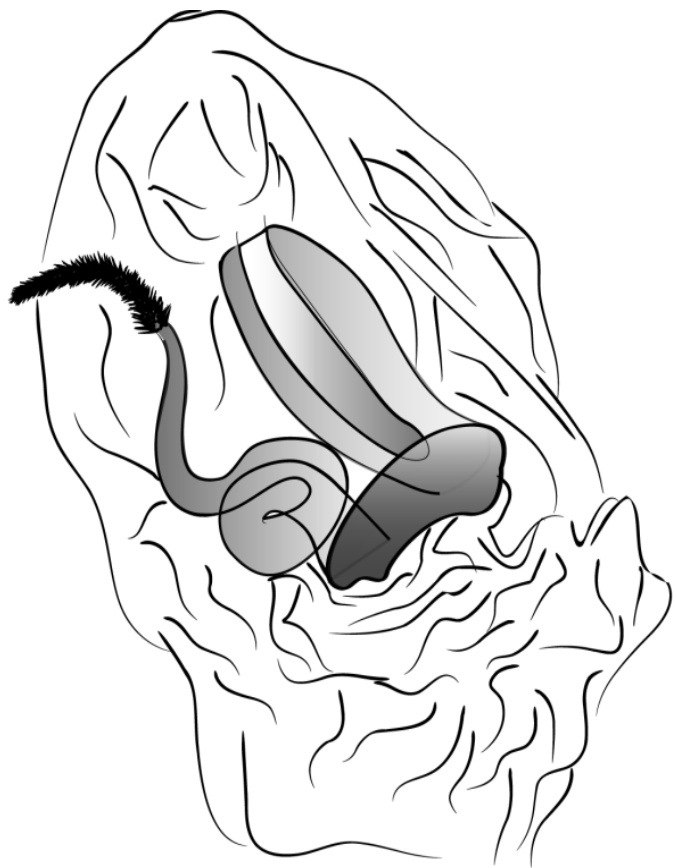

A

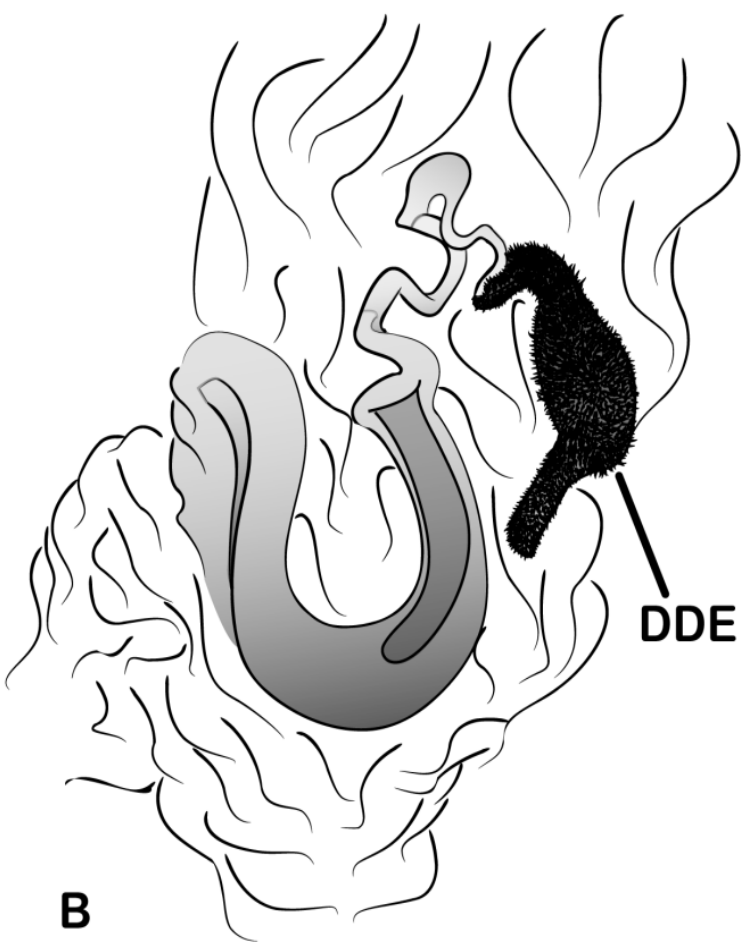

Figura 51. Vista dorsal esquemática do ducto espermático de Chrysopidae. A) Ducto espermático sem dilatação final; B) Ducto espermático com dilatação final. Dilatação do ducto espermático (DDE).

Caráter 25. Comprimento da vela interna em relação ao comprimento da vela externa da espermateca: (0) menor que a metade; (1) maior que a metade. IC: 0,5/IR: 0,92 (Fig. 52).

O comprimento da vela interna da espermateca maior que metade do comprimento da vela externa surgiu duas vezes em Ceraeochrysa, no clado 12 e em $(C$. fairchildi $+(C$. angulta + C. defreitasi)). 


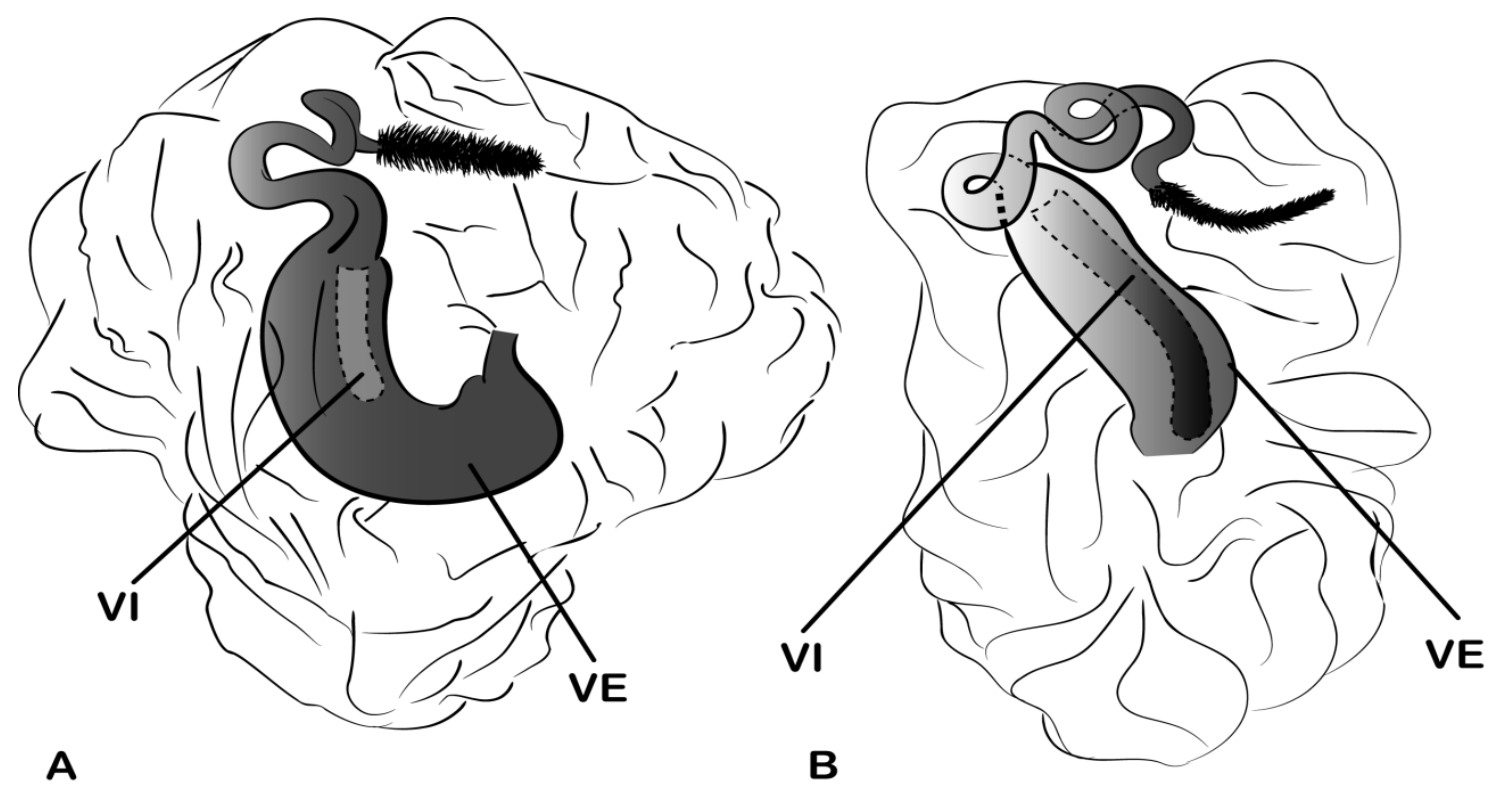

Figura 52. Vista esquemática dorsal da espermateca de Chrysopidae (Neuroptera), com destaque para a vela externa. A) Vela interna menor que a metade do comprimento da vela externa; B) Vela interna maior que metade do comprimento da vela externa. Vela interna (VI); vela externa (VE).

\section{Genitália masculina}

Caráter 26. Projeção ventral do tergito IX + ectoprocto masculino: (0) ausente; (1) presente. IC: 0,12/IR: 0,66 (Fig. 53).

A ausência de projeção ventral do tergito IX + ectoprocto masculino é plesiomórfico em Chrysopidae. Em Ceraeochrysa, a presença da projeção ventral do tergito IX + ectoprocto no ápice abdominal masculino ocorreu independentemente oito vezes. Cinco vezes ocorreu em grupos de espécies- $(C$. squamma $+(C$. squalidens $+(C$. torresi $+C$. costaricensis $))) ;(C$. arioles $+(C$. claveri $+C$. montoyana $)) ;(C$. belizensis $+(C$. discolor $+C$. inbio $)) ;(C$. fairchildi $+(C$. angulata $+C$. defreitasi $))$ - e três em espécies isoladas-C. cubana, $C$. sanchezi e C. acmon.

Caráter 27. Ápice da placa da fusão dos esternitos VIII + IX no macho: (0) arredondado; (1) bifurcado. IC: 1/IR: 1 (Fig. 54).

O estado 1 é sinapomorfia de $C$. cubana $+C$. scapularis. 

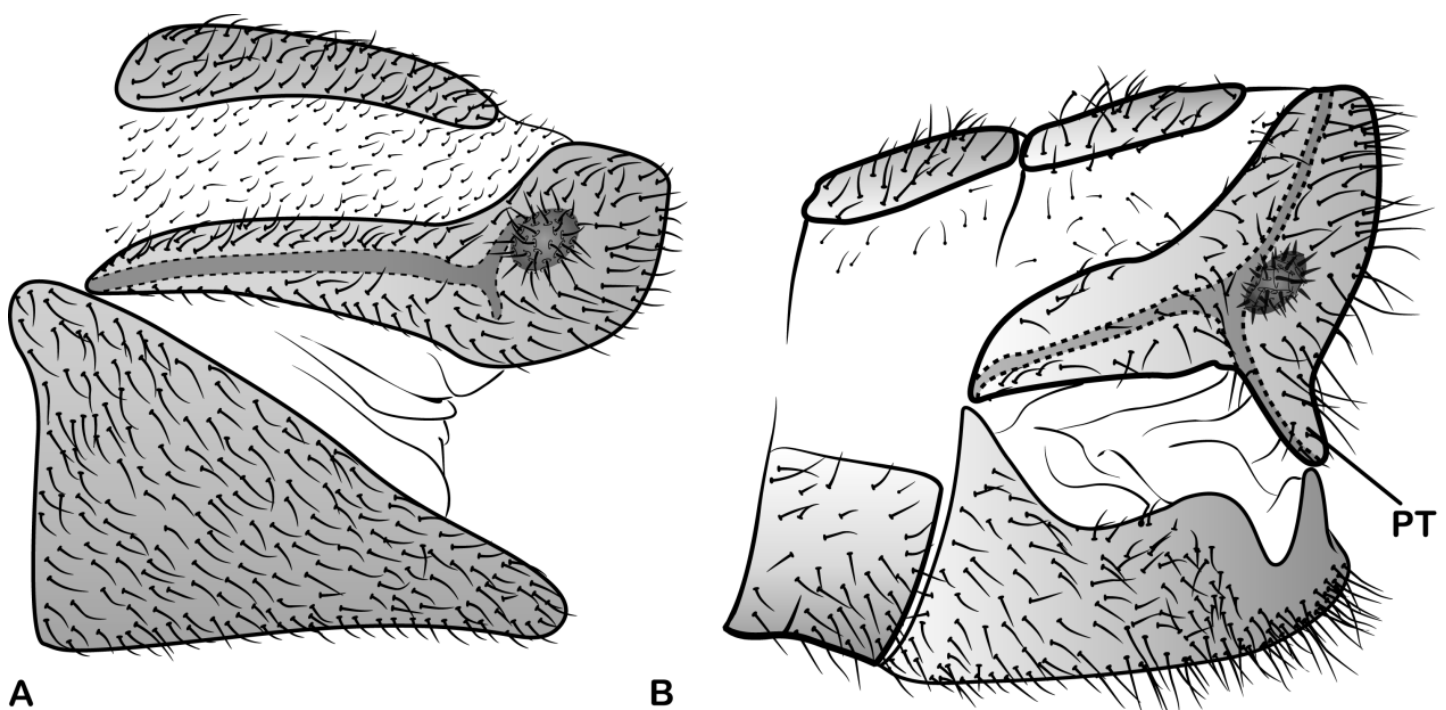

Figura 53. Vista lateral esquemática do abdômen masculino de Ceraeochrysa Adams, 1982 (Chrysopidae: Chrysopinae). A) Abdômen sem projeção ventral do tergito IX + ectoprocto; B) Abdômen com projeção ventral do tergito IX + ectoprocto. Projeção do tergito IX + ectoprocto masculino (PT).
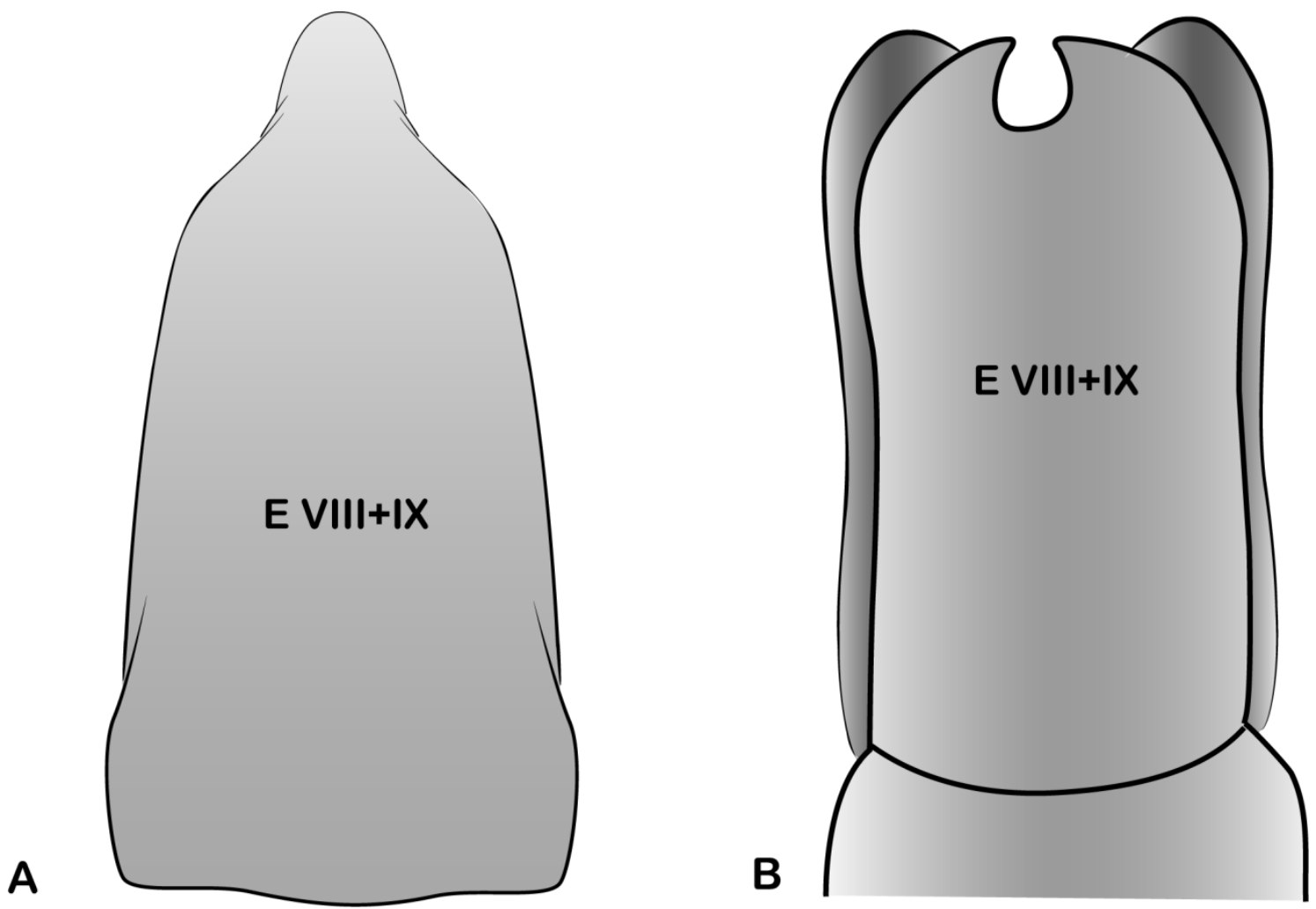

Figura 54. Vista ventral esquemática do esternito VIII+IX do abdômen masculino de Ceraeochrysa Adams, 1982 (Chrysopidae: Chrysopinae). A) Esternito VIII+IX rombudo; B) Esternito VIII+IX bifurcado. Esternito VIII + IX (E VIII+IX). 
Caráter 28. Ramo ventral do apodema abdominal masculino: (0) ausente; (1) presente. IC: 0,16/IR: 0,54 (Fig 55).

A presença do ramo ventral do apódema abdominal masculino surge no clado 5. Dentro deste clado, no entanto, podem ser observadas quatro reversões: $C$. nigripedis, $C$. ariasi, (C. cubana + C. scapularis) e clado 29, porém, no clado 31 existe a presença do ramo ventral do apódema abdominal masculino.

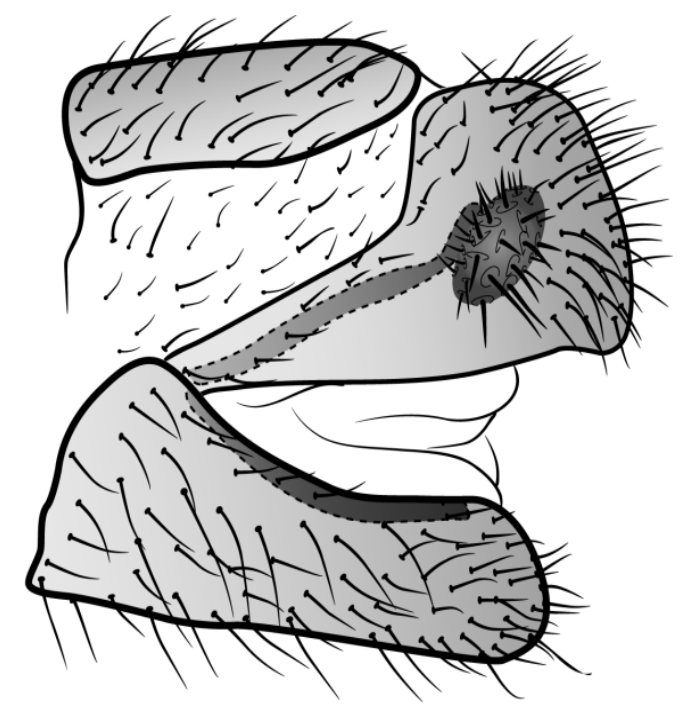

A

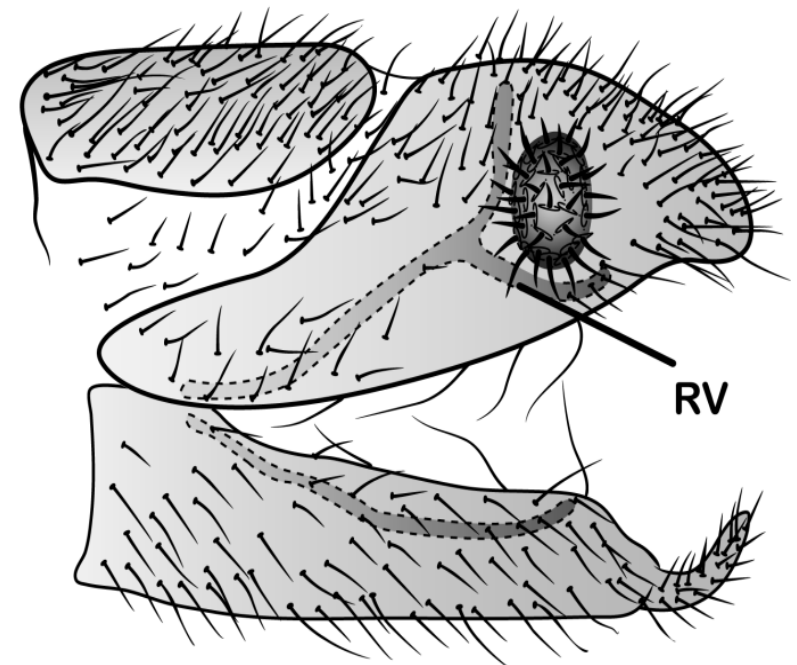

B

Figura 55. Vista lateral esquemática do abdômen masculino de Ceraeochrysa Adams, 1982. A) Apódema abdominal masculino de Chrysopidae sem ramo ventral; B) Apódema abdominal masculino de Chrysopidae com ramo ventral. Ramo ventral do apodema abdominal (RV).

Caráter 29. Forma do ramo ventral do apódema abdominal masculino. (0) retilínia; (1) em forma de gancho. IC: 1/IR: 1 (Fig. 56)

Este caráter é contingente à presença do ramo ventral do apódema abdominal masculino. O estado 1 aparece como sinapomorfia do clado 22, que corresponde ao grupo cincta.

Caráter 30. Gonosetas do gonossaco: (0) presentes; (1) ausentes. IC: 1/IR: 1 (Fig. 57). A ausência de gonosetas é sinapomorfia de (C. placita $+C$. intacta $)$. 


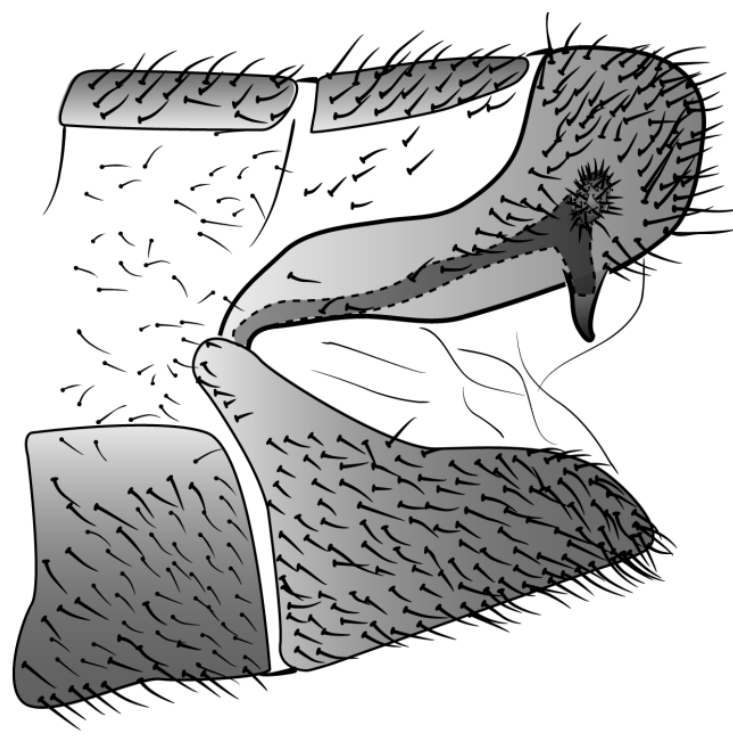

A

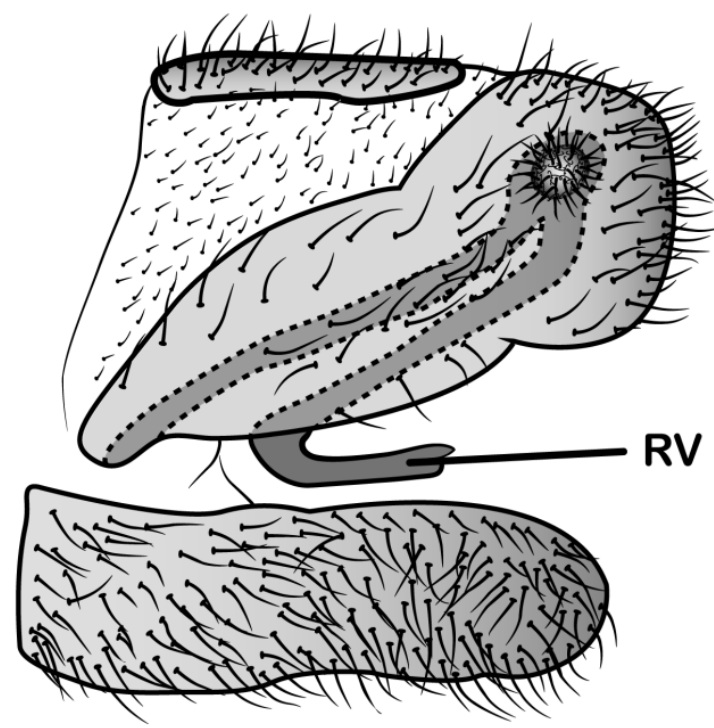

B

Figura 56. Vista lateral esquemática do abdômen masculino de Ceraeochrysa Adams, 1982 (Chrysopidae: Chrysopinae), com destaque para o ramo ventral do apodema abdominal masculino. A) Ramo ventral do apodema abdominal masculino Retílino; B) Ramo ventral do apodema abdominal masculino em forma de gancho. Ramo ventral do apodema abdominal (RV).

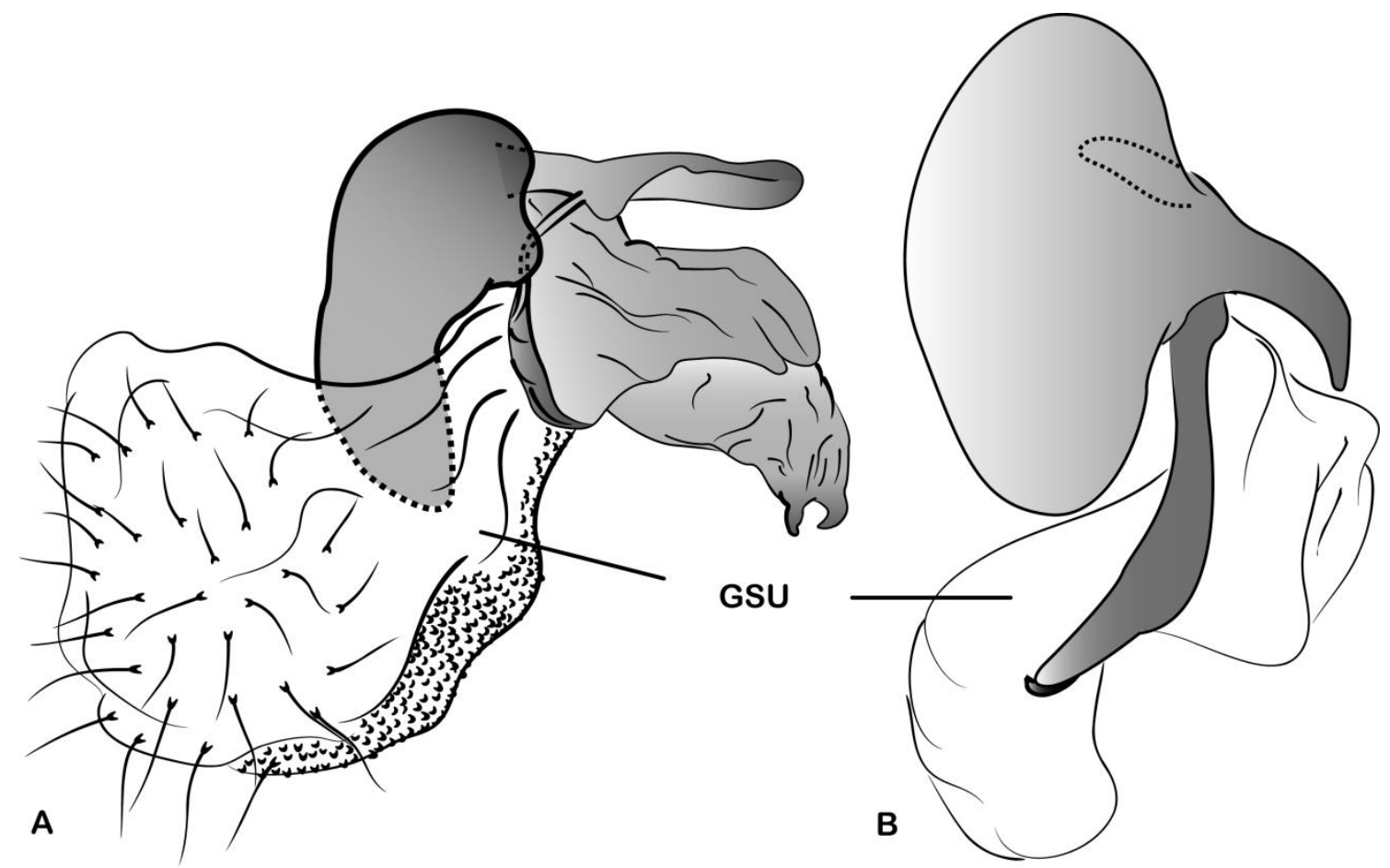

Figura 57. Vista lateral esquemática da genitália masculina de Ceraeochrysa Adams, 1982 (Chrysopidae: Chrysopinae). A) Gonossaco coberto por gonosetas; B) Gonossaco sem gonosetas. Gonossaco (GSU). 
Caráter 31. Disposição das gonosetas do gonossaco: (0) formando dois grupos; (1) esparsas. IC: 0,25/IR: 0,78 (Fig. 58).

Este caráter é contingente à presença de gonosetas no gonossaco. Joguina constellata não possui gonossaco, de maneira que a variação nesta análise ocorre apenas em Chrysopini. Gonosetas espalhadas sobre o gonossaco surgem no clado 5, houve três reversões, em Ceraeochrysa arioles, em C. tenuicornis Adams \& Penny, 1987 e no clado 29.

A

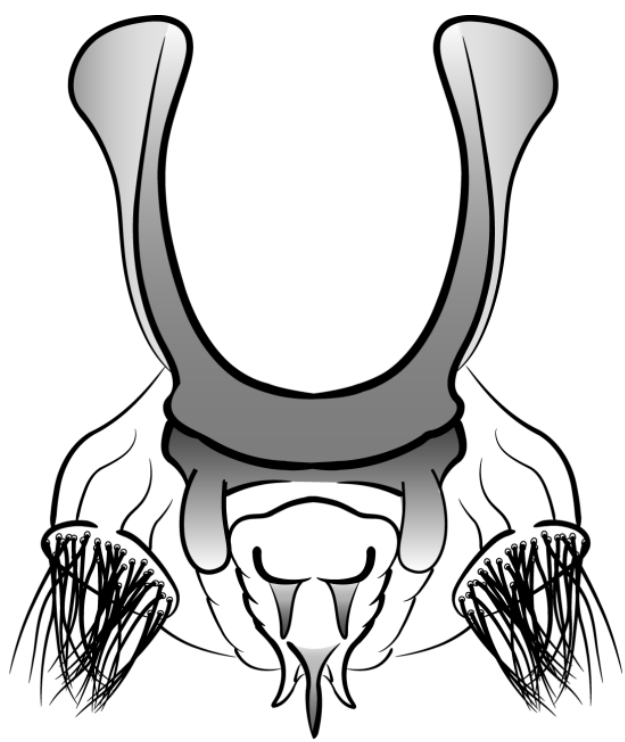

B

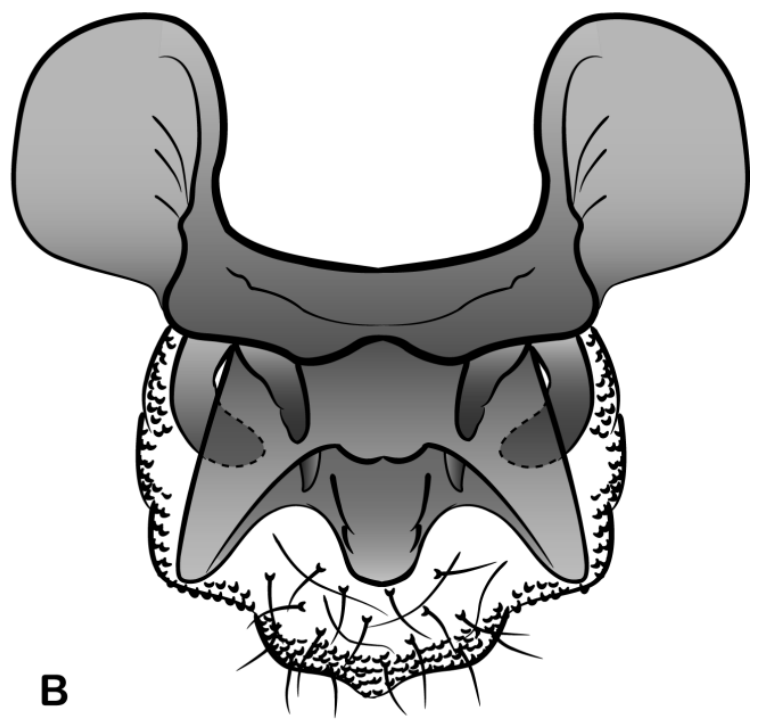

Figura 58. Vista esquemática dorsal do gonossaco de Ceraeochrysa Adams, 1982 (Chrysopidae: Chrysopinae). A) Gonosetas formado dois grupos; B) Gonosetas esparsas.

Caráter 32. Placa dorsal plana do gonarco: (0) ausente; (1) presente. IC: 1/IR: 1 (Fig. 59).

A presença da placa dorsal plana do gonarco é sinapomorfia do grupo de espécies conhecido como grupo everes (clado 16). As espécies que compõem esse grupo são $C$. dislepis, C. everes, C. melanopaeira, C. squamma, C. squalidens, C. costaricensis e $C$. torresi. Freitas et al. (2009) utilizaram um caráter similar a esse com três estados, porém, neste trabalho optou-se por dividi-lo nos caracteres 32 e 33.

Caráter 33. Processo digitiforme do gonarco: (0) ausente; (1) presente. IC: 0,50/IR: 0,50 (Fig. 60).

O processo digitiforme do gonarco surgiu independentemente duas vezes dentro de Ceraeochrysa, em (C. claveri + C. montoyana) e em (C. belizensis). 

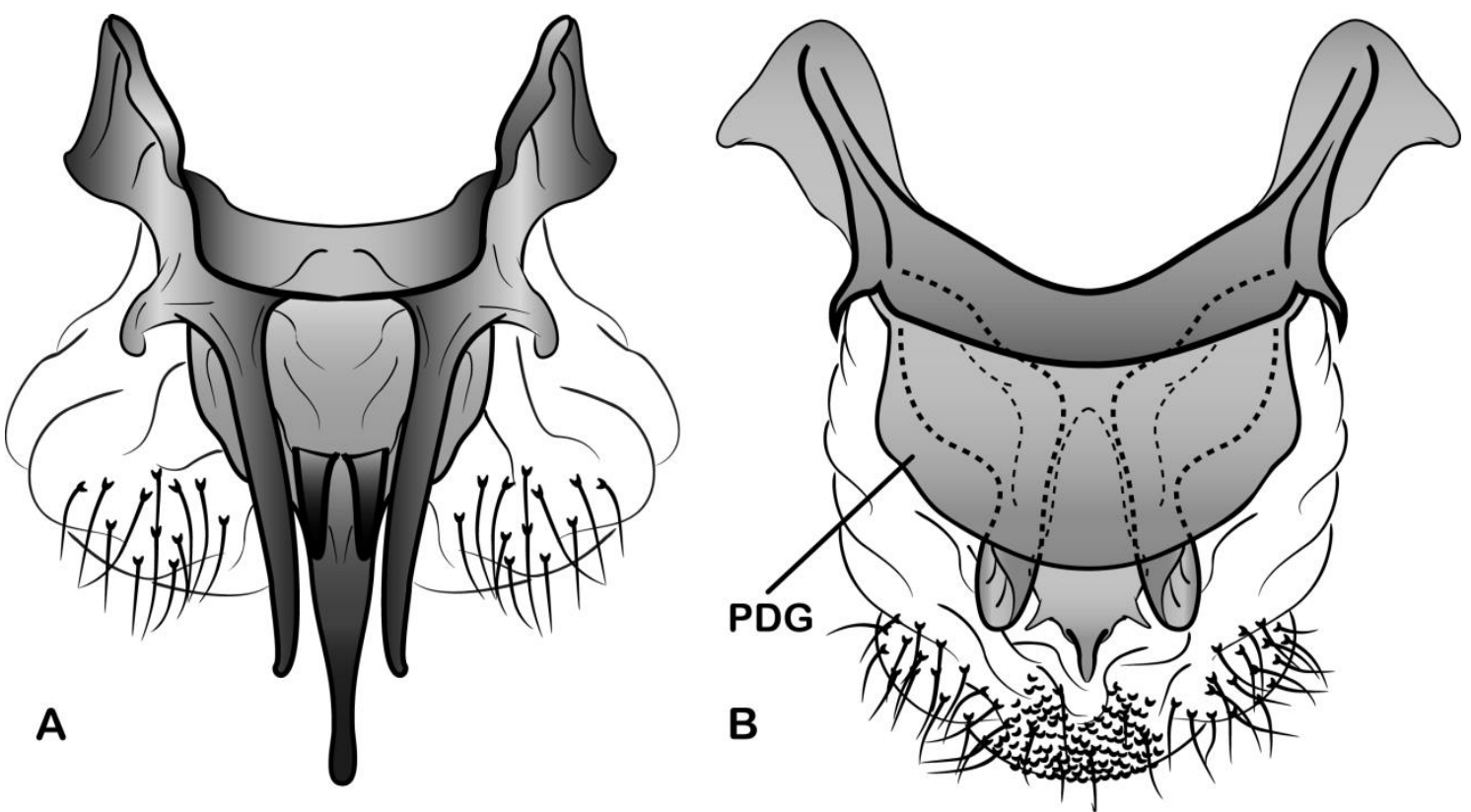

Figura 59. Vista dorsal esquemática da genitália masculina de Ceraeochrysa Adams, 1982 (Chrysopidae: Chrysopinae). A) Gonarco sem placa dorsal; B) Gonarco com placa dorsal plana. Placa dorsal do gonarco (PDG).

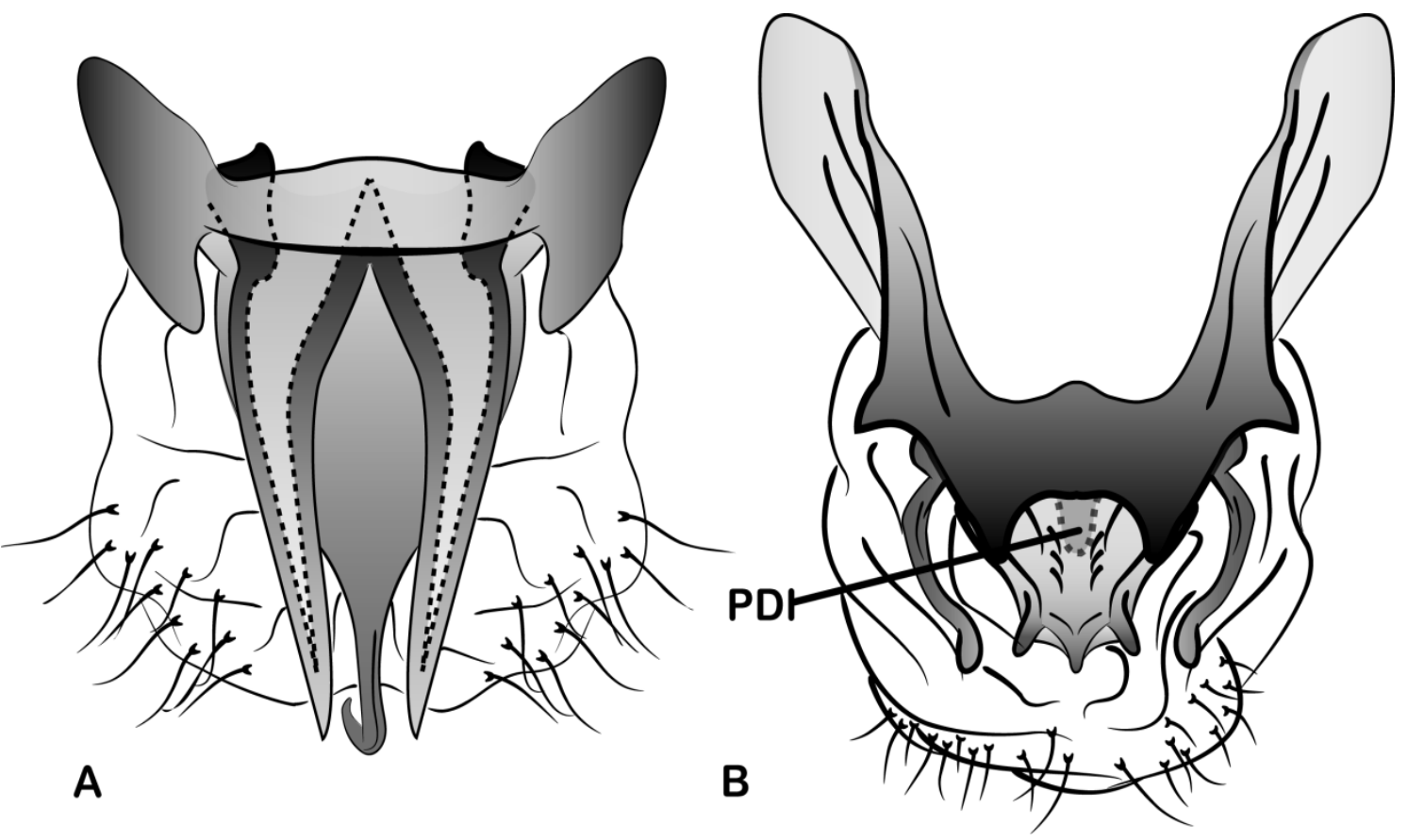

Figura 60. Vista dorsal esquemática da genitália masculina de Ceraeochrysa Adams, 1982 (Chrysopidae: Chrysopinae). A) Gonarco sem processo digitiforme; B) Gonarco com processo digitiforme. Processo digitiforme do gonarco (PDI). 
Caráter 34. Entoprocesso: (0) ausente; (1) presente. IC: 0,33/IR: 0,90 (Fig. 61).

O entoprocesso surgiu no clado 6, porém ocorreram duas perdas secundárias desta estrutura. Uma delas ocorreu no clado 12 e a outra no clado (Ceraeochrysa panamensis $+(C$. falcifera $+(C$. fairchildi $+(C$. angulata $+C$. defreitasi $)))$.

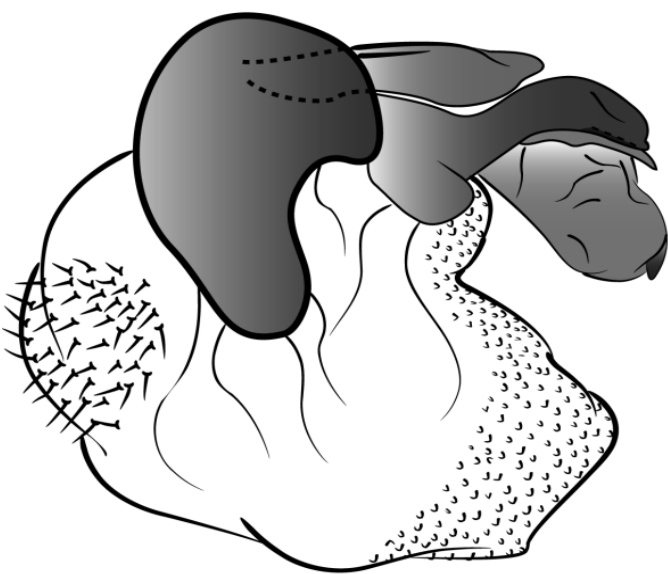

A

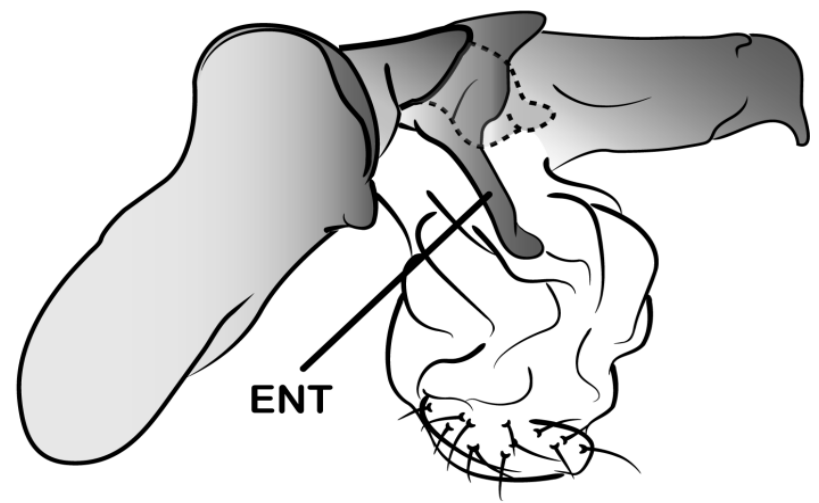

B

Figura 61. Vista lateral esquemática da genitália masculina de Ceraeochrysa Adams, 1982 (Chrysopidae: Chrysopinae). A) Gonarco sem entoprocesso; B) Gonarco com entoprocesso. Entoprocesso (ENT).

Caráter 35. Comprimento do entoprocesso: (0) menor que o gonocorno; (1) maior que o gonocorno. IC: 1/IR: 1 (Fig. 62).

Gonarco com entoprocesso maior que o gonocorno é sinapomorfia do clado 20, com um surgimento único no gênero.

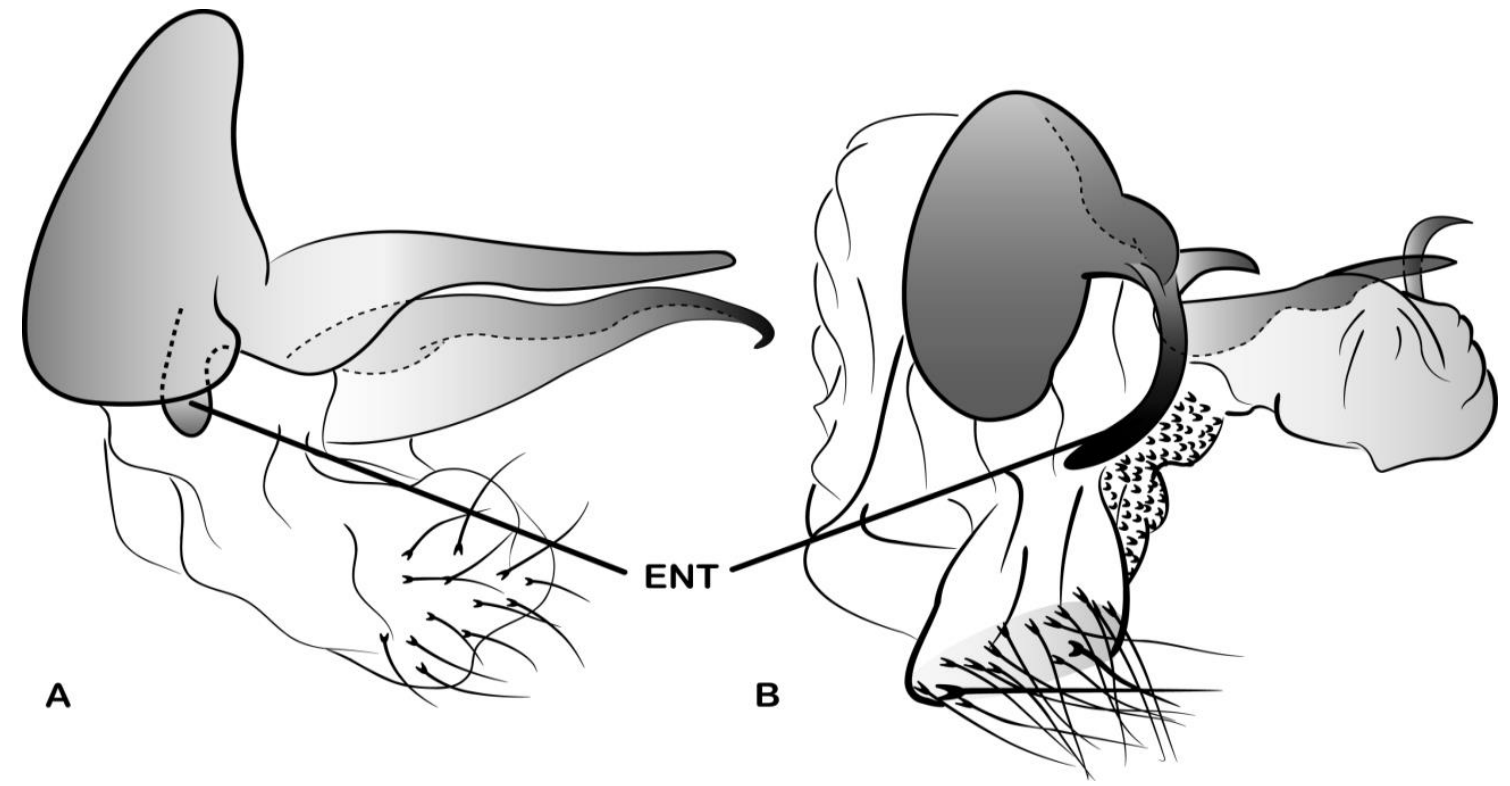

Figura 62. Vista lateral esquemática da genitália masculina de Ceraeochrysa Adams, 1982 (Chrysopidae: Chrysopinae). A) Entoprocessso menor que o gonocorno; B) Entoprocesso maior que o gonocorno. Entoprocesso (ENT). 
Caráter 36. Gonocorno: (0) ausente; (1) presente. IC: 0,50/IR: 0,66 (Fig. 63).

Nesta análise a presença do gonocorno é sinapomorfia de (Criptochrysa chloros + Ceraeochrysa), porém, há uma reversão em Ceraeochrysa nigripedis, que não tem esta estrutura.

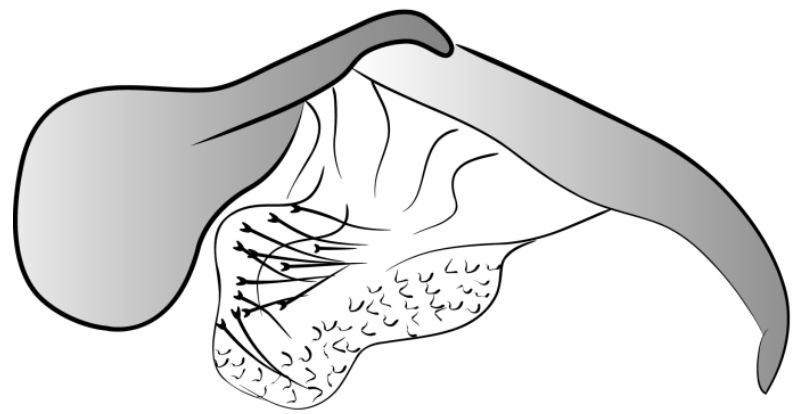

A

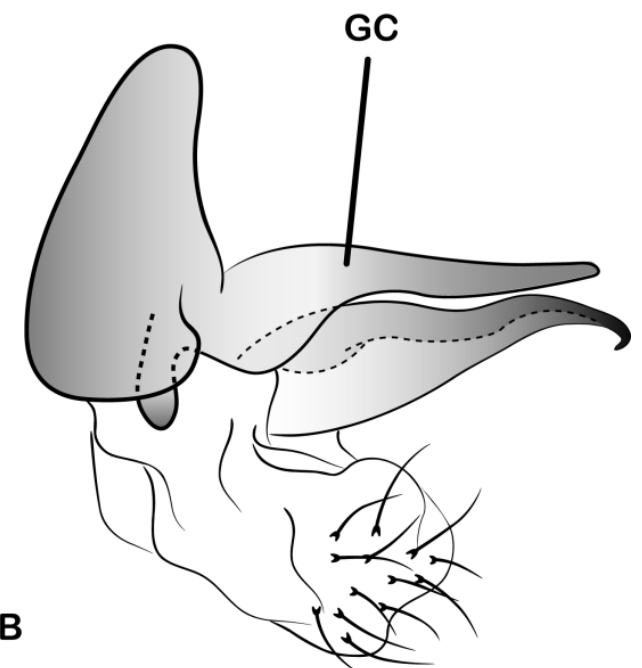

Figura 63. Vista lateral esquemática da genitália masculina de Ceraeochrysa Adams, 1982 (Chrysopidae: Chrysopinae). A) Gonarco sem gonocorno; B) Gonarco com gonocorno. Gonocorno (GC).

Caráter 37. Espessura do gonocorno (em vista lateral): (0) estreito; (1) largo. IC: 1/IR: 1 (Fig. 64).

O gonocorno largo é sinapomorfia das espécies pertencentes ao grupo everes (clado 16), tais espécies apresentam o gonocorno digitiforme, bastante largo quando comparado com o de outras espécies de Ceraeochrysa.

A
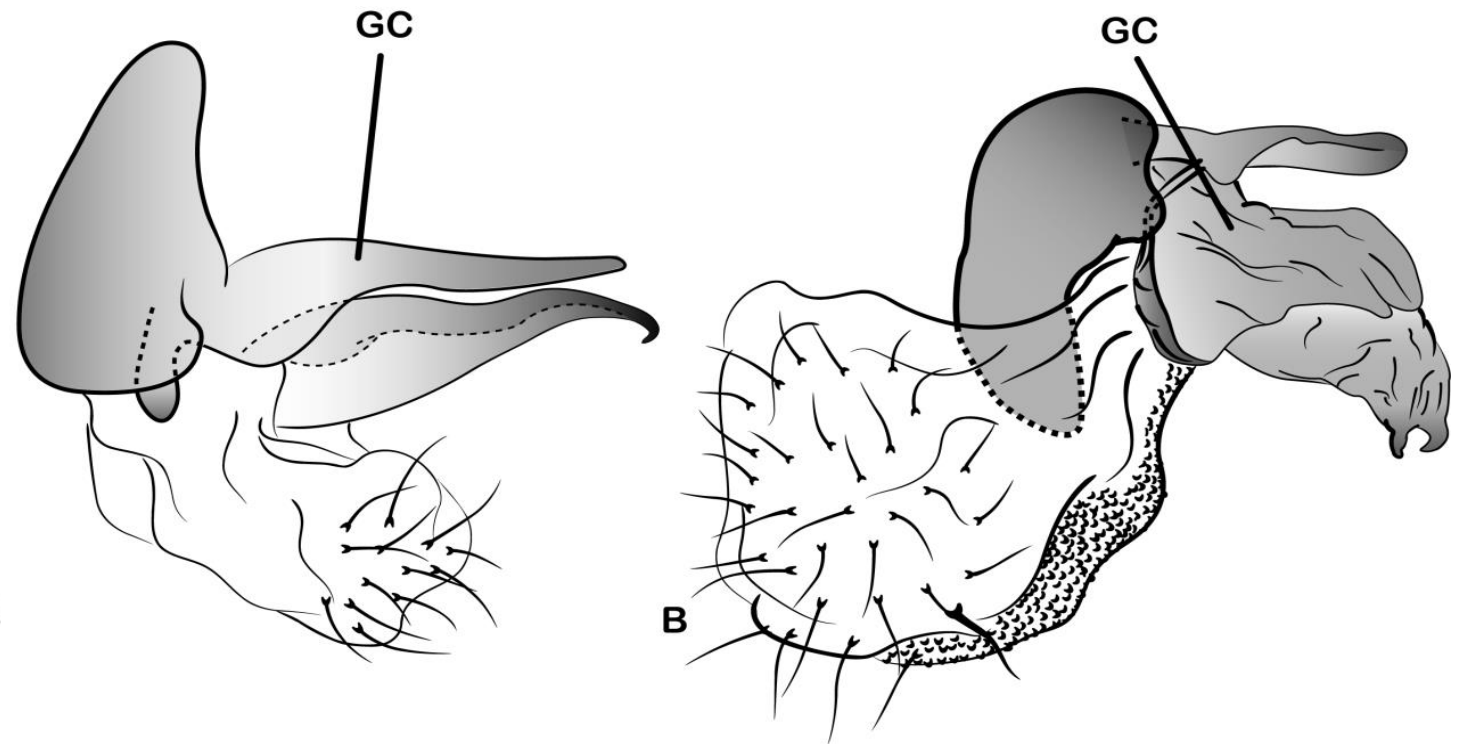

Figura 64. Vista lateral esquemática da genitália masculina de Ceraeochrysa Adams, 1982 (Chrysopidae: Chrysopinae). A) Gonarco com o gonocorno estreito; B) Gonarco com o gonocorno largo. Gonocorno (GC). 
Caráter 38. Comprimento do gonocorno em relação à largura do braço lateral do gonarco (em vista lateral): (0) menor; (1) maior. IC: 0,33/IR: 0,75 (Fig. 65).

O comprimento do gonocorno menor que a largura do braço lateral do gonarco é um estado plesiomórfico em Chrysopini. O estado 1, apomórfico, surgiu três vezes em Ceraeochrysa: no clado 16, em C. paraguaria e em C. tenuiconis. No entanto, as duas últimas espécies têm o gonocorno muito maior que o braço lateral do gonarco, enquanto que as espécies do clado 16 apresentam gonocorno pouco maior que o braço lateral do gonarco. Um caráter similar a esse com três estados foi utilizado por Freitas et al. (2009).

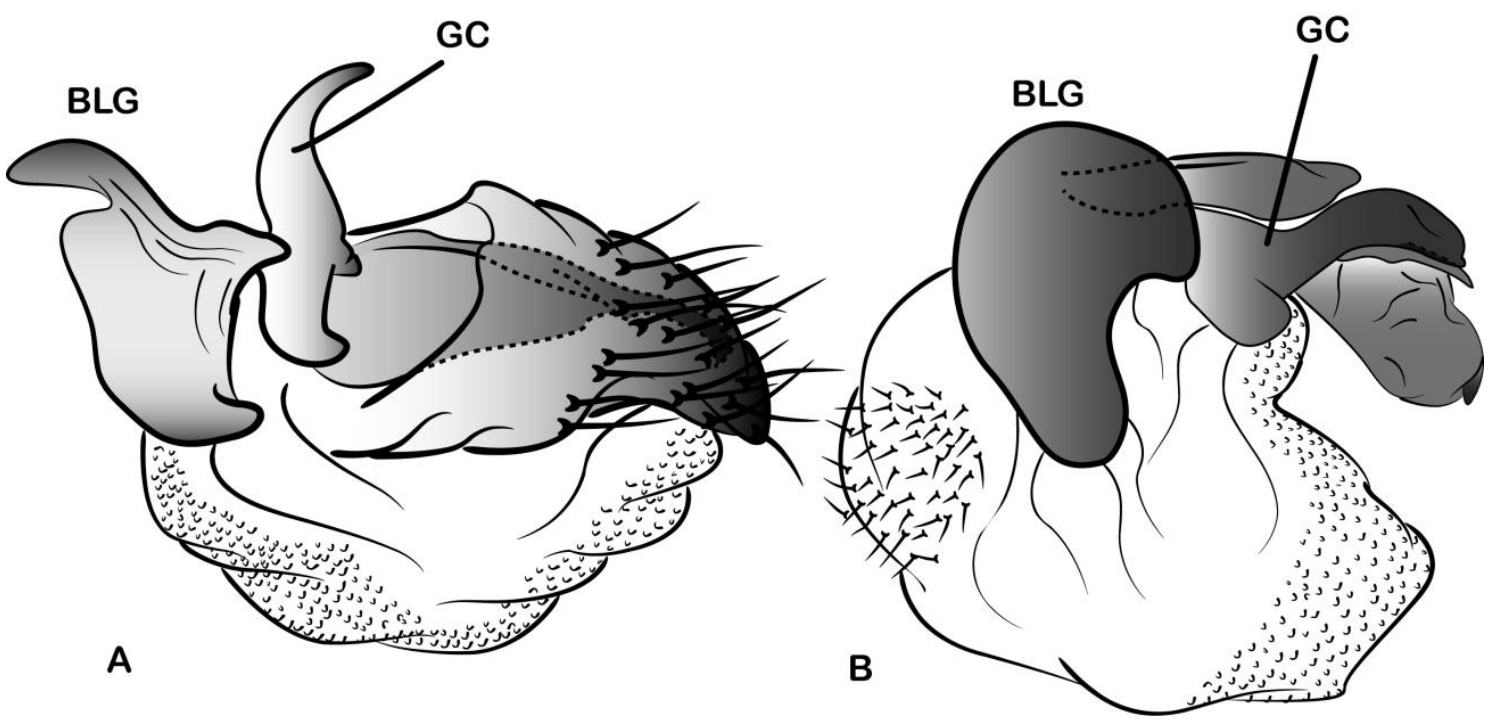

Figura 65. Vista lateral esquemática da genitália masculina de Ceraeochrysa Adams, 1982 (Chrysopidae: Chrysopinae). A) Gonocorno menor que o braço lateral do gonarco; B) Gonocorno maior que o braço lateral do gonarco. Braço lateral do gonarco (BLG); Gonocorno (GC).

Caráter 39. Processo ventral do gonocorno: (0) ausente; (1) presente. IC: 0,25/IR: 0,40 (Fig. 66).

Em Ceraeochrysa a presença do processo ventral do gonocorno surgiu independetemente três vezes, duas como autapomorfias (C. valida (Banks, 1895) e $C$. forcipata Freitas \& Penny, 2009) e como sinapomorfia do clado 26, com uma reversão em $C$. fairchildi.

Freitas et al. (2009) fazem referência a C. lineaticornis, C. achillea, C. michaelmuris, C. nigripedis, $C$. angusta, $C$. curvabilis e $C$. derospogon com a presença do processo ventral do gonocorno, entretanto, suas ilustrações deixam dúvidas se esse processo de fato é do gonocorno, ou se simplesmente é o entoprocesso; desta maneira foi decidido codificar a condição desse caráter como incerta para essas espécies. 

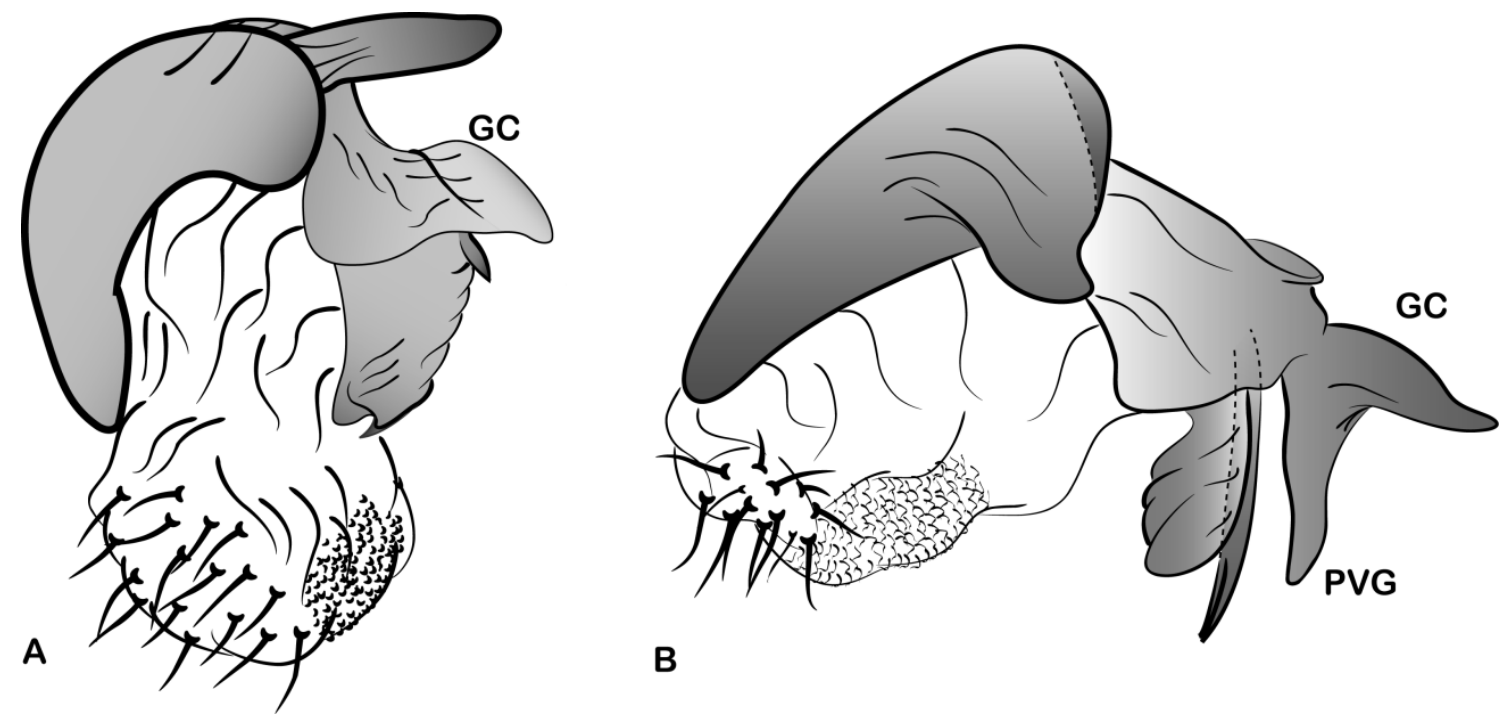

Figura 66. Vista lateral esquemática da genitália masculina de Ceraeochrysa Adams, 1982 (Chrysopidae: Chrysopinae). A) Gonocorno sem processo ventral; B) Gonocorno com o processo ventral. Gonocorno (GC); processo ventral do gonocorno (PVG).

Caráter 40. Largura do mediunco: (0) maior que seu comprimento; (1) menor que seu comprimento. IC: 0,50/IR: 0,87 (Fig. 67).

Mediunco mais longo que largo tem origem na base de Chrysopini, mas há uma reversão no grupo de espécies conhecido como grupo cincta, que corresponde ao clado 22 ( $C$. arioles, $C$. claveri, C. montoyana, $C$. cornuta, C. cincta, $C$. inbio, $C$. discolor e $C$. belizensis) no qual o mediunco é mais largo que longo.
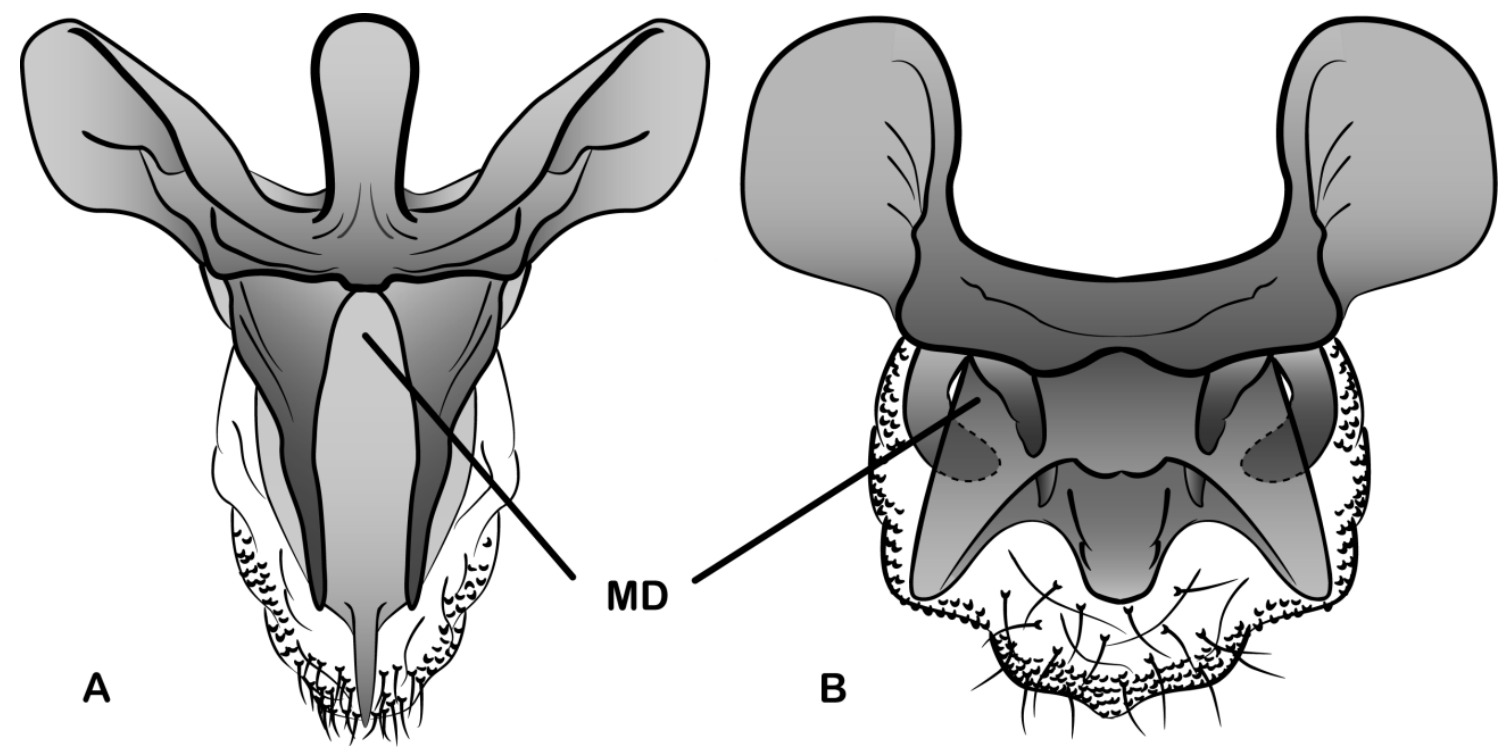

Figura 67. Vista dorsal esquemática da genitália masculina de Ceraeochrysa Adams, 1982 (Chrysopidae: Chrysopinae). A) Mediunco mais longo que largo; B) Mediunco mais largo que longo. Mediunco (MD). 
Caráter 41. Comprimento do arcesso em relação à largura do braço lateral do gonarco: (0) maior; (1) menor. IC: 0,16/IR: 0,79 (Fig. 68)

$\mathrm{O}$ arcesso com comprimento maior que a largura do braço lateral do gonarco é um estado plesiomórfico em Chrysopidae. $\mathrm{O}$ arcesso com comprimento menor que o braço lateral do gonarco surgiu cinco vezes em Ceraeochrysa: $C$. nigripedis; $C$. acmon; no clado $(C$. squamma $+(C$. squalidens $+(C$. torresi $+C$. costaricensis $)))$; no clado $(C$. cincta $+(C$. belizensis $+(C$. inbio $+C$. discolor $))$ ); e no clado 24 , com uma reversão em $C$. berlandi .
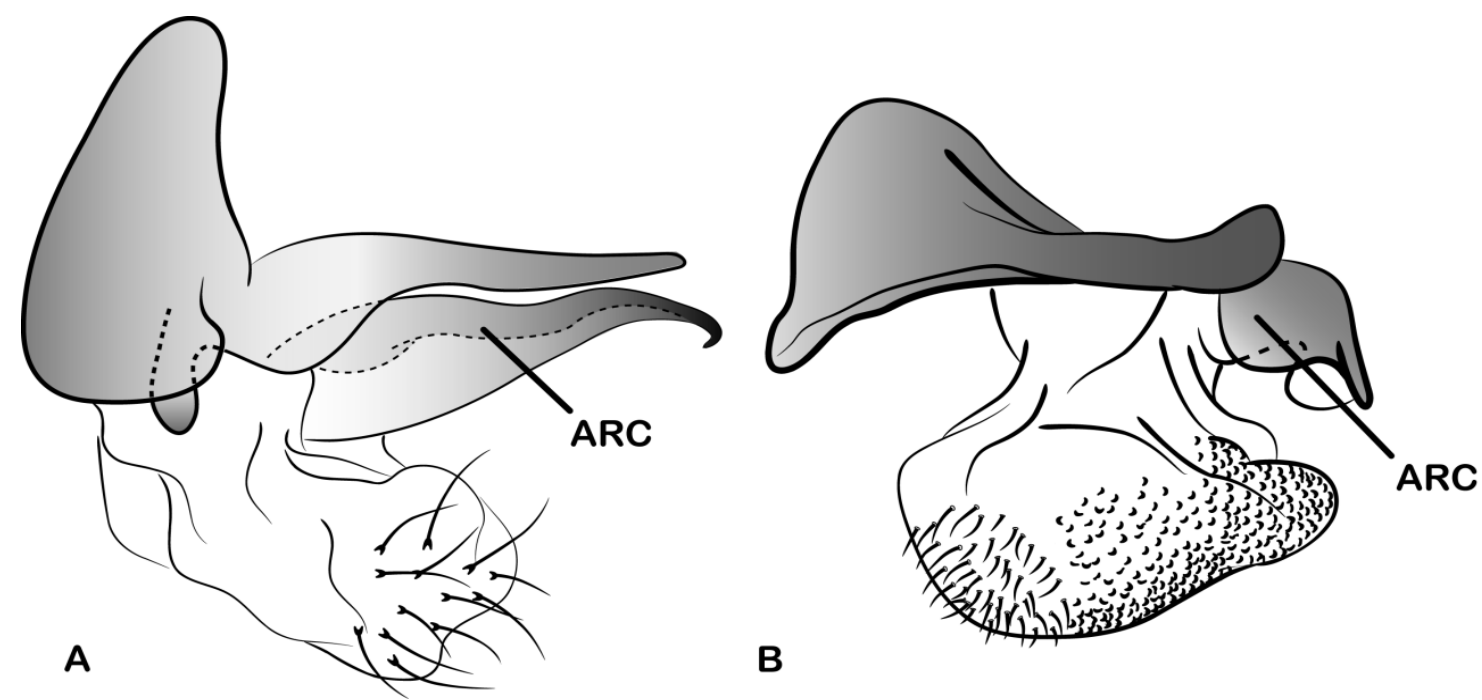

Figura 68. Vista lateral esquemática da genitália masculina de Ceraeochrysa Adams, 1982 (Chrysopidae: Chrysopinae). A) Arcesso maior que a largura do braço lateral do gonarco; B) Arcesso menor que a largura do braço lateral do gonarco. Arcesso (ARC).

Caráter 42. Relação entre a largura do ápice do arcesso e sua base (visão dorsal): (0) menor que 1; (1) maior ou igual a 1. IC: 0,50/IR: 0,80 (Fig. 69).

O ápice do arcesso mais largo que a base é uma sinapomorfia das espécies do grupo cincta (clado 22). Há, contudo, uma reversão em (C. montoyana $+C$. claveri), em que o arcesso possui o ápice mais estreito que sua base, o que lhe confere aspecto afunilado.

Caráter 43. Forma do arcesso (em vista lateral): (0) retilínio; (1) em forma de C. IC: 0,50/IR: 0,90 (Fig. 70).

$\mathrm{O}$ arcesso em forma de $\mathrm{C}$ surgiu independentemente duas vezes dentro de Ceraeochrysa: uma vez no clado 15 , ou seja, espécies do grupo everes $+C$. smithi, e no clado formado por $(C$. falcifera $+(C$. fairchildi $+(C$. angulata $+C$. defreitasi $)))$. 

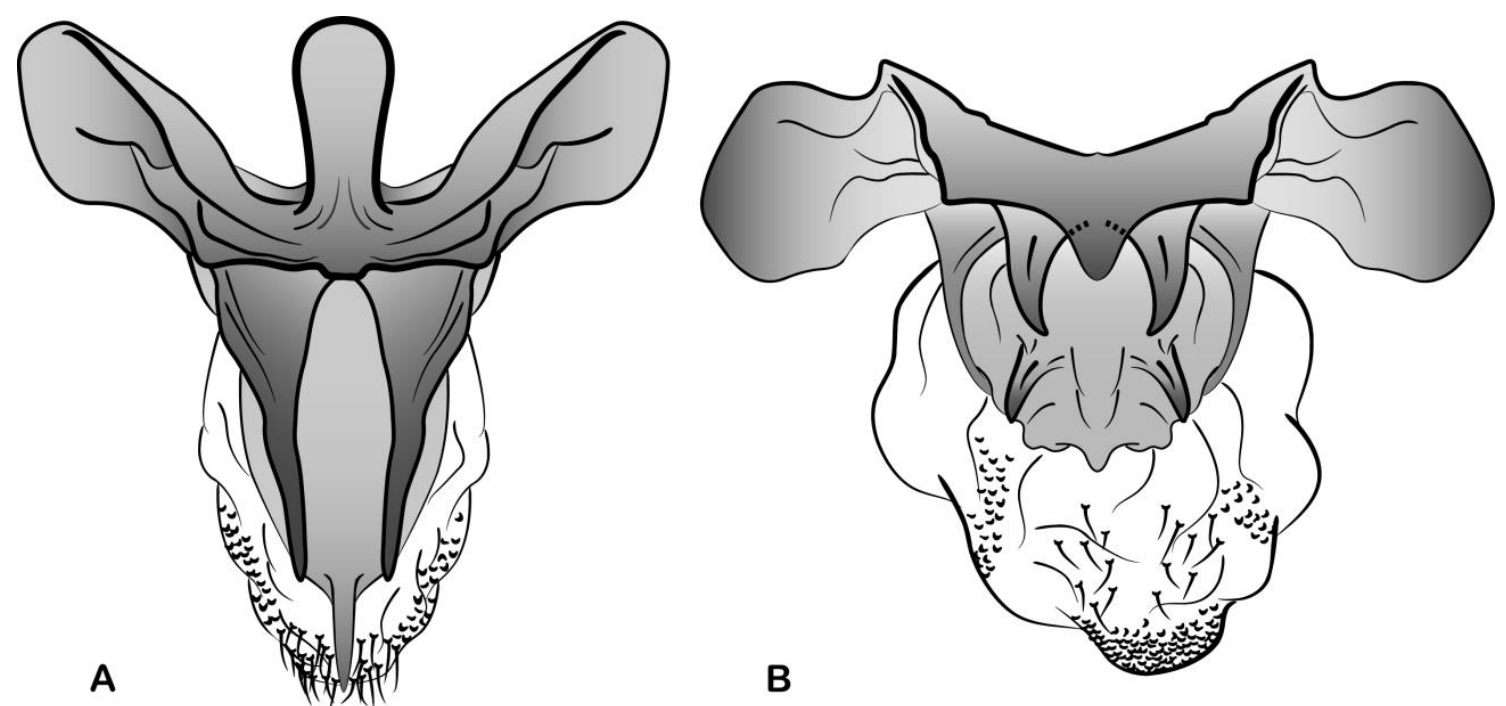

Figura 69. Vista dorsal esquemática da genitália masculina de Ceraeochrysa Adams, 1982 (Chrysopidae: Chrysopinae). A) Arcesso com a base mais larga que o seu ápice; B) Arcesso com o ápice mais largo que a base.

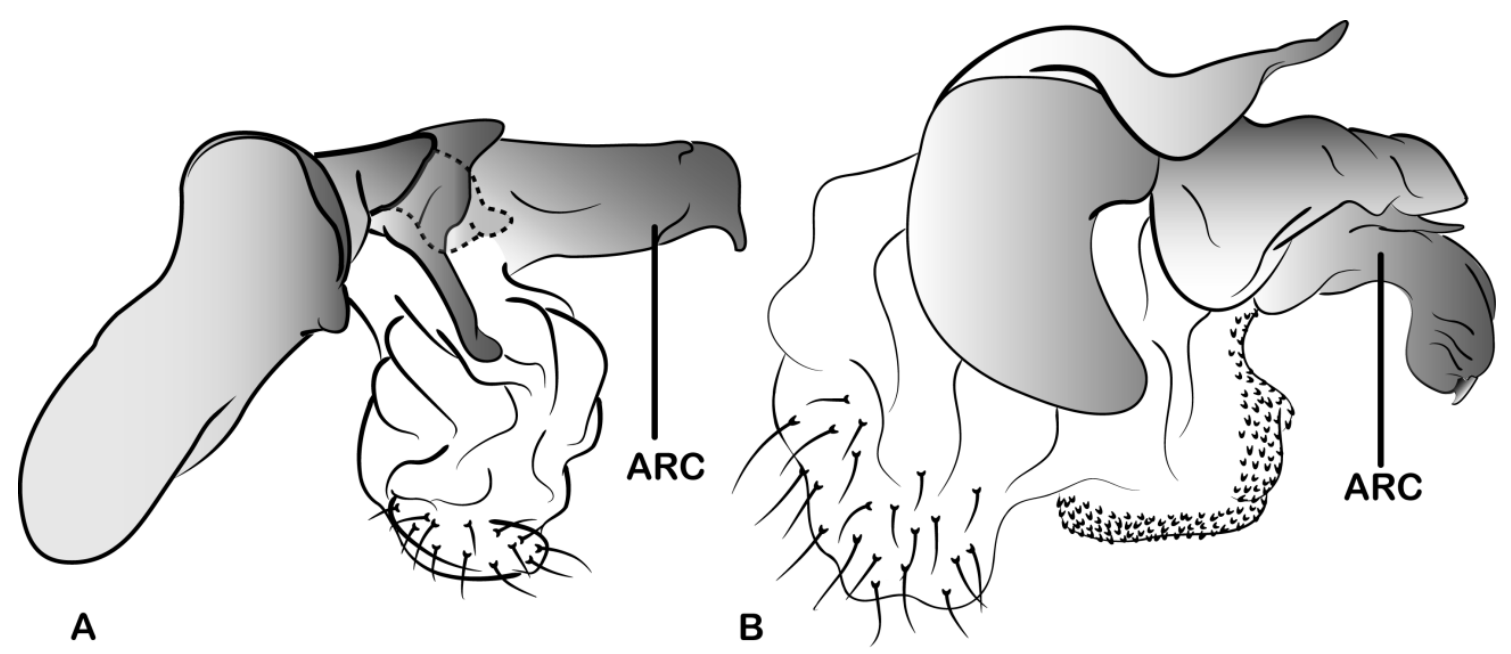

Figura 70. Vista lateral esquemática da genitália masculina de Ceraeochrysa Adams, 1982 (Chrysopidae: Chrysopinae). A) Arcesso retilínio; B) Arcesso em forma de C. Arcesso (ARC).

Caráter 44. Processos dorsais do arcesso: (0) ausente; (1) presente. IC: 0,11/IR: 0,69 (Fig. 71).

Os processos dorsais do arcesso surgiram independentemenete cinco vezes em Ceraeochrysa: clado (C. michaelmuris $+C$. tenuicornis); clado 14 , com uma reversão em $C$. squalidens; clado 23, com uma reversão em $C$. inbio; clado 25 , com uma reversão em $(C$. angulata + C. defreitasi); clado 30, com uma reversão em C. infausta (Banks, 1946). 


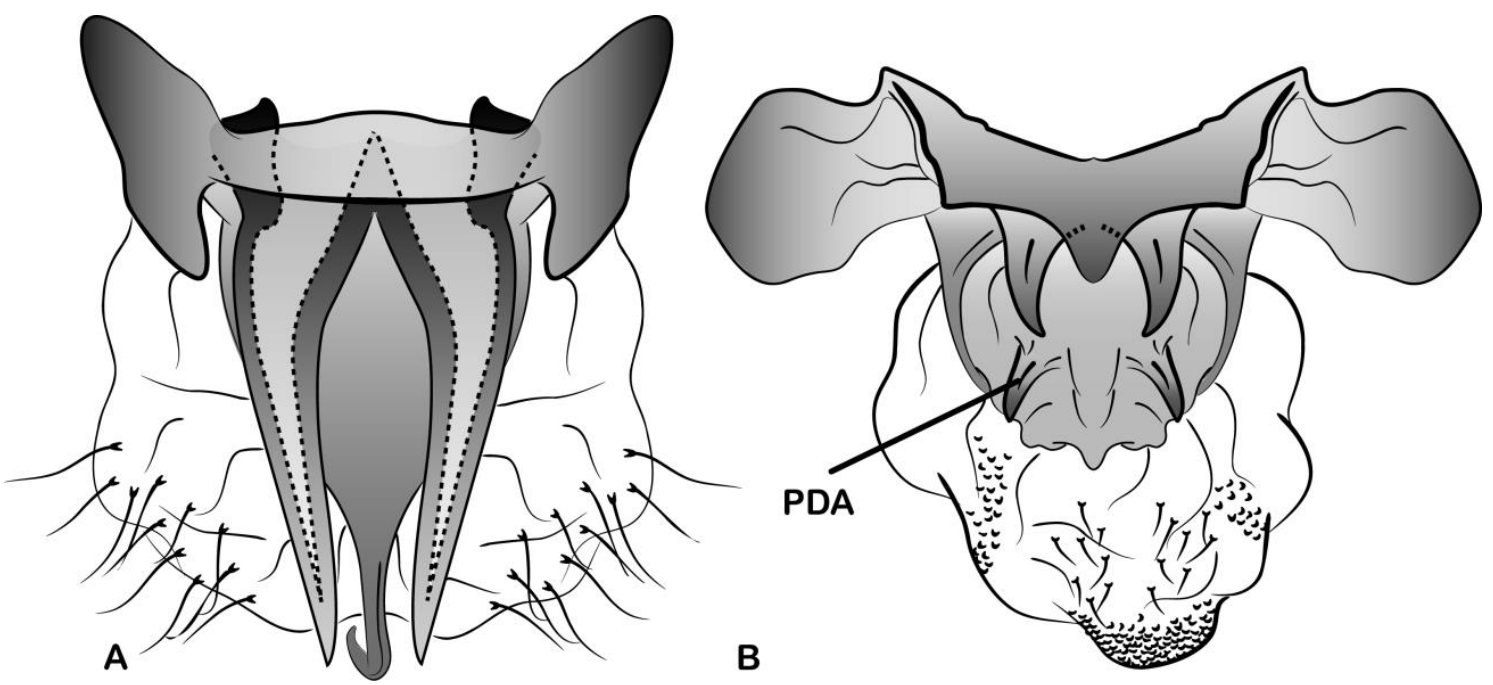

Figura 71. Vista dorsal esquemática da genitália masculina de Ceraeochrysa Adams, 1982 (Chrysopidae: Chrysopinae). A) Arcesso sem processos dorsais; B) Arcesso com processo dorsal. Processos dorsais do arcesso (PDA).

Caráter 45. Proximidade dos processos dorsais do arcesso: (0) juntos; (1) altamente separados. IC: 0,33/IR: 0,60 (Fig. 72).

Este caráter é contigente à presença dos processos dorsais do arcesso. Arcessos com processos dorsais juntos são considerados plesiomórficos. $\mathrm{O}$ estado 1 surgiu três vezes em Ceraeochrysa: C. falcifera; $C$. divaricata e no clado formado por $(C$. cornuta $+(C$. cincta + $(C$. belizensis $+(C$. inbio $+C$. discolor $))))$, embora $C$. inbio tenha perdido secundariamente os processos dorsais do arcesso.
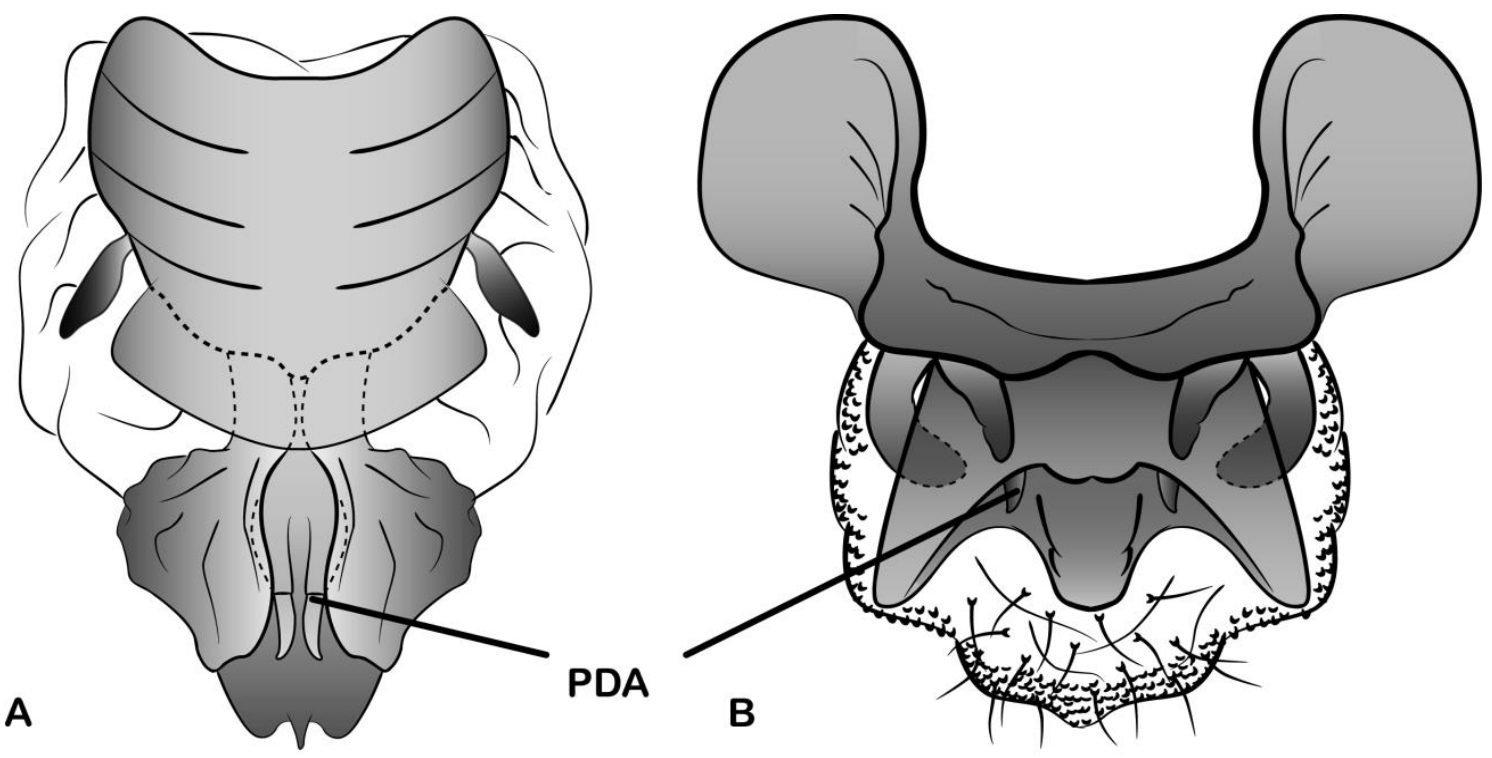

Figura 72. Vista dorsal esquemática da genitália masculina de Ceraeochrysa Adams, 1982 (Chrysopidae: Chrysopinae), com destaque para o arcesso. A) Processos dorsais do arcesso juntos; B) Processos dorsais do arcesso separados. Processos dorsais do arcesso (PDA). 
Caráter 46. Localização dos processos dorsais do arcesso: (0) região basal do arcesso; (1) região apical do arcesso. IC: 0,33/IR: 0,83 (Fig. 73).

Este caráter é contigente à presença dos processos dorsais do arcesso, e para sua codificação dividiu-se o arcesso em uma região basal e outra apical. Processos dorsais localizados na região apical do arcesso surgiram em C. acmon e nos clados 23 e 30.

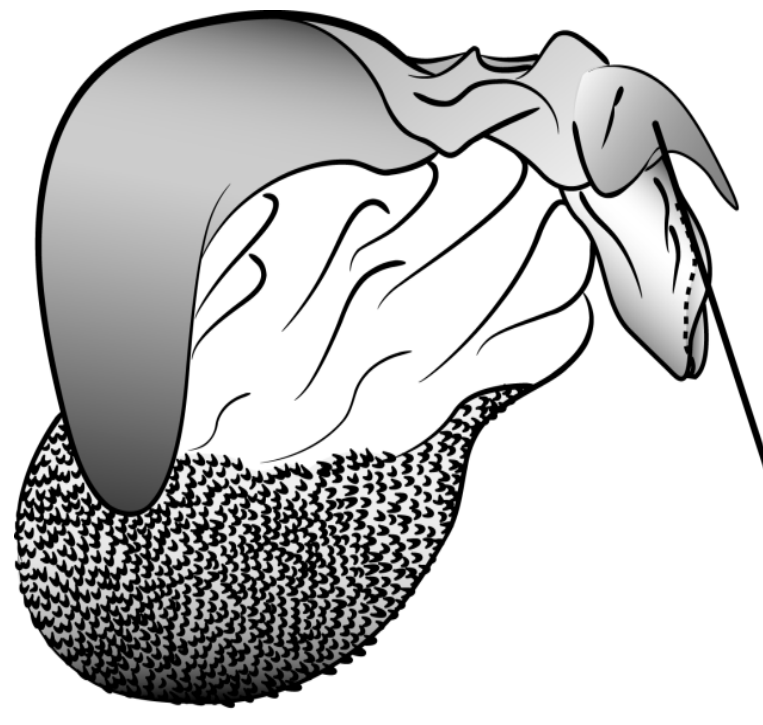

A

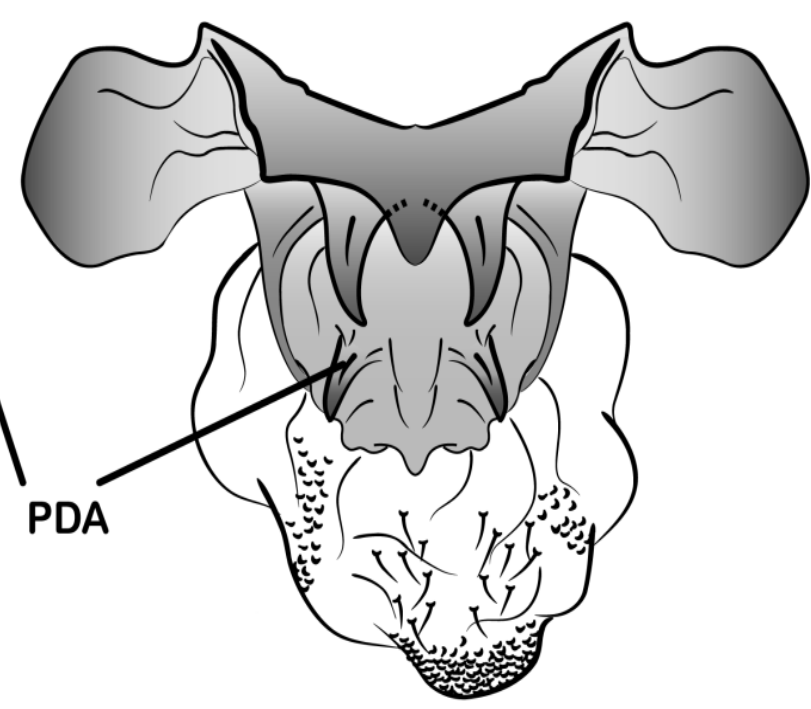

B

Figura 73. Vista esquemática da genitália masculina de Ceraeochrysa Adams, 1982 (Chrysopidae: Chrysopinae), com destaque para o arcesso. A) Arcesso com processos dorsais basais, vista lateral; B) Arcesso com processos dorsais apicais, vista dorsal. Processos dorsais do arcesso (PDA).

Caráter 47. Ápice do arcesso: (0) não dividido; (1) dividido. IC: 0,50/IR: 0,93 (Fig. 74).

O arcesso não dividido é um estado plesiomórfico encontrado em Chrysopidae. Em Ceraeochrysa, o arcesso dividido apicalmente surgiu duas vezes, nos clados 15 e 30 . Esse caráter também foi utilizado por Freitas et al., (2009) porém, ele apresentava quatro estados que foram fundidos em dois no presente trabalho.

Caráter 48. Placa apical do arcesso. (0) rombuda; (1) achatada lateralmente. IC: 1/IR: 1 (Fig. 75).

A placa apical do arcesso é achatada lateralmente somente nas espécies do grupo lineaticornis (clado 30) e é sinapomorfia desse clado 

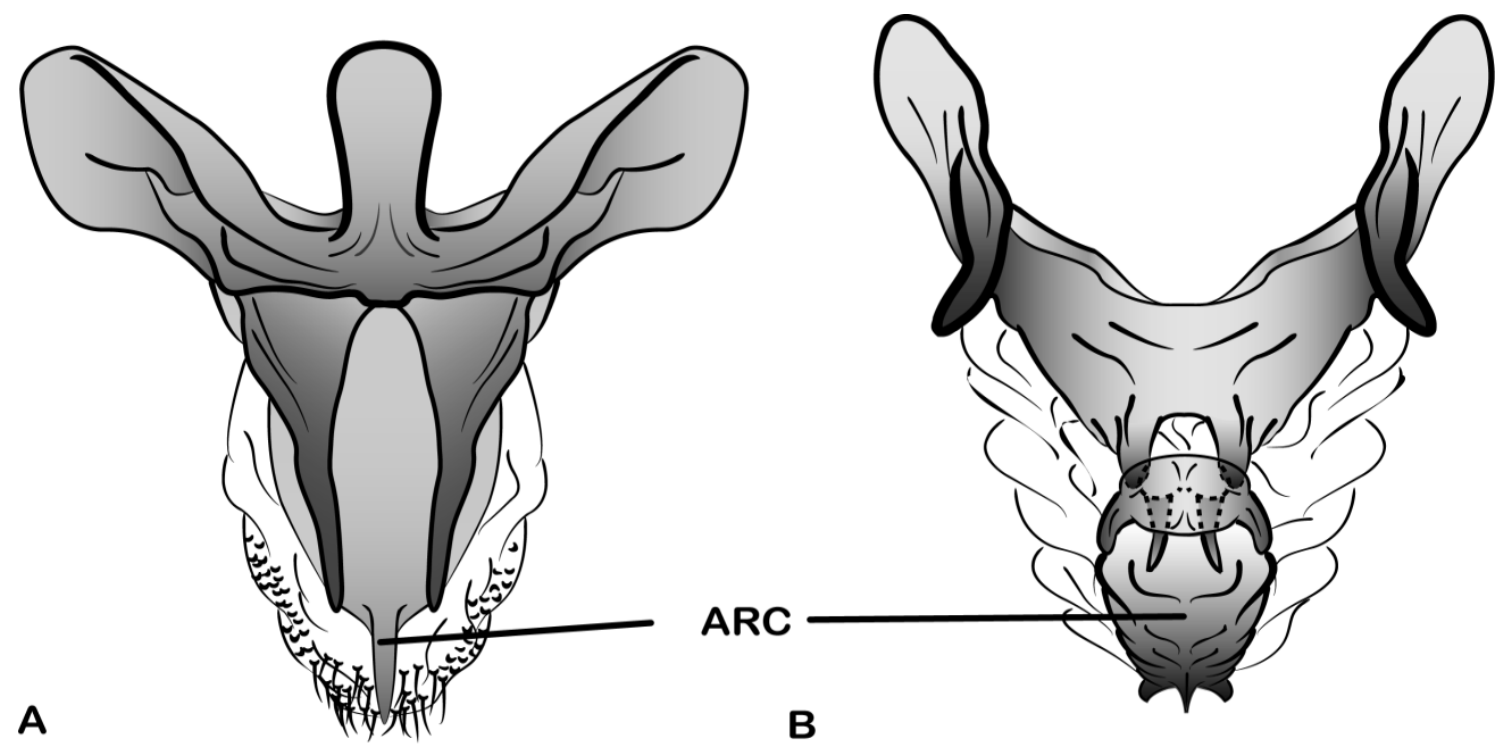

Figura 74. Vista dorsal esquemática da genitália masculina de Ceraeochrysa Adams, 1982 (Chrysopidae: Chrysopinae), com destaque para o arcesso. A) Ápice do arcesso não dividido; B) Ápice do arcesso dividido. Arcesso (ARC).
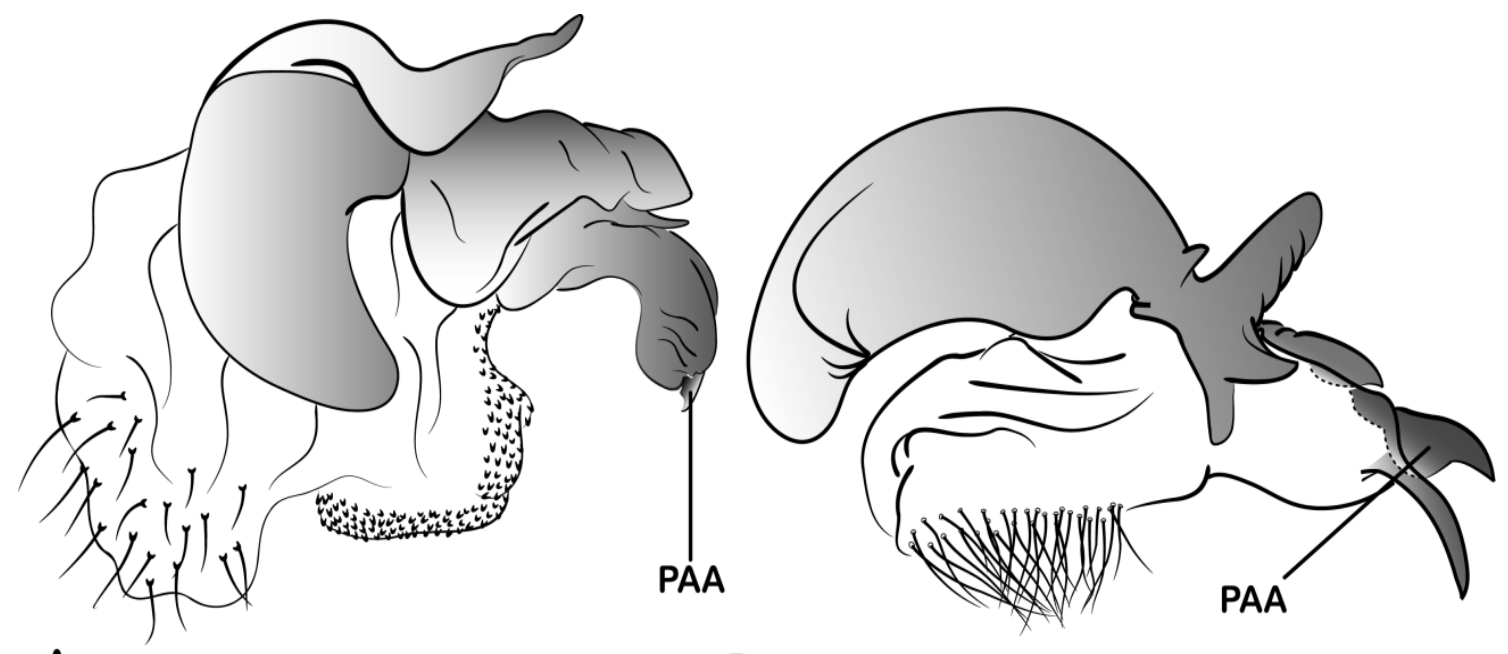

A

B

Figura 75. Vista lateral esquemática da genitália masculina de Ceraeochrysa Adams, 1982 (Chrysopidae: Chrysopinae), com destaque para o arcesso. A) Placa apical do arcesso rombuda; B) Placa apical do arcesso achatada lateralmente. Placa apical do arcesso (PAA).

\section{Caráter 49. Lobo apical do arcesso. (0) largos; (1) estreitos. IC: 1/IR: 1 (Fig. 76).}

A presença de lobos apicais laterais estreitos no ercesso é sinapomorfia do grupo de espécies lineaticornis, referenciado como clado 31, C. infausta apresenta somente um lobo apical estreito, então, este caráter foi codificado como dúvida para esta espécie. 


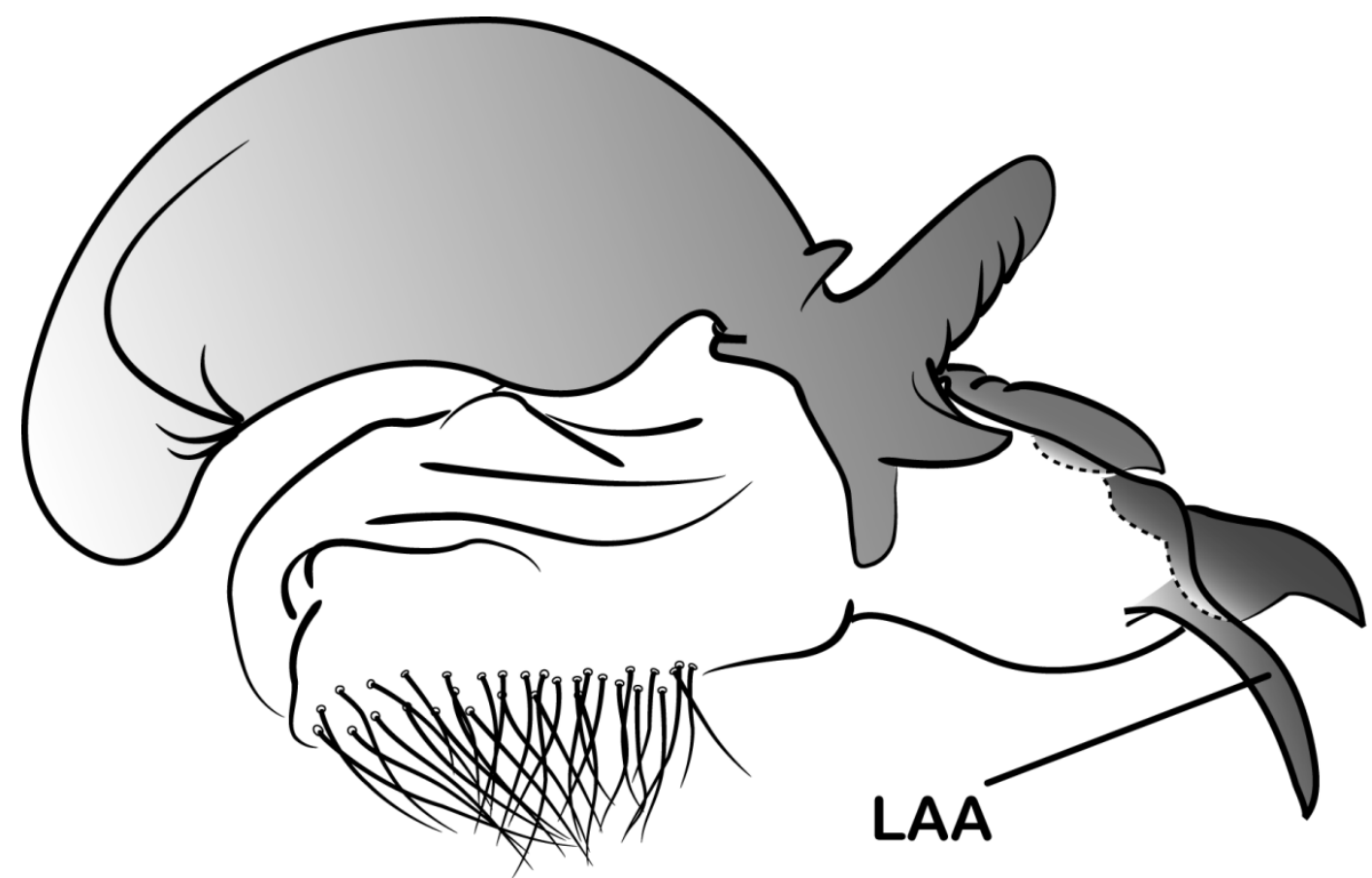

Figura 76. Vista lateral esquemática da genitália masculina de Ceraeochrysa Adams, 1982 (Chrysopidae: Chrysopinae), com destaque para o lobo apical estreito do arcesso. Lobo apical do arcesso (LAA).

Caráter 50. Gonapse: (0) ausente; (1) presente. IC: 0,50/IR: 0,50 (Fig. 77).

A presença de gonapse foi considerada uma sinapomorfia de Ceraeochrysa por Freitas et al. (2009), uma vez que nenhum dos gêneros utilizados em seu estudo como grupos externos tinha esta estrutura; no entanto, na análise aqui realizada foi adicionado Criptochrysa como grupo-externo, gênero que também possui gonapse. Dessa maneira, a presença desta estrutura é considerada sinapomorfia de (Ceraochrysa + Criptochrysa).
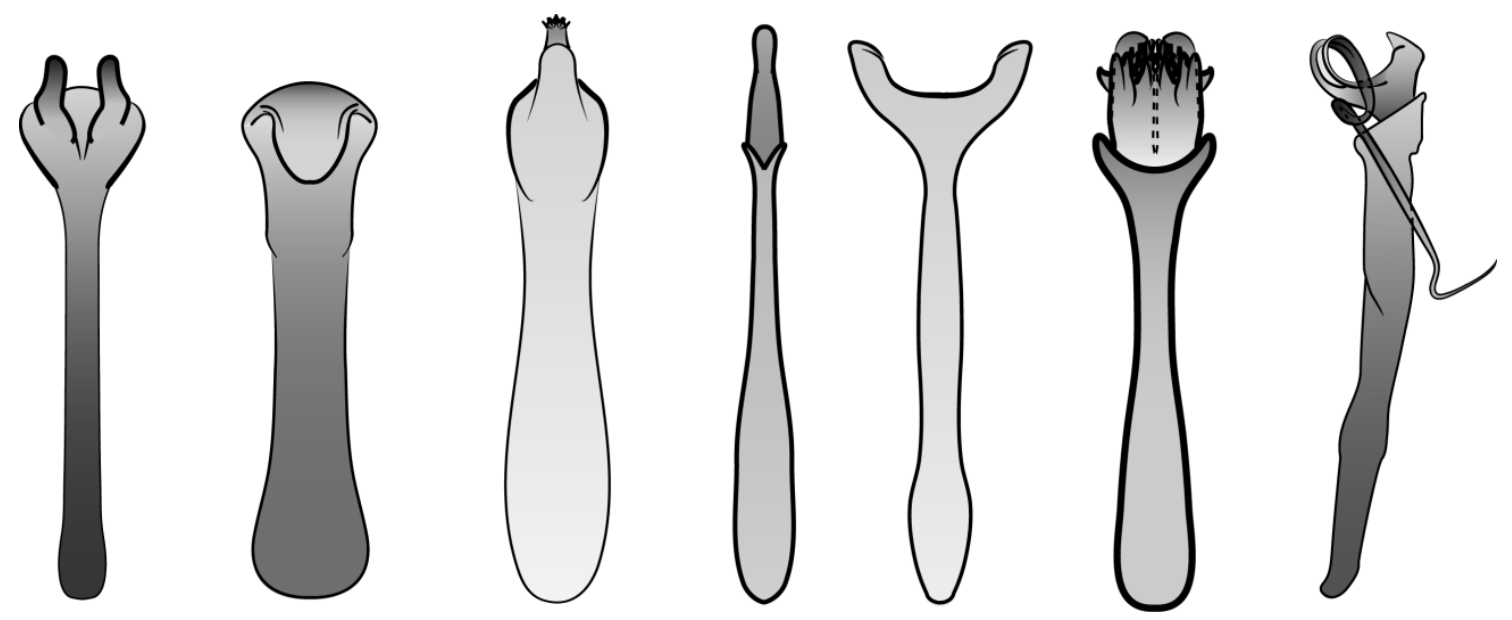

Figura 77. Gonapses de Ceraeochrysa Adams, 1982 (Chrysopidae: Chrysopinae), vista dorsal. 


\subsubsection{Relações filogenéticas entre as espécies de Ceraeochrysa Adams, 1982 (Chrysopidae: Chrysopinae).}

A topologia resultante desta análise apresentou grandes diferenças quando comparada à topologia de Freitas et al. (2009) (Fig. 78), contudo, algumas semelhanças foram notadas entre os dois estudos. Ceraeochrysa foi recuperada aqui como gênero irmão de Criptochrysa Freitas \& Penny, 2001, com a presença da gonapse como sinapomorfia do clado (Criptochrysa + Ceraeochrysa); em Freitas et al. (2009) (Chrysopodes Navás, 1913 + Chrysoperla Steinmann, 1964) foi o clado recuperado como irmão de Ceraeochrysa, e a presença da gonapse foi considerada sinapomorfia do gênero. Winterton \& Freitas (2006) recuperaram Ceraeochrysa como gênero irmão de Chrysoperla.

Nos dois estudos Ceraeochrysa placita e Ceraeochrysa intacta, nomeada erroneamente por Freitas et al. (2009) como Ceraeochrysa chiricahuae, foram recuperadas como irmãs das demais espécies de Ceraeochrysa, porém, em Freitas et al. (2009) C. placita foi recuperada como irmã do clado ((C. intacta + Ceraeochrysa pseudovaricosa Penny, 1998) + (demais espécies de Ceraeochrysa); neste estudo C. placita e $C$. intacta formaram um clado irmão das demais espécies de Ceraeochrysa. C. pseudovaricosa foi transferida por Sosa \& Freitas (2012) para o gênero Titanochrysa Sosa \& Freitas, 2012, então não foi utilizada na análise aqui realizada.

Com grande número de politomias na topologia, as relações internas do gênero Ceraeochrysa não apresentaram grande resolução no estudo de Freitas et al. (2009), provavelmente isto ocorreu devido à inserção de espécies cujos machos são desconhecidos na análise principal. Contudo, mesmo com grande número de politomias, alguns pequenos clados foram recuperados em ambos estudos: $(C$. angulata $+C$. defreitasi $) ;(C$. discolor $+C$. inbio $) \mathrm{e}$ (C. claveri + C. montoyana $)$. O gênero foi dividido basicamente em dois grupos de espécies nos dois estudos realizados, porém, as espécies recuperadas em cada grupo foram diferentes quando as duas topologias são comparadas.

Alguns grupos de espécies deste estudo foram parcialmente recuperado no estudo de Freitas et al. (2009). As espécies $C$. curvabilis, $C$. derospogon, $C$. digitata e $C$. berlandi recuperadas como parte do grupo de espécies lineaticornis, foram, recuperadas em um clado com $C$. indicata e $C$. panamensis. O mesmo ocorreu com $C$. costaricensis, $C$. dislepis, $C$. everes e C. squamma - espécies integrantes do grupo everes - que foram recuperadas no estudo de Freitas et al. (2009) em uma politomia junto com C. dolichosvela. Também é possível observar que $C$. claveri, $C$. montoyana e $C$. cincta recuperadas como parte do grupo cincta, formam um clado em conjunto com C. acmon e C. fiegrigi (Navás, 1913) no estudo de Freitas et al. (2009). 


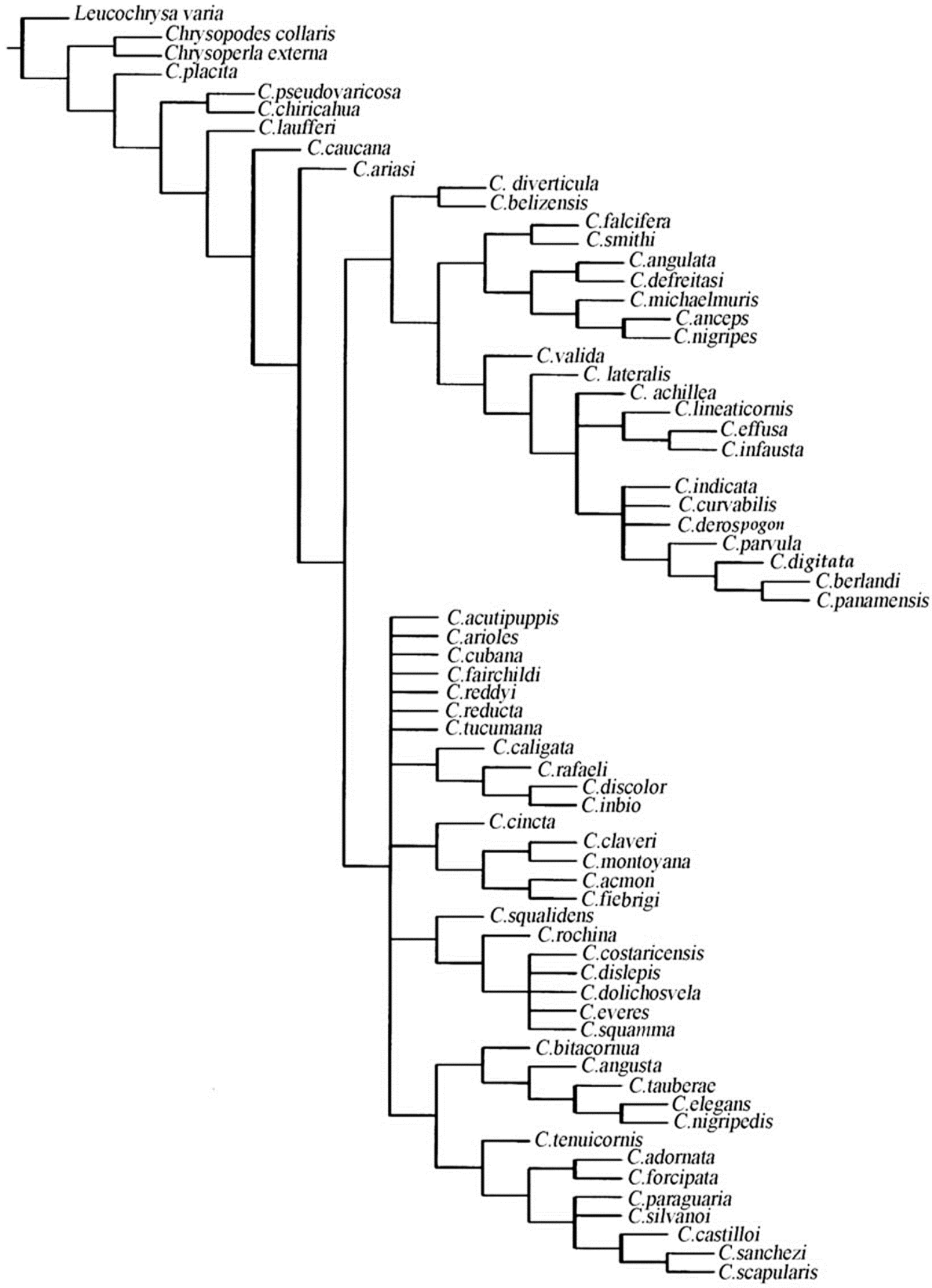

Figura 78. Árvore mais parcimoniosa da análise de Ceraeochrysa Adams, 1982 (Chrysopidae: Chrysopinae) (Freitas et al., 2009). 
Posição de (Ceraeochrysa placita (Banks, 1908) + Ceraeochrysa intacta (Navás, 1912)) dentro de Ceraeochrysa Adams, 1982 (Chrysopidae: Chrysopinae).

$\mathrm{Na}$ análise filogenética aqui realizada, o clado (Ceraeochrysa placita (Banks, 1908) + Ceraeochrysa intacta (Navás, 1912)) foi recuperado como grupo-irmão das demais espécies de Ceraeochrysa.

Estas duas espécies apresentaram diversas condições não encontradas nas demais espécies de Ceraeochrysa: adultos tem a fronte com manchas escuras; a fêmea dessas duas espécies tem espermateca no formato conhecido como "pill-box", condição plesiomórfica compartilhada com gêneros de outras subfamílias de Chrysopidae. O restante das espécies de Ceraeochrysa tem espermateca alongada, característica considerada anteriormente, como sinapomorfia de Ceraeochrysa.

Além do formato da espermateca divergir da condição no restante de Ceraeochrysa, a espermateca em $C$. placita e $C$. intacta se conecta com a bursa copulatrix pelo vellum e um ducto bursal curto, diferentemente do que é observado nas demais espécies do gênero, onde as espermatecas se conectam à bursa copulatrix por uma fenda alongada. As fêmeas de $C$. intacta e $C$. placita também possuem têm pré-genitália, o que não é encontrado nas fêmeas das demais espécies de Ceraeochrysa.

Apesar das diferenças entre as fêmeas, os machos de $C$. placita e $C$. intacta compartilham duas características importantes com o restante de Ceraeochrysa: a presença de gonapse e gonocorno. No entanto, todas as espécies do gênero apresentam gonossaco com gonosetas, as quais são ausentes em C. placita e C. intacta.

O número de caracteres de adultos e larvas de $C$. placita e de $C$. intacta que divergem da condição do restante do gênero justifica que essas duas espécies possam ser incluídas em um táxon genérico separado de Ceraeochrysa. Tauber \& Flint (2010) afirmaram que as discordâncias entre essas duas espécies e o restante de Ceraeochrysa, implicava mantê-las temporariamente no gênero e aceitá-lo como parafilético. Com esta análise fica claro que essa posição é parcialmente equivocada, pois, o gênero forma um grupo monofilético com ou sem (C. placita $+C$. intacta), mesmo que de fato há diferenças evidentes entre esse clado e o restante do gênero.

O restante das espécies de Ceraeochrysa, excluídas C. placita e C. intacta, formam um clado sustentado pela ausência de mancha escura no palpo maxilar (caráter 1), ausência de mancha negra na gena (caráter 2) e no clípeo (caráter 3), presença do ramo ventral do apódema dorsal do ápice abdominal masculino (caráter 28) e presença de espermateca alongada (caráter 22). Isso concorda com a descrição do gênero por Brooks \& Barnard 
(1990), os quais citaram que todas as espécies de Ceraeochrysa apresentam espermateca de forma alongada.

Os resultados obtidos - em relação ao clado $(C$. placita $+C$. intacta $)$ - foram semelhantes aos observados por Freitas et al., (2009). Na topologia resultante no trabalho realizados por tais autores a espécie $C$. placita foi recuperada como irmã do restante das espécies de Ceraeochrysa, já a espécie $C$. intacta - nomeada como C. chiricahuae por Freitas et al., (2009) - junto com Ceraeochrysa pseudovaricosa formaram um clado irmão do restante das espécies de Ceraeochrysa, com exceção de $C$. placita. O clado (C. chiricahuae + C. pseudovaricosa) apresentou como principal caráter compartilhado a fronte manchada e espermateca no formato "pill-box", considerados estados plesiomórficos, que são compartilhados com outros gêneros.

\section{Dois grandes clados em Ceraeochrysa Adams, 1982 (Chrysopidae: Chrysopinae).}

Com exceção de Ceraeochrysa placita, Ceraeochrysa intacta, Ceraeochrysa pittieri, Ceraeochrysa michaelmuris e Ceraeochrysa tenuicornis, as espécies de Ceraeochrysa formaram dois grandes clados na topologia obtida.

\section{Clado 8 (Fig. 27) "paraguaria".}

O primeiro grande subgrupo de espécies nomeado clado 8, sustentado pela ausência de manchas no escapo (caráter 6), é formado por Ceraeochrysa paraguaria + clado 9. Este último clado tem duas características em comum, nervuras anais 1 e 2 da asa anterior não se encontram (caráter 13) e a célula gradiforme 1 da asa anterior é menor que a metade do comprimento da primeira gradiforme externa até a base da terceira nervura transversal radial (caráter 18).

O clado 9, por sua vez, possui Ceraeochrysa nigripes como espécie irmã do clado 10, que é formado por 15 espécies, as quais não têm nenhuma sinapomorfia. O clado 10 tem dois clados irmãos. Um deles é formado por (Ceraeochrysa angusta + Ceraeochrysa tauberae), que apresentam grande semelhança na morfologia externa e de genitália, não possuem manchas no escapo e no pedicelo; flagelômeros são claros; pronoto com somente um par de manchas circulares; asas anteriores têm mancha na célula cubital distal (caráter 16); nervuras gradiformes negras não paralelas. Os machos das duas espécies têm tergito IX + ectoprocto triangular; apódema dorsal abdominal masculino bifurcado em Y, com um ramo ventral; arcesso estreito apicalmente, sem processos; gonarco espesso; gonocornos pequenos e gonossaco com grande quantidade de cerdas. A diferença principal entre as duas espécies é a 
espessura dos braços laterais do gonarco, $C$. angusta possui ele muito espesso quando comparado ao braço lateral do gonarco de C. tauberae.

O segundo subgrupo do clado 10 é o clado 11, cuja principal característica é a presença de manchas contínuas na lateral do pronoto (caráter 9). Todas as espécies têm manchas vermelhas em forma de listra, exceto Ceraeochrysa costaricensis, que tem uma mancha circular em cada lado do pronoto. O clado 11 é formado por Ceraeochrysa reddyi Adams \& Penny, 1987 + clado 12, o qual é composto por espécies que têm manchas no escapo (caráter 6) e entoprocesso (caráter 34), tais características são que consideradas reversões não são observadas em $C$. reddyi.

Dentro do clado 12 a espécie Ceraeochrysa valida é irmã das outras espécies (clado 13) e a característica que separa este grupo de espécies de $C$. valida é a nervura transversal basal costal localizada apicalmente à quarta nervura transversal costal (caráter 12), estado considerado plesiomórfico para Chrysopini. Este caráter apresentou reversão no clado 13, o qual é dividido em dois grupos: Ceraeochrysa cubana + Ceraeochrysa scapularis e o clado 14 (Ceraeochrysa acmon $+($ Ceraeochrysa smithi + clado 16) $)$.

As principais características que separam C. cubana + C. scapularis das demais espécies do clado 13 é a presença do esternito VIII + IX masculino bifurcado (caráter 27), sinapomorfia das duas espécies, e a ausência do ramo ventral do apódema dorsal abdominal masculino. As duas espécies têm ainda a gonapse não dividida, com o ápice rombudo e sem dentes apicais, bem como a espermateca curta. C. cubana têm grandes espiráculos no abdômen masculino que não são observados em nenhuma outra espécie de Ceraeochrysa.

No clado 14, que tem como principal característica a presença do processo dorsal do arcesso (caráter 44), C. acmon é considerada espécie irmã do clado 15 (C. smithi + clado 16 (grupo de espécie everes)), que têm como características compartilhadas o arcesso em forma de C (caráter 43) e o ápice do arcesso dividido (caráter 47). O clado 16 será discutido mais adiante.

\section{Clado 19 (Fig. 27) "forcipata".}

Esse clado agrupa a maioria das espécies de Ceraeochrysa e é sustentado por manchas em forma de listra contínua no pronoto (caráter 9), uma reversão. Ele é composto por Ceraeochrysa forcipata e um grande grupo de espécies reunidas no clado 20, o qual tem como sinapomorfias a espermateca alongada em forma de U (caráter 23) e entoprocesso com comprimento maior ou igual ao gonocorno (caráter 35). Dois grupos compõem o clado 20 . O primeiro deles, referenciado como clado 21, é formado por (Ceraeochrysa elegans + Ceraeochrysa sanchezi) e um grupo de espécies conhecido como grupo cincta, discutido 
adiante. $C$. elegans e $C$. sanchezi apresentam manchas no mesotórax (caráter 10) e forquilhas marginais negras da asa anterior (caráter 15), considerada uma reversão.

O outro subgrupo é o clado 24 , que tem como características principais a presença de uma mancha negra em forma de anel no pedicelo (caráter 8) e o arcesso mais curto que os braços laterais do gonarco (caráter 41). Este clado é dividido em dois grupos menores: os clados 25 e 27; o primeiro é composto por seis espécies (Ceraeochrysa ariasi, Ceraeochrysa panamensis, Ceraeochrysa falcifera, Ceraeochrysa fairchildi, Ceraeochrysa angulata e Ceraeochrysa defreitasi) e é sustentado pela presença do processo do arcesso (caráter 44), presentes na maioria das espécies deste clado, exceto em $C$. angulata e $C$. defreitasi. Além disso, a maioria das espécies não tem mancha escura no escapo (caráter 6), exceto $C$. panamensis, que apresenta uma reversão deste caráter e tem mancha em forma de listra na região dorsal do escapo.

C. panamensis $+(C$. falcifera $+(C$. fairchildi,$+(C$. angulata $+C$. defreitasi $)))$ não apresenta entoprocesso (caráter 34), reversão que separa este grupo de $C$. ariasi. Por sua vez, o clado $(C$. falcifera $+(C$. fairchildi,$+(C$. angulata $+C$. defreitasi $)))$ tem o arcesso em forma de C (caráter 43) e a primeira nervura intercubital da asa anterior sem manchas negras (caráter 15), o que corresponde a uma reversão, enquanto que (C. fairchildi, $+(C$. angulata $+C$. defreitasi)) têm a projeção ventral do tergito IX (caráter 26).

C. angulata e $C$. defreitasi são muito semelhantes e compartilham várias características: dois pares de pontos vermelhos no pronoto; gonapse com um pequeno lobo lateral e ápice estreito (Freitas et al., (2009); processo ventral do gonocorno (caráter 39) pontiagudo; arcesso com ápice bifurcado; escapo sem manchas; nervuras gradiformes da asa anterior convergentes (caráter 11) e nervuras gradiformes da asa posterior verdes (caráter 21). A principal característica que separa tais espécies é a presença de mancha na célula cubital distal (caráter 16) em $C$. angulata e a ausência desta mancha em $C$. defreitasi.

O segundo grupo que compõem o clado 24 , referenciado como clado 27 , é formado por 12 espécies, não apresenta sinapomorfias e é sustentado por reversões. Ceraeochrysa nigripes é irmã das demais espécies, que juntas formam o clado 28. A primeira não possui manchas negras no pedicelo (caráter 7), enquanto que as demais têm mancha negra em forma de anel em torno do pedicelo (caráter 8).

No clado 28, Ceraeochrysa bitacornua é irmã das demais espécies e tem gonossaco com gonosetas esparsas, ao contrário do que é observado no clado 29, formado pelas espécies restantes, que apresentam gonossaco com dois grupos separados de gonosetas (caráter 31). Além disso, C. bitacornua tem a condição plesiomórfica do caráter 44 , ou seja, seu arcesso 
não tem processos, estrutura presente na maioria das espécies do clado 29 , com exceção de $C$. infausta.

Ceraeochrysa tucumana é irmã do clado 30, que apresenta como principal característica o ápice do arcesso dividido (caráter 47). Nesse clado, Ceraeochrysa divaricata Freitas \& Penny, 2009 é irmã do grupo de espécies conhecido como grupo lineaticornis, referido aqui como clado 31 e discutido adiante.

\section{Grupos de espécies de Ceraeochrysa Adams, 1982 (Chrysopidae: Chrysopinae).}

Na literatura há referência (Adams, 1982; Freitas et al., 2009; Sosa \& Freitas, 2010 e 2011) para três grupos de espécies em Ceraeochrysa: everes, cincta e lineaticornis. Na análise, esses três grupos foram recuperados como monofiléticos e, devido à sua importância, serão discutidos separadamente.

\section{* Grupo everes (Fig. 79).}

O grupo everes - clado 16- é formado por sete espécies: Ceraeochrysa dislepis, Ceraeochrysa melanopaeira, Ceraeochrysa everes, Ceraeochrysa squamma, Ceraeochrysa squalidens, Ceraeochrysa costaricensis e Ceraeochrysa torresi, que têm grandes semelhanças entre si, principalmente em relação à genitália masculina. Este clado têm duas sinapomorfias: presença da placa dorsal plana do gonarcus (caráter 32) e os gonocornos muito espessos (caráter 37) (Fig. 79) e, apresenta o comprimento do gonocorno maior que a largura do braço lateral do gonarco (caráter 38), bem como a dilatação final do ducto espermatecal (caráter 24). C. dislepis é irmã das demais espécies do grupo, têm a espermateca alongada sem forma definida, enquanto que as demais espécies apresentam espermateca alongada em forma de $\mathbf{J}$ (caráter 23) e apresenta as forquilhas marginais esverdeadas na asa anterior (caráter 15).

$C$. melanopaeira é irmã do clado que inclui $C$. everes, $C$. squamma, $C$. squalidens, $C$. costaricensis e C. torresi, e apresenta como diferença o clípeo com mancha escura (caráter 3) e nervuras gradiformes da asa anterior verdes (caráter 21), que são reversões. C. squamma + (C. squalidens $+(C$. costaricensis $+C$. torresi $))$ têm a projeção ventral no tergito IX + ectoprocto (caráter 26) e o comprimento do arcesso menor que a largura do braço lateral do gonarco (caráter 41).

C. squamma têm reversão no caráter 17 , ou seja, apresenta nervuras gradiformes verdes na asa anterior, que são negras nas outras três espécies do clado. $C$. squalidens $+(C$. costaricensis + C. torresi) apresentam o pedicelo sem manchas negras (caráter 7) e gradiformes da asa anterior não paralelas (caráter 11). 
C. squalidens apresenta duas reversões: forquilhas marginais da asa anterior negras (caráter 15) e arcesso sem processos dorsais (caráter 44), características não observadas em $C$. costaricensis $+C$. torresi, que podem ser diferenciadas pela primeira nervura transversal intercubital da asa anterior, a qual é negra em $C$. costaricensis, bem como suas nervuras gradiformes da asa posterior, que são verdes.

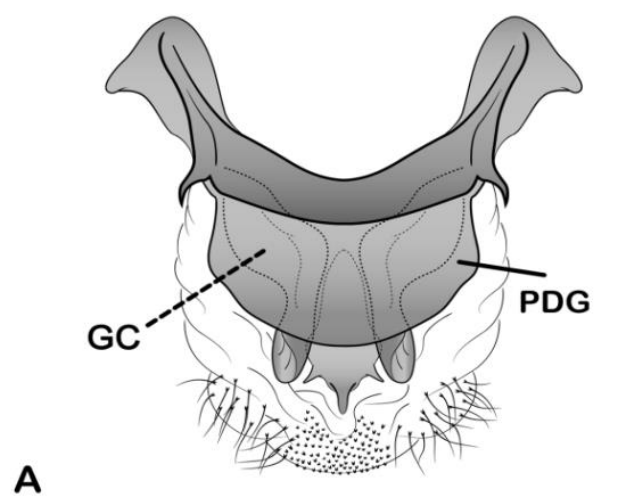

A

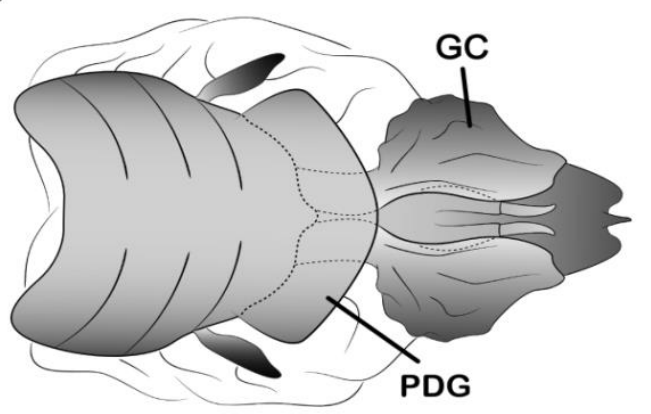

C

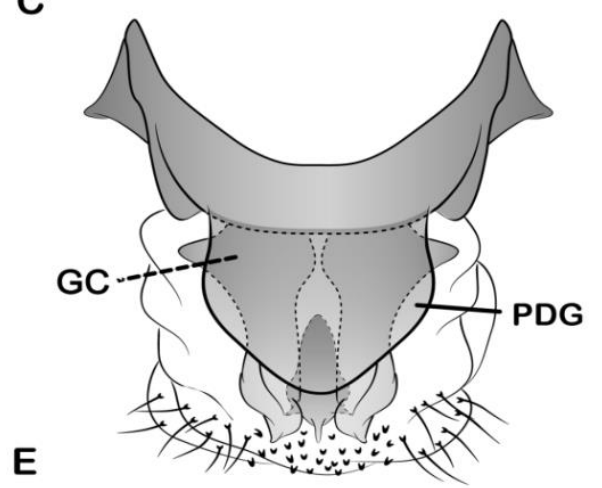

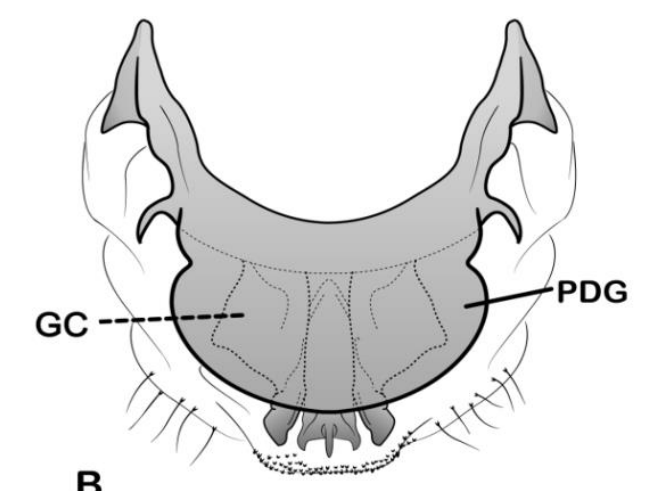

B

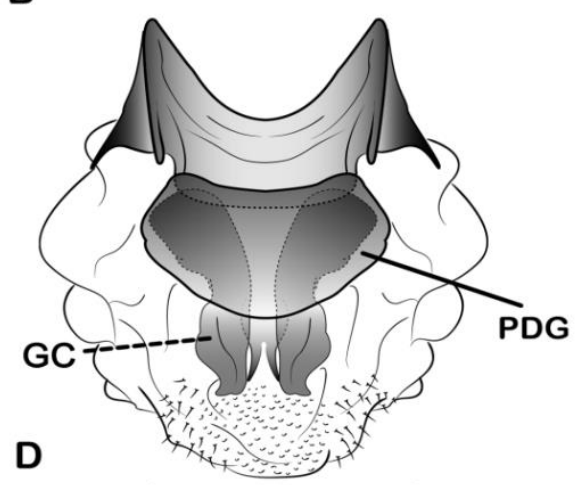

D

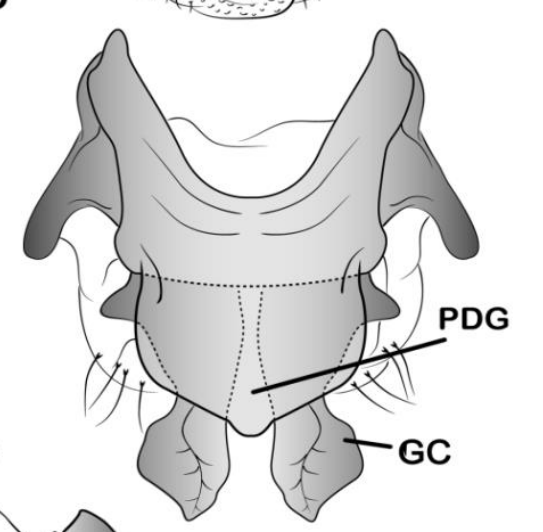

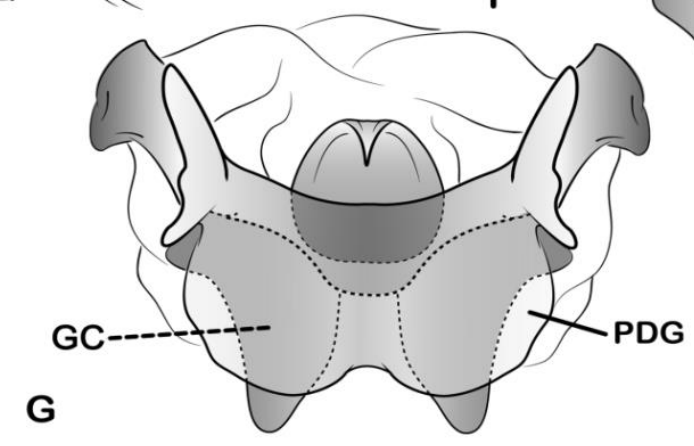

$0,1 \mathrm{~mm}$

Figura 79. Genitálias masculinas de Ceraeochrysa Adams, 1982 (Chrysopidae: Chrysopinae), grupo everes, vista dorsal. A) C. dislepis Freitas \& Penny, 2001; B) C. everes (Banks, 1920); C) C. melanopaeira Sosa \& Freitas, 2010; D) C. squamma Freitas \& Penny, 2001; E) C. costaricensis Penny, 1997; F) C. torresi Sosa \& Freitas, 2010; G) C. squalidens Adams \& Penny, [1987]. Gonocorno (GC); Placa dorsal do gonarco (PDG). 


\section{* Grupo cincta (Figs. 80-82).}

Esse grupo corresponde ao clado 22, é formado por oito espécies-Ceraeochrysa arioles, Ceraeochrysa claveri, Ceraeochrysa montoyana, Ceraeochrysa cornuta, Ceraeochrysa cincta, Ceraeochrysa belizensis, Ceraeochrysa discolor e Ceraeochrysa inbio - e, apresenta como sinapomorfia a projeção ventral do apódema dorsal abdominal em forma de gancho (caráter 29) (Fig. 80). Todas as espécies desse clado apresentam o mediunco mais largo que longo (caráter 40) (Fig. 81), reversão, e todas fêmeas têm dilatação no final do ducto espermático (caráter 24) (Fig. 82).

Essas espécies compõem dois grupos menores. O primeiro é formado por (C. arioles + (C. claveri + C. montoyana $)$, que compartilham a presença de projeção ventral do tergito IX + ectoprocto (caráter 26) e as nervuras gradiformes das asas posteriores negras (caráter 21).

C. claveri + C. montoyana apresentam grandes semelhanças, as duas espécies têm os flagelômeros negros, manchas em forma de listra no escapo e manchas em forma de listras vermelhas no pronoto, entretanto, as principais semelhanças são no processo digitiforme do gonarco (caráter 33), gonocornos reduzidos, arcesso estreito apicalmente, com dois lobos laterais pequenos e gonapse bifurcada. $C$. claveri e $C$. montoyana têm asas anteriores e posteriores semelhantes em tamanho, forma e coloração, com nervuras gradiformes paralelas e negras em ambas as asas. C. claveri, ao contrário de $C$. montoyana, tem antenas negras.

O segundo grupo dentro do clado 22 é formado por $C$. cornuta, C. cincta, $C$. belizensis, C. discolor e C. inbio, sustentado apenas por homoplasias. C. cornuta é irmã das outras quatro espécies, que compartilham a nervura transversal basal costal da asa anterior localizada apicalmente à quarta nervura transversal costal (caráter 12) e comprimento do arcesso menor que a largura do braço lateral do gonarco (caráter 41).

C. cincta não apresenta projeção ventral do IX tergito + ectoprocto (caráter 26), a qual é encontrada em $C$. belizensis $+(C$. discolor $+C$. inbio $)$. C. belizensis têm as gradiformes das asas anterior e posterior convergentes (caráter 11 e 19), célula gradiforme 1 da asa posterior menor que o comprimento da primeira gradiforme externa até a base da terceira transversal radial (caráter 20) e apresenta o processo digitiforme do gonarco (caráter 33), tais características não são encontradas em $C$. discolor e $C$. inbio, que compartilham três características principais: ausência de manchas escura no pedicelo (caráter 7), manchas do pronoto descontínuas (caráter 9) e manchas presentes no mesonoto (caráter 10).

C. discolor têm o arcesso com processo dorsal (caráter 44) e a primeira nervura transversal intercubital da asa anterior negra (caráter 14), características não encontradas em C. inbio. 

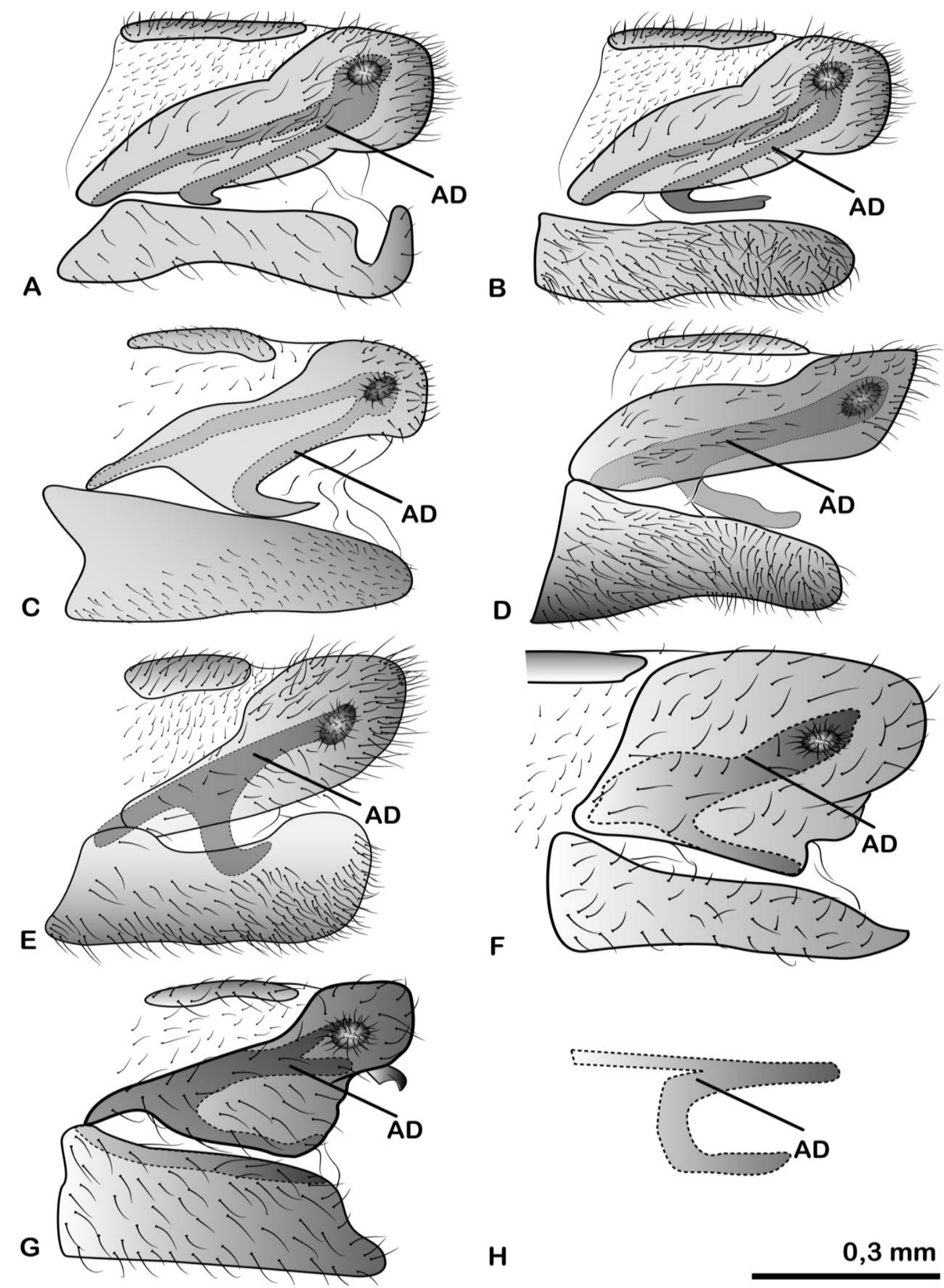

H

Figura 80. Abdômen lateral masculino de Ceraeochrysa Adams, 1982 (Chrysopidae: Chrysopinae), grupo cincta, vista lateral. A) C. arioles (Banks, 1944); B) C. claveri (Navás, 1911); C) C. montoyana (Navás, 1913); D) C. cornuta (Navás, 1925); E) C. cincta (Schneider, 1851); F) C. belizensis Freitas \& Penny, 2009; G) C. inbio Penny, 1997; H) Apódema dorsal de C. discolor (Navás, [1914]). Apódema dorsal (AD). A, F, G, H foram modificados de Freitas et al., 2009. 

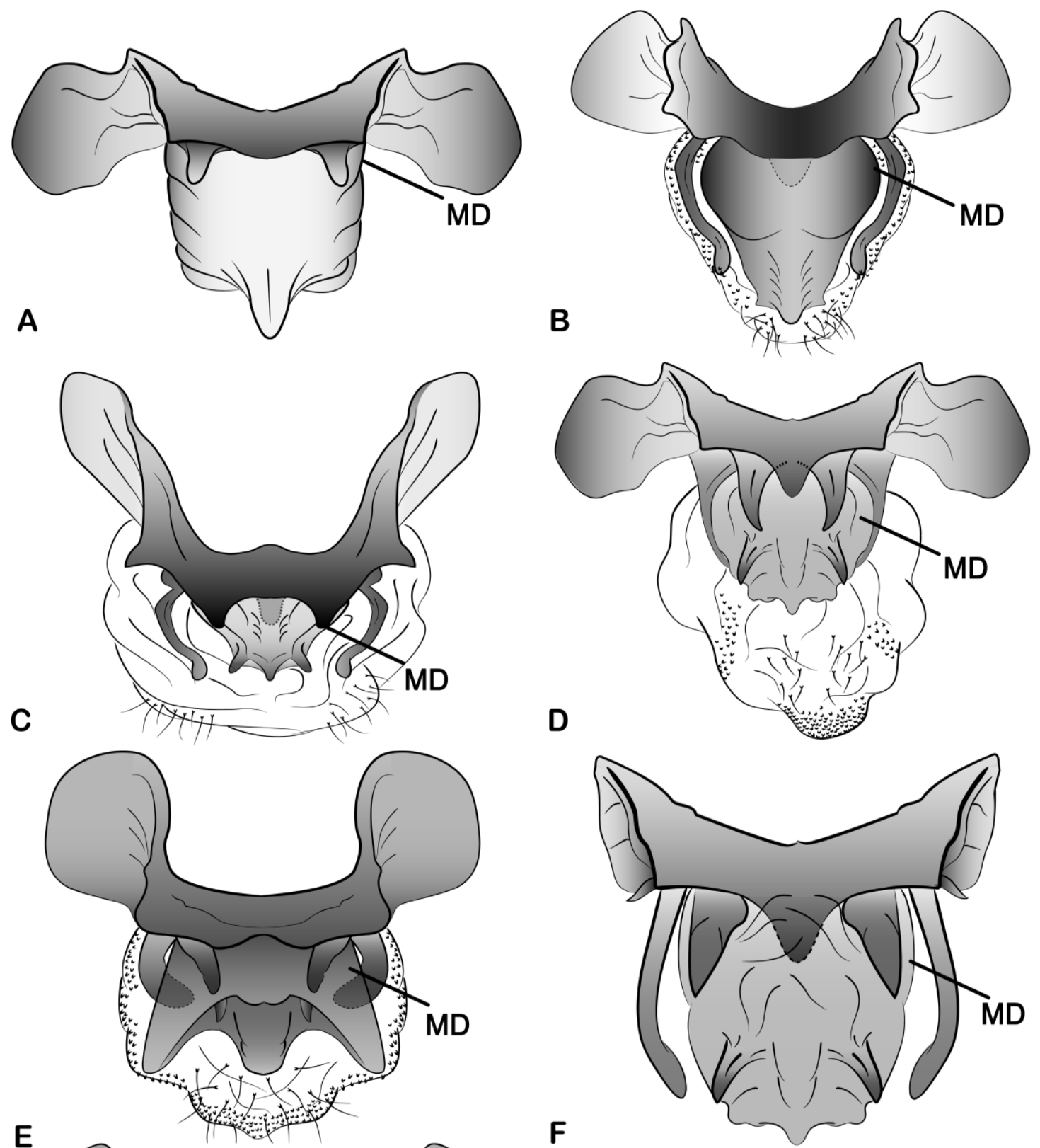

E

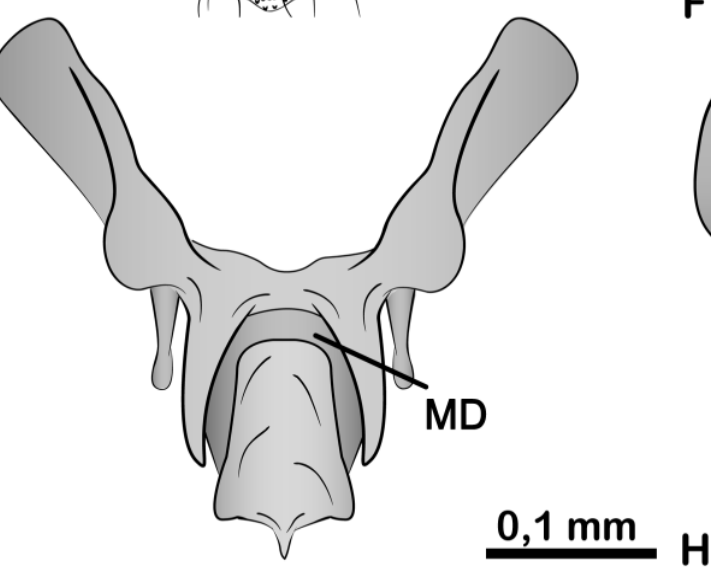

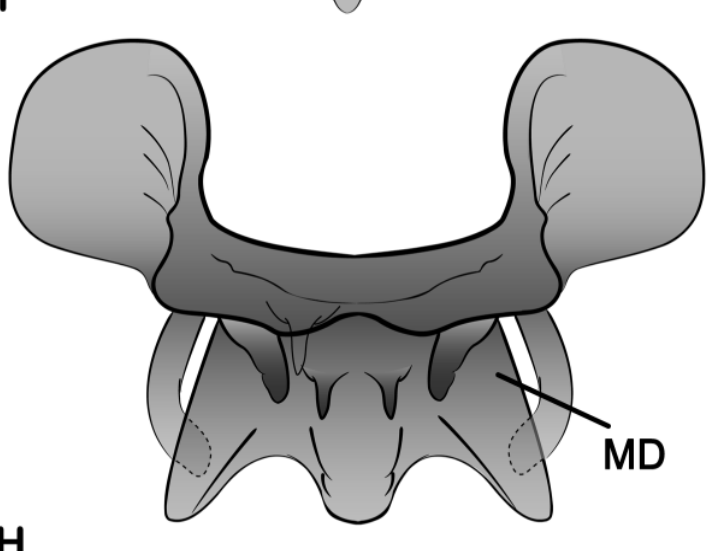

Figura 81. Genitália masculina de Ceraeochrysa Adams, 1982 (Chrysopidae: Chrysopinae), grupo cincta, vista dorsal. A) C. arioles (Banks, 1944); B) C. claveri (Navás, 1911); C) C. montoyana (Navás, 1913); D) C. cornuta (Navás, 1925); E) C. cincta (Schneider, 1851); F) C. belizensis Freitas \& Penny, 2009; G) C. inbio Penny, 1997; H) C. discolor (Navás, [1914]). Mediunco (MD). A, F, G, H foram modificados de Freitas et al., 2009. 


\section{$0,1 \mathrm{~mm}$}
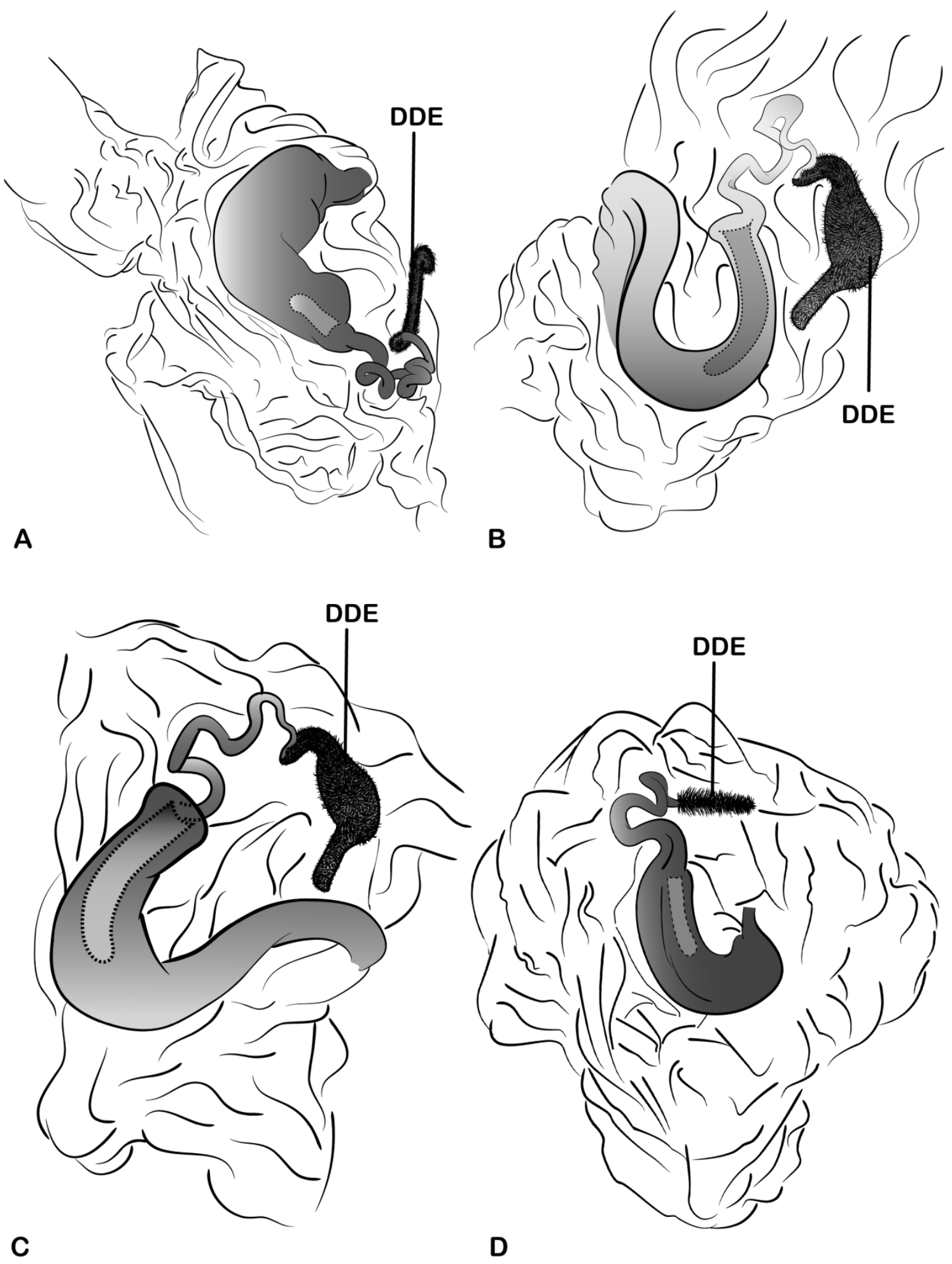

Figura 82. Espermateca de Ceraeochrysa Adams, 1982 (Chrysopidae: Chrysopinae), grupo cincta, vista dorsal. A) C. claveri (Navás, 1911); B) C. montoyana (Navás, 1913); C) C. cornuta (Navás, 1925); D) C. cincta (Schneider, 1851). Dilatação do ducto espermático (DDE). 


\section{* Grupo lineaticornis (Fig. 83).}

O grupo lineaticornis - clado 31-, também é formado por oito espécies: Ceraeochrysa berlandi, Ceraeochrysa infausta, Ceraeochrysa lineaticornis, Ceraeochrysa achillea, Ceraeochrysa curvabilis, Ceraeochrysa derospogon, Ceraeochrysa effusa e Ceraeochrysa digitata, que apresentam como sinapomorfias a placa apical do arcesso achatada lateralmente (caráter 48) e os lobos apicais do arcesso estreitos (caráter 49) (Fig. 83). Dentre as oito espécies do grupo lineaticornis, C. berlandi foi recuperada como irmã das demais (clado 32), que apresentam as gradiformes das asas anterior e posterior não paralelas (caracteres 11 e 19), nervuras A1 e A2 da asa anterior separadas (caráter 13), forquilhas marginais da asa anterior negras (caráter 15), célula gradiforme 1 da asa posterior menor que o comprimento da primeira gradiforme externa até a base da terceira transversal radial (caráter 20) e tergito IX + ectoprocto com processo ventral (caráter 26).

Dentro do clado 32, C. infausta é espécie irmã de C. lineaticornis, C. achillea, $C$. effusa, C. curvabilis, C. derospogon e C. digitata, apresenta primeira nervura intercubital sem manchas negras (caráter 14) e arcesso sem processos dorsais (caráter 44). C. lineaticornis, espécie sem manchas na gena, é irmã das outras quatro espécies, que apresentam mancha negra na gena (caráter 2), o que é uma reversão.

C. achillea, recuperada como irmã do clado C. effusa $+(C$. curvabilis $+(C$. derospogon $+C$. digitata)), tem nervura basal costal localizada apicalmente a quarta costal transversal, enquanto que as outras quatro espécies apresentam tal nervura localizada basalmente a quarta costal transversal.

C. effusa apresenta mancha escura no palpo maxilar (caráter 1) e nervuras gradiformes da asa posterior negras (caráter 21); já C. derospogon e C. digitata apresentam manchas escura no clípeo (caráter 3) e primeira nervura transversal intercubital negra (caráter 14), reversões que não são encontradas em C. curvabilis. 

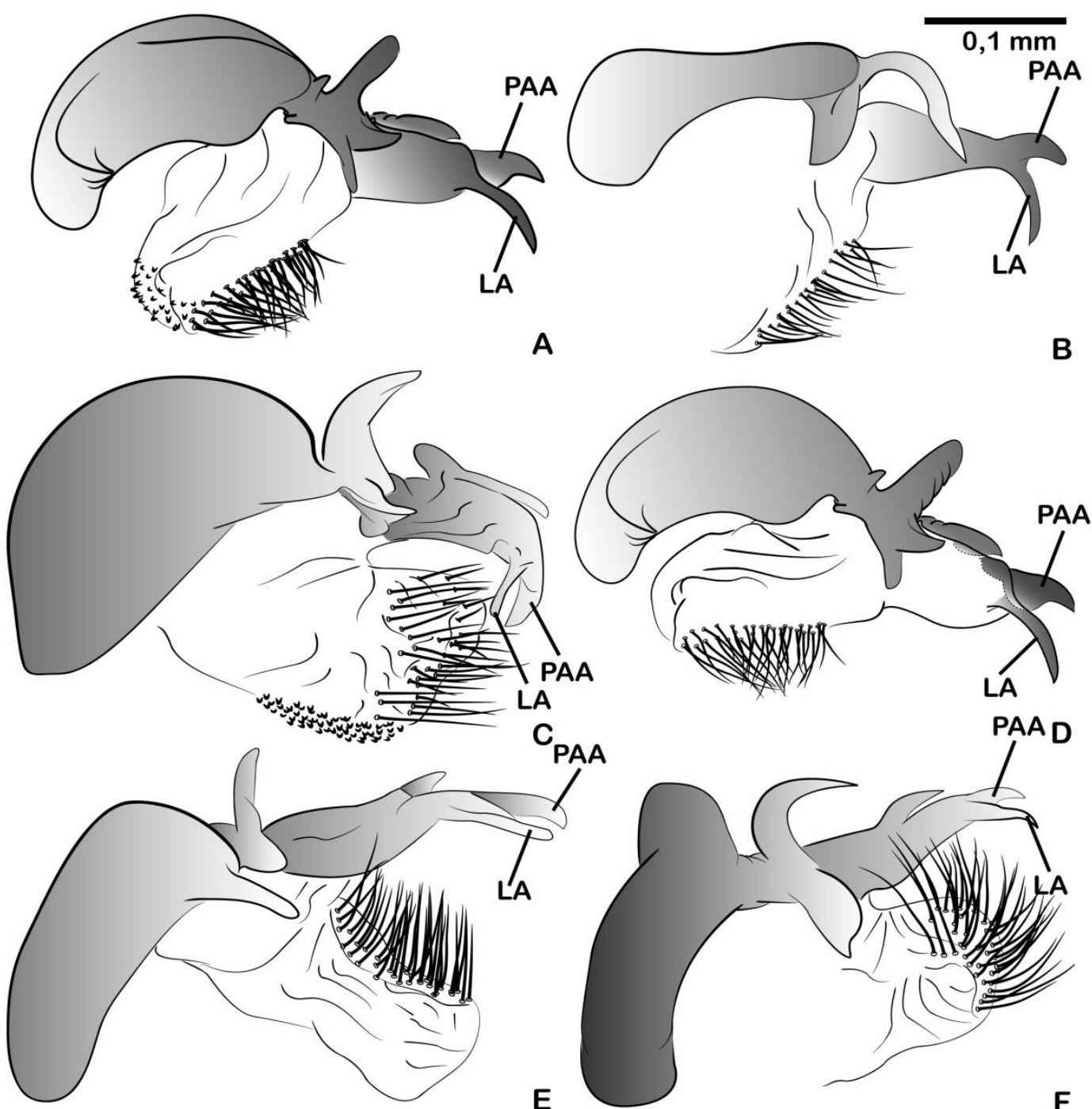

$\mathrm{C}_{\mathrm{PAA}}$

E
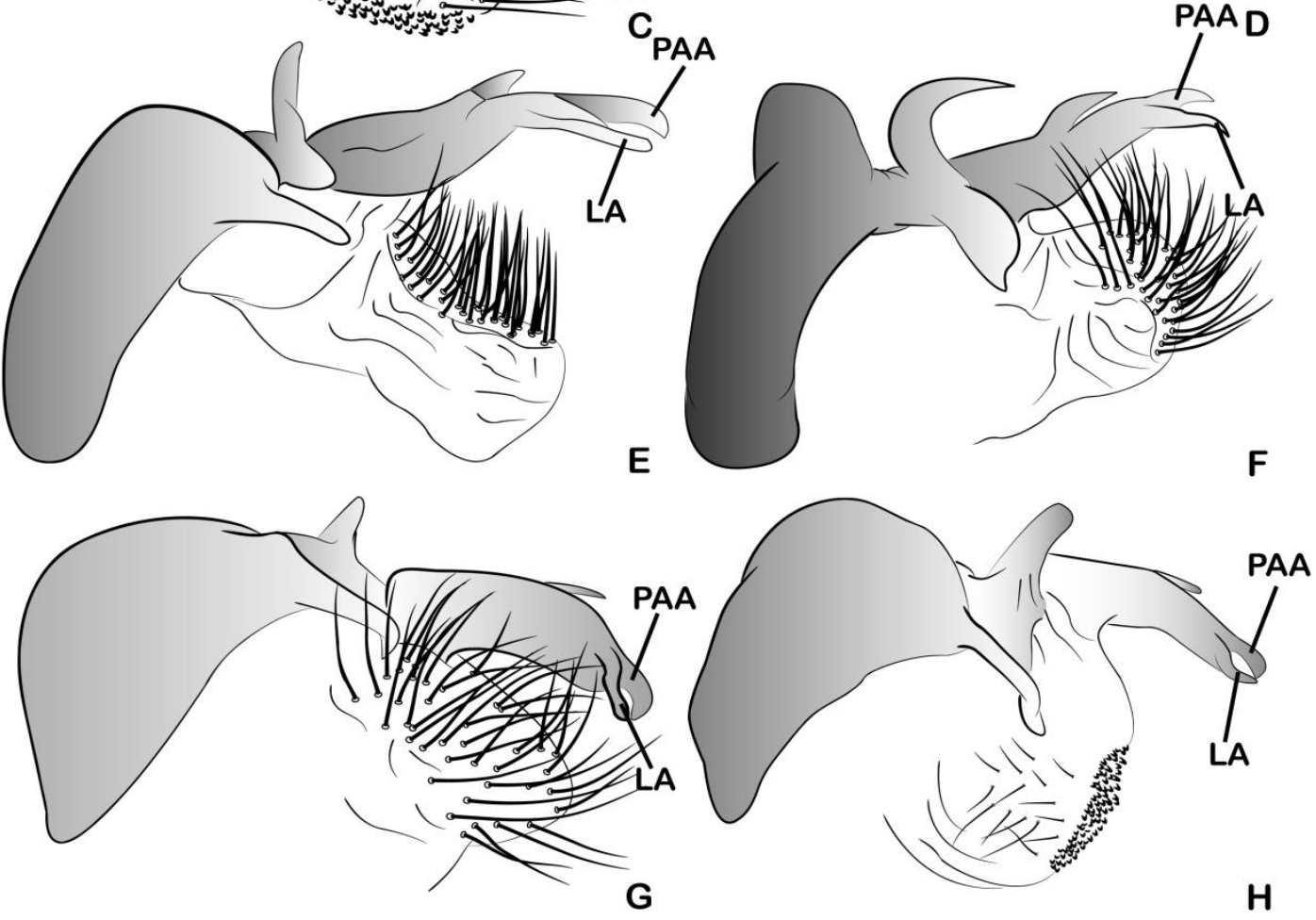

Figura 83. Genitália masculina de Ceraeochrysa Adams, 1982 (Chrysopidae: Chrysopinae), grupo lineaticornis, vista lateral. A) C. berlandi (Navás, [1924]); B) C. infausta (Banks, [1946]); C) C. lineaticornis (Fitch, [1855]); D) C. achillea Freitas \& Penny, 2009; E) C. effusa (Navás, 1911); F) C. curvabilis Freitas \& Penny, 2009; G) C. derospogon Freitas \& Penny, 2009; H) C. digitata Freitas \& Penny, 2009. Lobo apical do arcesso (LA); placa apical do arcesso (PAA). A-H modificado de Freitas et al. (2009). 


\section{Espécies cujos machos são desconhecidos.}

Há 11 espécies cujos machos não são conhecidos e que não foram inseridas em uma análise global do gênero, elas foram inseridas individualmente na matriz de maneira a estimar sua posição sem a interferência das demais espécies. Isso foi feito para que a grande quantidade de dados faltantes dessas espécies não interferisse na recuperação das relações entre as demais espécies do gênero.

Ceraeochrysa adornata - Sua posição é recuperada dentro do clado 14, mas sua inserção na análise gera uma politomia na árvore consenso das quatro árvores obtidas. C. adornata compartilha com as espécies desse clado a espermateca alongada em forma de $\mathrm{J}$ (caráter 23), dilatação final do ducto espermático (caráter 24), forquilhas marginais da asa anterior de coloração verde (caráter 15).

Ceraeochrysa dolichosvela - É recuperada como irmã do clado (C. fairchildi $+(C$. falcifera + $(C$. angulata + C. defreitasi))) (Fig. 26). Essas cinco espécies compartilham ausência de mancha escura no escapo (caráter 6) e nervuras anais 1 e 2 da asa anterior fundidas medianamente (caráter 13).

Ceraeochrysa fiebrigi - Essa espécie foi recuperada, em uma única árvore, como espécie irmã do clado que inclui $C$. infausta, C. lineaticornis, C. achillea, C. derospogon, C. digitata, $C$. effusa e C. curvabilis (Fig. 26). Essas espécies apresentam três características em comum: asas anteriores com nervuras anais 1 e 2 fundidas medianamente (caráter 13), nervuras gradiformes das asas posteriores não paralelas (caráter 19) e o comprimento da célula gradiforme 1 da asa posterior menor que a metade do comprimento da primeira gradiforme externa até a base da terceira nervura transversal radial (caráter 20).

Ceraeochrysa lateralis - Assim como C. fiebrigi, também foi recuperada como irmã de $C$. infausta, C. lineaticornis, C. achillea, C. derospogon, C. digitata, C. effusa e C. curvabilis (Fig. 26). Este clado apresenta as forquilhas marginais negras (caráter 15), estado considerado plesiomórfico.

Ceraeochrysa reducta - Da mesma maneira que $C$. lateralis e $C$. fiebrigi, C. reducta é recuperada como irmã do clado contendo (C. infausta, C. lineaticornis, C. achillea, $C$. derospogon, C. digitata, C. effusa e C. curvabilis) (Fig. 26). C. reducta + clado 32 apresentam 
gradiformes da asa anterior não paralelas (11), nervuras A1 e A2 não fundidas medianamente (caráter 13) e célula gradiforme 1 menor que o comprimento da primeira gradiforme externa até a base da terceira transversal radial da asa posterior (caráter 20).

Realizou-se uma análise que incluiu as espécies de Ceraeochrysa com dados de macho, $C$. reducta, $C$. fiebrigi e $C$. lateralis com o intuito de descobrir qual das três espécies é mais próxima do clado 32, e foi recuperado $C$. lateralis como a espécie mais próxima deste último clado. C. reducta e C. fiebrigi foram recuperados em uma politomia na base de $C$. lateralis + clado 32 .

Ceraeochrysa silvanoi - Foi recuperada como irmã de Ceraeochrysa defreitasi (Fig. 26) no lugar de C. angulata.

Ceraeochrysa anceps, Ceraeochrysa castilloi, Ceraeochrysa caucana, Ceraeochrysa indicata e Ceraeochrysa rafaeli - Cada uma dessas espécies, mesmo quando inseridas uma por vez na análise, geram grande distúrbio na topologia, o que resulta grandes politomias, de maneira que sua posição não pôde ser razoavelmente recuperada sem o conhecimento dos machos. 


\subsection{Distribuição geográfica das espécies de Ceraeochrysa Adams, 1982 (Chrysopidae: Chrysopinae) com registro para o Brasil.}

Dentre as 28 espécies de Ceraeochrysa que ocorrem no Brasil, 12 têm distribuição restrita ao país (Figs. 84 e 85). Ceraeochrysa nigripes apresenta registro de ocorrência para os Estados do Acre, Amazonas, Pará e Rondônia; Ceraeochrysa michaelmuris e Ceraeochrysa rafaeli somente para o Estado do Amazonas; Ceraeochrysa falcifera no Pará; Ceraeochrysa adornata em Minas Gerais; Ceraeochrysa reddyi no Maranhão; Ceraeochrysa ariasi em Amazonas e São Paulo; Ceraeochrysa anceps e Ceraeochrysa silvanoi no Estado do Rio de Janeiro; Ceraeochrysa dolichosvela tem registro de ocorrência para os Estados do Pará, Mato Grosso do Sul e São Paulo e já foi encontrada em plantações de Citrus sp. e abacate.

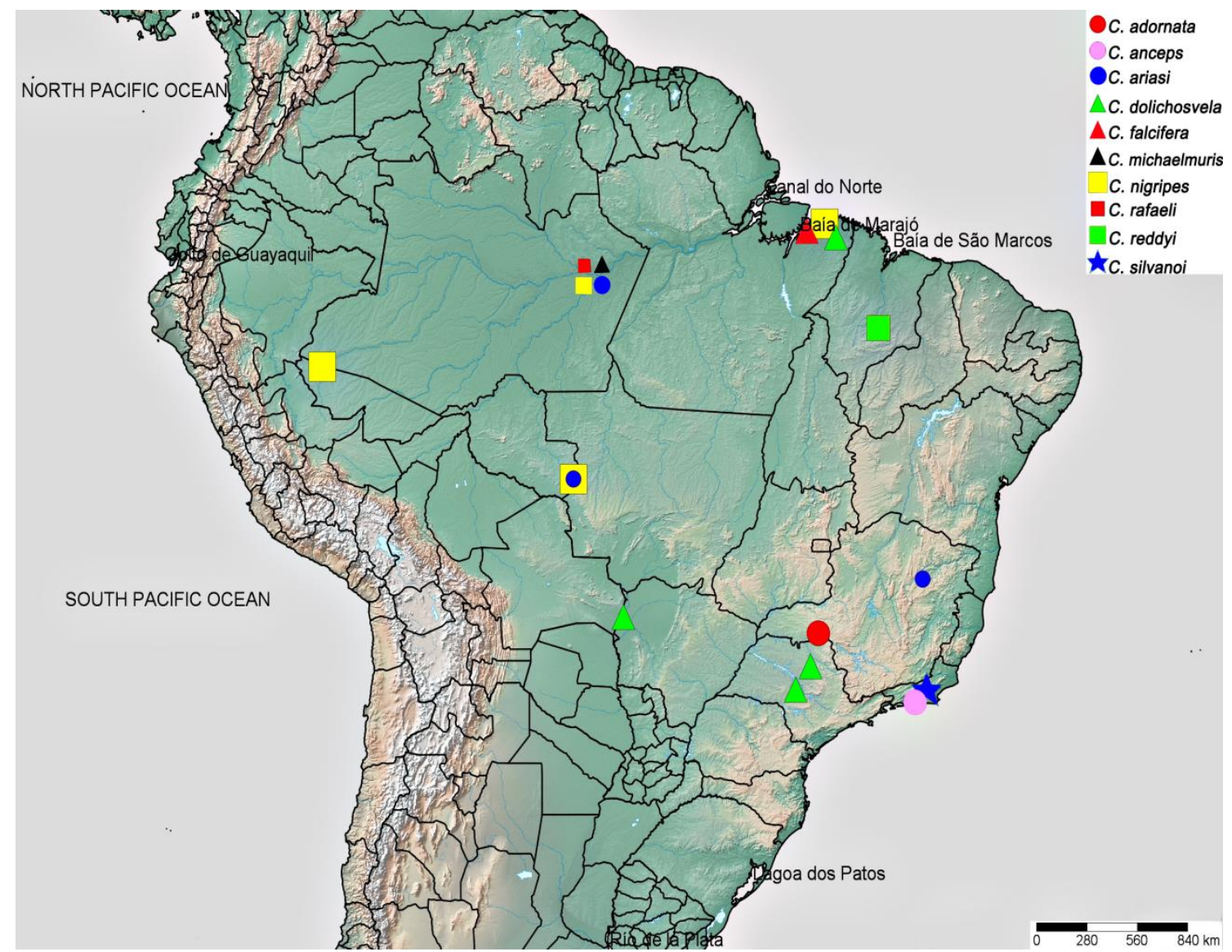

Figura 84. Distribuição geográfica de 10 espécies de Ceraeochrysa Adams, 1982 (Neuroptera: Chrysopidae) que ocorrem no Brasil. Ceraeochrysa adornata (Lacroix, [1926]), Ceraeochrysa anceps (Navás, 1926), Ceraeochrysa ariasi Adams \& Penny, [1987], Ceraeochrysa dolichosvela Freitas \& Penny, 2001, Ceraeochrysa falcifera Adams \& Penny, [1987], Ceraeochrysa michaelmuris Adams \& Penny, [1987], Ceraeochrysa nigripes Adams \& Penny, [1987], Ceraeochrysa rafaeli Adams \& Penny, [1987], Ceraeochrysa reddyi Adams \& Penny, [1987], Ceraeochrysa silvanoi (Navás, 1916). Fonte: http://www.simplemappr.net/ (Shorthouse, 2010).

Além de apresentar ampla distribuição no território brasileiro, Estados do Pará, Mato Grosso (Freitas et al., 2009), Bahia, Goiás, Minas Gerais e São Paulo (Freitas et al., 2009), 
Ceraeochrysa dislepis já foi coletada em várias plantações como manga, café, Citrus sp., pêssego, abóbora, milho, seringueira e eucalipto. Ceraeochrysa tenuicornis foi coletada somente em plantações de Citrus sp. e seringueiras e tem registro de ocorrência para os Estados do Amazonas (Freitas et al., 2009), Pará (Freitas et al., 2009), Maranhão, Mato Grosso, Minas Gerais e São Paulo.

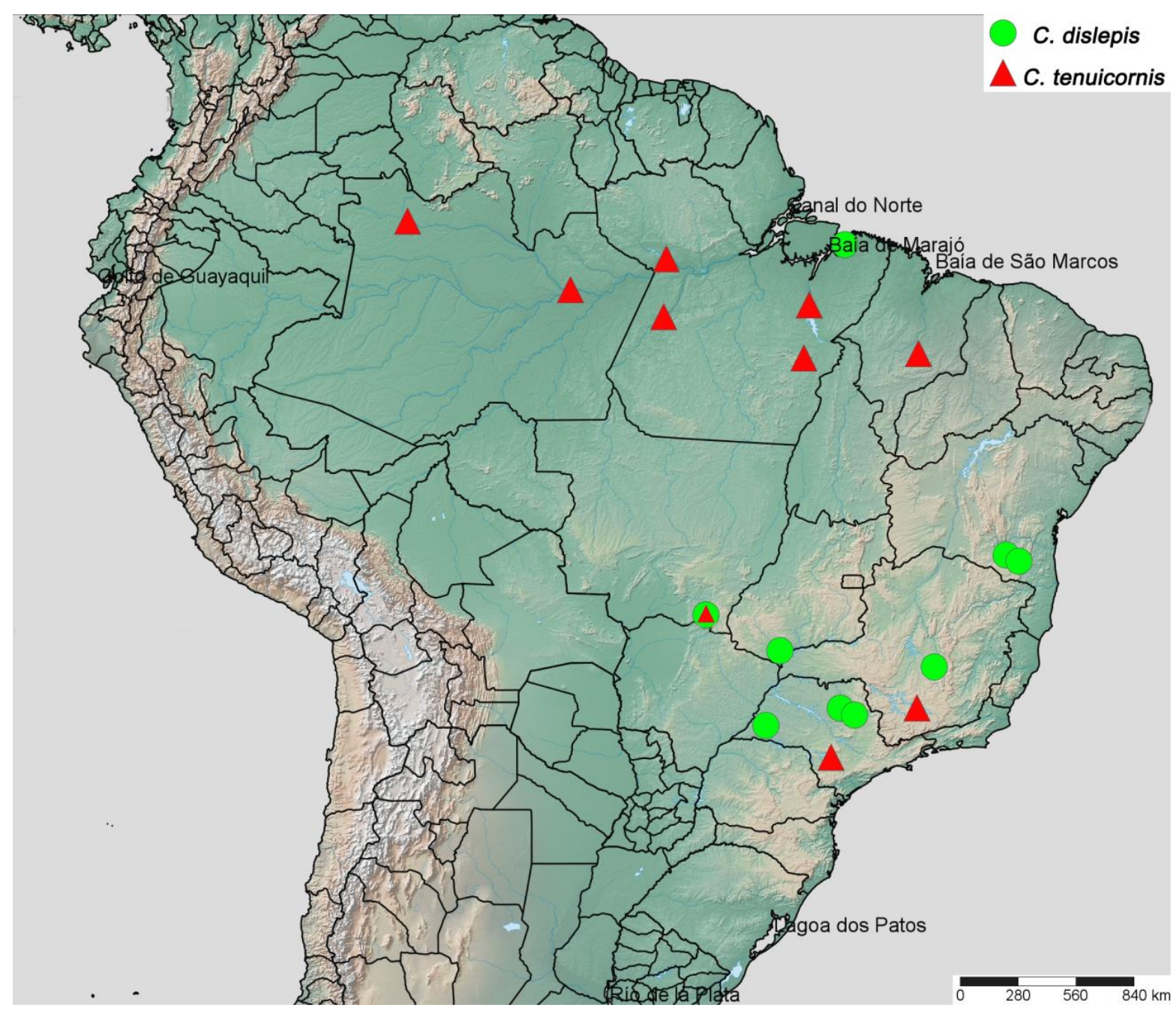

Figura 85. Distribuição geográfica de duas espécies de Ceraeochrysa Adams, 1982 (Neuroptera: Chrysopidae) que ocorrem no Brasil. Ceraeochrysa dislepis Freitas \& Penny, 2001 e Ceraeochrysa tenuicornis Adams \& Penny, [1987]. Fonte: http://www.simplemappr.net/ (Shorthouse, 2010).

As demais espécies de Ceraeochrysa que ocorrem no Brasil são encontradas em outros países da América do Sul, Central ou do Norte. 
Ceraeochrysa achillea Freitas \& Penny, 2001 (Fig. 86).

Essa espécie teve registros de ocorrência já foi encontrada no Panamá, Venezuela e no Brasil, onde foi coletada uma única vez em área de cerrado na cidade de Três Pontas em Minas Gerais, em uma altitude de 885 metros.

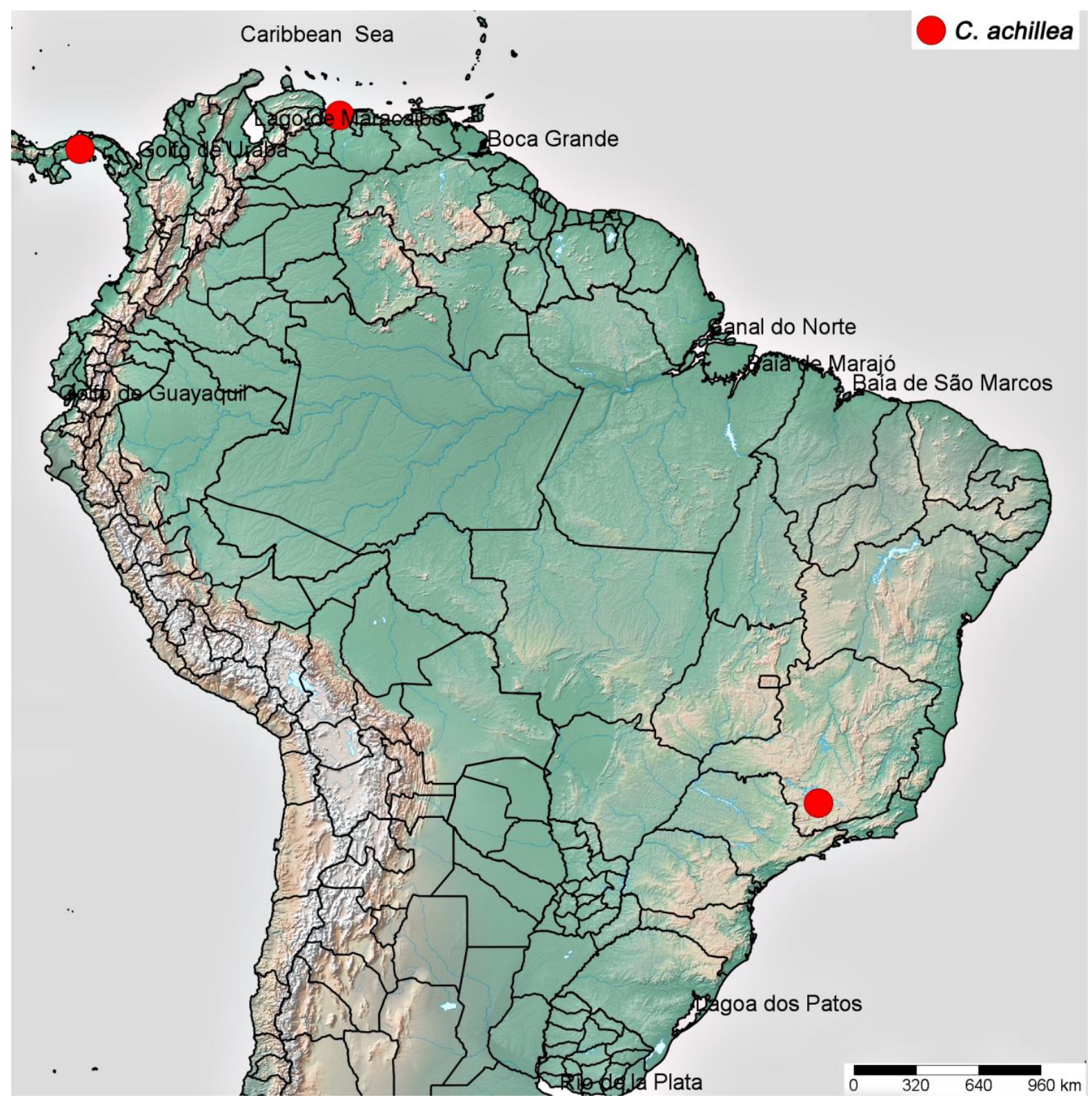

Figura 86. Distribuição geográfica de Ceraeochrysa achillea Freitas \& Penny, 2001 (Chrysopidae: Chrysopinae). Fonte: http://www.simplemappr.net/ (Shorthouse, 2010). 
Ceraeochrysa acmon Penny, 1998 (Fig. 87).

C. acmon foi relatada na Costa Rica e na Bolívia (Freitas et al., 2009). No Brasil, essa espécie tem ocorrência para os Estados de Roraima, Pará, Mato Grosso (Freitas et al., 2009), Goiás, Mato Grosso do Sul, Minas Gerais, São Paulo (Freitas et al., 2009) e Paraná (Freitas et al., 2009). Tal espécie foi coletada em plantações de Citrus sp., eucalipto e seringueira.

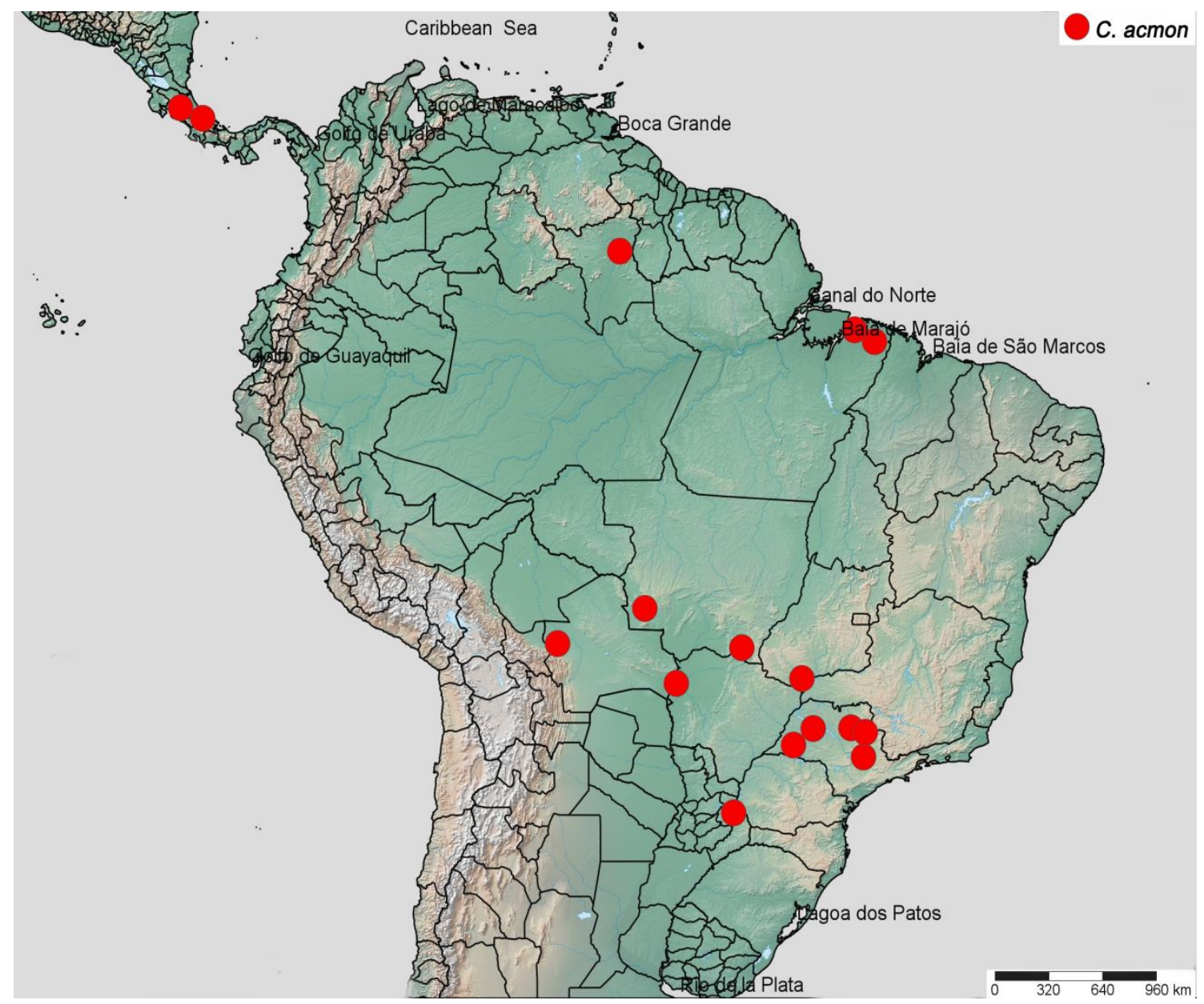

Figura 87. Distribuição geográfica de Ceraeochrysa acmon Penny, 1998 (Chrysopidae: Chrysopinae). Fonte: http://www.simplemappr.net/ (Shorthouse, 2010). 
Ceraeochrysa castilloi (Navás, 1913) (Fig. 88).

Essa espécie é encontrada no Paraguai (Freitas et al., 2009) e nos Estados brasileiros de Pernambuco e Rio de Janeiro (Freitas et al., 2009), em regiões de Mata Atlântica.

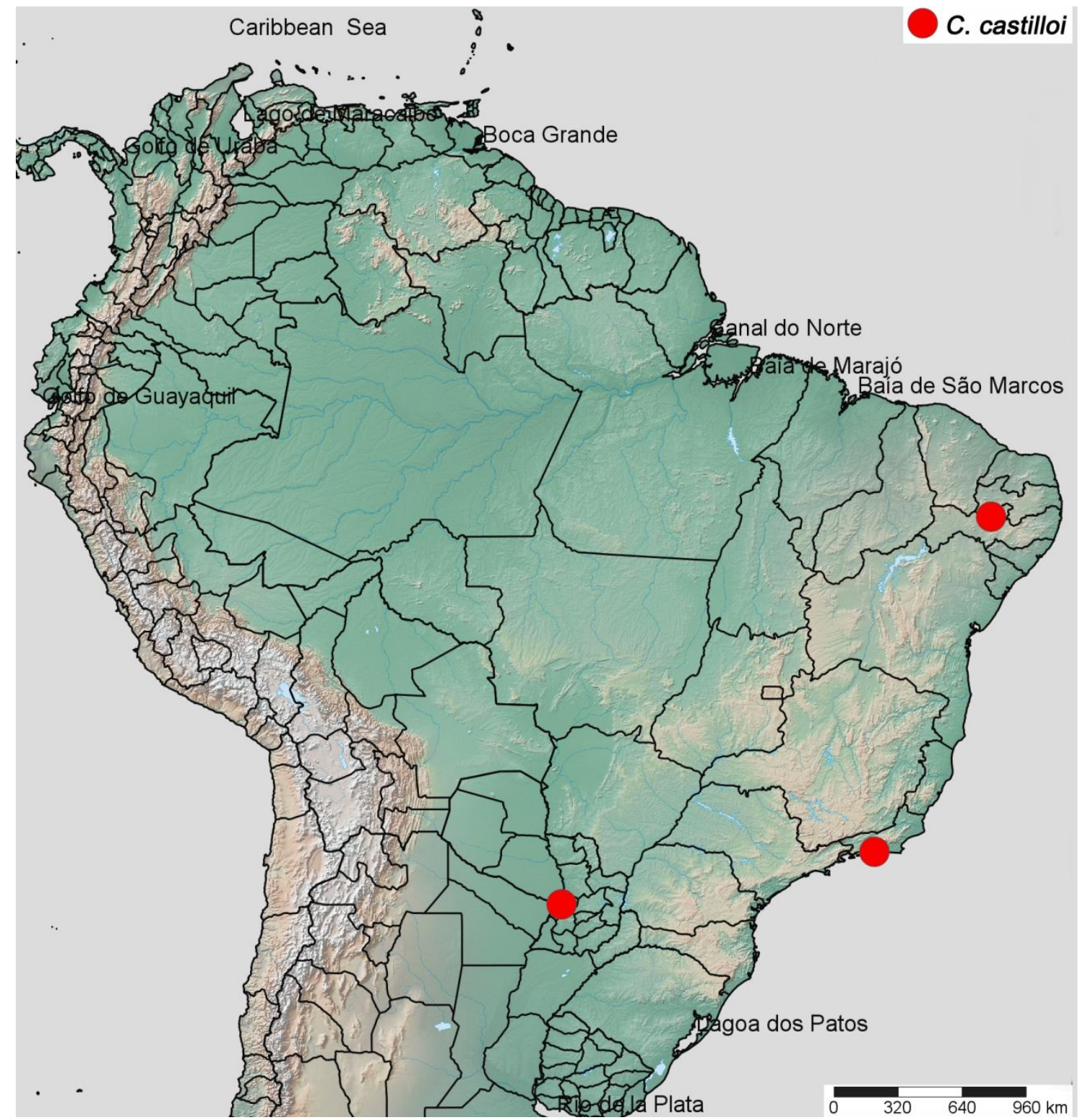

Figura 88. Distribuição geográfica de Ceraeochrysa castilloi (Navás, 1913) (Chrysopidae: Chrysopinae). Fonte: http://www.simplemappr.net/ (Shorthouse, 2010). 
Ceraeochrysa cincta (Schneider, 1851) (Fig. 89).

Segundo Freitas et al. (2009) essa espécie pode ser encontrada nos E.U.A., Mexico, Guatemala, Honduras, Cuba, Jamaica, Porto Rico, Costa Rica, Panamá, Guiana, Suriname, Equador (Ilhas Galápagos), Paraguai, Peru, Uruguai, e Argentina. No Brasil, C. cincta têm registro de ocorrência para os estados de Amapá, Amazonas, Pará, Ceará, Pernambuco, Bahia, Goiás, Minas Gerais, Rio de Janeiro (Freitas et al., 2009), São Paulo (Freitas et al., 2009) e Santa Catarina. A maior frequência de registros é para região de Mata Atlântica, mas esse pode ser um desvio de esforço de amostragem. As plantações agrícolas em que $C$. cincta já foi coletada são café, abacate, couve, Citrus sp., maçã, graviola, goiaba, abóbora, pêssego, batata doce, mandioca, eucalipto, manga, milho e algodão. $C$. cincta tem grande potencial para ser utilizada em futuros programas de controle biológico, pois apresenta grande distribuição geográfica e facilidade de criação, somada ao número de culturas e plantações agrícolas em que ocorre.

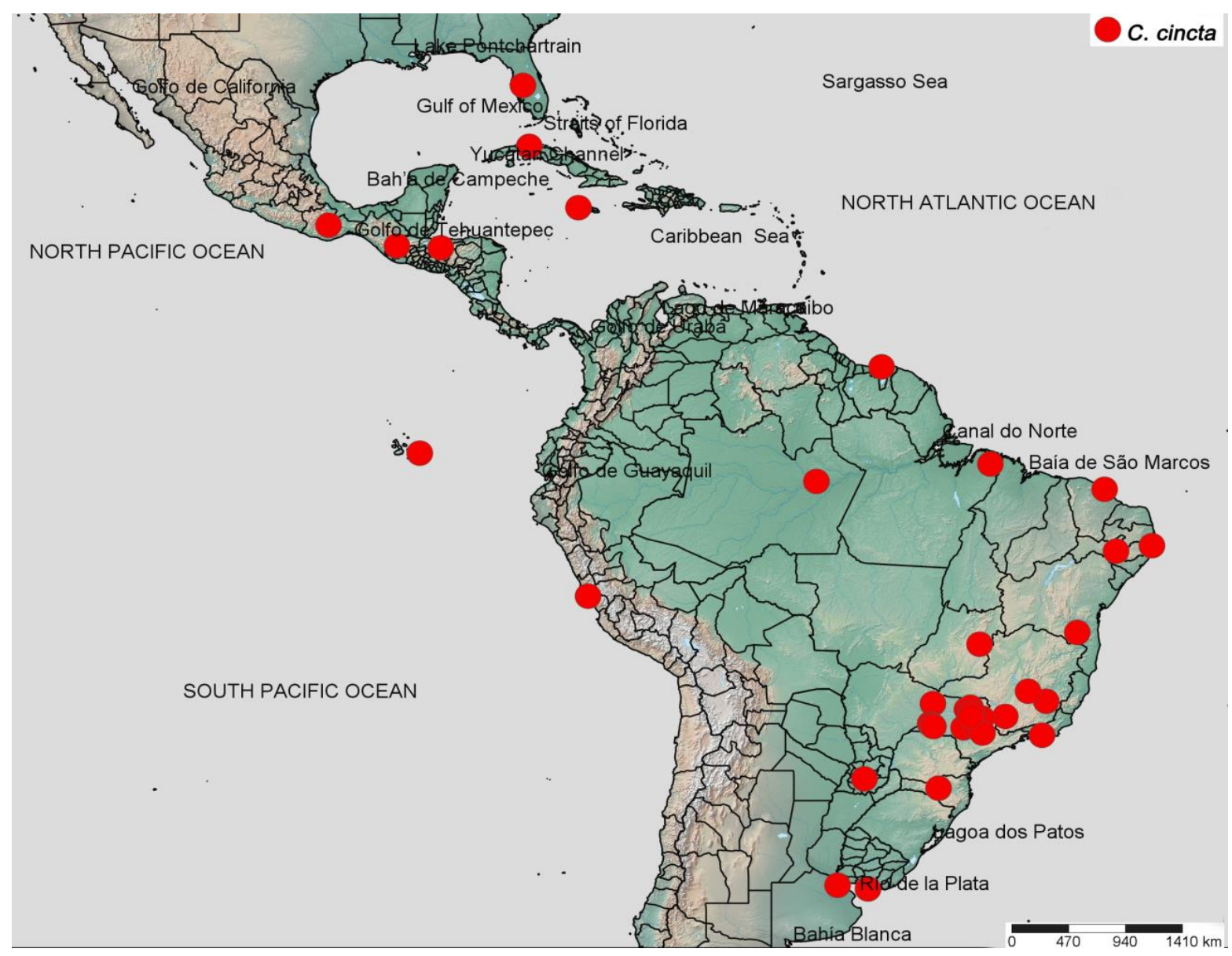

Figura 89. Distribuição geográfica de Ceraeochrysa cincta (Schneider, 1851) (Chrysopidae: Chrysopinae). Fonte: http://www.simplemappr.net/ (Shorthouse, 2010). 
Ceraeochrysa claveri (Navás, 1911) (Fig. 90).

Essa espécie tem grande distribuição geográfica, ocorre no México (Freitas et al., 2009), Haiti (Freitas et al., 2009), Honduras (Freitas et al., 2009), Colômbia (Freitas et al., 2009), Venezuela (Sosa \& Freitas, 2011), Guiana Francesa (Freitas et al., 2009), Argentina (Freitas et al., 2009), e Brasil (Freitas et al., 2009). No Brasil, C. claveri foi coletada em grande quantidade de plantações agrícolas: manga, couve, urucum, Citrus sp., maçã, eucalipto, seringueira, pinha, café, mandioca, milho e goiaba. Ela ocorre nos Estados do Amazonas (Freitas et al., 2009), Pará, Ceará (Freitas et al., 2009), Paraíba, Pernambuco, Bahia (Freitas et al., 2009), Mato Grosso (Freitas et al., 2009), Goiás, Minas Gerais, São Paulo (Freitas et al., 2009) e Santa Catarina.

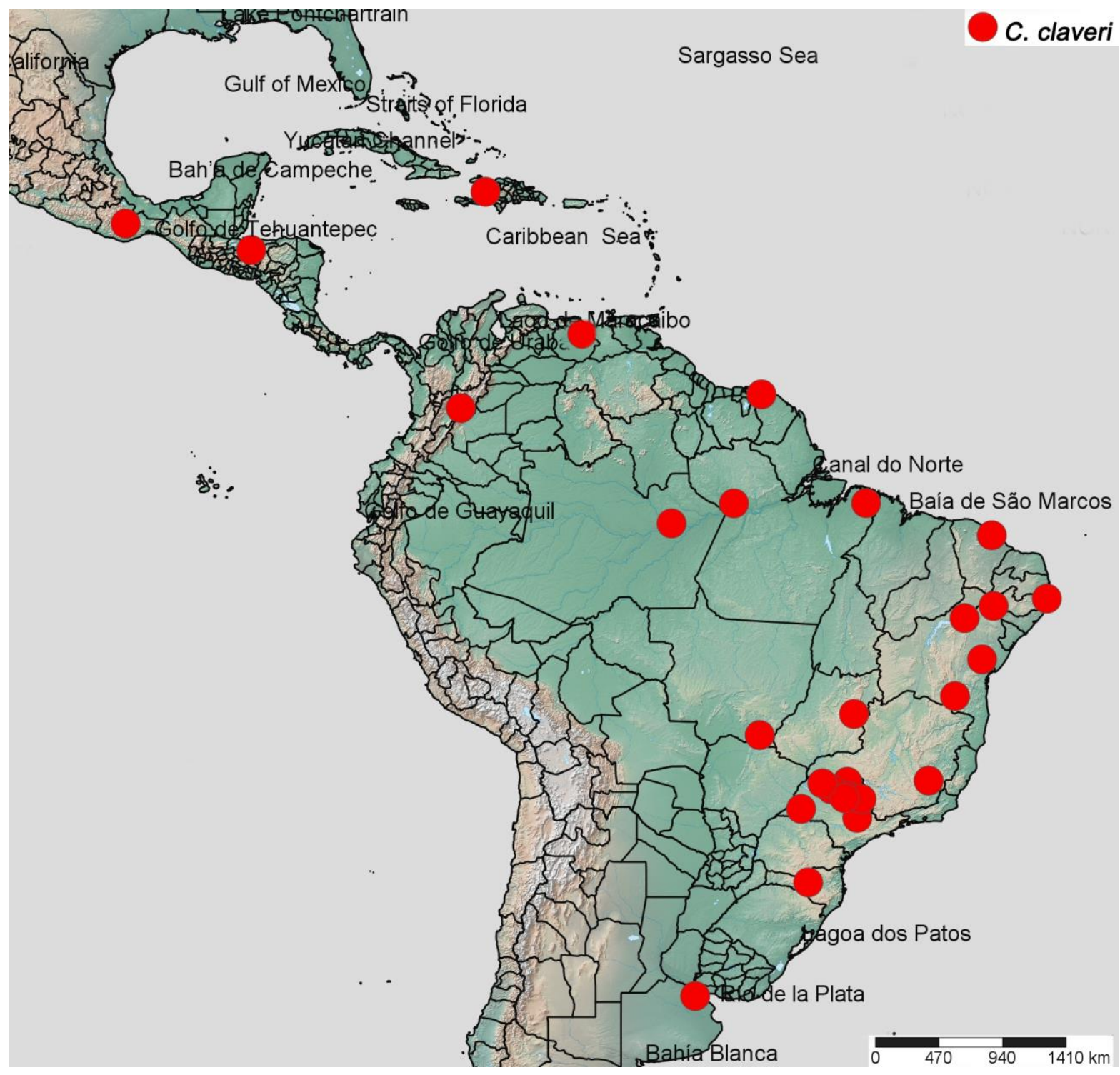

Figura 90. Distribuição geográfica de Ceraeochrysa claveri (Navás, 1911) (Chrysopidae: Chrysopinae). Fonte: http://www.simplemappr.net/ (Shorthouse, 2010). 
Ceraeochrysa cornuta (Navás, 1925) (Fig. 91).

C. cornuta é encontrada no Panamá e em oito Estados brasileiros (Roraima, Amazonas (Freitas et al., 2009), Pará (Freitas et al., 2009), Pernambuco, Mato Grosso (Freitas et al., 2009), Goiás, Minas Gerais e São Paulo (Freitas et al., 2009)); já foi encontrada em várias plantações agrícolas como abacate, couve, Citrus sp., graviola, seringueira, manga, goiaba e eucalipto.

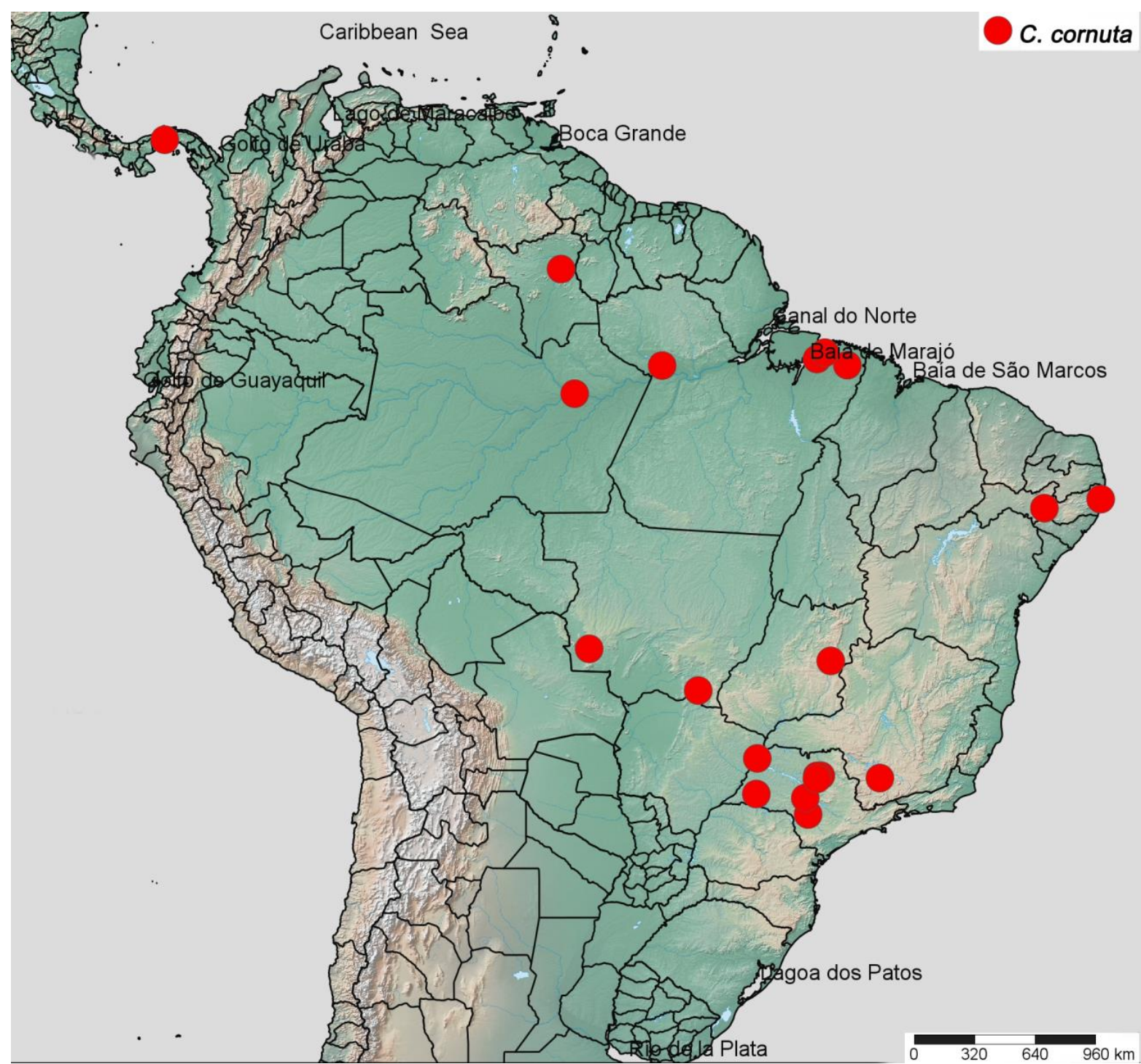

Figura 91. Distribuição geográfica de Ceraeochrysa cornuta (Navás, 1925) (Chrysopidae: Chrysopinae). Fonte: http://www.simplemappr.net/ (Shorthouse, 2010). 
Ceraeochrysa cubana (Hagen, 1861) (Fig. 92).

C. cubana conjuntamente com $C$. cincta, apresenta a maior distribuição geográfica entre as espécies de Ceraeochrysa que ocorrem no Brasil. Segundo Freitas et al. (2009) pode ser encontrada nos E.U.A., México, Cuba, Porto Rico, Jamaica, Ihas Cayman, República Dominicana, Haiti, Dominica, Barbados, Guatemala, Panama, Guiana, Bolívia. No Brasil tem registro de ocorrência para em 13 Estados (Roraima, Acre, Amazonas, Rondônia, Pará, Mato Grosso, Ceará, Rio Grande do Norte, Paraíba, Pernambuco, Bahia, Espírito Santo, São Paulo). Há registros de ocorrência de C. cubana em plantios de manga, café, abacate, algodão, seringueira, milho, goiaba, eucalipto, Citrus sp., melão, abóbora, pêssego, acerola e batata doce.

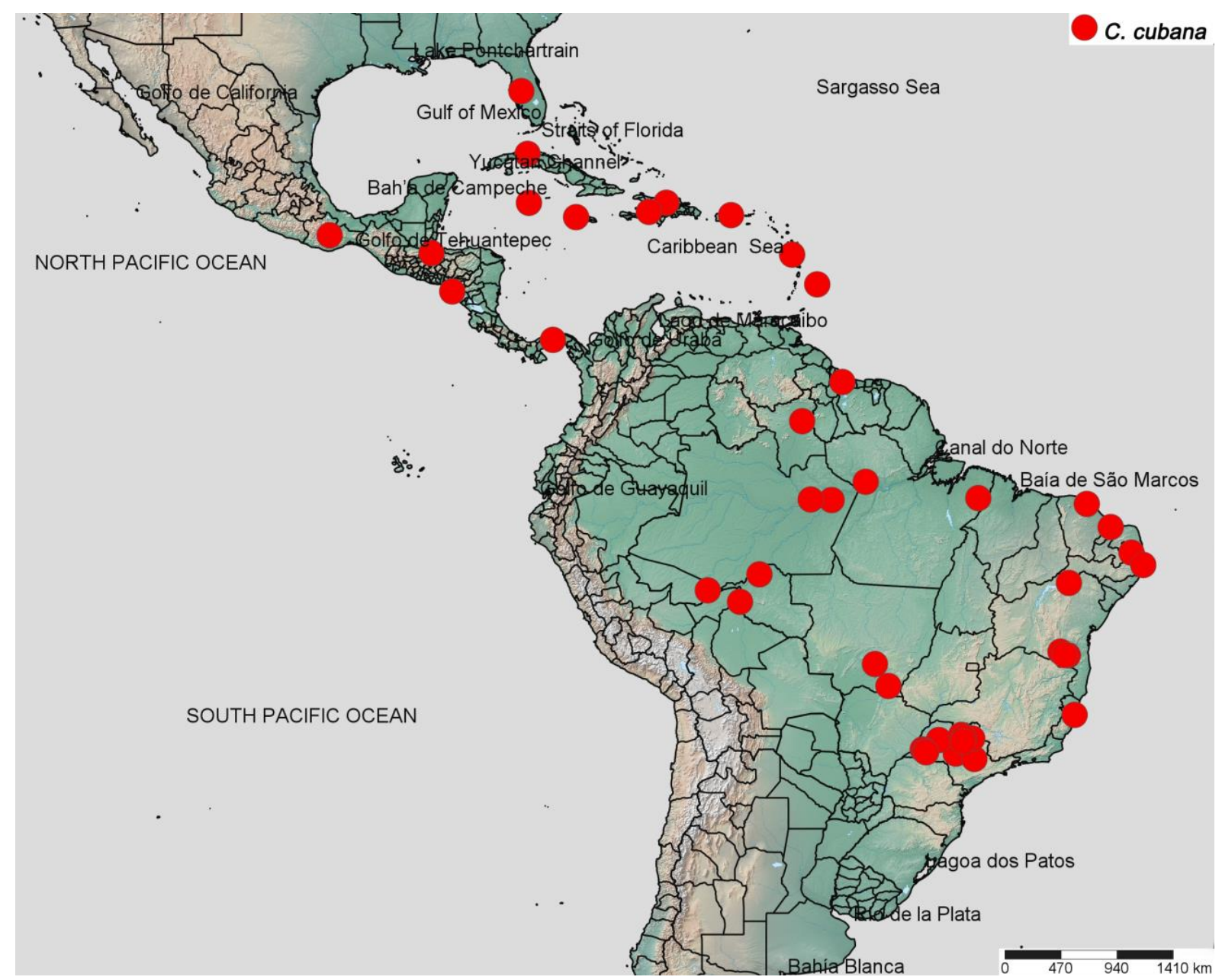

Figura 92. Distribuição geográfica de Ceraeochrysa cubana (Hagen, 1861) (Chrysopidae: Chrysopinae). Fonte: http://www.simplemappr.net/ (Shorthouse, 2010). 
Ceraeochrysa everes (Banks, 1920) (Fig. 93).

Essa espécie tem grande distribuição no território brasileiro, com registros de ocorrência nos Estados do Amazonas (Freitas et al., 2009), Rondônia (Freitas et al., 2009), Pará, Paraíba, Pernambuco, Bahia, Mato Grosso (Freitas et al., 2009), Minas Gerais (Freitas et al., 2009), São Paulo (Freitas et al., 2009), Rio de Janeiro (Freitas et al., 2009), Rio Grande do Sul. Já foi coletada nos cultivos e plantações de café, graviola, seringueira, goiaba, milho, eucalipto, Citrus sp., acerola, mandioca e manga. Os outros países nos quais ocorre (Freitas et al., 2009) são Cuba, México, Honduras, Colômbia, Trinidad, Venezuela, Suriname, Guiana Francesa, Paraguai.

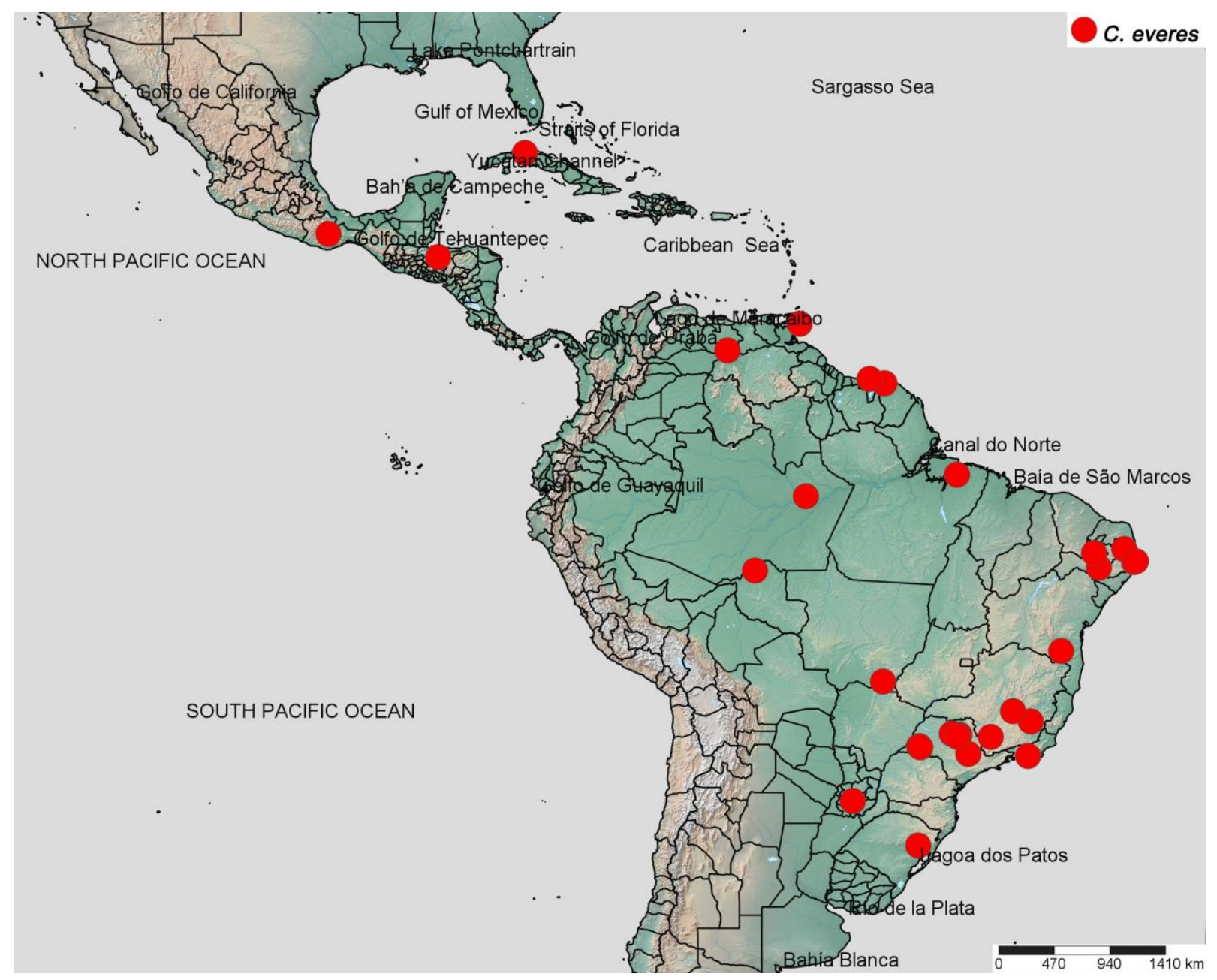

Figura 93. Distribuição geográfica de Ceraeochrysa everes (Banks, 1920) (Chrysopidae: Chrysopinae). Fonte: http://www.simplemappr.net/ (Shorthouse, 2010). 
Ceraeochrysa fairchildi (Banks, [1946]) (Fig. 94).

No Brasil, essa espécie foi coletada somente uma vez no Estado de Roraima (Freitas et al., 2009). Também há registros de $C$. fairchildi para o Panamá (Freitas et al., 2009), Trinidad (Freitas et al., 2009) e Venezuela (Sosa \& Freitas, 2011). Essa espécie não foi coletada em plantações agrícolas.

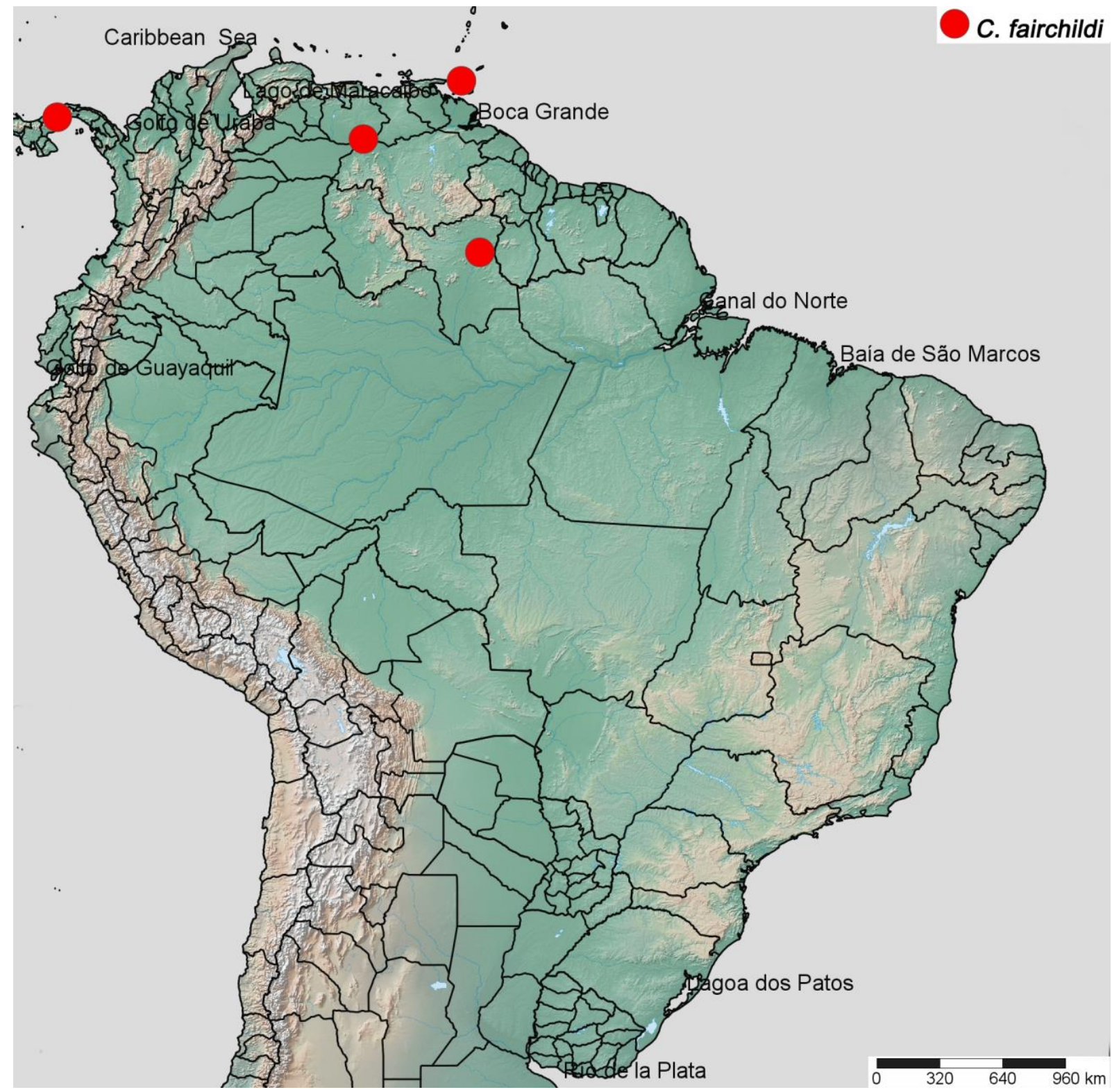

Figura 94. Distribuição geográfica de Ceraeochrysa fairchildi (Banks, [1946]) (Chrysopidae: Chrysopinae). Fonte: http://www.simplemappr.net/ (Shorthouse, 2010). 
Ceraeochrysa montoyana (Navás, 1913) (Fig.95).

Assim como ocorre com C. fairchildi, C. montoyana foi pouco coletada no Brasil. Essa espécie foi encontrada somente nos estados de Pernambuco e São Paulo (Freitas et al., 2009). Há também registros para o Paraguai (Freitas et al., 2009) e Venezuela (Sosa \& Freitas, 2011).

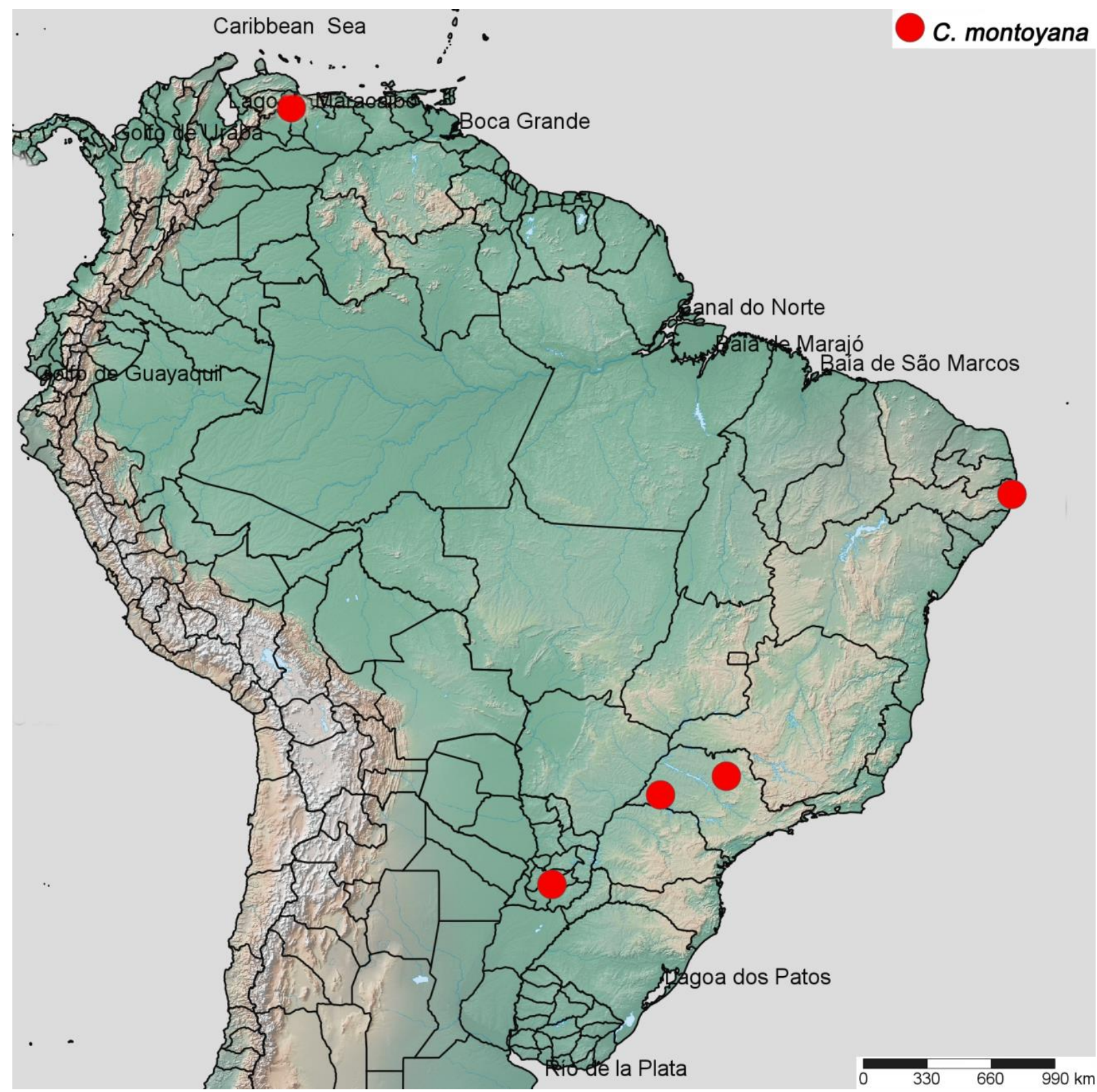

Figura 95. Distribuição geográfica de Ceraeochrysa montoyana (Navás, 1913) (Chrysopidae: Chrysopinae). Fonte: http://www.simplemappr.net/ (Shorthouse, 2010). 
Ceraeochrysa paraguaria (Navás, 1920) (Fig. 96).

Essa espécie tem relatos de ocorrência apenas para São Paulo (Brasil) (Freitas et al., 2009) e Paraguai (Freitas et al., 2009). No Brasil, há registro de $C$. paraguaria em plantações de sorgo, abóbora, acerola, batata doce, eucalipto e manga.

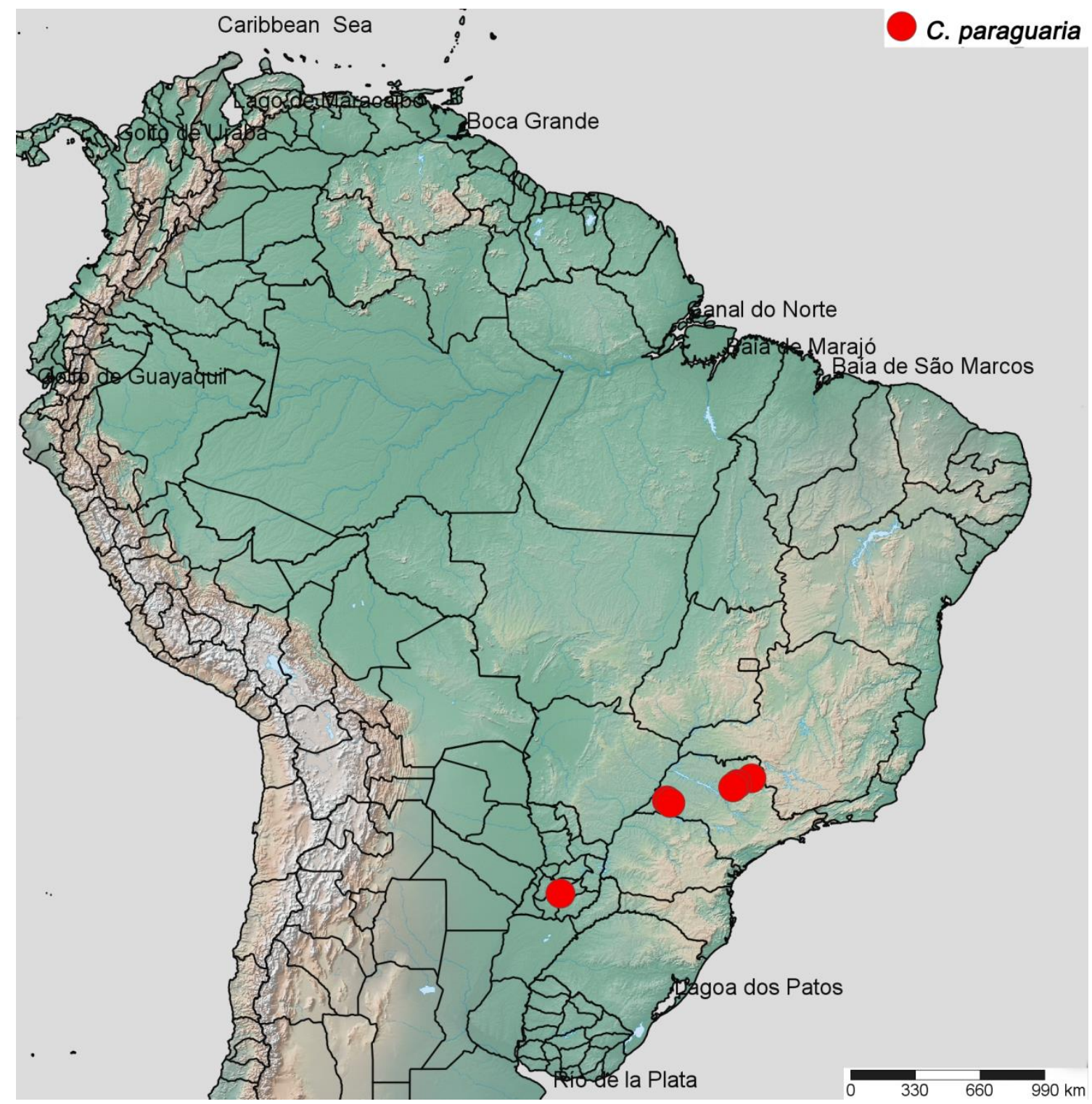

Figura 96. Distribuição geográfica de Ceraeochrysa paraguaria (Navás, 1920) (Chrysopidae: Chrysopinae). Fonte: http://www.simplemappr.net/ (Shorthouse, 2010). 
Ceraeochrysa sanchezi (Navás, 1924) (Fig. 97).

C. sanchezi é conhecida de quatro países (Freitas et al., 2009), Cuba, Honduras, México e Brasil, onde tem registro de ocorrência para seis Estados, Amazonas, Mato Grosso (Freitas et al., 2009), Rio Grande do Norte (Freitas et al., 2009), Bahia, Minas Gerais e São Paulo (Freitas et al., 2009). Apesar de sua distribuição geográfica relativamente restrita, essa espécie já foi encontrada em cultivos de manga, melão, seringueira, goiaba e Citrus sp.

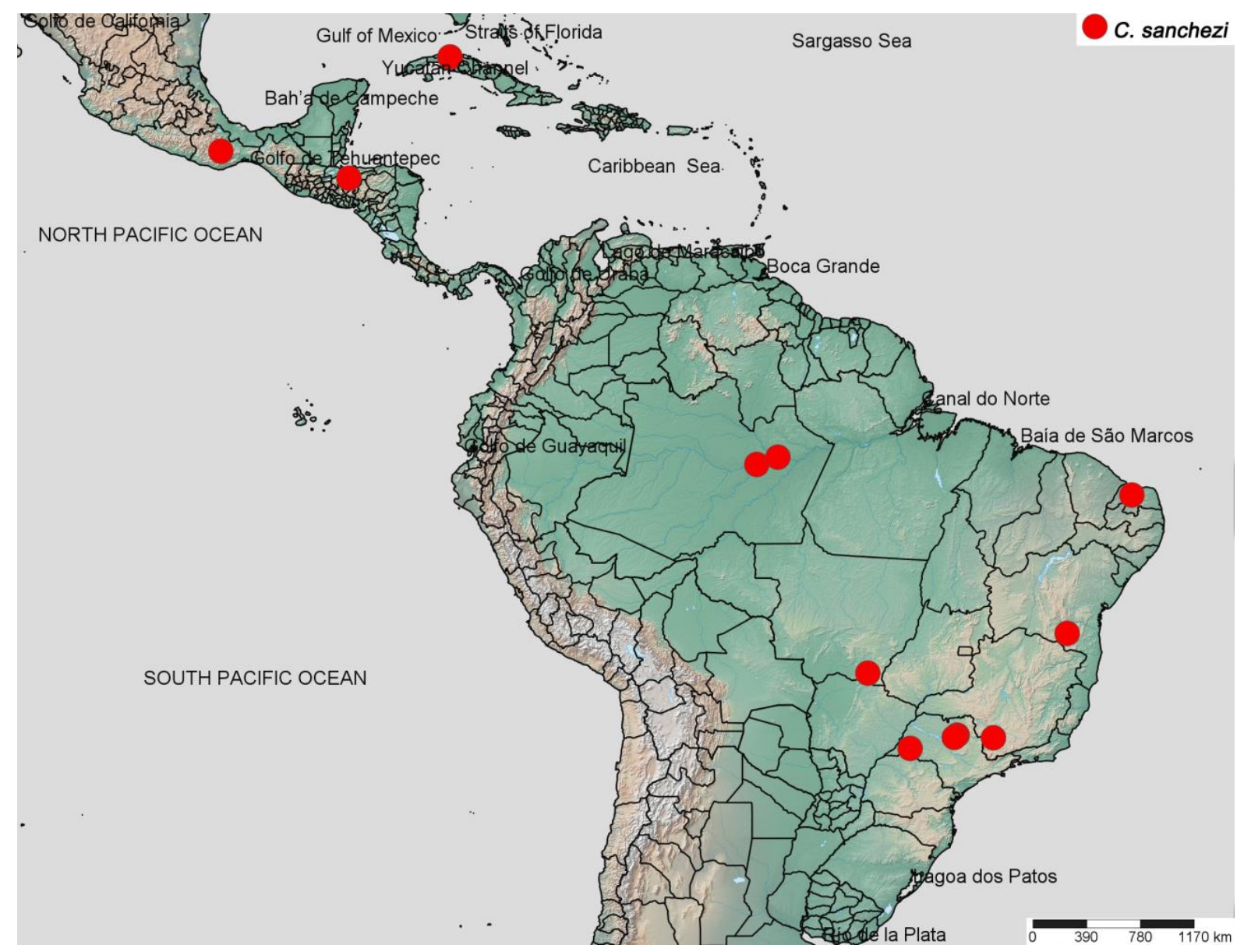

Figura 97. Distribuição geográfica de Ceraeochrysa sanchezi (Navás, 1924) (Chrysopidae: Chrysopinae). Fonte: http://www.simplemappr.net/ (Shorthouse, 2010). 
Ceraeochrysa scapularis (Navás, [1914]) (Fig. 98).

Essa espécie é conhecida somente da Colômbia e do Brasil (Freitas et al., 2009), onde é encontrada nos estados de Roraima (Freitas et al., 2009), Pará (Freitas et al., 2009), Mato Grosso, Minas Gerais e São Paulo (Freitas et al., 2009). Assim como C. sanchezi, essa espécie é encontrada em poucos cultivos agrícolas (seringueira, Citrus sp., eucalipto, pêssego e café).

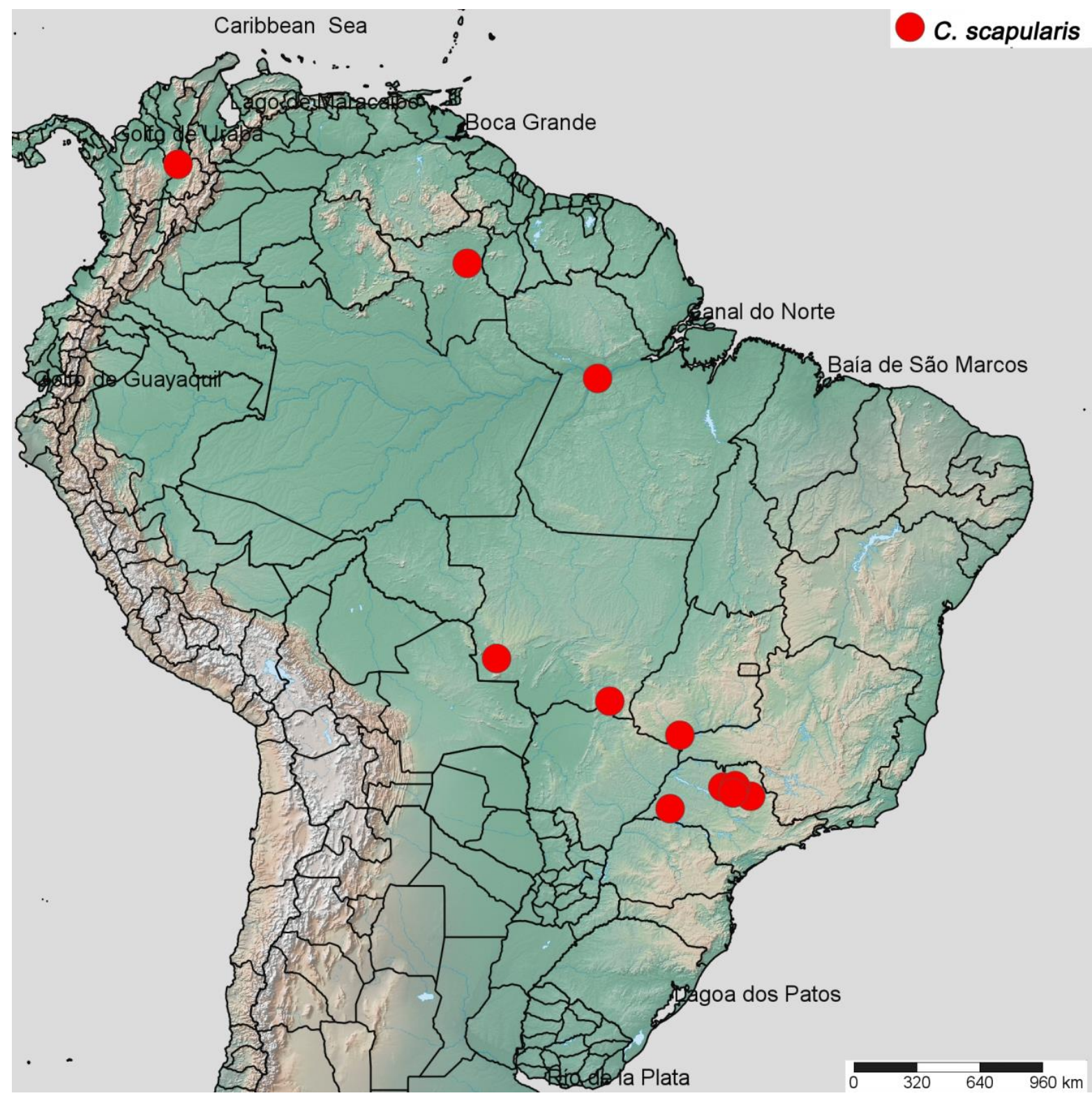

Figura 98. Distribuição geográfica de Ceraeochrysa scapularis (Navás, [1914]) (Chrysopidae: Chrysopinae). Fonte: http://www.simplemappr.net/ (Shorthouse, 2010). 
Ceraeochrysa squalidens Adams \& Penny, [1987] (Fig. 99).

C. squalidens foi encontrada somente na Venezuela e no Brasil no Estado do Amazonas (Freitas et al., 2009). Nunca foi observada em agroecossistemas.

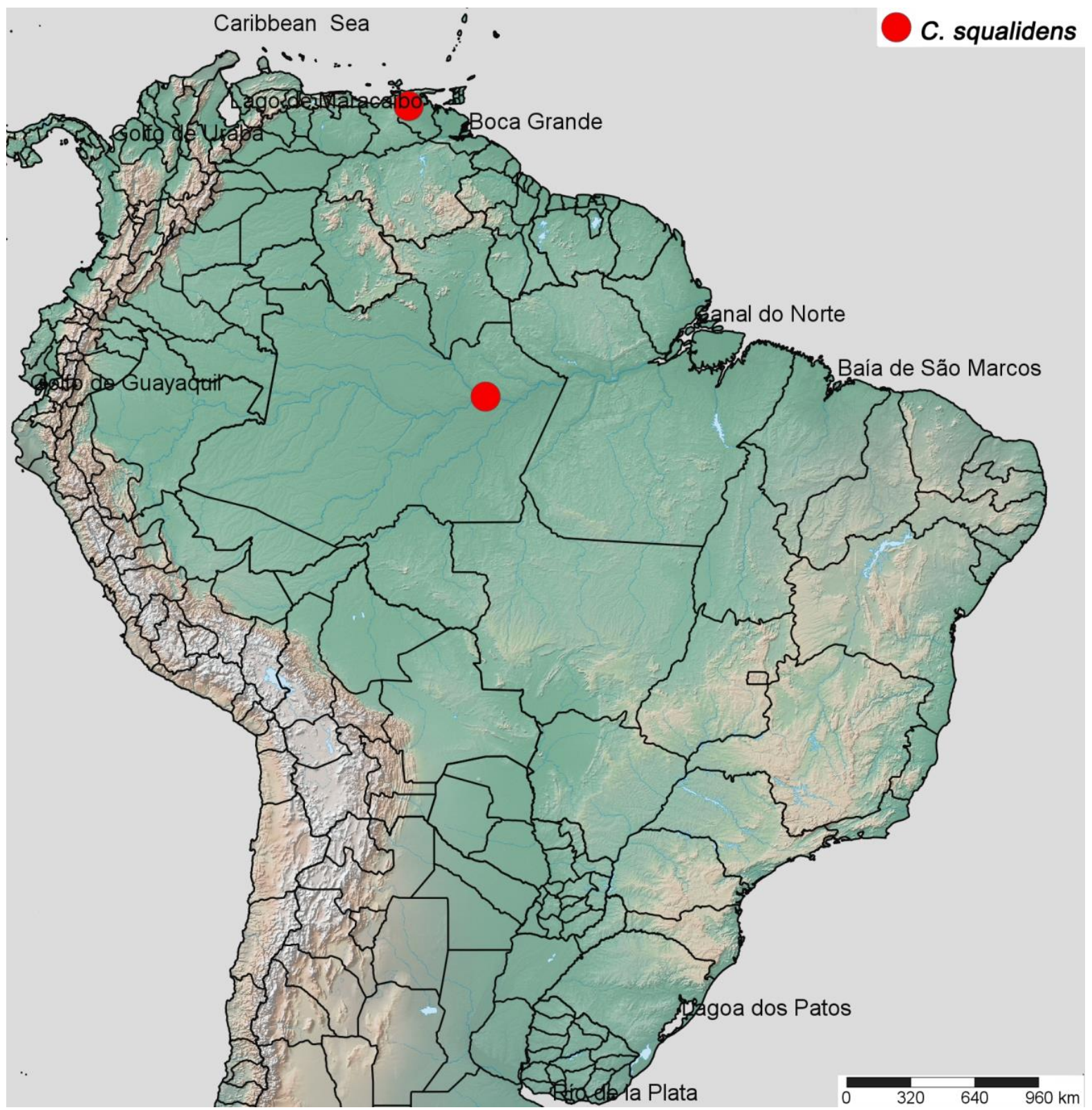

Figura 99. Distribuição geográfica de Ceraeochrysa squalidens Adams \& Penny, [1987] (Chrysopidae: Chrysopinae). Fonte: http://www.simplemappr.net/ (Shorthouse, 2010). 
Ceraeochrysa tucumana (Navás, 1919) (Fig. 100).

Além de ocorrer na Argentina (Freitas et al., 2009), esta espécie é conhecida de quatro Estado brasileiros (Mato grosso, Minas Gerais, São Paulo (Freitas et al., 2009), Santa Catarina). Apesar de ter distribuição geográfica relativamente restrita, C. tucumana foi encontrada em cultivos de Citrus sp., goiaba, pastagens, eucalipto e pinus.

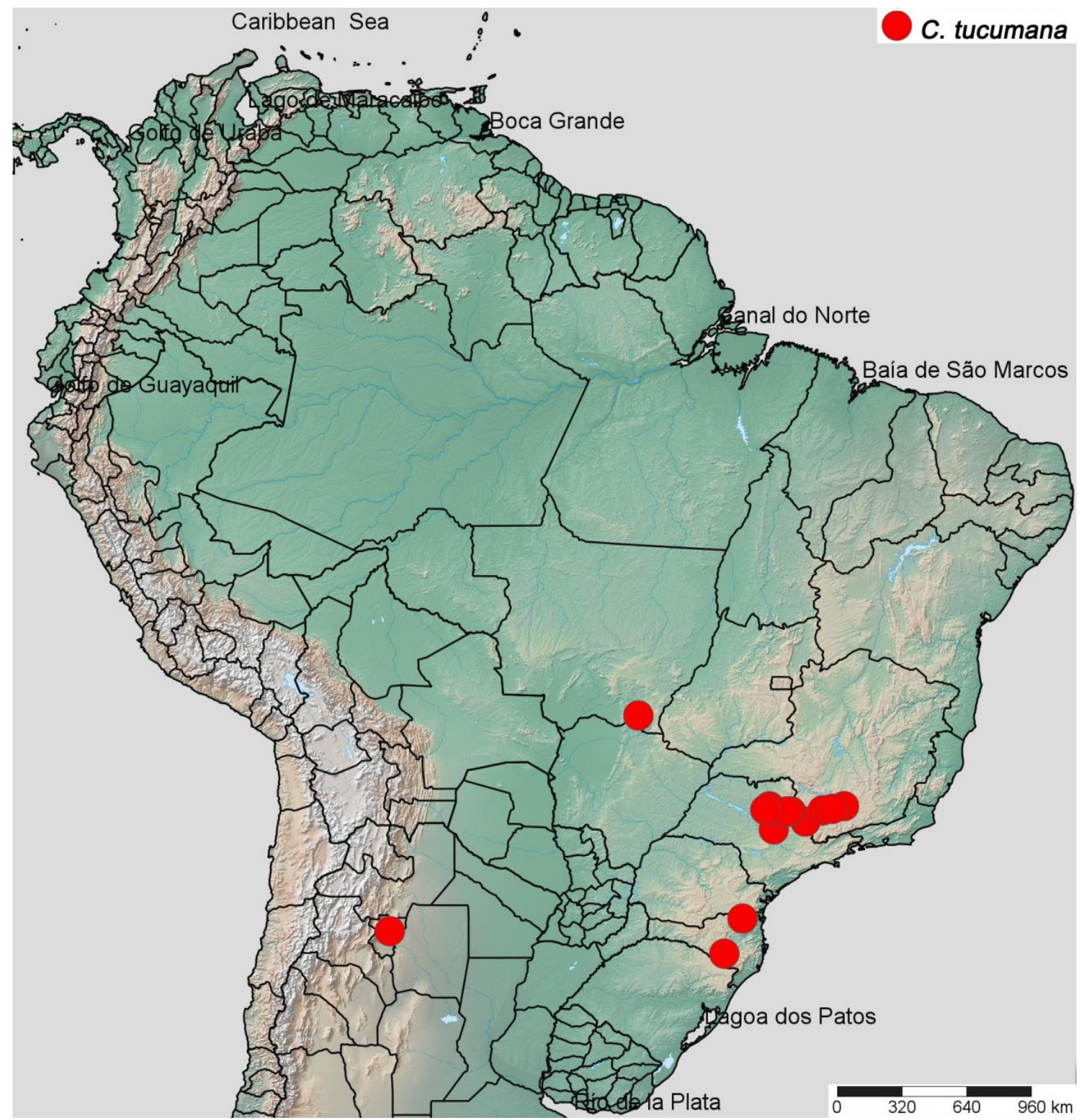

Figura 100. Distribuição geográfica de Ceraeochrysa tucumana (Navás, 1919) (Chrysopidae: Chrysopinae). Fonte: http://www.simplemappr.net/ (Shorthouse, 2010). 
Ceraeochrysa valida (Banks, 1895) (Fig. 101).

Apesar de ocorrer somente no Estado brasileiro de Roraima, esta espécie tem ampla distribuição geográfica, conhecida também dos E.U.A., México, Guatemala, El Salvador, Honduras, Costa Rica, República Dominicana, Haiti, Venezuela e Peru (Freitas et al., 2009). Não tem registro de ocorrência em agroecossistemas.

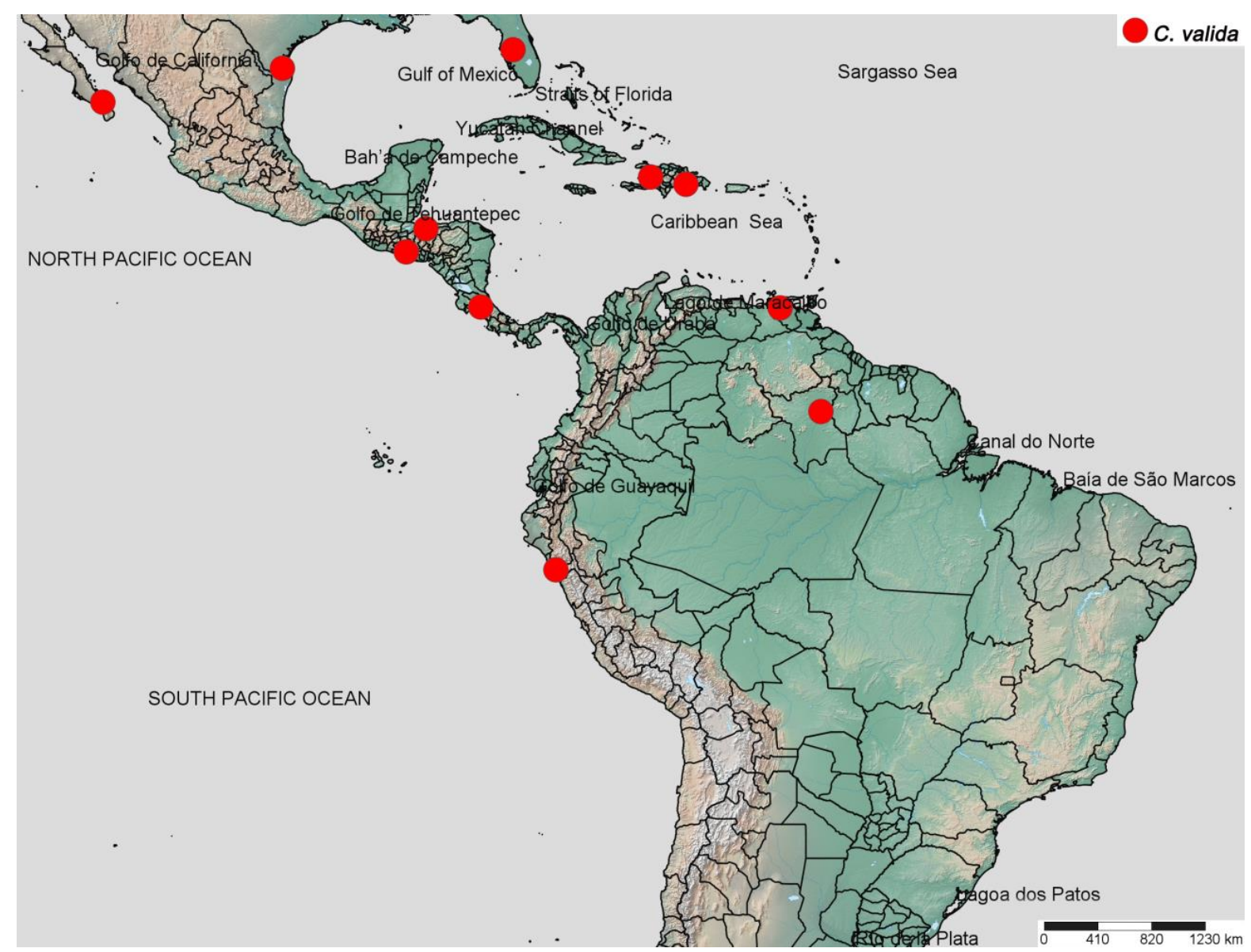

Figura 101. Distribuição geográfica de Ceraeochrysa valida (Banks, 1895) (Chrysopidae: Chrysopinae). Fonte: http://www.simplemappr.net/ (Shorthouse, 2010).

Ainda existem poucos dados sobre distribuição geográfica da maioria destas espécies, o que não permite a realização de um estudo biogeográfico. 


\section{CONCLUSÕES}

Foi feita uma descrição detalhada da morfologia externa e interna de Ceraeochrysa, o que auxilia na compreensão da evolução morfologica de Chrysopidae como um todo. O estudo morfológico comparativo permitiu a construção de uma hipótese de relações filogenéticas entre as espécies de Ceraeochrysa. O gênero aparece como monofilético, dentro da amostragem de grupos-externos. O clado $(C$. placita $+C$. intacta $)$ foi recuperado como irmão de todo o restante do gênero. Essas espécies apresentam diferenças morfológicas em fêmeas e larvas bastante consideráveis em relação ao restante das demais espécies do gênero, e por isso poderiam formar um novo gênero de Chrysopidae. Outros caracteres, principalmente de escleritos torácicos, ainda podem ser incluídos nesta análise, tornando-a mais robusta.

O gênero Ceraeochrysa, exceto $C$. placita e $C$. intacta, foi dividido em dois grandes clados. O primeiro, nomeado como paraguaria, possui 17 espécies, e, o segundo clado, forcipata, inclui 29 espécies divididas em três clados menores, excluindo C. forcipata que foi recuperada como irmã do restante das espécies.

Ao contrário de hipóteses anteriores na literatura, Chrysoperla e Chrysopodes não foram recuperados como irmãos de Ceraeochrysa. Criptochrysa apareceu como o gênero mais próximo. Ceraeochrysa compartilha com Criptochrysa a presença de gonocornos e gonapsis, na terminália masculina.

A compilação de informação sobre ocorrências de espécies do gênero em cultivos agrícolas apontam que $C$. cincta, $C$. claveri e $C$. cubana são as espécies com maior distribuição geográfica dentro do gênero Ceraeochrysa, bem como são as que ocorrem em maior número de cultivos agrícolas. 


\section{REFERÊNCIAS}

Adams, P.A. \& Penny. N.D. 1987. Neuroptera of the Amazon Basin. Part 11a. Introduction and Chrysopini. Acta Amazonica, vol.15, p. 413-479.

Adams, P.A. 1982. Ceraeochrysa, a new genus of Chrysopinae (Neuroptera). (Studies in New World Chrysopidae, Part II). Neuroptera International, vol. 2, p. 69-75.

Adams, P.A. 1996. Venational homologies and nomenclature in Chrysopidae, with comments on the Myrmeleontoidea (Insecta: Neuroptera), p. 19-30. In: Canard, M.; Aspöck, H.; Mansell, M.W. (eds.), Pure and applied research in Neuropterology. Proceedings of the Fifth International Symposium on Neuropterology. (2-6 May 1994 Cairo, Egypt). Privately printed, Toulouse, France. 341pp.

Aspöck, U. 1992. Crucial points in the phylogeny of the Neuroptera (Insecta), p. 63-73. In: Canard, M.; Aspöck, H.; Mansell, M.W. (eds), Current Research in Neuropterology. Proceedings of the Fourth International Symposium on Neuropterology, (24-27 June 1991, Bagnères-de-Luchon, Haute-Garonne, France). Privately printed, Toulouse, France. 414 pp.

Aspöck, U. 1993. Geklärtes und Ungeklärtes im System der Neuroptera (Insecta: Holometabola). Mitteilungen der Deutschen Gesellschaft für Allgemeine und Angewandte Entomologie, vol. 8, p. 451-456.

Aspöck, U. 1995. Neue Hypothesen zum System der Neuropterida. Mitteilungen der Deutschen Gesellschaft für Allgemeine und Angewandte Entomologie, vol. 10, p. 633636.

Aspöck, U; Haring, E. \& Aspöck, H. 2012. The phylogeny of the Neuropterida: long lasting and current controversies and challenges (Insecta: Endopterygota). Arthropod Systematics \& Phylogeny, vol. 70, p. 119-129.

Aspöck, U.; Plant, J.D.; Nemeschkal, H.L. 2001. Cladistic analysis of Neuroptera and their systematic position within Neuropterida (Insecta: Holometabola: Neuropterida: Neuroptera). Systematic Entomology, vol. 26, p. 73-86.

Aspöck, U. \& Aspöck, H. 2008. Phylogenetic relevance of the genital sclerites of Neuropterida (Insecta : Holometabola). Systematic Entomology, vol. 33, p. 97-127.

Banks, N. 1944. Neuroptera of Northern South America. Part III. Boletín de Entomología Venezolana, vol. 3, p. 1-34.

Beutel, R.G.; Friedrich, F. \& Aspöck, U. 2010b. The larval head of Nevrorthidae and the phylogeny of Neuroptera. Zoological Journal of the Linnean Society, vol. 158, p. 533 562. 
Brooks, S.J. \& Barnard, P.C. 1990. The green lacewings of the world: a generic review (Neuroptera: Chrysopidae). The Bulletin of the British Museum (Natural History), vol. 59, p. 117-286.

Ferris, G.F. 1940b. The morphology of Plega signata (Hagen) (Neuroptera: Mantispidae). Microentomology, vol. 5, p. 35-56.

Forey, P.L. \& Kitching, I.J. 2000. Experiments in coding multistate characters, p. 54-80. In: Scotland R.W \& Pennington R.T. (eds.). Homology and systematics: coding characters for phylogenetic analysis. London: Taylor and Francis. 217pp.

Freitas, S. \& Penny, N. D. 2012. Neuroptera Linnaeus, 1758. p. 537-546. In: Rafael, J. A. et al., (eds.). Insetos do Brasil. Ribeirão Preto: Holos. 810p.

Freitas, S.; Penny, N.D.; Adams, P.A. 2009. A revision of the New World genus Ceraeochrysa (Neuroptera: Chrysopidae). Proceedings of the California Academy of Sciences, vol. 60, p. 503-610.

Friedrich, F. \& Beutel, R.G. 2010. Goodbye Halteria? The thoracic morphology of endopterygota (Insecta) and its phylogenetic implications. Cladistics, vol. 26, p. 1-34.

Goloboff, P.A., Farris, J.S. \& Nixon, K.C. 2003-2007. TNT: Tree analysis using new technology. Publicado pelos autores. Tucuman, Argentina (v. 1.1, Novembro de 2007).

Grimaldi, D. \& Engel, M.S. 2005. Evolution of Insects. Cambridge University Press, 755 pp.

Handlirsch, A. 1906-1908. Die fossilen Insekten und die Phylogenie der rezenten Formen. W. Engelmann, Leipzig, Germany. Ein Handbuch für Paläontologen und Zoologen. 1430 pp.

Haring, E. \& Aspöck, U. 2004. Phylogeny of the Neuropterida: a first molecular approach. Systematic Entomology, vol. 29, p. 415-430.

Haruyama, N.; Mochizuki, A.; Duelli, P.; Naka, H. \& Nomura, M. 2008. Green lacewing phylogeny, based on three nuclear genes (Chrysopidae, Neuroptera). Systematic Entomology, vol. 33, p. 275-288.

Matsuda, R. 1970. Morphology and evolution of the insect thorax. Memoir of the Entomological Society of Canada, Vol, 76, p. 5-431.

Morse, M. 1931. The external morphology of Chrysopa perla L. (Neuroptera: Chrysopidae). Jounal of the New York Entomological Society, vol. 39, p. 1-43.

Navas, L. 1923. Entomología de Catalunya. Neurdòpters. Fasc. I. Neuròpters propis.1 pl. Institut d'Estudis Catalans, Secció de Ciences, Barcelona, España. 271 pp.

New, T.R. 1989. Planipennia, Lacewings. Handbuch der Zoologie, vol. 4, part. 30. Walter de Gruyter, Berlin, Germany. 
Nixon, K.C. 2002. WinClada ver. 1.00.08. Ithaca, NY. Publicado pelo autor, disponível em http://taxonomy.zoology.gla.ac.uk/rod.

Nixon, K.C. \& Carpenter, J.M. 1993. On outgroups. Cladistics, vol. 9, p. 413-426.

Schneider, W.G. 1851. Symbolae ad monographiam generis Chrysopae, Leach. Sexaginta picturarum tabulis, in lapide acu delineatis, quarum quinquaginta quatuor coloribus impressae sunt, illustratae. Editio major. Ferdinandum Hirt, Vratislaviae. 178 pp.

Shorthouse, P. 2010. SimpleMappr, an online tool to produce publication-quality point maps. [Retrieved from http://www.simplemappr.net. Accessed 28 November, 2013].

Snodgrass, R. E. 1935. Principles of insect morphology. New York. 667 pp.

Sosa, F. \& Freitas, S. 2010. New Neotropical species of Ceraeochrysa Adams (Neuroptera: Chrysopidae). Zootaxa, vol. 2562, p. 57-65.

Sosa, F. \& Freitas, S. 2011. A new synonym, a new male description and new geographical records for three Ceraeochrysa species (Neuroptera: Chrysopidae). Zootaxa, vol. 2913, p. 47-58.

Tauber, C.A. \& Flint Jr., O.S. 2010. Resolution of some taxonomic and nomenclatural issues in a recent revision of Ceraeochrysa (Neuroptera: Chrysopidae). Zootaxa, vol. 2565, p. 55-67.

Tillyard, R. J. 1916b. Studies in Australian Neuroptera. No. 1. The wing venation of the Chrysopidae. Proceedings of the Linnean Society of New South Wales, vol. 41, p. 221248.

Triplehorn, C. A. \& Johnson, N. F. 2011. Estudo dos Insetos. Tradução da $7^{\circ}$ Edição de Borror and Delong's introduction to the study of insects. São Paulo, Cengage Learning. 809pp.

Winterton, S.L.; Hardy, N.B. \& Wiegmann, B.M. 2010. On the wings of lace: phylogeny and Bayesian divergence time estimates of Neuropterida (Insecta) based on morphological and molecular data. Systematic Entomology, vol. 35, p. 349-378.

Winterton, S. L. \& Brooks, S. J. 2002. Phylogeny of the Apochrysine green lacewings (Neuroptera: Chrysopidae: Apochrysinae). Annals of the Entomological Society of America, vol. 95, p. 16-28.

Winterton, S. L. \& Freitas, S. 2006. Molecular phylogeny of the green lacewings (Neuroptera: Chrysopidae). Australian Journal of Entomology, vol. 45, p. 235-243.

Zimmermann, D.; Randolf, S.; Metscher, B.D. \& Aspöck, U. 2011. The function and phylogenetic implications of the tentorium in adult Neuroptera (Insecta). Arthropod Structure \& Development, vol. 40, p. 571-582. 


\section{APÊNDICES}

Tabela III. Espécies de Ceraeochrysa Adams, 1982 (Chrysopidae: Chrysopinae) utilizadas para a análise filogenética do gênero, que não foram observados espécimes.

\begin{tabular}{|c|c|}
\hline C. adornata (Lacroix, 1926) & C. anceps (Navás, 1926) \\
\hline C.ariasi Adams \& Penny, 1987 & C.belizensis Freitas \& Penny, 2009 \\
\hline C. berlandi (Navás, 1924) & C. bitacornua Freitas and Penny, 2009 \\
\hline C. caucana (Banks, 1910) & C. curvabilis Freitas \& Penny, 2009 \\
\hline C. defreitasi Penny, 2002 & C. derospogon Freitas \& Penny, 2009 \\
\hline C. digitata Freitas \& Penny, 2009 & C. divaricata Freitas \& Penny, 2009 \\
\hline C. elegans Penny, 1998 & C. falcifera Adams \& Penny, 1987 \\
\hline C. fiebrigi (Navás, 1913) & C. forcipata Freitas \& Penny, 2009 \\
\hline C. inbio Penny, 1997 & C. indicata (Navás, 1914) \\
\hline C. infausta (Banks, 1946) & C. intacta (Navas, 1912) \\
\hline C. lateralis (Guérin-Méneville, 1844) & C. lineaticornis (Fitch, 1855) \\
\hline C. nigripedis Penny, 1997 & C. panamensis Freitas \& Penny, 2009 \\
\hline C. placita (Banks, 1908) & C. rafaeli Adams \& Penny, 1987 \\
\hline C. reddyi Adams \& Penny, 1987 & C. reducta (Banks, 1944) \\
\hline C. silvanoi (Navás, 1916) & C. tauberae Penny, 1997 \\
\hline
\end{tabular}


Tabela IV. Espécies de Ceraeochrysa Adams, 1982 (Chrysopidae: Chrysopinae) utilizadas estudo comparativo de morfologia de Ceraeochrysa e sua análise Filogenética.

\begin{tabular}{|c|c|}
\hline Espécie & $\begin{array}{l}\text { Localização de coleta, coletores dos espécimes e museu ou } \\
\text { coleção }\end{array}$ \\
\hline $\begin{array}{l}* C \text {. achillea Freitas \& } \\
\text { Penny, } 2009\end{array}$ & $\begin{array}{l}2 \hat{\jmath} \text { e } 2 \uparrow \text {, Venezuela, Lara, Pampero, 02/ii/21010, Francisco, S e } \\
\text { J. Torres col., Museo Entomológico Dr. "José Manuel Osorio". }\end{array}$ \\
\hline *C. acmon Penny, 1998 & $\begin{array}{l}2 \hat{\jmath} \text { e } 1 \text {, } \text {, Brasil, SP, Jaboticabal, 24/v/2010, Freitas, S. col., } \\
\text { Coleção Prof. Dr. Sergio de Freitas Universidade Estadual } \\
\text { Paulista Jaboticabal. }\end{array}$ \\
\hline C. angulata (Navás, 1929) & 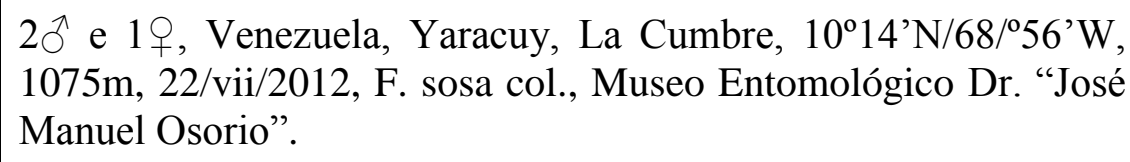 \\
\hline $\begin{array}{l}\text { *C. angusta Freitas \& } \\
\text { Penny, } 2009\end{array}$ & $\begin{array}{l}\text { 1ठ̀, Venezuela, Aragua, Rancho Grande, } 1100 \mathrm{~m}, 29 / \mathrm{v} / 1981, \mathrm{~F} . \\
\text { Fernandes e J.Clavijo col., Museo Entomológico Dr. "José } \\
\text { Manuel Osorio". }\end{array}$ \\
\hline${ }^{*}$ C. arioles (Banks, 1944) & $\begin{array}{l}\text { 1ð̊, México, Chiapas, Vergel, } 13 \text { May 1935, A. Dampf., Museo } \\
\text { Entomológico Dr. "José Manuel Osorio". }\end{array}$ \\
\hline $\begin{array}{l}\text { *C. castilloi (Navás, } \\
1913)\end{array}$ & $\begin{array}{l}1 \text { \&, Brasil, SP, Jaboticabal, 24/v/2010, Freitas, S. col. Coleção } \\
\text { Prof. Dr. Sergio de Freitas Universidade Estadual Paulista } \\
\text { Jaboticabal. }\end{array}$ \\
\hline $\begin{array}{l}\text { *C. cincta (Schneider, } \\
1851)\end{array}$ & $\begin{array}{l}\text { 7ð e 7q, Brasil, SP, Jaboticabal, 03/viii/2013, Caleb Martins. e } \\
\text { Sosa, F. col.; } 8 \hat{\text { e }} 8 \text { } 9 \text {, Brasil, SP, Jaboticabal, 27/i/2004, Toledo, } \\
\text { M. B. F. col., Coleção Prof. Dr. Sergio de Freitas Universidade } \\
\text { Estadual Paulista Jaboticabal. }\end{array}$ \\
\hline *C. claveri (Navás, 1911) & 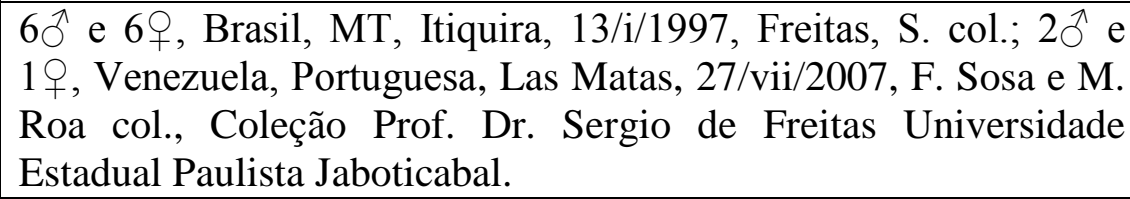 \\
\hline *C. cornuta (Navás, 1925) & $\begin{array}{l}2 \hat{\jmath} \text { e } 2 \text { +, Brasil, SP, Jaboticabal, Citrus, 03/viii/2013, Caleb } \\
\text { Martins e Francisco Sosa col.; 5ð e 5q, Brasil, MT, Itiquira, } \\
\text { P.E.M., 16/vii/2001, Freitas, S. col., Coleção Prof. Dr. Sergio de } \\
\text { Freitas Universidade Estadual Paulista Jaboticabal. }\end{array}$ \\
\hline $\begin{array}{l}\text { *C. costaricensis Penny, } \\
1997\end{array}$ & $\begin{array}{l}1 \partial^{\lambda}, \text { Venezuela, Aragua, Rancho Grande, } 1100 \mathrm{~m}, 27 / \mathrm{vi} / 2012, \text { F. } \\
\text { Sosa e M. Roa col., Museo Entomológico Dr. "José Manuel } \\
\text { Osorio". }\end{array}$ \\
\hline C. cubana (Hagen, 1861) & 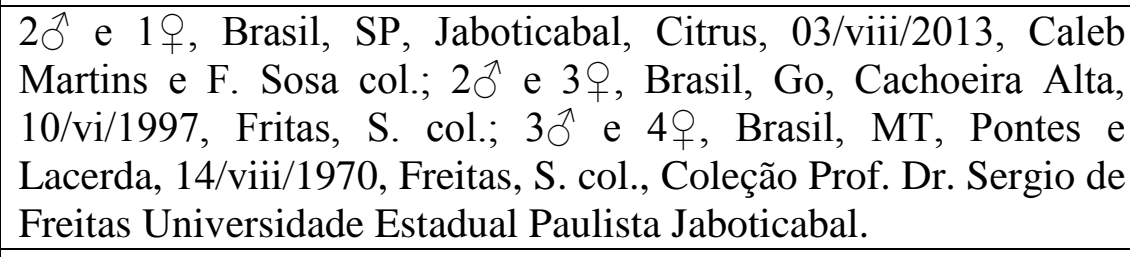 \\
\hline $\begin{array}{l}\text { *C. discolor (Navás, } \\
\text { 1914) }\end{array}$ & $\begin{array}{l}1 \lesssim \text { e } 1 \text {, , Venezuela, Lara, Pampero, } 648 \mathrm{~m}, 24 / \mathrm{ii} / 2008 \text { J. Torres } \\
\text { col., Museo Entomológico Dr. "José Manuel Osorio". }\end{array}$ \\
\hline $\begin{array}{l}\text { *C. dislepis Freitas \& } \\
\text { Penny, } 2001\end{array}$ & 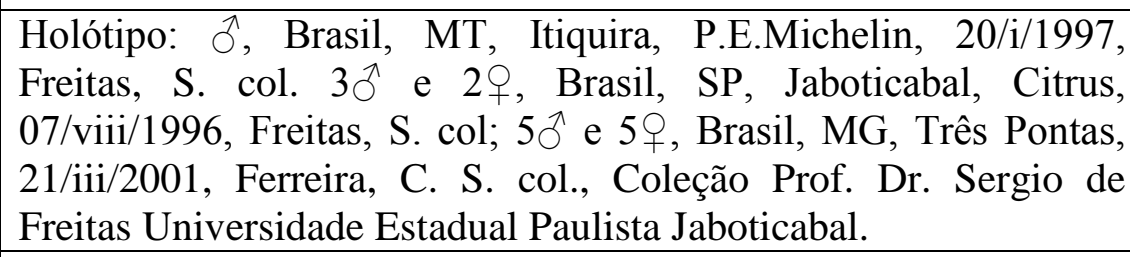 \\
\hline $\begin{array}{l}\text { C. dolichosvela Freitas \& } \\
\text { Penny, } 2001\end{array}$ & $\begin{array}{l}\text { 1q, Brasil, PE, Petrolina, xi/2006, Freitas, S. col.; } 1 \text {, Brasil, } \\
\text { MS, Corumba, 23/viii/1995, Freitas, S. col., Coleção Prof. Dr. } \\
\text { Sergio de Freitas Universidade Estadual Paulista Jaboticabal. }\end{array}$ \\
\hline
\end{tabular}




\begin{tabular}{|c|c|}
\hline *C. effusa (Navás, 1911) & $\begin{array}{l}\text { 1§^, Venezuela, Lara, Pampero, 648m, 24/ii/2008 J. Torres col., } \\
\text { Museo Entomológico Dr. "José Manuel Osorio". }\end{array}$ \\
\hline C. everes (Banks, 1920) & $\begin{array}{l}3 \hat{\jmath} \text { e } 2 \uparrow \text {, Brasil, SP, Jaboticabal, Citrus, 03/viii/2013, Caleb } \\
\text { Martins e F. Sosa col.; } 5 \hat{\jmath} \text { e } 5 \uparrow, \text { Brasil, SP, Jaboticabal, Manga, } \\
\text { 03/viii/2013, Caleb Martins col.; } 3 \hat{\jmath} \text { e } 3 \uparrow \text {, Brasil, MT, Itiquira, } \\
\text { P.E. Michelin, 16/viii/2001, Freitas, S. col., Coleção Prof. Dr. } \\
\text { Sergio de Freitas Universidade Estadual Paulista Jaboticabal. }\end{array}$ \\
\hline $\begin{array}{l}\text { C. fairchildi (Banks, } \\
\text { 1946) }\end{array}$ & $\begin{array}{l}2 \delta^{\wedge} \text { e } 1 q \text {, Brasil, SP, Jaboticabal, xi/1994, Ville C, R. col., } \\
\text { Coleção Prof. Dr. Sergio de Freitas Universidade Estadual } \\
\text { Paulista Jaboticabal. }\end{array}$ \\
\hline $\begin{array}{l}* \text { C. melanopaeira Sosa \& } \\
\text { Freitas, } 2010\end{array}$ & $\begin{array}{l}\text { 1§,, Venezuela, Lara, Pampero, 648m, 07/ii/2009, F. Sosa e J. } \\
\text { Torres col.; } 1 \text {, } \text {, Venezuela, Lara, El Pampero, } 645 \text { m, 13/ii/201, } \\
\text { J.Torres col., Museo Entomológico Dr. "José Manuel Osorio". }\end{array}$ \\
\hline $\begin{array}{l}* \text { C. michaelmuris Adams } \\
\text { \& Penny, } 1987\end{array}$ & $\begin{array}{l}\text { 1§, Venezuela, Portuguesa, Ospino La Veja, } 127 \mathrm{~m} \text {, Sorgo, } \\
\text { 14/ii/2008, F. sosa col.; } 19 \text {, Venezuela, Portuguesa, Ospino La } \\
\text { Veja, 127m, Sorgo, 10/ii/2008, F. Sosa col., Museo Entomológico } \\
\text { Dr. "José Manuel Osorio". }\end{array}$ \\
\hline $\begin{array}{l}\text { C. nigripes Adams \& } \\
\text { Penny, } 1987\end{array}$ & $\begin{array}{l}1 \text {, Brasil, Rondonia, Vilhena, 22/xi/2012, Farias. C. col., } \\
\text { Coleção Prof. Dr. Sergio de Freitas Universidade Estadual } \\
\text { Paulista Jaboticabal. }\end{array}$ \\
\hline $\begin{array}{l}\text { C. montoyana (Navás, } \\
\text { 1913) }\end{array}$ & 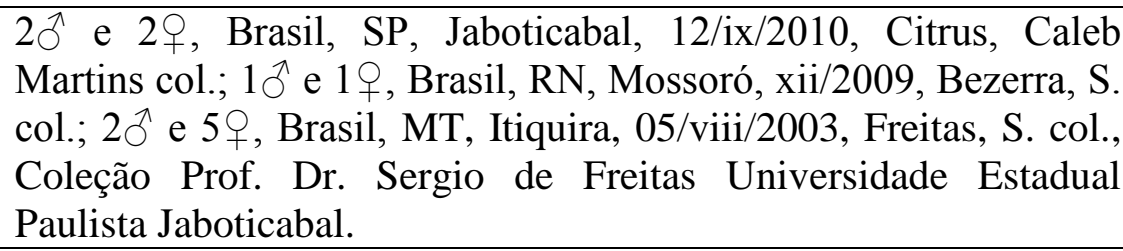 \\
\hline $\begin{array}{l}\text { C. paraguaria (Navás, } \\
\text { 1920) }\end{array}$ & 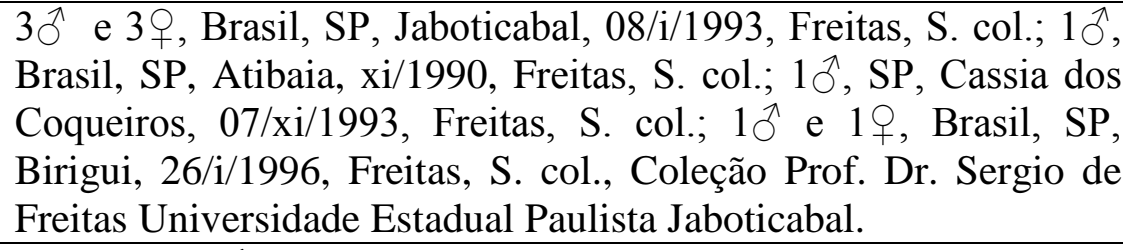 \\
\hline $\begin{array}{l}\text { C. pittieri Sosa \& Freitas, } \\
2010\end{array}$ & $\begin{array}{l}\text { Holótipo: 10َ, Venezuela, Aragua, PN Henrry Pittier, 1140m, } \\
\text { 20/ii/2008, F.Sosa, F. Diaz e R. Zuñiga col., Museo Entomológico } \\
\text { Dr. "José Manuel Osorio". }\end{array}$ \\
\hline $\begin{array}{l}\text { C. sanchezi (Navás, } \\
1924 \mathrm{e})\end{array}$ & 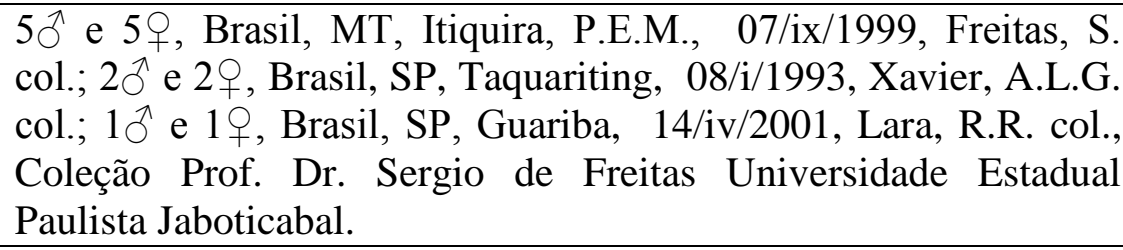 \\
\hline $\begin{array}{l}\text { C. scapularis (Navás, } \\
\text { 1914a) }\end{array}$ & $\begin{array}{l}10 \AA \text { e } 10 \text {, , Brasil, SP, Jaboticabal, citrus, } 15 / \text { vi/2000, Takahashi, } \\
\text { K. M. col., Coleção Prof. Dr. Sergio de Freitas Universidade } \\
\text { Estadual Paulista Jaboticabal. }\end{array}$ \\
\hline C. smithi (Navás, 1914) & $\begin{array}{l}\text { 1q, E.U.A., Florida, Gainesville, 03/x/1998, Takahashi, K. M. } \\
\text { col.; } 1 \delta^{\lambda} \text {, Venezuela, Lara, Tarabana, } 10^{\circ} 01^{\prime} \mathrm{N} / 69^{\circ} 16^{\prime} \mathrm{W}, 514 \mathrm{~m} \text {, } \\
\text { 05/v/2012, light Trap, F.Sosa col.; } 1 \mathrm{O}^{\lambda} \text {, Venezuela, Lara, } \\
\text { Pampero, 648m, 18/ii/20008, J. Torres col., Coleção Prof. Dr. } \\
\text { Sergio de Freitas Universidade Estadual Paulista Jaboticabal. }\end{array}$ \\
\hline
\end{tabular}




\begin{tabular}{|c|c|}
\hline $\begin{array}{l}\text { C. squalidens Adams \& } \\
\text { Penny, } 1987\end{array}$ & $\begin{array}{l}\text { 1§, Venezuela, Aragua, PN Henrry Pittier, 1140m, 20/ii/2008, } \\
\text { F.Sosa, F. Diaz e R. Zuñiga col., Museo Entomológico Dr. "José } \\
\text { Manuel Osorio". }\end{array}$ \\
\hline $\begin{array}{l}\text { C. squamma Freitas \& } \\
\text { Penny, } 2001\end{array}$ & $\begin{array}{l}60^{\wedge} \text { e } 69 \text {, Brasil, MG, Três Pontas, 13/vi/2009, Ferreira, C. S. } \\
\text { col., Coleção Prof. Dr. Sergio de Freitas Universidade Estadual } \\
\text { Paulista Jaboticabal. }\end{array}$ \\
\hline $\begin{array}{l}\text { C. tenuicornis Adams \& } \\
\text { Penny, } 1987\end{array}$ & $\begin{array}{l}2 \hat{\jmath} \text { e } 2 \text {, } \text {, Brasil, MG, Três Pontas, } 13 / \text { vi/2009, Ferreira, C. S. } \\
\text { col.; } 2 \hat{\jmath} \text { e } 2 \text {, } \text {, Brasil, SP, Jaboticabal, } 10 / \text { iv/2008, Freitas, S. col., } \\
\text { Coleção Prof. Dr. Sergio de Freitas Universidade Estadual } \\
\text { Paulista Jaboticabal. }\end{array}$ \\
\hline $\begin{array}{l}\text { C. torresi Sosa \& Freitas, } \\
2010\end{array}$ & 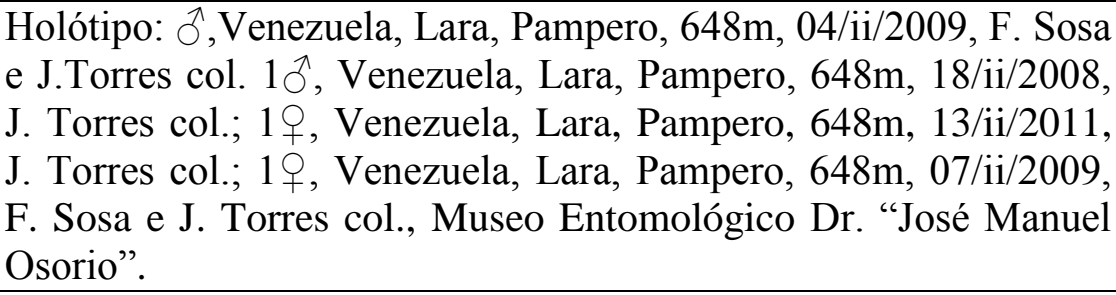 \\
\hline $\begin{array}{l}\text { C. tucumana (Navás, } \\
\text { 1919) }\end{array}$ & $\begin{array}{l}3 \hat{0} \text { e } 3 q \text {, Brasil, SP, Jaboticabal, Citrus, 03/viii/2003, Caleb } \\
\text { Martins e F. Sosa col.; } 2 \hat{\bigcirc} \text { e } 3 \uparrow \text {, Brasil, SP, Jaboticabal, Citrus, } \\
\text { 03/vii/2008, Freitas, S. col., Coleção Prof. Dr. Sergio de Freitas } \\
\text { Universidade Estadual Paulista Jaboticabal. }\end{array}$ \\
\hline C. valida (Banks, 1895) & $\begin{array}{l}4 \hat{\jmath} \text { e } 5 \text {, , Venezuela, Lara, Pampero, } 648 \mathrm{~m}, 02 / \mathrm{ii} / 2011 \text {, F. Sosa e } \\
\text { J. Torres col., Museo Entomológico Dr. "José Manuel Osorio". }\end{array}$ \\
\hline
\end{tabular}

*Fotos de outros espécimes fornecidas pelo Prof. Dr. Francisco Sosa 
Tabela V. Índice de abreviações de estruturas.

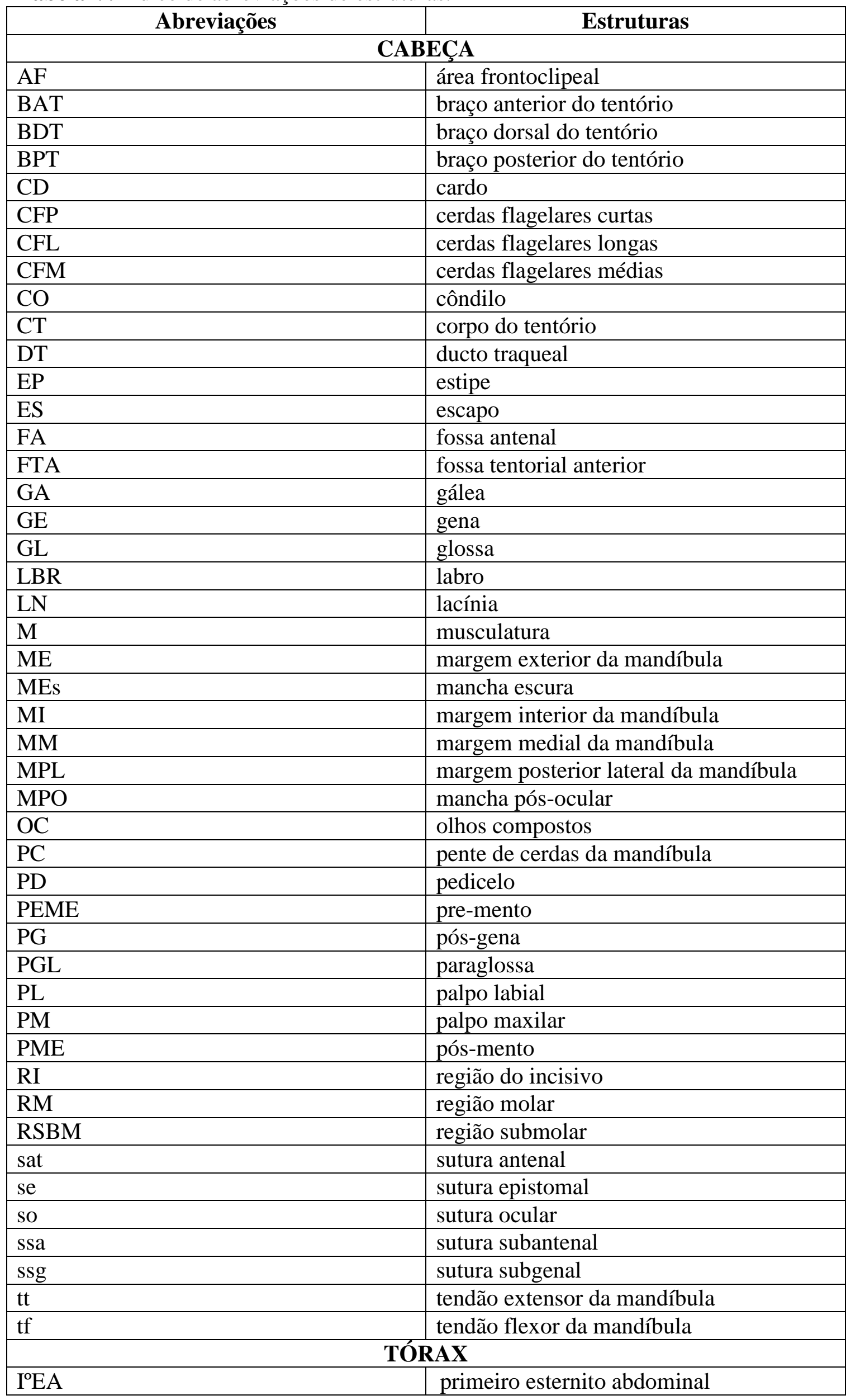




\begin{tabular}{|l|l|}
\hline ITA & primeiro tergito abdominal \\
\hline AN & anepímero \\
\hline ANP & anepisterno \\
\hline BPL & braço pleural \\
\hline BS & basisterno \\
\hline CAE & cordão axilar do escutelo \\
\hline CAT & catepisterno \\
\hline CM & catepímero \\
\hline CP & crista pleural \\
\hline EB & esclerito basalar \\
\hline ECD & esclerito cervical dorsal \\
\hline ECO & escutelo \\
\hline EPM & epímero \\
\hline EPO & episterno \\
\hline EO & espinasterno \\
\hline ESA & esclerito subalar \\
\hline ESP & espiráculo \\
\hline EST & escuto \\
\hline FRG & fragma \\
\hline MR & meron \\
\hline PE & pré-episterno \\
\hline PECL & primeiro esclerito cervical lateral \\
\hline PES & pró-esterno \\
\hline PN & pronoto \\
\hline PNM & processo noto-medial \\
\hline PNP & processo noto-posterior \\
\hline PO & posnoto \\
\hline PPA & processo pleural alar \\
\hline PPC & processo pleural coxal \\
\hline PR & prescuto \\
\hline sa & sutura anapleural \\
\hline SECL & segundo esclerito cervical lateral \\
\hline see & sutura escuto-escutelar \\
\hline slp & sutura lateral parapsidal \\
\hline smm & sutura mediana mesonotal \\
\hline sp & sutura pleural \\
\hline spc & sutura paracoxal \\
\hline st & sutura transepimeral \\
\hline TEA & terceiro esclerito axilar \\
\hline TR & arólio \\
\hline VE & coxa \\
\hline & esporão \\
\hline AR & fêmur \\
\hline CX & garras tarsais \\
\hline ESR & tarso \\
\hline FM & tíbia \\
\hline GT & \\
\hline TA & tocantin \\
\hline TR & \\
\hline & \\
\hline &
\end{tabular}




\begin{tabular}{|l|l|}
\hline A1 & nervura anal 1 \\
\hline A2 & nervura anal 2 \\
\hline BC & nervura basal costal \\
\hline C & nervura costal \\
\hline CCD & célula cubital distal \\
\hline CG1 & célula gradiforme 1 \\
\hline CI & célula intramediana \\
\hline CUA & nervura cubital anterior \\
\hline CUP & nervura cubital posterior \\
\hline FU & forquilhas marginais \\
\hline GE & nervuras gradiformes externas \\
\hline GI & nervuras gradiformes internas \\
\hline MA & nervura medial anterior \\
\hline MP1 & ramo medial posterior 1 \\
\hline MP2 & ramo medial posterior 2 \\
\hline PEA & primeiro esclerito axilar \\
\hline PSC & "nervura" pseudocubital \\
\hline PSM & "nervura" pseudomediana \\
\hline RA & nervura radial anterior \\
\hline SC & nervura subcostal \\
\hline SEA & segundo esclerito axilar \\
\hline SAL & suralar \\
\hline SR & setor radial \\
\hline TC & nervuras transversais costais \\
\hline TG & tégula \\
\hline TIC & transversal intercubital \\
\hline TR & nervuras transversais radiais \\
\hline & GENIÁLIA \\
\hline AD & apódema dorsal \\
\hline AMG & arco medial do gonarco \\
\hline ARC & arcesso \\
\hline BC & bursa copulatrix \\
\hline BLG & braços laterais do gonarco \\
\hline CLC & callus cerci \\
\hline DE & ducto espermático \\
\hline DDE & dilatação do ducto espermático \\
\hline E & esternito \\
\hline EC & ectoprocto \\
\hline ENT & entoprocesso \\
\hline EPA & espermateca \\
\hline GB & glândula bursal \\
\hline GC & gonocorno \\
\hline GCA & gonocrista \\
\hline GL & gonapófises laterais \\
\hline GPS & gonapse \\
\hline GST & gonosetas \\
\hline GSU & gonossaco \\
\hline LAA & lobo apical do arcesso \\
\hline MD & mediuncus \\
\hline PAA & placa apical do arcesso \\
\hline PDA & processo dorsal do arcesso \\
\hline & \\
\hline
\end{tabular}




\begin{tabular}{|l|l|}
\hline PDG & placa dorsal do gonarco \\
\hline PDI & processo digitiforme do gonarco \\
\hline PVG & projeção ventral do gonocorno \\
\hline PT & $\begin{array}{l}\text { projeção do ix tergito + ectoprocto } \\
\text { masculino. }\end{array}$ \\
\hline RV & $\begin{array}{l}\text { ramo ventral do apodema abdominal } \\
\text { masculino }\end{array}$ \\
\hline SB & subgenitália \\
\hline T & tergito \\
\hline VEE & vela externa da espermateca \\
\hline VIE & vela interna da espermateca \\
\hline
\end{tabular}


Tabela VI. Matriz com os 66 táxons terminais e 50 caracteres utilizados na análise filogenética.

Joguina constellata Chrysopōdes_polygonica Chrysoperla_genanigra Criptochrysa. chloros C._placita C.-intacta c.-pittieri c. michaelmuris C.-tenuicornis c._paraguaria C.-nigripedis C.-tauberae c.-angusta c.-_reddyi

C.-valida

c.-cubana

c.-scapularis

c.-acmon

c. smithi

c. dislepis

c. melanopaeira

c. - everes

c. squarma

c. torresi

C._costaricensis

c. squalidens

c. forcipata

c. elegans

c. sanchezi

C._arioles

c. claveri

c. -montoyana

c. cornuta

c.-cincta

C. belizensis

c. -inbio

C._discolor

c.-_ariasi

C.-panamensis

c. falcifera

c. fairchildi

c. angulata

c.-defreitasi

c.-nigripes

c. bitacornua

c.-tucumana

c.-divaricata

C.-_berlandi

c.-infausta

C.-lineaticornis

c.-achillea

C. derospogon

c.-digitata

c. effusa

C._curvabilis

c. adornata

c.-anceps

C.-castilloi

c. caucana

c. dolichosvela

c. fiebrigi

c. indicata

C.-lateralis

c.-rafaeli

c. reducta

c. silvanoi

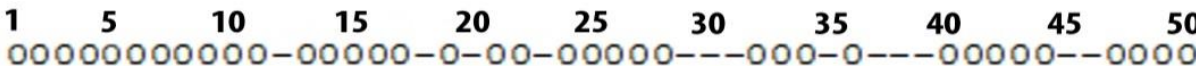
$0000111-00000100100010-00000-00000-0---10000--0000$ $0000011-00000010000000-00000-00000-0---10000--0000$ 0000011-00010010000000-00000-00000-100010000--0001 0001111-10000010100010-0?000-1-000-100010000--0001 0001111-11000010100010-0?000-1-000-100010000--0001 $111000001000011010000 ?-? ? 101001000-100010000--0001$ 1110001-1100010010000100000100100?-100?10001000001 1110001-100001101000010000010000010101010001000001 1110011-100001101100010000010010010101010000--0001 1110011-11001110110101??0?00-??00100---11000--0001 1110011-1011110111010????0010010010100010000--0001 1110011-1011110111010????00100100??100?10000--0001 1110011-0001110011?11????00?-010010100010000--0001 $1110001-00011100110111001001001000-100110000--0001$ 0110001-00001100110111001010-0100?-100?10000--0001 $1110000101001100110111001010-01000-100010000--0001$ $1110000000101010110111 ? 01101001000-100011001010001$ $1110000100001100110111001001001000-10001 ? 011001001$ $1110000000001100110111011001001100-111010011001001$ $1100000 ? 00001110110101111001001100-111010011001001$ $1110000000001110110111111001001100-111010011001001$ $1110000000001110010111111101001100-111011011001001$ 1110001-001010101101011?1101001100-111011011001001 1110001-00101110110111111101001100-111011011001001 1110001-001?1100110111111101001100-111011010--1001 1110001-00000110110?0100?0010010010100110000--?001 $111000001101010011000 ? ? ? ? 001-? ? 0011100010000--0001$ $11100000010 ? 010011001120010100100 ? ? 100010000--0001$ $111000000001001011001 ? ? ? ? 1011000011100000100--0001$ $11100000000101101100112101011010111100000000-0001$ $1110000000010110110011210101101011110000 ? 000--0001$ 11100000010101101100012100011010011100000101110001 11100000000000101100012100011010011100001101110001 111000000010001011110 ????1011010111100001101110001 1110001-1100001011000????1011010011100001100--0001 1110001-11000110110001210?011??0011100001101110001 1010011-000101101100?1200000-010011100011001000001 1010101-000?011011000????001001000-100111001000001 $11100101-00100101100 ? ? ? ? ? 001001000-100111011100001$ 1110011-00010010110001211101001000-100011011000001 $1110010110100011110011211101001000-10011 ? 010--0001$ 1110011-101?001011001????101001000-100111010--0001 1110001-000100001100012000010010011100011000--0001 $11100001000000101 ? 000 ? ? ? ? 00100100 ? ? 100011000--0001$ $1110000100000010110011200000-000011100011001000001$ 111000010000001011000 ????000-000011100011001111001 $11001001000 ? 00101100012000010000011100010001011111$ 111000010010100011110 ????10100000??100011000--11?1 $11100001001011001111112 ? ? 10100000 ? ? 100 ? 11001011111$ $101000010010110011110120010100000 ? ? 100 ? 11001011111$ 100000010011100011110 ????1010000011100?11001011111 $100010010111100111110 ? ? ? ? 1010000011100011001011111$ 001000010011110011111 ????101000001110001?001011111 $101000010011110011110 ? ? ? ? 10100000 ? ? 100 ? 11001011111$

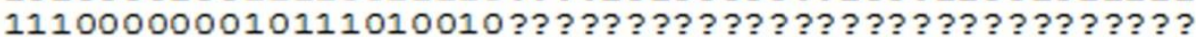
1010111-00011010111101000?????????????????????? $1110000000000100100101100 ? ?$ ???????????????????? 1011000-0000011011010???????????????????????????? $1110010000010010110111000 ? ? ? ? ? ? ? ? ? ? ? ? ? ? ? ? ? ? ? ? ? ? ? ?$ $1110000000011010111101100 ? ? ? ? ?$ ?? ??????????????? 100000000011001011010 ??????????????????????????? 1110000100 ?? ?0001? ?? ?1201???? ?????? ?? ?? ?? ?? ?? ? 111000000101100011 ??0121???????????????????????? $1110011-00121010110101200$ ?? ?? ?? ??? ?? ??? ??? ?? ? 1110011-?011101010?????????????????????????????? 